BNL- -52010

DE86 014888

\title{
LONG-TERM PROLIFERATION AND SAFEGUARDS ISSUES IN FUTURE TECHNOLOGIES
}

Bernard Keisch, Clemens Auerbach, Anthony Fainberg, Sidney Fiarman, Leslie G. Fishbone, William A. Higinbotham, James R. Lemley, and John O'Brien

\section{February 1986}

\author{
Prepared for \\ OFFICE OF SAFEGUARDS AND SECURITY \\ UNITED STATES DEPARTMENT OF EMERGY
}

Technical Support Organization

Department of Huclear Energy

BROOKHAVEN NATIONAL LABORATORY

ASSOCIATED UNIVERSITIES, INC.

UPTON, LONG ISLAND, NEW YORK11973

UNDER CONTRACT NO. DE-AC02-76CH00016 WITH THE

UNITED STATES DEPARTMENT OF ENERGY 


\section{DISCLAIMER}

This report was prepared as an acconnt of work sponsored by an agency of the United States Government. Neither the United States Government nor any agency thereof, nor any of their employees, nor any of their coutractors, subcontractors, or their employees, makes any warranty, express or implied, or aseumes any legzal liability or responsibility for the accuracy, completeness, or usefulness of any information, apparatus, product, or process disclosed, or represents that its use would not infringe privately owned rights. Reference herein to any specific commercial product, process; or service by trade name, trademark, manufacturer, or otherwise, does not necessarily constitute or imply its endorsement, recommendation, or favoring by the United States Government or any agency, contractor or subcontractor thereof. The views and opinions of anthors expressed herein do not necessarily state or reflect those of the United States Government or any agency, contractor or subcontractor thereof.

\section{Printed in the.United States of America}

Available from

National Technical Information Service

U.S. Department of Commerce

5285 Port Royal Road

Springfield, VA 22161

NTIS price codes:

Printed Copy: A14; Microfiche Copy: A01 
List of Figures.....................................

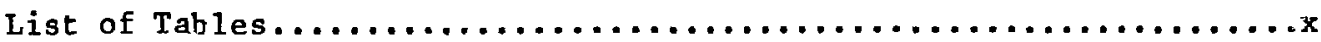

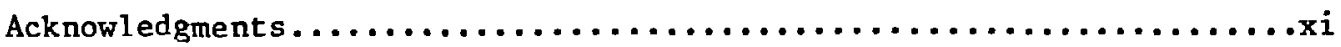

EXECUTIVE SUMMARY....................................

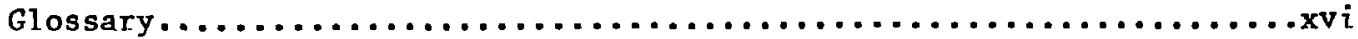

I. Introduction...................................

I.1 Purpose of the Task.............................

I.2 Genera 1 Approach.............................. I-1

I.3 Technologies Covered...........................

I.3.1 New Enrichment Technologies....................

I.3.2 Non-Aqueous Reprocessing Technologies............. I-2

I.3.3 Fusion..................................

I.3.4 Accelerator-Driven Reactor Systems............... I-3

I.3.5 New Reactor Types.......................... I-3

I. 3.6 Heavy Water and Deuterium.................... I-4

I.3.7 Long-Term Storage of Spent Fue1................

I.3.8 Other Future Technologies....................

I.4 Summary of Proliferation Concerns..................... I-4 Appendix - The Nonproliferation Alternative Systems Assessment

Program................................ I-5

II. Future Enrichment Technology..........................

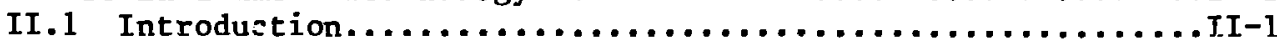

II.2 Atomic Vapor Laser Isotope Separation................. II-4

II.2.1 Description.............................

II.2.2 AVLIS Proliferation Considerations.............. II-6

II.2.3 AVLIS Safeguards Considerations................ II-8

II.3 Plasma Separation Process.........................II-10

II.3.1 Description.............................II-10

II.3.2 PSP Proliferation Considerations...............II-10

II.3.3 PSP Safeguards Considerations................II-12

II.4 Molecular Laser Isotope Separation..................... II-13

II.4.1 Description............................II-13

II.4.2 MLIS Proliferation Considerations...............II-13

II.4.3 MLIS Safeguards Considerations.................I-15

II.5 Policy Issues.................................... $\ldots \ldots$

II.5.1 Uranium Enrichment........................ II-15

II.5.2 Plutonium Isotope Separation.................II-17

References - Chapter II...............................II-21

III. Non-Aqueous Reprocessing Technology.................... III-1

III.1 Introduction.................................... III

III.2 Reference Facilities.......................... III-4 
III.2.1 The Salt Transport Process................III-4

III.2.1.1 Background...................III-4

III.2.1.2 Description of Reference Facility...III-5

III.2.1.3 Safeguards-Related Design Con'ıpts...III-9

III.2.2 The Fluoride Volatility Process.............III-12

III.2.2.1 Background....................III-12

III.2.2.2 Description of Reference Facility....III-14

III.2.2.3 Safeguards-Related Design Concepts...III-27

III.2.2.3.1 Flows..............III-27

III.2.2.3.2 Inventories............III-28

III.2.2.3.3 Plant Layout Concept... IIJ.-28

III.3 Safeguards Considerations......................III-3I

III.3.1 General Discussion.......................II-31

III.3.2 The Salt Transport Process................. III-32

III.3.3 The Fluoride Volatility Process...............II-33

III.3.4 Conclusions.................................

III.4 Non-Proliferation Considerations.........................

References - Chapter III............................. III-39

IV. Fusion......................................

IV.1 Principles of Nuclear Fusion........................ IV-4

TV.2 Nuclear-Fusion Reactor Systems................... IV-6

IV.2.1 Magnetic-Fusion Reactors...................

IV.2.2 Inertial-Confinement Reactors................ IV-8

IV.2.3 Hybrid Fusion-Fission Systems................. IV-8

IV. 3 Proliferation of Fission and Fusion Weapons............ IV -11

IV. $l_{\text {r }}$ liagnetic-Confinement Fusion Reactors................. IV -14

IV.4.1 Physical Description of the Reactor and

Power Plant.............................. IV-14

IV.4.2 Proliferative Materials.................... IV-22

IV.4.3 Time Scale of Development.................... IV-24

IV 4.4 Other Fuel Cycles...........................

IV.4.5 Proliferation Concerns........................

IV 4.5.1 Fusion Materials and Their Measurement...IV-28

IV 4.5.2 Undeclared Production of Fissile

Material......................... IV-31

IV.5 Inertial-Confinement Fusion Reactors................IV-33

IV.5.1 Fhysical Description of the Reactor and

Power Plant.................................. IV -33

IV.5.2 Proliferative Materials.................... IV-36

IV.5.3 Time Scale of Development.................. IV -38

IV.5.4 0ther Fuel Cycles.........................

IV.5.5 Proliferation Concerns.........................

IV.6 Hybrid Fusion-Fission Reactors...................... IV-41

IV.6.1 Physical Description of the Reactor and

Power Plant.............................. IV-41

IV .6.2 Proliferative Materials....................... IV 49

IV.6.3 Time Scale of Development.....................

IV.6.4 Other Fuel Cycles........................... IV-50

IV.6.5 Proliferation Concerns................... IV-51 
Appendices

IV.A Calculation of the Uranium Content of Tritium Generators

(Storage Beds)................................. IV-56

IV.B Calculation of the Possible Clandestine Plutonium

Production from a Tokamak Pure Fusion Reactor by

Emplacing Uranium in the Structure................. IV-57

IV.C Calculation of the Possible Clandestine Plutonium

Production from a Pure Fusion Tokamak Reactor by

Dissolving Uranium in the Primary Coolant.............. IV-60

IV.D Calculation of the Tritium and Deuterium Flows in

an Inertia1-Fusion Plant..........................

IV.E Calculation of the Uranium and Plutonium Content in a

Hybrid Blanket................................. IV 65

References - Chapter IV . . . . . . . . . . . . . . . . . . . . . IV 68

v. Accelerator-Driven Reactor Systems........................

V.1 Principles of Accelerator Drivers....................

V.2 Linear-Accelerator-Driven Systems....................

V.3 Linear-Accelerator Reactors and Fuel Breeders..............

V.3.1 Physical Description of the Facility............... -7

V.3.2 Proliferative Materials.........................

V.3.3 Time Scale for Development.....................

V.3.4 other Fuel Cycles............................

v.3.5 Proliferation Concerns.........................

Appendices

V.A Calculation of Some Fuel Characteristics of the LAFP Core...V-22

V.B Calculation of Possible Clandestine Plutonium Production

from Neutron Diversion in Accelerator-Driven Reactor

Systems........................................v-22

V.C Calculation of the Plutonium Production Capability of

Existing and Proposed Linear Accelerators.................

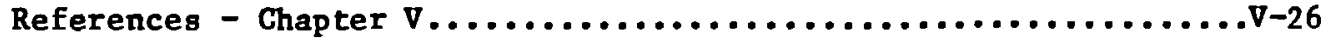

VI. New Reactor Types................................

VI.1 Types of Reactors..............................

VI.1.1 Water-Cooled Breeder Reactors................VI-2

VI.1.2 Gas-Cooled Fast Breeder Reactors (GCFRs)..........VI-2

VI.1.3 Liquid Metal Fast Ereeder Reactors (LMFBRs).......VI-3

VI.1.4 Spectral-Shift-Controlled Reactors (SSCRs)........VI-4

VI.1.5 Accelerator-Driven Reactors.................... VI-4

VI.1.6 Fission-Fusion Hybrid Reactors................. VI-4

VI.1.7 Fast Mixed Spectrum Reactors (FiSRs).............VI-4

VI.1.8 Gaseous-Core Reactors....................... VI-5

VI.1.9 Molten Sa1t Reactors........................VI-5

VI.1.10 High Temperature Gas-Cooled Reactors (HTGRs)......VI-6

VI.2 Molten Salt Reactors..............................VI-7

VI.2.1 Physical Description of the Reactor.............VI-8

VI.2.2 Proliferative Materials.....................

VI.2.3 System Configuration........................ VI-11

VI.2.4 Time Scale of Engineering and Other Developments..VI-12 
Section

Table of Contents (cont'd)

$\underline{\text { Page }}$

VI.2.5 Other Fuel Cycle Choices..................

VI.2.6 Proliferation Problems......................

VI.2.7 Perceived Safeguards Development Requirements......VI-16

VI.3 HTGRs and Process Heat............................

VI.3.1 Prismatic and Pebble-Bed Reactors..............VI-17

VI.3.2 Low Temperature Heat Applications............... VI-20

VI.3.3 High Temperature Heat Applications.............VI-22

VI.3.4 Proliferation Concerns......................VI-23

VI.4 Fast Mixed Spectrum Reactors (FMSRs)................. VI-25

VI.4.1 (CM) FMSR...............................

VI.4.2 (EC) FMSR. ..............................

VI.4.3 Anti-Proliferation Development Requirements.......VI-28

References - Chapter VI.............................VI-29

VII. Heavy Water and Deuterium Production................... VII-1

VII.1 Introduction. ..............................

VII.1.1 Domestic Safeguards.......................VII-2

VII.1.2 International Safeguards.................VII-3

VII.2 Extraction of Deuterium from Hyörogen Sources...........VIr-5

VII.2.1 Material Accounting for Hydrogen-Fed HWPPs of

Types Now in Servi.ce.................... VII-5

VII.2.2 HW Safeguards Implications of Future

Hydrogen Usage........................ VII-9

VII.3 Conclusions................................. VII-10

References - Chapter VII............................VII-11

VIII. Long-Term Storage of Spent Fue1....................VIII-1

VIII.1 Introduction...............................VIII-1

VIII.2 Safeguards Guidelines.......................VIII

VIII.3 Safeguards Systems Recommended for Long-Term Storage

Facilities ...............................

VIII.3.1 Spent Fuel Storage Pools.................VIII-4

VIII.3.2 Dry Storage at an AR Storage Facility........VIII-5

VIII.3.3 Dry Storage at an AFR Storage Facility......VIII-7

VIII.3.4 Dry Storage in Casks Stored On-Site or

off-Site...................................

VIII.3.5 Dry Storage in Concrete Silos.............VIII-9

VIII.3.6 Dry Storage of Canisters Placed

Underground........................virin-9

VIII.3.7 Dry Storage of Canisters in Water...........VIII-10

VIII.3.8 Waste Repository......................VIII-10

VIII.4 Conclusions..............................VIII-11

Appendices - Chapter VIII.........................VIII-2C

Appendix VIII-A-I

Active Ultrasonic Surveillance of Spent Fuel Storage

Buildings................................vIII-20

Appendix VIII-A-II

Safeguards Applications of the Sandia or VACoss-3

Electronic Seal...............................VIII-24

References - Chapter VIII...........................VIII-30 
IX. Impacts of 0ther Future Technologies................... IX-1 IX.1 Introduction.................................... IX IX.2 Robotics.....................................

IX.3 Genetic Engineering Applications.....................IX-8

IX.3.1 Genetic Engineering...................... IX-8

IX.3.2 Uranium Enrichment....................... IX-10

IX.3.3 Plutonium Extraction....................... IX-11

IX.4 Materials Technology............................. IX 12

References - Chapter IX............................. IX-14

x. Summary of Proliferation Concerns.......................

$\mathrm{X} .1$ Future Enrichment Technology.......................

$\mathrm{X} .2$ Non-Aqueous Reprocessing...........................

$\mathrm{X} .3$ Fusion systems................................

$\mathrm{X} .4$ Accelerator-Driven Reactor Systems.................

X.5 New Reactor Types...............................

X.6 Heavy Water.......................................

$\mathrm{X} .7$ Long-Term Storage..............................

X.8 Other Future Technologies........................ 
Conceptual Schematic of AVLIs.....................

Conceptual Salt Transport Process for $\mathrm{UO}_{2}-\mathrm{PuO}_{2}$ Fuel......III-6 Conceptual Fluoride-Volatility Process for LMFBR Fuels....III-17 Fluorination of Actinides and Fission Products............III-21 Schematic Diagram of Uranium Fluorinator (Reactor A).......III-22 Plutonium Purification and Separation from UF $6 \ldots \ldots \ldots \ldots$ III-24 $\mathrm{UF}_{6}$ Purification system.......................... III-26

IV-1 Thermonuclear conditions achieved in and projected for fusion experiments............................ IV -2

Principal features of a DT fusion reactor............... IV-2 Inertial-confinement fision - the concept............... IV-9 Fusion breeder concepts............................ IV-10 Nuclear-material fuel flows associated with hybrid fusionfission reactors .................................. IV-12 STARFIRE reactor building and hot cel1................ IV-16 STARFIRE reactor design in an exploded view.............. IV-17 STARFIRE power-flow diagram.........................

Fue1-cycle scenario for STARFIRE..................... IV-20 STARFIRE first-wa11 and blanket concept............... IV-21 Inertial-fusion laser duct and beam concept............... IV-34 Reaction chamber concept for the laser-driven reactor.......IV-35 Power-flow diagram for the reference laser-fusion reactor..IV-37 Trimetric view of the Westinghouse reference CTHR.........IV-42 CTHR Power flows................................. IV 44 Cross section of a typical CTHR fertile-fuel blanket sector......................................... Cross section of a CTHR cylindrical fertile-fuel modules...IV-47

(a) Yield measurement of neutrons-bombardment of heavy metal target with protons.........................

(b) Neutron-yield and heat production................. Linear-accelerator-driven reactor (LADR) ................ Linear-accelerator fuel enricher and regenerator (LAFER) ....V-6

Linear-accelerator fuel producer (LAFP) ...............

LAFP target system and containment building .............

LAFP target-blanket configuration...................

LAFP power flows................................ Fissile-material buildup and neutron absorption during

LAFER enrichment and LWR burn cycle..............
$V-9 \quad$ Research, development, and demonstration cost and time schedule for the LAFER...................... 


\section{List of Figures (cont'd)}

Figure

Page

$\mathrm{v}-10$

APEX nuclear fuel cycle for uranium and plutonium..........

VI-I

Simplified Diagram for Once-Through DMSR..............VI-9

VIII-1

Dose Rate from PWR Spent Fuel Assembly.................VIII-13

VIII-2

VIII-3

Perspective Cutaway of Dry Store at Wylfa............VIII-14

VIII-4

Typical Section Through an LWR Store...............VIII-15

VIII-5

Perspective View of LWR Store Adjacent to Pond Building. .VIII-16 Concrete Canister for Dry Interim Storage of GANDU

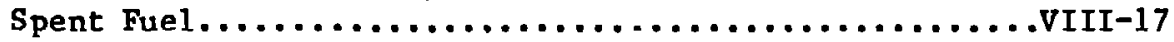

VIII-6

VIII-7

Drywel1 storage Arrangement...................... . . . .

VIII-AI-1 Basic Layout of Ultrasonic Surveillance System.........VIII-23

VIII-AII-1 A Cask Storage Arrangement....................... VIII-27

VIII-AII-2 Electronic Seal with LWR.......................

VIII-AII-3 Light Pulse Repeater Circuit...................... VIII-29 


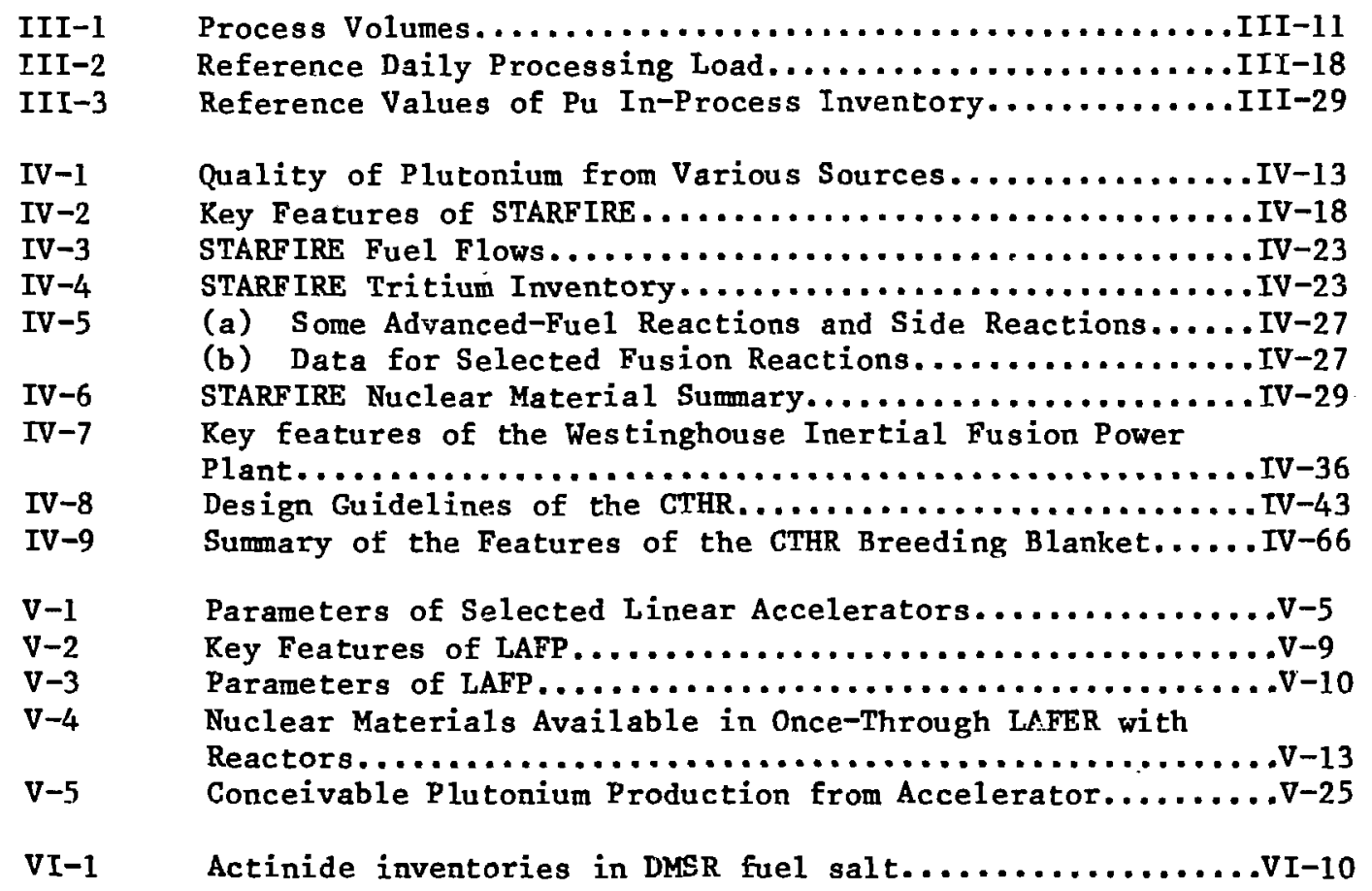




\section{Acknowledgments}

The authors received assistance from many individuals at Brookhaven and other national laboratories, U.S. Government contractors, and private organizations in the preparation of this report and are grateful for it. They include A.W. Maschke, A.î́. Bieber, Jr., C.H. Bean, M. Benedict, D. Berwald, T. Binford, J. Cate, D.0. Coffin, L. Eisenhart, R. Fuller, D.M. Gordon, J. Gordon, P. Grand, J.B. Knighton, R. Larsen, Y.Y. Lee, J.C. Miles, M. Miller, J.B. Moegling, C.M. Newstead, J.R. Powell, G. Rathjens, R. Rose, J. Sanborn, V. Smith, M. Steinberg, and E.V. Weinstock.

Perscnnel in the Office of Safeguards and Security of the United States Department of Energy suggested the study. Along with colleagues in other Department of Energy Offices, they provided criticisms of earlier versions of the report. The authors appreciate the encouragement and counsel.

Donna Albertus, the authors' 1ib:arian, performed yeoman service in acquiring the multitude of background references necessary to conduct the study. Other Brookhaven colleagues read and commented upon manuscript versions during the course of the work. Lynn Kelly, Nora Davies and the Word Processing Center patiently typed many drafts. To all of them, the authors express their appreciation. 


\section{EXECUTIVE SUMMARY}

The purpose of the task was to assess the effect of potential new technologies, nuclear and non-nuclear, on safeguards needs and con-proliferation policies, and to explore possible solutions to some of the problems envisaged.

Eight subdivisions were considered:

(1) New Enrichment Technologies

(2) Non-Aqueous Reprocessing Technologies

(3) Fusion

(4) Accelerafor-Driven Reactor Systems

(5) New Reactor Types

(6) Heavy Water and Deuterium

(7) Long-Term Storage of Spent Fuel

(8) Other Future Technulogies (Non-Nuclear)

For each of these subdivisions, a careful review of the current world-wide effort in the field provided a means of subjectively estimating the viability and qualitative probability of fruition of promising technologies. Technologies for which safeguards and non-proliferation requirements have been thoroughly considered by others were not re-studied here (e.g., the Fast Breeder Reactor). The time scale considered was 5-40 years for possible initial demonstration although, in some cases, a somewhat optimistic viewpoint was embraced.

Conventional nuclear-material safeguards are only part of the overall non-proliferation regime. Other aspects are international agreements, export controls on sensitive technologies, classification of information, intelligence gathering, and diplomatic initiatives. The focus here is on safeguards, export controls, and classification.

The following is a summary of the conclusions subjectively arranged in approximate order of priorities. This order represents a judgment based on the 
time scale for development in each field, the effort needed to develop safeguards in each case, and the probability that the assumed development takes place at all.

Long-term fuel storage schemes considered tend to create impediments for surveillance and measurement systems because of space-saving designs, biological shielding, and sheer weight of numbers. It would appear that new, long-1ife, active surveillance systems that guard against scenarios not usually considered (such as tunnelling) will be needed. Such systems will also require other special features such as remote interrogation capability.

Three new enrichment technologies are discussed: Atomic Vapor Laser Isosope Separation (AVLIS), the Plasma Separation Process (PSP), and Molecular: Laser Isotope Separation (MLIS). (Others are briefly mentioned.) In these cases, new procedures and instrumentation for safeguards need to be developed, but there would probably be sufficient time to do this. The conclusion is that even with good control over the export of U.S. technology, other nations might develop the methods in 5-1C years (AVLIS and MLIS) or 20-30 years (ISP). Export of the technologies should be handled as for gas-centrifuge technology, notwithstanding the recent decisions of the U.S. Department of Energy to concentrate development effort on AVLIS and halt construction of the Gas Centrifuge Enrichment Plant (GCEP). The use of these technologies for plutonium enrichment is of limited significance to non-proliferation in addition to being more difficult than other proliferation routes.

The order of the next four subjects should be considered very indefinite. New reactor types considered in detail include Molten Salt Reactors (MSRs). High Temperature Gas-Cooled Reactors (HTGRs), and Fast Mixed Spectrum Reactors (FMSRs). For MSRs, safeguards-related measurements and monitoring that require development resemble those required for reprocessing plants rather than those 
for today's reactors. There are a number of special technical considerations as we11. HTGRs, while well along in development by comparison, may be used as small, process-heat-producing units, a use that may require the development of special safeguards procedures. FMSRs will require the development of special, reliable, long-term seals and also new institutional arrangements because the FMSRs are designed to be operated for very long periods without fuel removal. For deuterium production, the possible viability of hydrogen-fed plants, which may result from the development of a hydrogen-based economy, would require additional safeguards techniques as compared to more typical water-fed facilities.

The non-aqueous reprocessing technologies considered in detail include the Salt Transport Process and the Fluoride Volatility Process. While compactness of such plants may enhance the possible concealment of clandestine facilities, it also aids in inspectability. The uniqueness or the equipment used requires some developmental effort in material control and accountability (MC\&A) techniques but also might prevent a nation from obtaining materials wi thout arousing suspicion.

Certain future technologies that are non-nuclear were consideret. These included the use of robotics by divertors, the development of genetics and other biologically oriented technologies to be used in new separation methods, and new developments in material science. While these possibilities are highly speculative, some seem well worth consideration.

Fusion technologies discussed include a magnetic-confinement tokamak reactor, a laser-driven inertial-confinement reactor, and a magnetic-confinement tokamak hybrid fusion-fission reactor. Proliferation concerns include the involvement of large quantities of tritium and lithium, the relationship to thermonuclear-weapons technology, the use of neutrons to breed fissile material, 
and the possibility of small, clandestine fusion reactors. Possible scenarios envisioned seem far less plausible than those involving fission reactors largely because of the complexity of the technology.

Accelerator-driven reactors include three types. The conclusions drawn are similar to those for hybrid fusion-fission technologies. Size and complexity seem to preclude their use for proliferative purposes. 
Glossary

\begin{tabular}{|c|c|}
\hline $\begin{array}{l}\text { a.a. } \\
\text { AFR }\end{array}$ & $\begin{array}{l}\text { - acceptor alloys } \\
\text { - Away-From-Reactor }\end{array}$ \\
\hline $\begin{array}{l}\text { AFR } \\
\text { AGS }\end{array}$ & $\begin{array}{l}\text { - Away-From-Reactor } \\
\text { - Alternating Gradient Synchrotron }\end{array}$ \\
\hline AIS & $\begin{array}{l}\text { - Alternating Gradient Synchrotron } \\
\text { - Advanced Isotope Separation }\end{array}$ \\
\hline amp & - Ampere \\
\hline AMSFFR & - Actinide Molten-Salt-Fueled Fast Reactor \\
\hline $\begin{array}{l}\text { AVR } \\
\text { ANL }\end{array}$ & - Arbeitsgemeinschaft Versuchs-Reaktor \\
\hline $\begin{array}{l}\text { ANL } \\
\text { AR }\end{array}$ & - Argonne National Laboratory \\
\hline AR & - At-Reactor \\
\hline $\begin{array}{l}\text { AVLIS } \\
\text { at. } \%\end{array}$ & $\begin{array}{l}\text { - Atomic Japor Laser Isotope Separation } \\
\text { - atom per cent }\end{array}$ \\
\hline BNL & - Brookhaven National Laboratory \\
\hline BOL & - Beginning of Life \\
\hline BOP & - Balance of Plant \\
\hline BWR & - Boiling Water Reactor \\
\hline C & - Curie \\
\hline CA. & $\begin{array}{l}\text { - circa (about) } \\
\text { - Computer-Aidad Deoign }\end{array}$ \\
\hline CALUTRON & - California University Cyclotron \\
\hline CAM & - Computer-Aided Ilanufacture \\
\hline CANDU & - Canadian Deuterium Uranium (Reactor, etc.) \\
\hline $\begin{array}{l}\text { CHEMEX } \\
\text { (CM)FMSR }\end{array}$ & $\begin{array}{l}\text { - Chemical Exchange } \\
\text { - Centrally Moderated FMSR }\end{array}$ \\
\hline $\mathrm{cm}$ & $\begin{array}{l}\text { - Centrally Moderated FMSR } \\
\text { - centimeter }\end{array}$ \\
\hline $\mathrm{c} / \mathrm{s}$ & - Containment/Surveillance \\
\hline $\begin{array}{l}\text { CTHR } \\
\text { d }\end{array}$ & $\begin{array}{l}\text { - Commercial Tokamak Hybrid Reactor } \\
\text { - day }\end{array}$ \\
\hline $\begin{array}{l}\text { d.a. } \\
\text { dia. }\end{array}$ & - donor allojs \\
\hline $\begin{array}{l}\text { dia. } \\
\text { dis }\end{array}$ & $\begin{array}{l}\text { - dianeter } \\
\text { - disintegration }\end{array}$ \\
\hline DMSR & - Denatured MSR \\
\hline DNA & - Deoxyribonocleic Acid \\
\hline DOE & - Department of Energy \\
\hline $\begin{array}{l}\text { EBR } \\
\text { (EC)FMSR }\end{array}$ & $\begin{array}{l}\text { - Experimental Breeder Reactor } \\
\text { - Extended-Cycle FMSR }\end{array}$ \\
\hline ECRH & - Electron Cyclotron Resonance Heating \\
\hline EF & - Equilibrium (Magnetic) Field \\
\hline EOL & - End of Life \\
\hline eV & - electron volt \\
\hline FAID & - Fuel Assemb1y Identification Device \\
\hline FBR & - Fast Breeder Reactor \\
\hline FE & - Fue1 Elements \\
\hline FF & - Fissile Fuel \\
\hline $\begin{array}{l}\text { FM } \\
\text { FMIT }\end{array}$ & $\begin{array}{l}\text { - Fertile Material } \\
\text { - Fusion Materials Irradiation Test (Facility) }\end{array}$ \\
\hline FMSR & - Fast Mixed Spectrum Reactor \\
\hline FNAL & ermi National Accelerator Laboratory \\
\hline $\begin{array}{l}\text { FP } \\
\text { ft. }\end{array}$ & Fission Products \\
\hline GP & Im \\
\hline & \\
\hline
\end{tabular}

xvi 


\section{Glossary (Cont'd)}

\begin{tabular}{|c|c|}
\hline GCFR & - Gas-Cooled Fast (Breeder) Reactor \\
\hline $\mathrm{GeV}$ & - Giga electron volt \\
\hline GS & - Girdler-Sulfide (Process) \\
\hline GWE & - Gigawatt (electric) \\
\hline HEDL & - Hanford Engineering Development Laboratory \\
\hline HEU. & - High1y Enriched Uranium \\
\hline hr. & - hour \\
\hline HSR & - Heat Supply Remova1 \\
\hline HTGR & - High Temperature Gas-Cooled Reactor \\
\hline HW & - Heavy Water \\
\hline HWBR & - Heavy Water Breeder Reactor \\
\hline HWR & - Heavy Water Reactor \\
\hline $\begin{array}{l}\text { IAEA } \\
\text { in. }\end{array}$ & $\begin{array}{l}\text { - International Atomic Energy Agency } \\
\text { - inch }\end{array}$ \\
\hline INFCE & - International Fuel Cycle Evaluation \\
\hline $\begin{array}{l}\text { INFCIRC } \\
\text { J }\end{array}$ & $\begin{array}{l}\text { - Information Circular } \\
\text { - Joule }\end{array}$ \\
\hline JIRA & - Japan Industrial Robot Industry Association \\
\hline kg & - kilogram \\
\hline $\mathrm{kW}$ & - kilowatt \\
\hline$\ell$ & - 1iter \\
\hline LADR & - Linear-Accelerator Driven Reactor \\
\hline ILAFER & - Linear-Accelerator Fuel Enricher and Regenerator \\
\hline LAFP & - Linear-Accelerator Fuel Producer \\
\hline IAMPE & - Los Alamos Meson Physics Facility \\
\hline IANL & - Los Alamos National Laboratory \\
\hline LED & - Light-Emitting Diode \\
\hline LEMUF & - Limit of Error of MUF \\
\hline LEU & - Low-Enriched Uranium \\
\hline LLFP & - Long-Lived Fission Products \\
\hline LLNL & - Lawrence Livermore National Laboratory \\
\hline LMFBR & - Liquid Metal Fast Breedez Reactor \\
\hline LPR & - Light Pulse Repeater \\
\hline LWBR & - Light Water Breeder Reactor \\
\hline LFR & - Light-Water Reactor \\
\hline m & - meter \\
\hline MC\&A & - Material Control and Accountability \\
\hline MEU & - Medium-Enriched Uranium \\
\hline $\mathrm{MeV}$ & - Million electron volts \\
\hline MFGCR & - Mixed-F1ow Gaseous Core Reactor \\
\hline $\mathrm{Mg}$ & - Megagram \\
\hline MITI & - Ministry of Trade and Industry (Japan) \\
\hline MLIS & - Molecular Lasèr Isotope Separation \\
\hline $\begin{array}{l}\text { MOL } \\
\text { MPa }\end{array}$ & $\begin{array}{l}\text { - Middle of Life } \\
\text { - Megapascal absolute (a unit of pressure) }\end{array}$ \\
\hline $\begin{array}{l}\text { MSBR } \\
\text { MSR }\end{array}$ & $\begin{array}{l}\text { - Molten-Salt Breeder Reactor } \\
\text { - Molten-Salt Reactor }\end{array}$ \\
\hline MSRE & - Molten-Salt Reactor Experiment \\
\hline MSID & - Mass-Spectrometric-Isotope Dilution \\
\hline MTA & - Materials Testing Accelerator \\
\hline MTR & - Materials Testing Reactor \\
\hline
\end{tabular}




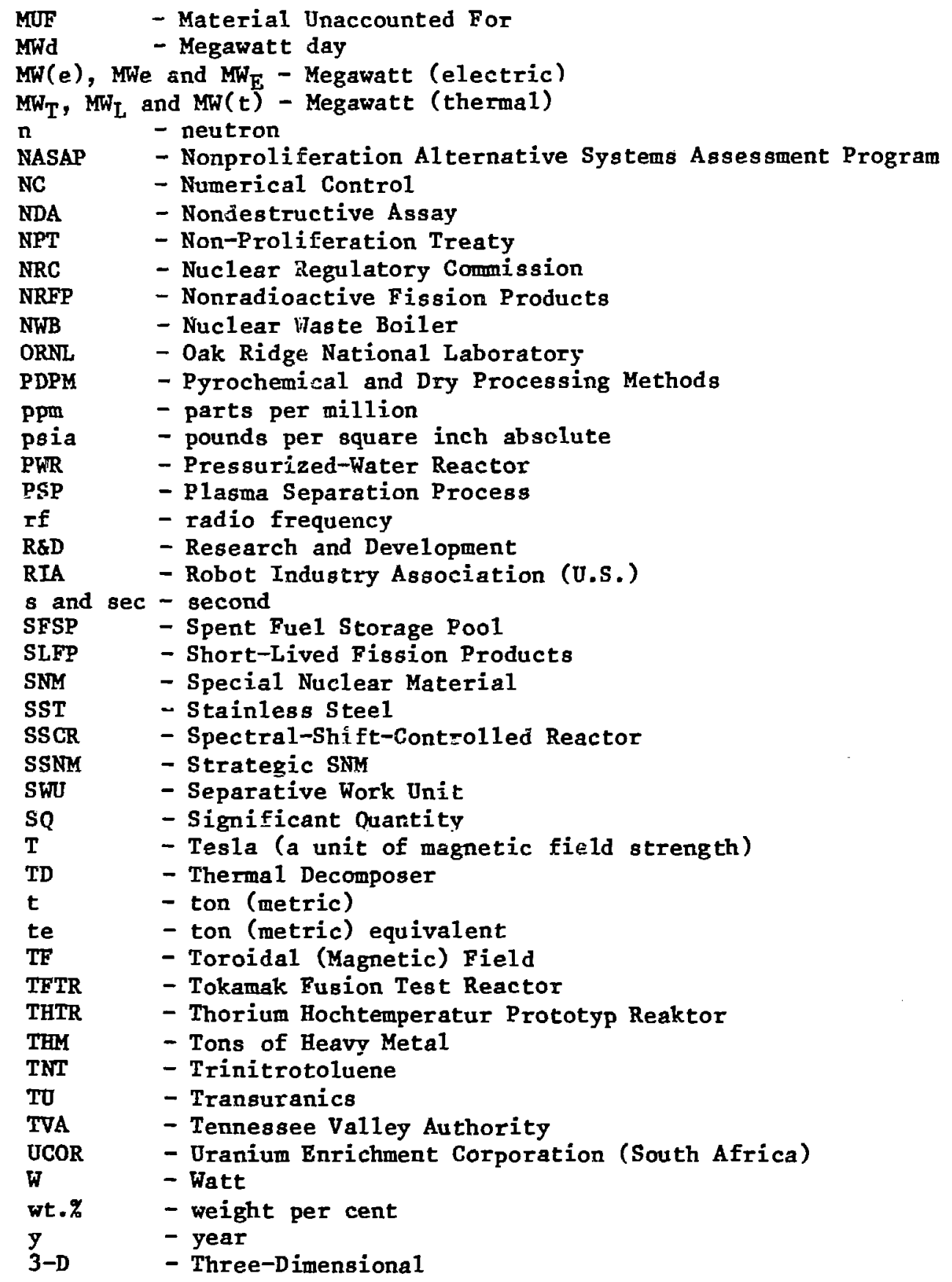




\section{INTRODUCTION}

\section{I.l. Purpose of the Task}

The general purpose of the task has been stated as:

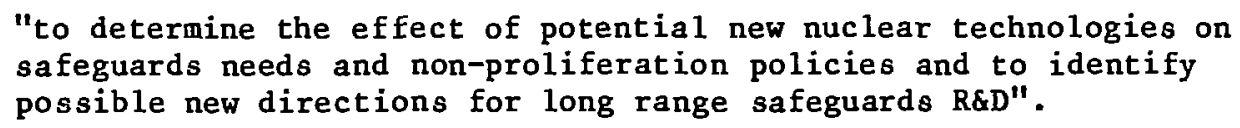

More specifically, new technologies that were selected on the basis of likelihood of being exploited were considered. Then, future safeguards needs not now available for these technologies were envisioned and suggested for possible development. In addition, also addressed was the more inclusive concept that an overall improvement in world-wide technology will enhance the abilities of a potential proliferator.

The overall discussion has been divided into seven sub-fields, each of which is covered in a separate chapter. In addition, a chapter has been devoted to a discussion of other, non-nuclear technologies that may also affect safeguards eventually. Finally a summary of the entire work is presented which reviews all the potential safeguards issues. Generally spedking, the technical descriptions contained herein reflect developments through late 1982 . Chapters II, IV, and $V$ include certain more recent developments as well.

\section{I.2. General Approach}

For most of the auclear technologies considered, a careful review of the on-going effort in the field led to an admittedly subjective appraisal. This appraisal was used to determine if there were a reasonable chance that new developments would occur in the next 20 to 40 years which would lead to "special" safeguards problems. The term, "special" safeguards problems, is understood to mean those safeguards problems which have not yet been considered for existing systems or would require the development of new technical solutions or both. In many of the cases discussed, such problems are readily envisaged. The solu- 
tions to the problems are not so obvious. It is valuable, however, to elucidate the problems so that solutions can eventually be developed on a time scale concurrent with the development of the technologies themselves. In that way, the application of safeguards to each successful technology of the future will be well planned and integrated rather than be a stop-gap, expensive, and imperfect exercise, which is typical of many situations today.

Conventional nuclear-material safeguards are only part of the overall nonproliferation regime. Other aspects are international agreements, export controls on sensitive technologies, classification of information, intelligence gathering, and diplonatic initiatives. The focus here is on aafeguards, export controls, and classification.

I.3. Technologies Covered

1.3.1. New Enrichment Technologies

Chapter II is a discussion of new enrichment technologies. Some of these are discussed quite briefly because they are not so new and safeguards concerns have already been addressed or because the technology did not originate or was not developed in the U.S. and is, therefore, out of U.S, hands. Such technologies include the gas centrifuge (already addressed), the aerodynamic and chemical exchange methods (non-U.S.), and magnetic separation (not new). The remaining technologies, Atomic Vapor Laser Isotope Separation, Molecular Laser Isotope Separation, and the Plasma Separation Process, are discussed more fully. The question of plutonium isotope enrichment also is addressed.

I.3.2. Non-Aqueous Reprocessing Technologies

Chapter III deals with non-aqueous reprocessing technologies. This topic was considered in two main sub-groups: (a) Pyrochemical and Pyrometallurgical Processes and (b) Volatility Processes. Such processes are considered to have advantages over the currently used separation based on solvent extraction but 
will require different safeguards technology. Two examples, one representing each main topic, have been selected as being closest to actual application. Possible safeguards systems for these examples were explored in a general way.

\section{I.3.3. Fusion}

Chapter IV deals with three different fusion reactor concepts, magneticconfinement, inertial-confinement, and hybrid fission-fusion reactors. In addition, a description of the principles of fusion is included because this subiect is less familiar to workers in safeguards than is nuclear fission. The discussion of proliferation concerns is reasonably specific considering the very longrange nature and complexity of fusion power development.

\section{I.3.4. Accelerator-Driven Reactor Systems}

Chapter $\mathrm{V}$ deals with accelerator-driven systems and particularly with proliferative material breeding with them. Though such systems have been studied only in a conceptual design stage, the proliferative concerns are sinilar to those of other technologies. Nevertheless, the details of three possible systems are enumerated in this chapter.

\section{I.3.5. New Reactor Types}

Chapter VI deals primarily with those reactor types for which, although a significant period of time remains before commercialization, there is substantial world-wide interest for technical and economic reasons. There have been a large number of reactor types proposed in the past several years, especially for the Nonproliferation Alternative System Assessment Program (see Appendix Chapter I). From these, three have been selected for further discussion on the basis of (a) world-wide interest or (b) unusual safeguards issues. These are molten salt reactors, high temperature gas-cooled reactors for process heat, and fast mixed-spectrum reactors (a1though for the last there is less attention given as commensurate with interest). 


\section{I.3.6. Heavy Water and Deuterium}

Chapter VII reviews the needs and current safeguards status of heavy-water production. Possible new routes are discussed which are based on a feed of hydrogen instead of water. The importance of future increased uses for hydrogen in commerce and j.ts effect on heavy-water production is considered.

\section{I.3.7. Long-Term Storage of Spent Fue1}

Chapter VIII presents currently proposed or planned storage schemes. A number of safeguards issues are described and discussed together with some possible solutions.

\section{I.3.8. Other Future Technologies}

In Chapter IX there is a discussion of some technologies that, while nonnuclear in nature, are thought to have a potential impact on future nonproliferation questions. The material is highly speculative, of course, but, based on published literature and on contacts with experts, a prediction is that at least some of the situations presented are quite likelv to occur. Emphasis is given to two main subjects, robotics and genetics and bioengineering. I.4. Sumary of Proliferation Concerns

A summary of all the proliferation concerns as elucidated in the preceeding chapters is presented to provide an overall view of future safeguards issues. In addition, this summary serves as a means of selecting particular details of interest from the body of the report as the reader desires. 


$$
\text { Appendix - Chapter I }
$$

The Nonproliferation Alternative Systems Assessment Program

This progran, genera1ly referred to as NASAP, was initiated by President Ford in the fall of 1976 and expanded under the Carter Administration. There was some hope at that time that the United States could persuade the rest of the world to postpone reprocessing and the use of plutonium fuels, and that it might be possible to design equally attractive, alternative fuel cycles which would be less likely than plutonium fuel cycles to contribute to proliferation. The findings of this program were published as: "Nuclear Proliferation and Civilian Nuclear Power, Report of the Nonproliferation Alternative Systems Assessment Program" (U.S. Dept. of Energy, DOE/NE-0001, Dec. 1979).

NASAP was a very large study project which produced large amounts of useful information regarding nuclear resources, electrical power projections, technical status, economic considerations, environmental impacts, etc. in addition to assessing the proliferation implications of existing and possible alternative nuclẹar fuel cycles.

The alternative nuclear fuel cycles were assessed as to relative "proliferation resistance", with account given to the resources required and the time required to produce a few nuclear weapons by "abuse" of a given fuel cycle, and the risks that such an operation would be detected in time for sanctions to be applied.

The present study does not treat existing fuel cycies and facilities, as did NASAP, but reexamines some possible future nuclear and non-nuclear technologies which might be of particular concern as regards proliferation or which may call for special research and development (R\&D) on behalf of IAEA safeguards. Although some of these topics are also treated in more or less detail in the NASAP report, the approach is different. 
On the assumption that some readers of this report may also be interested in the different aspects treated in the NASAP report, the major "ASAP topics are listed here:

- Executive Sumnary

o Volume I: Program Summary. The proliferation problem, policy history, program organization, forecasts, and assessment of future choices and approaches .

- Volume II: Definition of "proliferaticn resistance", assessment procedure, assessment of existing and alternative nuclear fuel cycles, assessment of "sensitive" facilities (enrichment, reprocessing, refabrication), and IAEA and domestic safeguards. The discussion of dedicated enrichment and reprocessing facilities in sections 3.1 .3 and 3.3.5, respectively, may $?=$ of interest.

- Volume III: Resources and Fuel Cycle Tacilities

- Volume IV: Commercial Potential

- Volume V: Economics and Systems Analysis

- Volume VI: Safety and Environmental Considerations

o Volume VII: International Perspectives. Past and present U.S. policies, considerations for future policies, present and possible future international arrangements, etc.

o Volume VIII: Advanced Concepts. Fast mixed-spectrum reactor, denatured molten-salt reactor, mixed-flow gaseous core reactor, linear-accelerator fue1-regenerator reactor, ternary metal-fuelled electronuclear fuelproducer reactor, tokamak fusion-fission hybrid reactor.

- Volume IX: Reactor and Fuel Cycle Descriptions. All of those in Volume VIII plus upgraded light-water reactors (LWRs) and heavy-water reactors (HWRs), water-cooled breeders, high temperature gas-cooled reactors 
(HTGRs), gas-cooled fast breeders, liquid metal fast hreeder reactors (JMFBRs), spectral-shift reactors, mining and milling, enrichment, fuel fabrication, reprocessing, and waste handling and disposal. Some of the fuel cycles considered are already in widespread use. Steps could be taken to improve the resurce utilization of HWRs and LWRs in the near future, including Pu-recycle. The denatured $U / T h$ fuel cycles were not found to have important proliferation-resistance advantages. The advenced fuel cycles including the LMFBR will be very expensive to develop, and it will be many years before they could be deployed in significant numbers. For these advanced eyetems, the NASAP study noted that the context of proliferation concerns and the world energy regime will have changed by the time that they might be deployed. 


\section{FUTURE ENRICHMENT TECHNOLOGY}

II. 1. Introduction

At present, more than $95 \%$ of the currently available separative capacity for uranium enrichment is provided by the gaseous-diffusion process. However, several additional methods for separating uranium isotopes are under development. In comparison with gaseous diffusion, some of these have several potential advantages, including greater energy efficiency and lower cost.

The gas-centrifuge uranium-enrichment process has heen developed over the last three decades, and plants based on this process are operating or under construction in Europe and Japan. The holders of gas-centrifuge technology together with the international inspectorates--Euratom and the IAEA--have agreed upon safeguards approaches for these gas-centrifuge uranium-enrichment

plants. (1) In addition, it should be noted that Pakistan is reported to be building its own centrifuge enrichment plant.

The United States has placed in force export controls for centrifuges and centrifuge components. However, the existence of this technology in several other countries limits the ability of the U.S. to prevenc completely the spread of centrifuge technology. This is not at all to say that export controls sh ruld be dropped, but rather to say that without similar effective controls by a number of other nations, such controls may not be sufficient to control proliferation of this technology.

The Becker nozzle process and the UCOR* process are aerodynamic methods for uranium enrichment that have been developed in the Federal Republic of Germany (FRG) and the Union of South Africa, respectively.

*Uranium Enrichment Corporation of South Africa, Ltd. 
In the former case, the technology is thoroughly described in the open literature and is known to rely on centrifugal force acting on a curved stream of UF$_{6}$ in a carrier gas to effect enrichment. (2) A full-size operating plant has not yet been built but the FRG is constructing a pilot facility in Brazil. Current plans call for eventual expansion of the plant, which is intended to produce only low-enriched uranium (LEU). It is to come under International Atomic Energy Agency (IAEA) safeguards (INFCIRC/66/Rev. 2), (3) and the FRG is pursuing the development of safeguards procedures for this purpose. (4)

The basis of the UCOR process is only incompletely described in published literature ${ }^{(5)}$ but is also an aerodynamic process. One small plant producing highly enriched uranium (HEU) is operating and another, for LEU, is under construction in the Union of South Africa; neither is under IAEA safeguards. The UCOR process has a high specific power (comparable to the gaseous-diffusion process) and a plant with moderate capacity would consume large amounts of electrical power. Hence a clandeatine version would be relatively difficult to conceal (nor has there been any attempt by the South Africans to do so).

Chemical-exchange reactions can also be used to enrich uranium. A muchpublicized version of this technique has been developed in France and given the name "CHEMEX". $(6,7,8)$ It is based on chemical exchange of uranium between two immiscible liquid phases. Another chemical-exchange process, which is being developed at the Asahi Chemical Company in Japan, makes use of chemical exchange between a liquid phase and a solid phase, which is a specially developed ionexchange resin.

The technologies for the Becker nozzle, UCOR, and chemical-exchange methods are not simple. However they are beyond direct U.S. control and thus will not be further discussed here. Any control over the spread of these technologies 
would have to rely upon successful political and diplomatic cooperation with these four countries.

Electromagnetic isotope-separation techniques were developed at the time of the Manhattan Project. (9) Scaled-up versions of the decades-old "CALUTRON" ( California University Cyclotron) concept theoretically could be used to enrich uranium, physically separating isotopes of different charge-to-mass ratios by using a large magnet as a mass spectrometer. The problem with this method is that such devices have very low rates of production. For a small number of weapons to be produced over a few years, the process would clearly work, having done so decades ago. Costs are quite high, probably higher than for other methods, although the technology is not difficult. For a larger program, improvements in ion sources would be required. Such improvements, however, are almost certain to occur over the next forty years. Problems limiting the concept are ion-source intensity and space-charge effects; the latter tend to cause the beam to become seriously defocussed. For these reasons, and the fact that other less expensive methods are available, we do not further consider the CALUTRON concept within the time frame covered in this report.

Three other advanced methods of uranium enrichment are being investigated, in the U.S. and also elsewhere, for possible large-scale implementation in the mid-to-long term (10-30 years). Their safeguards and proliferation aspects are being addressed as well. What follows is an abbreviated discussion of the principal conclusions, together with some observations about potential problems connected with these technologies in the future. The advantages of such methods relative to the common gaseous-diffusion methods would lie in their potential for much lower energy demands and lower cost for separative work. Energy requirements for the laser techniques would be comparable to that for the centrifuge enrichment froess, but the chief advantage relative to that process lies 
in the potential for greatly reduced capital and operating costs. Another potential advantage is the capability of these processes to operate economically with very low tails assays, thus extending uranium resources.

Two of these techniques use advanced lasers for isotope separation while the third uses a plasma method. Each will be described separately. Ouestions to be covered include new policy issues which may arise and long-term considerations which could result from the future availability of sensitive related technologies.

The following descriptions of these advanced methods for uranium enrichment were correct as of April, 1982, when the atomic vapor laser isotope separation (AVLIS) process was selected by the U.S. Department of Energy (DOE) for further development. Continued development of the AVLIS process since then has resulted in modifications. In 1985, DOE also decided to halt construction of its Gas Centrifuge Enrichment Plant (GCEP) in favor of concentrated effort on AVLIS.

\section{II.2. Atomic Vapor Laser Isotope Separation (AVLIS)}

\section{II.2.1. Description}

This technique has been developed primarily at the Lawrence Livermore National Laboratory. (10) In this process, uranium metal is first vaporized by an electron beam. Once the uranium is in the vapor phase, intense beams of laser light in a rapid-fire sequence of precisely determined frequencies preferentially ionize $235_{\mathrm{U}}$ rather than $238_{\mathrm{U}}$ atoms. An electromagnetic field is then applied to the vapor. Neutral atoms (preferentially 238 $\mathrm{U}$ ) are unaffected, whereas $U^{+}$ions (preferentially ${ }^{235} U$ ) are deflected and deposited on collector surfaces (see Figure II-1).

This is only an outline of the technique; details are rather complicated. A high level of technology is now required for such a system, as is the case for al1 three methods. Those parts of themethod which represent sensitive high 


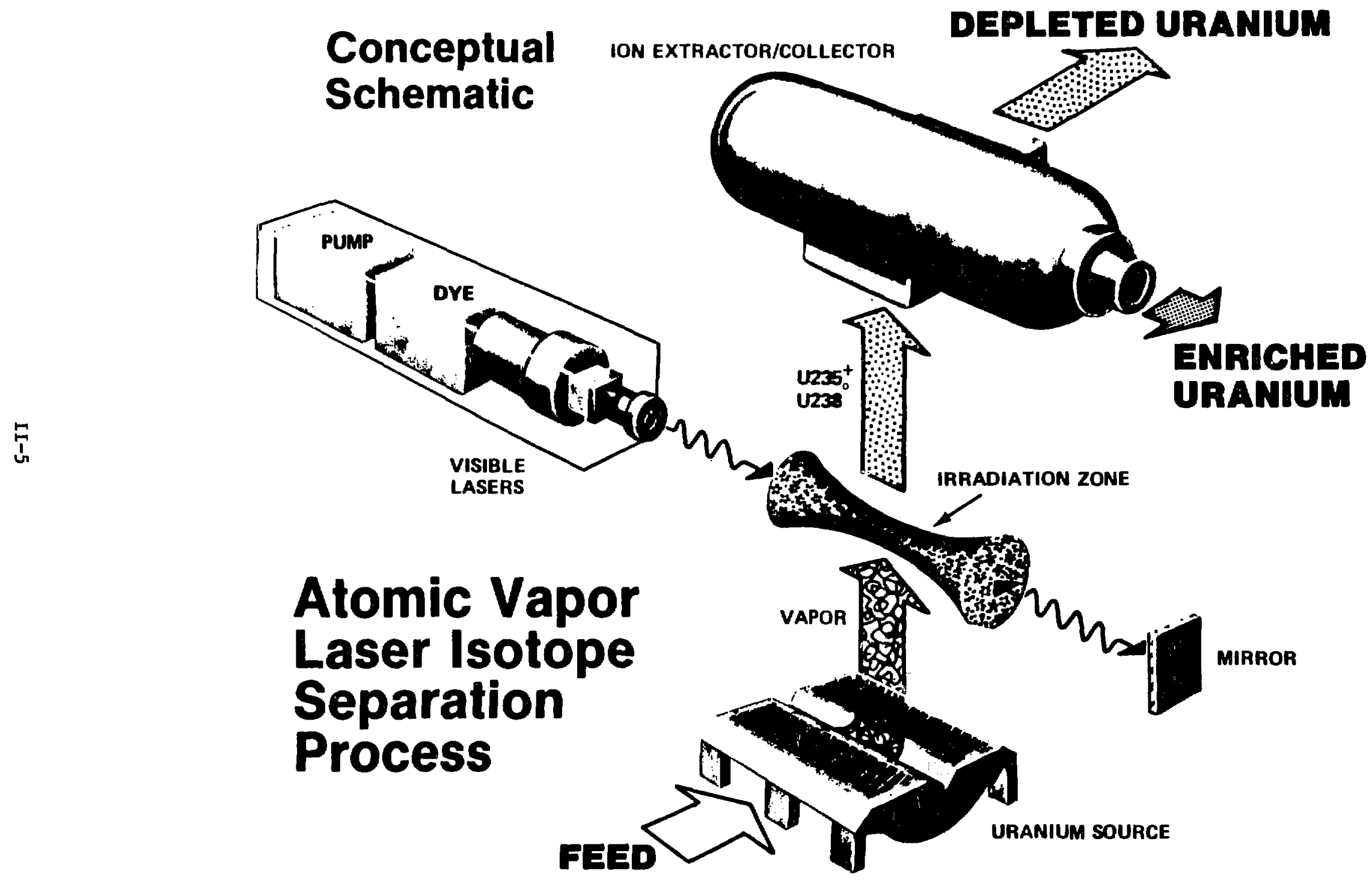

Figure II-1. Conceptual Schematic of AVLIS (after ref. 14) 
technology include a knowledge of the optimal light frequencies to use, longlived high-intensity lasers with a high repetition rate, the technology of handling uranium at very high temperatures, switches capable of passing high currents, and, to a lesser degree, the geometrical requirements for the irradiation zone and collector, in order to produce a reasonably high product assay.

\section{II.2.2. AVLIS Proliferation Considerations}

An integrated AVLIS system is not yet workable on a large scale anywhere. However, one ful1-scale demonstration module is scheduled to operate in the U.S. in the late $1980^{\prime} \mathrm{s}$. For a relatively short period of time (estimated at 5 additional years after that), the necessary lasers will probably not be avai able to most nations, except perhaps for a few which are now activly working in the field; these include both nuclear-weapons states and non-nuclear-weapons states. Beyond this time (c. 1995), one should assume the possibility that the necessary laser equipment and materials could be available, one way or another, to a nation with a moderate amount of resources, and, possibly somewhat later, to subnational groups with large financial backing. Another obstacle is the classified knowledge of the necessary, detailed uranium atomic spectroscopy. It is not easy to estimate how long a barrier surrounding detailed energy-level and cross-section data could hold. Some classified data (e.g., diffusion-barrier technology) have been controlled fairly well for a substantial length of time. However, control of dissemination of diffusion-barrier technology has been successful partly because this technology has essentially no application other than uranium enrichment. In contrast, uranium atomic spectroscopy, laser spectroscopy, and high-power lasers are subjects of general interest and application and will be pursued whether or not AVLIs is pursued. In other words, development of gaseous-diffusion technology implies uranium-enrichment capability, whereas the basic knowledge and laser technology necessary for AVLIS have the potential of 
becoming generally available, in a period of more than 5 but probably less than 30 years, without any commitment to develop uranium-enrichment capability.

Therefore, it is reasonable to conclude that, between the years 2000 and 2010 , it would be possible for a substantial number of nations to develop AVLIS as a means of enriching uranium. However, the classification of AVLIS process technology would still serve to slow (but probably not stop) the acquisition of national capabilities to enrich uranium by a process of this kind; it might also limit the number and type of nations which could develop this process.

The necessary technical information could perhaps also be obtained by sophisticated subnational groups. However, the probable magnitude of the operation, in terms of physical size and the level and diversity of technology required, would make the successful operation of a clandestine facility by subnational groups unlikely.

While the separation of the uranium isotopes by the AVLIS process is clearly relevant and important to the issue of nuclear proliferation, the separation of the plutonium isotopes by this process is of limited significance. It is obvious that one cannot separate significant quantities of plutonium isotopes without first having a source of plutonium. But the acquisition of such plutonium (either reactor-grade Pu from a power reactor or weapons-grade Pu from a production reactor) in and of itself confers the potential for nuclear-weapons production; separation of these isotopes is not a necessary step. Thus, while separation of $\mathrm{Pu}$ isotopes by an AVI.IS process could assist a nation or subnational group in achieving a weapon with a higher yield or greater reliability, it would not significantly affect the ability to produce a nuclear weapon of some type. Plutonium isotope separation would be of greater significance to large-scale production--beyond the initial proliferation stage--of reliable weapons-grade plutonium. 


\section{II.2.3. AVLIS Safeguards Considerations}

Both domestic and international safeguards can be applied at an AVLIS uranium-enrichment facility in the U.S. with effectiveness comparable to that achievable for conventional (diffusion and centrifuge) technologies. There appear to be no insurmountable barriers to effective safeguards for a U.S. facility, as currently planned. Safeguards for an AVLIS plant can be implemented with techniques now in use for material measurements, containment, surveillance, and material control, although some will have to be adapted in a timely manner for application to the AVLIS process.

Unique safeguards considerations arise from the following characteristics of the AVLIS process (and also the latest version of the PSP process, discussed below): 1) The principal flows of uranium to and from the process consist of large numbers of relatively small uranium-metal ingots which may not be homogeneous (or easily homogenized) with regard to elemental and isotopic compositions, and thus may be difficult to characterize for material accountancy with the required accuracy and with a reasonably small number of measurements. 2) Since sma11 items of uranium metal (unlike $\mathrm{UF}_{6}$ in large cylinders) can be handled, moved, and stored without special containers or equipment, the AVLIS process provides little intrinsic containment for the uranium except when it is in the separation modules. 3) It is more difficult to deduce ${ }^{235} \mathrm{U}$ concentrations from measurements of passive radiations from process equipment than in the conventional $\mathrm{UF}_{6}$-based processes because uranium metal is strongly selfabsorbing for ${ }^{235} \mathrm{U}$ garma rays, because the $(\alpha, n)$ contribution to the neutron emission rate is greatly reduced due to the absence of fluorine, and because this rate is not simply correlated with the ${ }^{235} \mathrm{U}$ concentration. However, there appear to be tractable safeguards approaches in spite of these characteristics. 
The U.S. Department of Energy is actively sponsoring the development of both domestic and international safeguards approaches for the AVLIS productionplant design as it continues to evolve. As regards international safeguards, the objective is to develop an effective and efficient safeguards approach which would enable the IAEA to detect, with sufficient sensitivity and timeliness, both the diversion of nuclear materials and the production of highly enriched uranium (HEU), and which at the same time would protect sensitive enrichment technology.

As regards domestic safeguards, the present methods of material accountability, material control, and physical protection that have been developed for DOE facilities are applicable to the advanced-isotope-separation (AIS) enrichment plants. We anticipate that domestic safeguards can be applied at AIS plants with an effectiveness equivalent to that achieved at other" DOE facilities. Considerable experience has been gained at U.S. Government facilities concerning the control of and accounting for uranium metal. For the metal-based AIS processes, there may be some complexities in the details of the accountability procedures (e.g.: sampling methods and frequency), since the product and tails from these processes may consist of large numbers of relatively sma11 items with varying U-235 concentrations. It may be necessary to develop some specialized safeguards instrumentation in order to satisfy domestic accountability requirements, but no substantial problems are anticipated. The product from the metal-based processes may consist of small slugs of uranium which need not be contained continuously in process equipment and require no special container for movement. Thus, small slugs of enriched uranium could be removed with relative ease by an individual. This lack of intrinsic containment cculd be compensated for by special material-control procedures and by special 
containment facilities (e.g., portal monitors, vaults, etc.) such as are employed at HEU-metal processing facilities.

\section{II.3. Plasma Separation Process (PSP)}

\section{II.3.1. Description}

The Plasma Separation Process has been developed by TRW, Inc.(11) The principles involved here are simple and straightforward. First, a plasma of $U^{+}$ions is created within the field of a solenoid magnet. The plasma is heated and a rotating radial electric field is applied to the plasma at the cyclotron frequency of $235 \mathrm{U}^{+}$ions. The ions travel down the axial magnetic field in helical orbits, accelerated by an electric field. The ${ }^{235} \mathrm{U}^{+}$ions have more energy and larger orbital radii than the ${ }^{238_{U^{+}}}$ions because of the match between their cyclotron frequency and the frequency of the driving field. These differences are utilized to separate $235 \mathrm{U}$ from ${ }^{238} \mathrm{U}$. Uranium of various enrichment assays is deposited at different locations within the separation module and can be extracted (see Figüre II-2).

\section{II.3.2. PSP Proliferation Considerations}

Most of the questions related to proliferation are different from the two laser separation processes. Neither state-of-the-art laser technology nor optical cross-section data are required here. Barriers to proliferation consist of somewhat less complicated engineering problems, summarized below.

A major component, which is currently at state-of-the-art levels, is the large solenoid magnet which restricts the radius of the plasma. Equipment with specifications similar to those required for the PSP will soon be available commercially for the magnetic-fusion program. Large superconducting magnets are also being developed for high-energy particle accelerators in several countries, and it is reasonable to suppose that, by the year 2000 , when PSP could be fully 


\section{Plasma Isotope Separation Process}

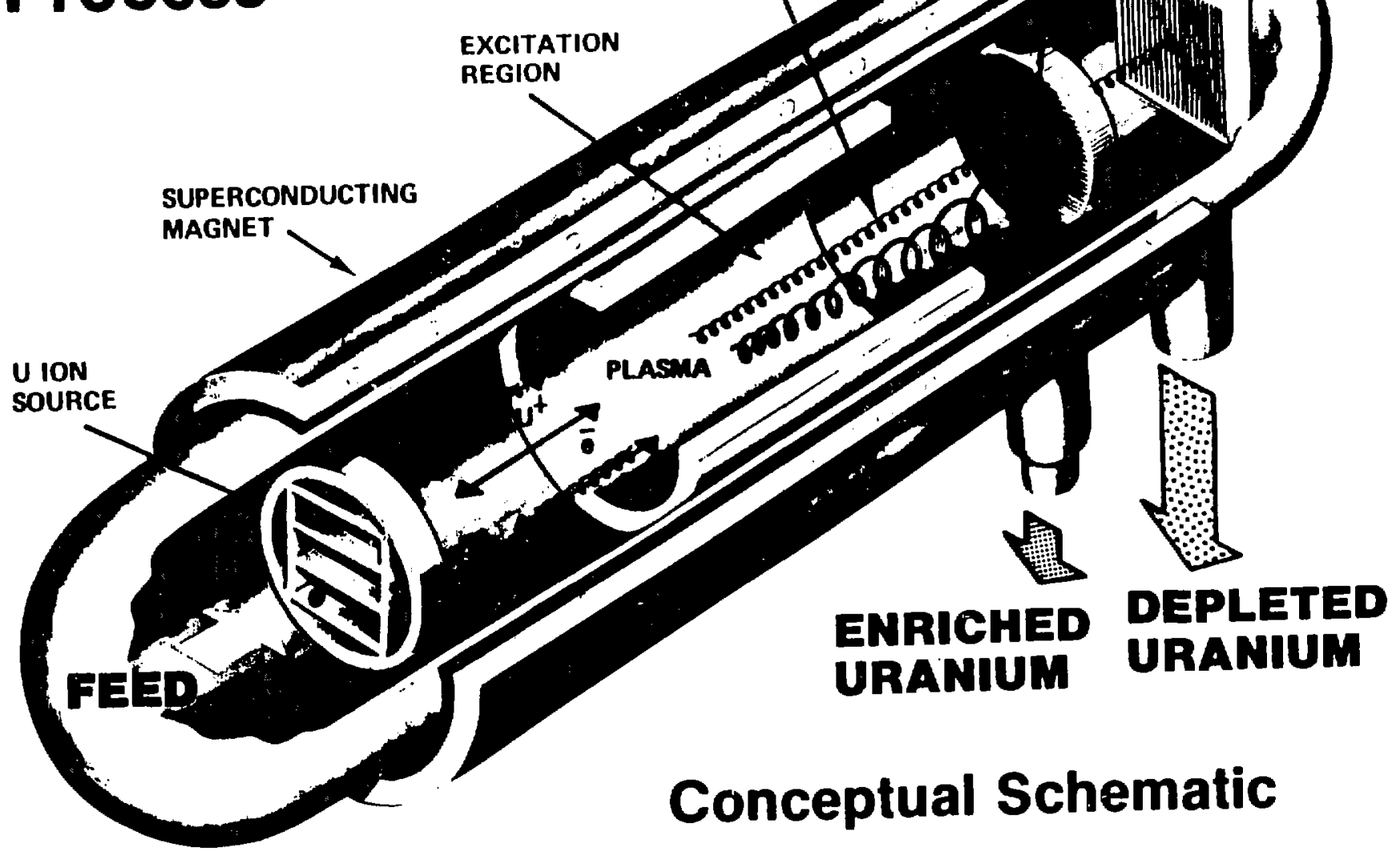

Figure II-2. Conceptual Schematic of PSP (after ref. 14) 
operational in a large plant, the magnet technology will be wideiy available, if not inexpensive. Details of magnet-building techniques are available in the open literature. Further, to build a small clandestine facility, it may not even be necessary to use superconducting magnets. A large conventional magnet would require more power, but would, even today, be relatively easy to procure and operate.

A more serious barrier to proliferation would be the gyrotrons (powerful, high-frequency vacuum tubes) which produce the rapidly rotating electric field. But these too, although not yet available, are being built at the Massachusetts Institute of Technology for use in magnetic-fusion devices. Consideration should be given to placing export controls on large gyrotrons.

The final engineering barrier to proliferation is the technology for handling high-temperature uranium, as is the case for AVLIS. Regarding PSP, the situation is similar: the technology is controlled and is not well-known or widely known. The technology could be duplicated in a country with moderate technological and industrial capability in the course of the next two to three decades.

It is unlikely that, within the next forty years, it would be possible for subnational groups to produce a clandestine plant, primarily because the necessary highly specialized materials and items would probably leave a clear trail which would be difficult to conceal.

II.3.3. PSP Safeguards Considerations

Comments concerning application of international safeguards to detect diversion of nuclear material or production of HEU are similar to those mentioned above in Section II.2.3. Domestic safeguards considerations also would be similar to those discussed for the AVLIS process. Large numbers of relatively small netal items, possibly with varying $235 \mathrm{U}$ concentrations, must be sampled and 
characterized with a practicably small number of measurements. More stringent material-control procedures, relative to $\mathrm{UF}_{6}$-based processes, may be necessary because of the relative ease with which small metal items can be handiea and transported without spesial containers or equipment. However, the safeguards needs are well within current capabilities.

II.4. Molecular Laser Isotope Separation (MLIS)

II.4.1. Description

The method was developed to the level of laboratory-size modules at Los Alamos National Laboratory, (11) and, unlike the other two methods, uses $\mathrm{UF}_{6}$ rather than $U$ metal as the chemical form for feed, product, and tails. Thus, it should immediately be noted that the technology of handling high-temperature uranium does not play a role as a barrier to proliferation. In other respects, however, the situation as regards proliferation and safeguards is similar to that for AVLIS.

The process is as follows. A stream of $\mathrm{UF}_{6}$ gas is forced through an expansion nozzle at high speeds to cool. the gas, thereby decreasing the population of higher-lying states. Then, infrared lasers of high power and high repetition rate preferentially excite ${ }^{235} \mathrm{UF}_{6}$ molecules to higher states. Following this, an ultraviolet laser dissociates the excited $\mathrm{UF}_{6}$ molecules to $\mathrm{UF}_{5}+\mathrm{F}$. The enriched $\mathrm{UF}_{5}$ condenses and is retrieved for later refluorination to produce a $\mathrm{UF}_{6}$ product (see Figure II-3). The process must be repeated several times to achieve the desired product enrichment.

II.4.2. MLIS Proliferation Considerations

Laser technology and spectroscopic cross sections are engineering and physics barriers here to the same extent as is true with AVLIS. The conclusions for this case would be the same. The only additional barrier would be the information and the technology related to high-velocity flow of $\mathrm{UF}_{6}$ gas. One would not 


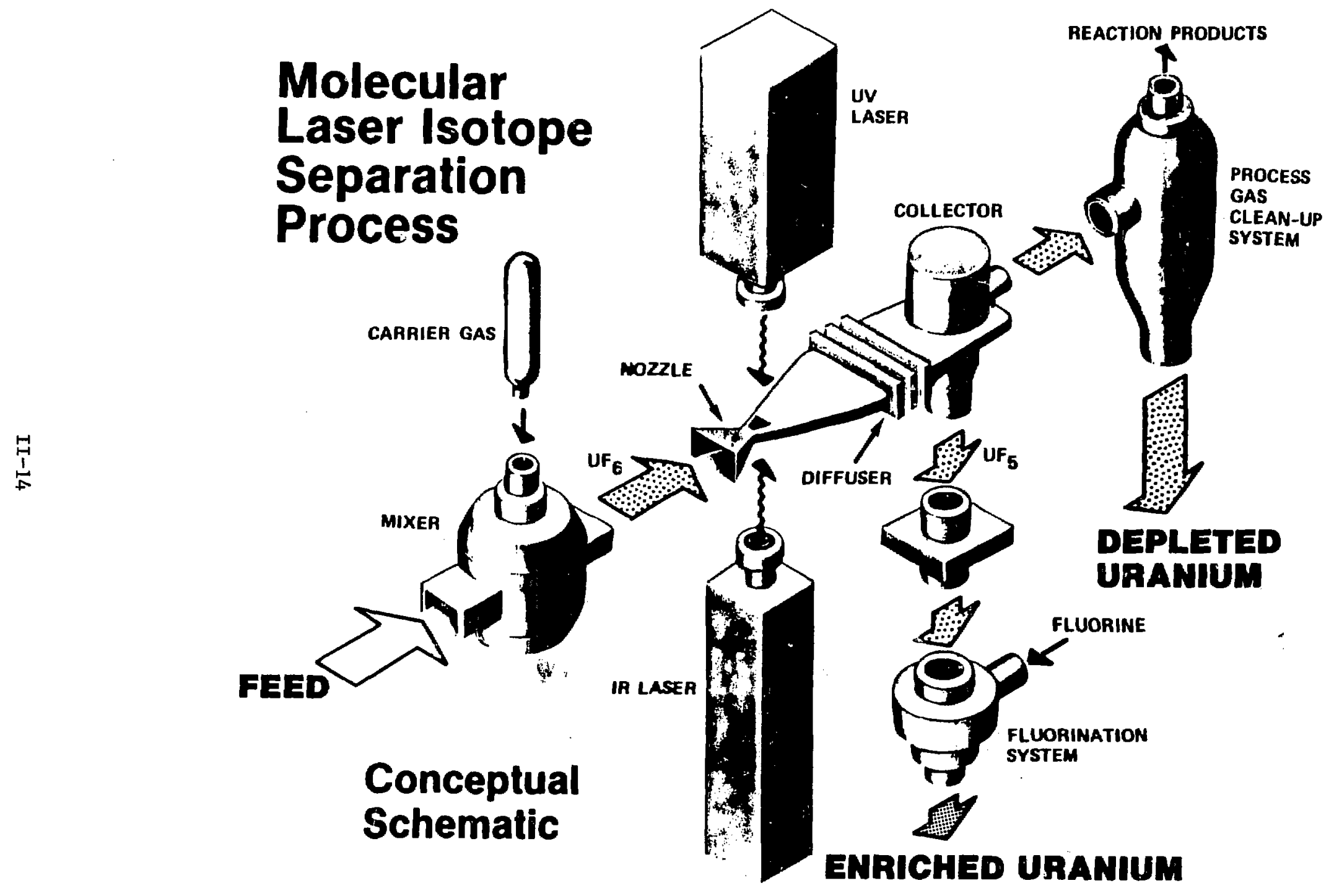

Figure II-3. Conceptual Schematic of MLIS (after ref. 14) 
expect this barrier to resist an assault by a nation with a moderate technical. base for more than a decade or two, if that long.

On a subnational level, for the foreseeable future, it is unlikely that even a small clandestine separation plant would be possible because of the varied high technology required and the difficulties of concealing such a program.

II.4.3. MLIS Safeguards Considerations

Roughly speaking, the same comments are in order as for the other two processes. That $\mathrm{UF}_{6}$ is used instead of metal gives some advantages over the metal-based processes: standard safeguards techniques in use at the existing enrichment plants are generally applicable for detecting diversion. Also, batches are fewer, larger; and easily homogenized, thus simplifying containment, sealing, and the taking of representative samples.

II.5. Policy Issues

II.5.1. Uranium Enrichment

Policy questions regarding the adoption of AIS techniques for uranium enrichment deal with proliferation possibilities and the applicability of international safeguards.

Proliferation is, perhaps, the greatest concern. As mentioned in Sections II.2 through II.4, it is unlikely that any of the three AIS technologies, if developed weuld be secure against duplication by a determined nation of middle technological ability over a period of 40 years. Completely independent development could also be accomplished over that period; on-gsing development in the U.S. would be an incentive.

A question which could be asked is, over a 20 to $30-j$ ear time frame, would laser or other advanced separation techniques become more proliferation-prone than the competing technique, namely, centrifuge enrichment? It is probably 
impossible to answer this with any pretense to accuracy, but a guess may be hazarded. It is, in our opinion, very unlikely that any of the advanced techniques described here will be very resistant to proliferation by nations with even moderate technological bases. Lasers, magnets, and gyrotrons wi11 a11 be developed for non-strategic reasons, and it will likely become impossible to prevent relevant research in these areas at any national university in the world, if the motivation is there to perform such research. Centrifuges of the type used for isotope separation have little other evident use at this time, hut, given the lead time of centrifuges over the alternative methods, the relevant technology will have been on the scene for a longer time and will be that much more vulnerable to spreading. The conclusion to which we are drawn is that there is no clear advantage of any of the newer separation technologies over the others with respect to the potential for proliferation over the long term.

If the U.S. develops one of the techniques, the question arises, should the technology be sold abroad, with IAEA safeguards serving to detect diversion or HEU production contrary to (assumed) non-proliferation agreements? While IAEA safeguards should, in principle, be capable of detecting the undeclared production of HEU and diversions of significant quantities of uranium, there are other scenarios which cause concern. First, the host nation could renounce the NonProliferation Treaty (NPT) and seize the plant, with the intention of rapidly converting it to tine production of HEU. Second, the state could use the knowledge acquired by operation of the facility to build a clandestine dedicated facility. None of the AIS techniques has an irherent barrier to such actions. Therefore, the same policy considerations which apply to transfer of, e.g., centrifuge enrichment or reprocessing technology should logically appl $j$ to transfer of AIs technology. 
Another matter which deserves consideration is the cost involved in placing any U.S. AVLIS plant on the list of facilities eligible for application of safeguards by the IAEA. According to the U.S.-IAEA Agreement, (12) only U.S. facilities having direct national-security significance are to be excluded. An AVLIS plant used exclusively for production of LEU for the commercial fuel cycle might be expected to have national-security significance similar to that of the GCEP, which was, in fact, offered and was selected by the IAEA for application of IAEA safeguards before it was terminated. The costs of safeguards for an AVLIS plant would include those necessary to protect sensitive technology under conditions of international inspection, a situation similar to that faced in designing a safeguards approach for the gas-centrifuge enrichment plants. (1)

But the expense of protecting sensitive technology is a burden inherent in. the Agreement. Therefore, to reduce the ultimate costs of applying international safeguards, it would be iesirable to take safeguards and nonproliferation concerns into account as the plant is designed. Non-nuc?earweapons states which are party to the NPT are obligated to place all their peaceful nuclear facilities under IAEA safeguards. In offering an AVLIS plant designed to produce exclusively LEU, the U.S. would be fulfilling its voluntary undertaking to offer its advanced peaceful nuclear facilities for IAEA inspections, thereby subjecting itself to the same economic burdens and risks of technology disclosure as non-nuclear-weapons states subject to IAEA safeguards.

II.5.2. Plutonium Isotope Separation

There are several issues which arise from the contemplated adaptation of the AIS techniques (probably AVLIS) to plutonium. The main purpose of developing plutonium isotope separation on a large scale presumably is to provide a method for removing unwanted Pu isotopes from materials irradiated in military reactors. In particular, this means separating ${ }^{238} 8_{\mathrm{Pu}}, 240 \mathrm{Pu}$, and $241_{\mathrm{Pu}}$ 
from old Pu stockpiles or from irradiated fuel generated by the Hanford NReactor. Removing the unwanted isotopes would transform reactor-grade plutonium into high-quality weapons-grade plutonium, far more suitable for efficient weapons of predictable yield. Further, the weapons-grade plutonium would be significantly less radioactive, making handling far easier and reducing health hazards to personnel. An additional minor purpose of plutonium AIs would be purification of ${ }^{238} \mathrm{Pu}$, used as a power source for deep-space vehicles.

There are some arguments which have been made to oppose development of plutonium-separation capability. First, the use of laser separation appears to be primarily aimed at use of irradiated reactor fuel for military purposes. Using commercial spent fuel for weapons is illegal. The law (13) was passed because the use of commercial spent fuel for weapons would bind commercial and military nuclear programs closely, marking a reversal of long-standing D.S. Government policy (in effect since the Atoms-For-Peace program of the 1950's) to separate the peaceful and military uses of nuclear energy.

A further argument offered against development of laser-isotope separation of plutonium is that the inability to restrict dissemination of the technology might result in the spread of nuclear weapons. This argument is less than convincing, since isotope separation does not create plutonium for weapons, but just makes the material more efficient for weapons purposes. It is now we11known that reactor-grade plutonium can be used to make a nuclear weapon. If a country (or sub-national group) has obtained plutonium, isotope separation would not add significantly to its capability. Without plutonium, Pu isotopeseparation capability would be useless and would not confer any nuclear-weapon capability. Given the expense and technological. development involved, it would appear more reasonable for the country to devote its efforts to the problem of obtaining the plutonium in the first place. 
Another relevant question is whether plutonium isotope-separation capability offers any significant advantages to a state which already possesses the capability for separation of uranium isotopes and is contemplating diversion of. nuclear material for production of nuclear weapons. Clearly if a state is contemplating a program for separation of plutonium isotopes, it has already acquired the plutonium, e.g., through reprocessing. By assumption, it also possesses the capability for enrichment of uranium. For a state which is just acquiring the minimum amounts of material necessary for production of nuclear explosives, the capability for separation of plutonium isotopes contributes little to its weapons capability, which is constrained by the quantity of weapon-usable material available and the capacity to produce such material (either plutonium or HEU).

For a state which already possesses some (plutonium) nuclear weapons or large quantities of plutonium and wishes to become a major nuclear-weapons power, the capability for separation of plutonium isotopes--in addition to the capabilities for uranium enrichment and reprocessing--would be advantageous in improving the quality or reducing the costs of the nuclear-weapons program. This scenario is obviously well beyond the level of initial proliferation and is most obviously relevant for the existing nuclear-weapons states.

Technological barriers to the use of AVLIS for plutonium separation are similar to those which hold regarding uranium: the atomic spectroscopy of the plutonium isotopes must be studied in detail, techniques for handling plutonium at high temperature must be developed, and lasers of sufficient power, lifetime, and repetition rate must be obtained. For MLIS, there are additional problems caused by the high neutron background rate in $\mathrm{PuF}_{6}$, arising from $(\alpha, n)$ reactions, and the difficulty of handling the material. For PSP, the process in- 
volves complicated nuclear-material handling, and expensive and difficult steps would have to be taken to reduce the health hazards to manageable proportions. 
References - Chapter II

1. Hexapartite Safeguards Project, J.H. Menzel, ed., "Safeguards Approach for Gas Centrifuge Type Enrichment Plants," Nuc. Mat. Management, V.XII

(4), 30, Winter, 1983.

2. E.W. Becker, W. Bier, P. Bley, W. Ehrfeld, K. Schubert, D. Seidel, "Development and Technical Implementation of the Separation Nozzle Process for Enrichment of Uranium-235", RfR 3310, Presented at the AICHE 1982 Winter Meeting, Orlando, Florida, February 28, 1982.

3. "The Agency's Safeguards (1965, as Provisionally Extended in 1966 and 1968)", INFCIRC/66/Rev. 2, International Atomic Energy Agency, Vienne, Austria, 1968 .

4. W. Bahm, D. Gupta, H.J. Didier, J. Weppner, "Nuclear Materials Management in a Uranium Enrichment Facility Based on the Separation Nozzle Process", Nuc. Mat. Management, V.VII (Proceedings Issue), 337-374, 1978.

5. P.C. Haarhoff, "The Helikon Technique for Isotope Enrichment", Translation of Article in Tydskrif vir Natuurwetenskappe, 16, 3-4, 68-126 (1976). (November 1976).

6. C. Frejacques, M. Gelee, D. Massignon and P. Plurien, "Evolution des Procedes de Separation des Isotopes de l'Uranium en France," Nuclear Power and Its Fuel Cycles, International Atomic Energy Agency, Vienna, Austria, 1977, Vol. 3, p. 203 (Proc. Conf. Salzburg, Austria, 2-13 May 1977).

7. J.H. Coates, C. Bernaud, P. Plurien, M. Gelee and J.M. Lerat, "Status of the Chemical Exchange Uranium Enrichment Process," Nuclear Power Experience, International Atomic Energy Agency, Vienna, Austria, 1982, Vol. 3, p. 497 (Proc. Conf. Vienna, 13-17 September 1982).

8. J-M Lerat, C. Lorrain, G. Sauzay and P. Venot, "Improving the Commercial Competitiveness of Chemex," Nuc. Eng. Internat., 29 (350), 25, January, 1984 .

9. S. Villani, Isotope Separation, American Nuclear Society, Hinsdale, Illinois, $19 \overline{76 .}$

10. "Atomic Vapor Laser Isotope Separation," LLL-TB-035, U.S. Government Printing Office: 1982/1-587-055/15, Washington, D.C., 1982.

11. Environmental Development P Lan-Advanced Isotope Separation, DOE/EDP-0061, U.S. Department of Energy, Washington, D.C., May 1979.

12. Envirommental and Natural Resources Policy Division, Library of Congress, "The International Atomic Energy Agency: Application of Safeguards in the United States", prepared for the Committee on Foreign Relations, United States Senate, 96th Congress, 1st Session, U.S. Government Printing Office, Washington, D.C., 1979. 
13. Public Law 97-415, 4 January 1983. Section 14 of this law amended Section 57 of the Atomic Energy Act of 1954 to include the prohibition as a new subsection (e). 


\section{NON-AQUEOUS REPROCESSING TECHNOLOGIES}

\section{III.1. Introduction}

Aqueous methods based on solvent extraction, such as the well-known Purex process, have become the basis of the most widely accepted technology for reproressing spent fuel on a production scale, both for present applications and for future projections. The chemical and engineering principles underlying these methods have been known and applied for a long time. In addition, the methodology and equipment involved draw on widely known and accepted industrial practice, both within and outside the nuclear field. The methods in question were originally developed with the object of achieving a high degree of fission product decontamination and U-Pu partition, However, urgent safeguards and non-proliferation considerations have recently prompted interest in options involving partial fission product retention, or "spiking", and incomplete U-Pu partition (coprocessing).

Despite the success of aqueous methods, development work on non-aqueous reprocessing technologies has been pursued intermittently since the middle 1950 's, both in the U.S. and abroad. The driving force behind these efforts has been the prospect of commercial deployment of fuel cycles centered on advanced reactor concepts, notably fast breeder reactors (FBRs). Non-aqueous methods have some intrinsic features which have long been recognized as being attractive in connection with reprocessing of advanced reactor fuels, from the viewpoint of both economics and safety. These are (a) relatively simple and compact apparatus, (b) production of waste predominantly in solid and therefore compact form, and (c) use of materials which are substantially more resistant to heat and radiation than aqueous and organic solutions. On the other hand, new and advanced concepts are involved, and it was clear from the outset that very substantial efforts in high temperature chemistry, metallurgy, material science, 
and engineering would be required to develop non-aqueous technologies suitable for implementation on a commercial production scale. Because of lack of sustained support for advanced reactor concepts and associated fuel cycles, progress has been sporadic, despite a great deal of significant and sophisticated work which was done both in the U.S. and abroad.

Two broad categories of non-aqueous technologies are defined for purposes of this report; a considerable number of avenues have been pursued in both areas, depending on the chemical and physical form of the fuel and on the resources available at the time the work was carried out.

- Pyrochemical Processes

These techniques are based on separations in which the chemical species involved are distributed between molten salt and molten metal phases. In essence these methods employ high temperature non-aqueous solvent extraction.

- Halide Volatility Processes

This approach is iased on the formation of volatile halides. Although techniques based on volatilization of chlorides have received some attention, their applicability appears to be limited to Th-based fuels. Most interest has focussed on fluoride volatility processes in which separations are effected on ...

the basis of the relative volatilities of $\mathrm{UF}_{6}, \mathrm{PuF}_{6}$, and various fission product fluorides.

Concern with safeguards and non-proliferation issues has led to renewed interest in non-aqueous reprocessing technologies. In particular, it was recognized during the latter half of the 1970's that the chemical equilibria involved in pyrochemical processes can be manipulated with relative ease to lead to partial retention of fission products and incomplete U/Pu partition, thereby providing a potential mechanism for implementing a spiking, or coprocessing option (or Doth). In 1977, ERDA outlined a Pyrochemical and Dry Processing Methods 
(PDPM) Program(1), closely related to the NASAP and International Fuel Cycle Evaluation (INFCE) efforts, and specifically aimed at development of reprocessing systems that reduce the risk of nuclear weapons proliferation. Argonne National Laboratory (ANL) was asked to act as the lead laboratory in this effort. Some valuable preliminary studies have emerged from PDPM, but further progress is contingent on broader policy decisions.

The present chapter will describe reference facilities based on two typical non-aqueous reprocessing technologies and briefly examine the safeguards and non-proliferation issues which would arise if these processes were to be. implemented on a commercial scale. The extensive work which has been done in various areas of non-aqueous reprocessing has produced a very substantial literature over the last 20-25 years, much of it in the form of reports and contributions to meetings and symposia. Some of this literature is difficult to obtain (especially on work performed outside the U.S.) and also difficult to judge in terms of future commercial exploitability, because lack of support has in many cases prevented adequate follow-up. After careful review of selected literature, it was decided to limit this report to the salt transport and fluoride volatility processes as applied to reprocessing mixed-oxide LMFBR fuels, with emphasis on work performed in the U.S. This choice was made for the following reasons:

- It will provide for a disscussion of one example each of the two categories identified above.

- It will emphasize a type of fuel which presents particularly intricate and pressing issues with regard to safeguards and non-proliferation in its deployment.

- Finally, a great deal of fundamental information, including conceptual flowsheets, has resulted from work carried out in the U.S. $(2,3,4)$ Experimental 
work includes both laboratory and pilot plant studies; at least two applications have become small scale production operations. Although much significant work has been performed abroad (especially in France, Japan, and the USSR), scanning of the available literature has failed to reveal developments which would materially affect conclusions derived from the U.S. work.

It is assumed that the fuel under consideration is clad with stainless steel, that the core consists of mixed oxide containing natural or depleted $\mathrm{UO}_{2}$ and about $20 \% \mathrm{PuO}_{2}$, and that burnup ranges between $6 \times 10^{4}$ and $10^{5} \mathrm{MWd} / \mathrm{te}$. It is further assumed that the reference facilities being discussed will handle an average of 6 core/axial blanket and about 4 radial blanket fuel assemblies per day, corresponding to about $1000 \mathrm{~kg}$ heavy metal, or $100 \mathrm{~kg} \mathrm{Pu}$, per day. This plant capacity is based on the fuel discharge rate from a 15,000 MW(e) network of LMFBR, approximately one third of the core fuel assemblies being replaced twice a year. It should be emphasized that the available process information is based on extrapolation from laboratory and limited pilot plant data. Furthermore, there continues to be widespread ambivalence as to the overall role of non-aqueous techniques in fuel reprocessing. Any conclusions drawn in this chapter are therefore rather general and must be regarded as speculative.

III.2. Reference Facilities

III.2.1. The Salt Transport Process

IIi.2.1.1. Background

Pyrometallurgical processes were first developed in the 1950 's, with the object of providing purification procedures which would leave fuels in their original metallic state throughout the process. These developments culminated in the successful use of melt refining as a method of reprocessing the enriched $U$ alloy fuel of the Experimental Breeder Reactor-II (EBR-II). In this technique the fuel is melted and 1 iquated for a prolonged period in a $\mathrm{ZrO}_{2}$ crucible. Fission 
products are removed partly through volatilization, partly through oxidation by the crucible material.

Further work in this area led to the development of a variety of processes characterized by the use of chemical oxidation-reduction reactions (hence the term "pyrochemical") accompanied by such separation techniques as distillation, precipitation, electrolysis, and liquid metal-molten salt solvent extraction, either singly or in combination. Most of these processes have remained in the laboratory and pilot plant stages; a few have become smal1-scale production operations, e.g., the molten-salt refining of Pu (LANL) and the extraction of Am from Pu metal (Rocky Flats).

The Salt Transport Process is based on selective transfer of actinides from one molten alloy to another, by extraction into and stripping out of an intermediate molten salt phase (transport salt). The present description of the process as applied to LMFBR fuel is based primarily on work published in $1969,(2,3)$ supplemented by a discussion of conceptual modifications for implementing a partial fission product retention and U/Pu coprocessing option, published about ten years later in connection with the PDPM Program. (1) In addition to the Salt Transport Process, the PDPM Program proposed to evaluate six other processes as applied to metal, oxide, and carbide fuels, from the viewpoint of safeguards and non-proliferation. One of these, the zinc distillation process, was actually selected as a reference pyrochemical process for the PDPM program. Flowsheets and detailed procedures were developed in concept. However, it has not been possible, to date, to accumulate the degree of laboratory and pilot plant information which is available for the Salt Transport Process.

III.2.1.2. Description of Reference Facility

Figure III-1(5) gives a schematic flowsheet for the process. The diagram illustrates the coprocessing option with partial fission product retention; 


\section{Figure III-1}

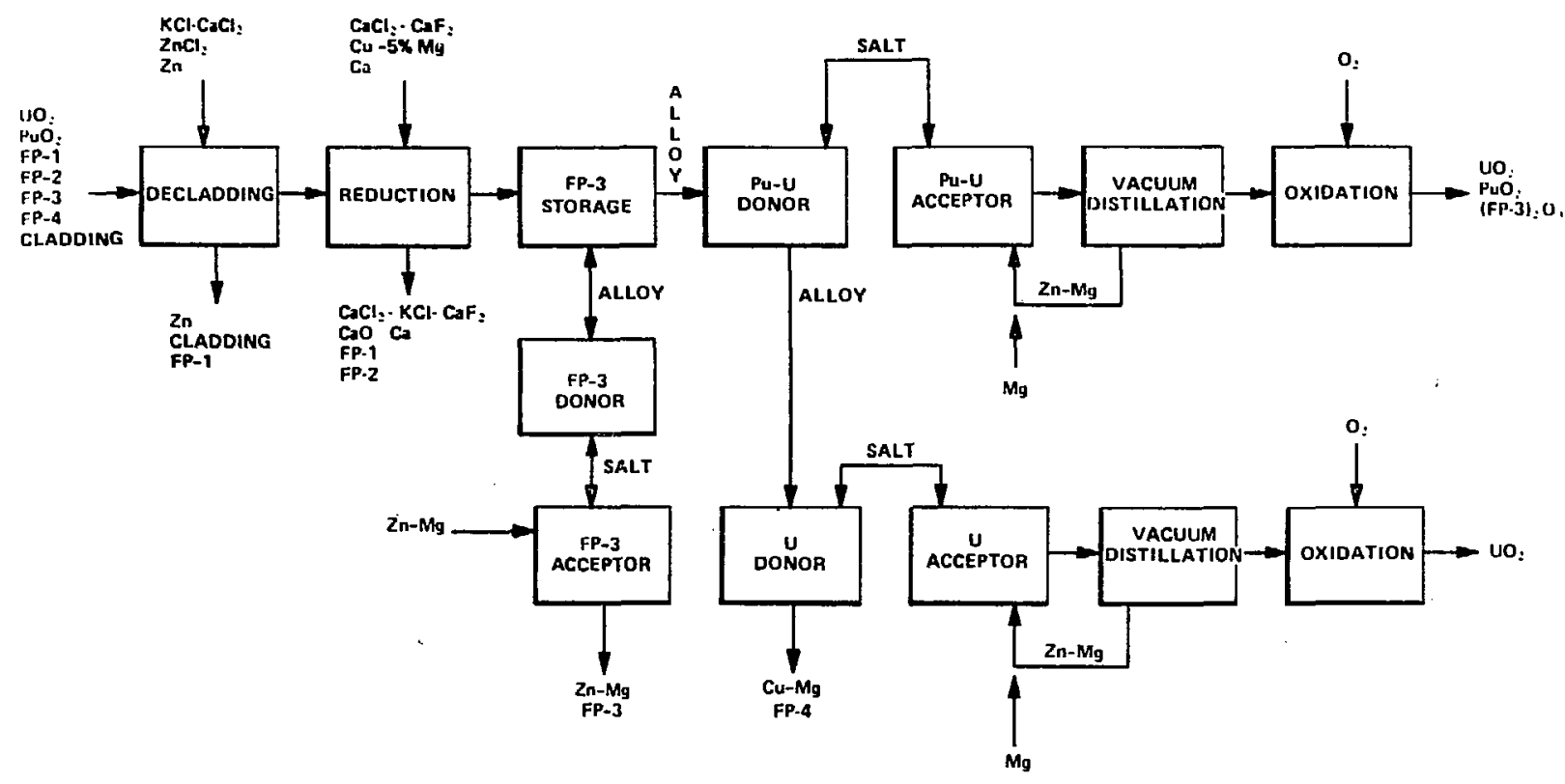

Conceptual sult tramsport process for $\mathrm{UO}_{2}-\mathrm{PuO}$, fuel 
modifications for complete separation would affect the schematic only in minor ways. The process consists of the steps outlined below; unless otherwise noted, the steps apply to either option.

(1) Decladding - the stainless steel cladding is dissolved by immersing fuel elements in liquid $\mathrm{Zn}$ at about $800^{\circ} \mathrm{C}$. A molten $\mathrm{CaCl}_{2}-\mathrm{CaF}_{2}$ layer is placed on top of the liquid metal to inhibit vaporization. The gaseous fission products (FP-1) are released as the cladding is breached. The $\mathrm{Zn}$-stainless steel alloy, which may have dissolved some of the more noble fission products, is separated from the oxide fuel and may be recovered.

(2) Oxide reduction - This step is performed in the same vessel as the preceding one. It consists of contacting the oxide with a two-phase system made up of a Cu-Mg-Ca alloy and molten $\mathrm{CaCl}_{2}-\mathrm{CaF}_{2}$ at about $800^{\circ} \mathrm{C}$; the $\mathrm{Cu} / \mathrm{Mg}$ ratio in the alloy, while not critical for this step, is selected with a view to further operations (see below). The oxide is reduced by $\mathrm{Ca}$, and the resulting metals are taken up by the alloy along with fission products more noble than $\mathrm{Ca}(\mathrm{FP}-3$ and 4). Uranium is present in excess of its solubility limit under these conditions and precipitates as a U-Cu intermetallic compound; the extent to which U separates out depends on the $\mathrm{Cu} / \mathrm{Mg}$ ratio in the alloy. The CaO produced in the reduction step and FP-2 fission products are taken up by the molten salt which can be recycled.

(3) Separations - This category includes several steps which are being combined in this report for the sake of clarity. It is at this stage that a choice can be made between attainment of virtually complete U-Pu partition and the coprocessing option. The principle involved is illustrated by the following schematic chemical reaction which represents an equilibrium between a liquid alloy and the active component of a molten salt phase (transport salt):

$$
M(a 1 l o y)+3 / 2 \mathrm{MgCl}_{2}(s a 1 t) \ddagger M C \ell_{3}(s a 1 t)+3 / 2 M g(a 1 l o y) .
$$


Here $\mathrm{M}$ represents $\mathrm{U}, \mathrm{Pu}$, and rare earth fission products (FP-3). It may be shown that the distribution coefficient of $M, D=X_{M C l} / X_{M}$ ( $X=$ mole fraction) depends not only on the relative thermodynamic stability of the chlorides involved but also on the nature and composition of the alloy (i.e., the "activity" of $\mathrm{Mg}$ in the alloy phase). Furthermore, the rate of transfer depends on the solubility of $\underline{M}$ in the alloy phase. Cu-Mg alloys tend to bring about a distribution of $M$ which is more in favor of the salt phase ("donor alloys", d.a.) than is the case for $\mathrm{Zn}-\mathrm{Mg}$ alloys ("acceptor alloys," a.a.). Appropriate choice of alloys therefore makes possible a degree of control over the distribution of the various elements between the alloy and salt phases, and hence over the relative extent of the separations achieved.

Based on these considerations, the $\mathrm{Cu}-\mathrm{Mg}$ alloy from step (b) is next used in the role of a donor alloy and contacted with a $\mathrm{NaCl}-\mathrm{KCl}-\mathrm{MgCl}_{2}-\mathrm{MgF}_{2}$ melt in a multi-stage, mixer-settler battery at about $650^{\circ} \mathrm{C}$. The NaCl and $\mathrm{KC1}$ serve as diluents to lower the melting point of the salt below this convenient working temperature. Under these conditions the FP-3s are extracted into the salt phase, achieving a very high Pu-rare earth decontamination factor (about $10^{2}$ per stage). Alternatively, the process can be designed in such a manner that only a fraction of the FP-3s is separated from the actinides while the rest follows the $\mathrm{Pu}$ through the rest of the process.

The next step is designed to achieve either a virtually complete or a partial partition of $\mathrm{U}$ and $\mathrm{Pu}$. In the original concept a $\mathrm{Mg}-\mathrm{rich}$ ( $\mathrm{Cu}-57$ at. $\% \mathrm{Mg}$ ) alloy is used as d.a. and contacted with the $\mathrm{MgCl}_{2}$-containing molten salt, using the final stages of the aforementioned mixer-settler battery; a $\mathrm{Zn}-30$ at.\% $\mathrm{Mg}$ alloy serves as a.a. Separation of $U$ from Pu under these conditions is aided by the fact that (a) the distribution coefficient of $\mathrm{Pu}$ in the d.a.-sa1t system is greater than that of $U$ and (b) the rate of $U$ transfer is inhibited by the exceed- 
ingly low solubility of $\mathrm{U}$ in the $\mathrm{Mg-rich} \mathrm{d} . \mathrm{a} .(0.005 \%)$. To achieve a higher degree of decontamination of Pu from the noble fission products (FP-4), the trans-port salt may, if desired, be contacted with an intermediate alloy (Cd-50 at.\% $\mathrm{Mg}$ ) before being exposed to the a.a.

By contrast, use of a $\mathrm{Cu}-16$ at.$\% \mathrm{Mg}$ alloy as $\mathrm{d} . \mathrm{a}$. can be shown to result in an incomplete U-Pu separation, as would be desirable for a coprocessing option. Because $\mathrm{U}$ is quite insoluble even in the low-Mg d.a., the rate of transfer of $\mathrm{U}$ will still be less than that of $\mathrm{Pu}$, so that the actinides recovered in the a.a. will be enriched in Pu to a degree desirable for LMFBR recycle.

(4) U salt transport separation - The U precipitate in the decladding/reduction vesse 1 may be decontaminated from FP-4s and small amounts of coprecipitated $\mathrm{Pu}$ by dissolution in a $\mathrm{Cu}-6$ at.\% $\mathrm{Mg}$ d.a. and transfer to a suitable $\mathrm{Zn}-\mathrm{Mg}$ a.a. via the transport salt.

(5) Vacuum distillation - All the a.a. matrixes are volatile and can be separated from the $\mathrm{U}$ and $\mathrm{Pu}$ (or $\mathrm{U}-\mathrm{Pu}$ ) solutes.

(6) Fuel oxidation - U product is converted to oxides for either blending or fabrication of blanket fuel. Pu product or coprocessed U-Pu is converted to oxide for fuel fabrication.

III.2.1.3. Sareguards-Related Design Concepts

Although the Salt Transport Process has not been implemented as an $j a^{-}$ tegrated operation, extensive experimental work was done during the 1960's on many of the unit processes discussed above, mostly at ANL. These activities included both laboratory and larger bench scale studies, involving $\mathrm{U}, \mathrm{Pu}$, fissium* mixtures as well as small mockup $\mathrm{UO}_{2}$ fuel assemblies. The efficiency of the decladding and oxide reduction steps was demonstrated conclusively. A

*Fissium is defined as "an alloy containing nonradioactive fission elements in approximately equilibrium concentrations"( 6$)$. 
number of salt transport experiments were done individually on $U, P u$, and representative rare earth elements and indicated recoveries of $99 \%$ or better or the basis of predictions from laboratory data. Information on the engineering feasibility of the materials, equipment, and glove box operations involved was an important by-product of this work. Preliminary studies were made on a conceptual design of a Salt Transport Process with a capacity of 1 te/day of LMFBR core and blanket fuel; the process is summarized by the following quotation(2): "It appears that two decladding. vessels about $7 \mathrm{ft}$. tall and $18 \mathrm{in}$. in diameter would be required with three fuel assemblies being declad at a time in each vessel. These vessels would most likely be made of tungsten or have a tungsten 1 ining. The oxide reduction operation would be done in the same vessels. The mixer-settler bank for rare earth removal and plutonium salt transport would be about $20 \times 24$ in. and about $6 \mathrm{ft}$. long. Niobium appears to be a suitable material for this unit, except in the last stage where tantalum or a tantalum lining might be used. In the plutonium retorting step, criticality considerations probably would require three units of slab geometry about $20 \times 30 \mathrm{in.} \mathrm{by} 1-1 / 2$ in. thick, although a single unit may be feasible. The three-stage mixer-settler for uranium decontamination would be about $10 \times 20 \mathrm{in}$. and $2 \mathrm{ft}$. long. This equipment and the plutonium retort would both be made of a refractory metal such as tungsten. The uranium accumulation vessel could be made of graphite and would be about $18 \mathrm{in}$. in diameter and $5 \mathrm{ft}$. tall. For fuel resynthesis, tro 8-in. dia. and two 24-in. dia. fluidized bed reactors about $6 \mathrm{ft}$. tall would be used for core and blanket material, respectively. Stainless steel would be a suitable material for these units. In addition to the major process equipment, various other vessels would be required for making up and charging solvents, holding process solutions and disposing of waste streams. Nevertheless, it appears that a plant of this type would be quite compact."

Activities sponsored by the PDPM Program on a coprocessing option have so far been limited to conceptual design studies. A key feature of the proposed design is the avoidance of remote transfer of solids. It is proposed, instead (5), to adopt a rotating assembly with dedicated precess stations designed to operate sequentially on the same tungsten crucible. For example, four stations would be designed to carry out decladding, oxide reduction, FP-3 decontamination, and salt extraction of $\mathrm{U}-\mathrm{Pu}$, respectively. Although calculations of $\mathrm{U} / \mathrm{Pu}$ flows and inventories do rot appear to be available, Table III-1(5) gives an idea of 
Table III-1

Process Volumes

\begin{tabular}{|c|c|c|c|c|c|c|c|}
\hline \multirow[b]{2}{*}{ Operation } & \multicolumn{3}{|c|}{$\mathrm{Kg}$} & \multicolumn{3}{|c|}{ Liters } & \multirow[b]{2}{*}{$\begin{array}{l}\text { Design } \\
\text { Vol ume }\end{array}$} \\
\hline & Salt & Metal & Total & Salt & Metal & Totál & \\
\hline $\begin{array}{l}\text { Decladding } \\
\text { Reduction } \\
\text { FP-3 Donor } \\
\text { FP-3 Acceptor } \\
\text { U-Pu Donor } \\
\text { U-Pu Acceptor } \\
\text { U Donor } \\
\text { U Acceptor }\end{array}$ & $\begin{array}{r}15.0 \\
202.1 \\
30.0 \\
30.0 \\
270.0 \\
270.0 \\
270.0 \\
270.0\end{array}$ & $\begin{array}{r}581.9 \\
378.0 \\
49.6 \\
22.0 \\
371.9 \\
224.3 \\
331.5 \\
265.8\end{array}$ & $\begin{array}{r}596.9 \\
580.1 \\
79.6 \\
52.0 \\
641.9 \\
494.3 \\
601.5 \\
535.8\end{array}$ & $\begin{array}{r}7.0 \\
89.4 \\
16.7 \\
16.7 \\
150.0 \\
150.0 \\
150.0 \\
150.0\end{array}$ & $\begin{array}{r}78.4 \\
-45.6 \\
5.6 \\
4.6 \\
42.4 \\
32.6 \\
42.8 \\
45.5\end{array}$ & $\begin{array}{r}85.4 \\
135.0 \\
22.3 \\
21.3 \\
192.4 \\
182.6 \\
192.8 \\
195.5\end{array}$ & $\begin{array}{r}250 \\
250 \\
30 \\
30 \\
250 \\
250 \\
250 \\
250\end{array}$ \\
\hline
\end{tabular}


the various process weight and volumes of salt and metal present at each major operation, for the vessel design volume selected. The numbers correspond to a feed of one core-axial blanket fuel assembly.

\section{III.2.2. The Fluoride Volatility Process}

III.2.2.1. Background

It was recognized in the $1950^{\prime} \mathrm{s}$ that conceptually attractive fuel reprocessing schemes could be based on the high volatility of the actinide hexafluorides, especially in view of the considerably lower volatility of the fluorides of several key fission products (Fig. III-2) ${ }^{(4)}$. A large body of work resulted, in the U.S. as well as abroad, involving various types of reactor fuels, fluorinating agents, and separation/decontamination techniques. Much fundamental information emerged from these activities and led in turn to increasingly sophisticated approackss towards solving the intricate experimental problems inherent in the technology.

In the earlier years interest focused on high enrichment fuels for test reactors (e.g., the Materials Testing Reactor; MTR), mobile power reactors, and others. A typical approach was to immerse the fuel in a molten fluoride salt mixture and dissolve it by sparging the melt with anhydrous $H F$. Conversion to $\mathrm{UF}_{6}$ and fission product fluorides was originally carried out using elemental $\mathrm{F}_{2}$ gas, an approach which remained of interest for some time in connection with development work on the Molten Salt Reactor at Oak Ridge National Laboratory (ORNL). However, the need for rapid removal of the heat developed by the highly exothermic fluorination reactions led to studies on the use of liquid interhalogen compounds (mainly $\mathrm{ClF}_{3}$ and $\mathrm{BrF}_{3}$ ) as a replacement for $\mathrm{F}_{2}$. At the same time the development of fluidized bed technology led to the use of inert granular media with more favorable heat capacity and heat transfer properties than those afforded by molten salts. 


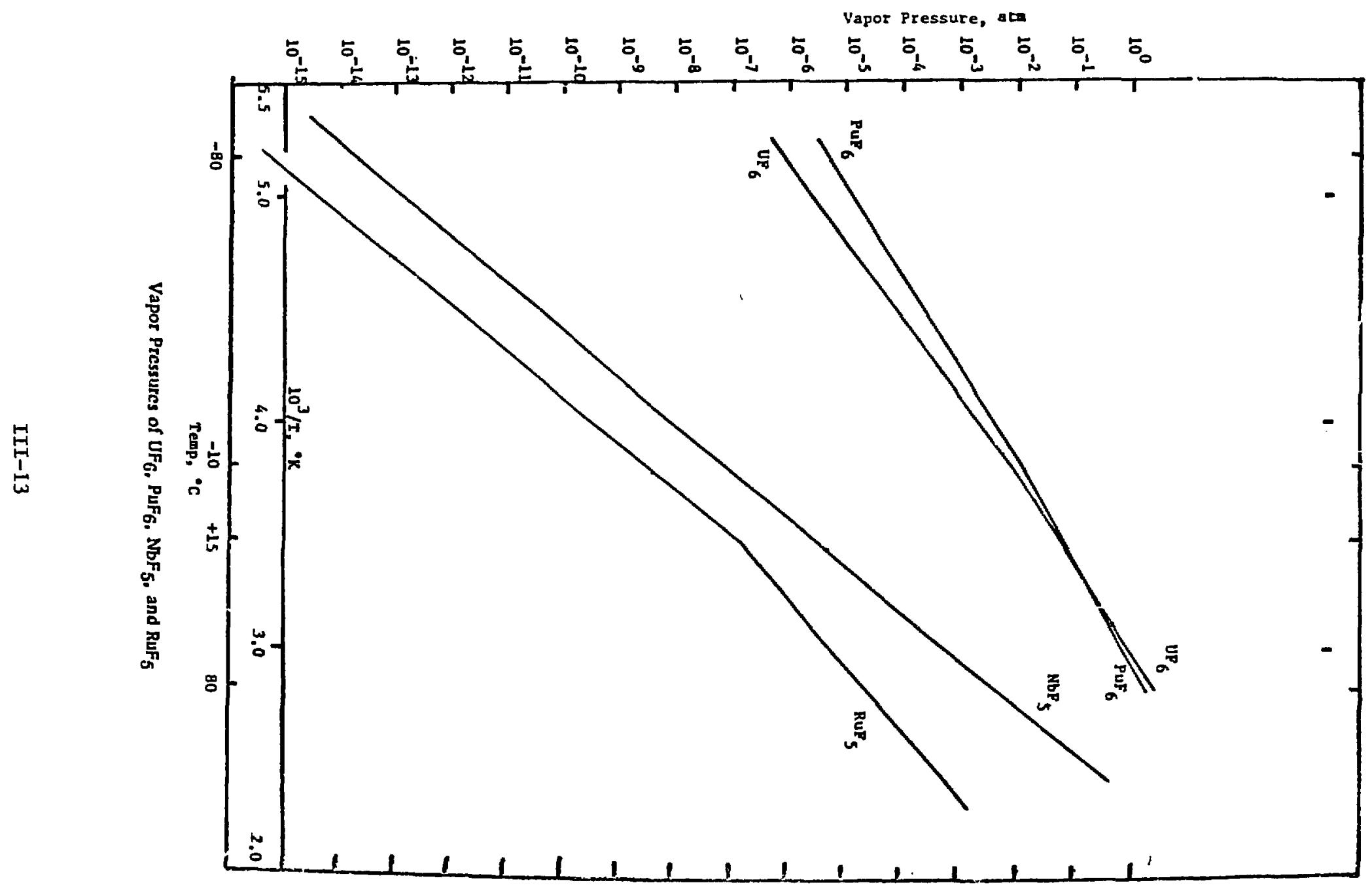


Interest in low-enrichment fuels has centered around reprocessing of ceramic fuels contemplated for power reactors. Successful. application to this type of fuel necessitated systematic studies of the properties of $\mathrm{PuF}_{6}$, including its formation, stability, and separability from $\mathrm{UF}_{6}$ and assorted fission product fluorides. It was concluded that interhalogen compounds are not sufficiently powerful fluorinating agents for effective conversion of $\mathrm{PuO}_{2}$ or $\mathrm{PuF}_{4}$ to $\mathrm{PuF}_{6}$. Practical concepts are therefore based on the use of elemental $\mathrm{F}_{2}$ in a fluidized bed medium. A variety of separation techniques was explored, including fractional distillation, selective adsorption, and selective thermal decomposition. Several decladding schemes were similarly explored, chemical as well as mechanical. As the 1960 's progressed, the focus of interest shifted to mixed-oxide FBR fuel. In 1969 ANL summarized its efforts in a detailed conceptual design study (ANL-7583)(4) of a reference fluoride volatility plant for reprocessing stainless steel clad mixed-oxide LMFBR fuel, which serves as hasis for the discussion below. In the absence of adequate support, publication of this report essentially marked the end of U.S. efforts in fluoride volatility reprocessing. Although sporadic work appears to be continuing abroad, notably in France, Japan, and the USSR, there are no indications of major efforts or breakthroughs. Nevertheless, a sufficiently sound technical foundation of a non-aqueous approach to reprocessing of FBR fuel has been established to warrant consideration as a non-proliferating technology within a long-term perspective.

III.2.2.2. Description of Reference Facility

This section summarizes the reference process described in ANL $7583,(4)$ with the main emphasis on safeguards-related aspects. The process was designed by extrapolating experimental information that had been accumulated from laboratory and limited pilot plant studies. No attempt is made to optimize the process steps; instead, emphasis is placed on available equipment and known techno1- 
ogy. Numerous alternative steps were recognized as the report was written and are identified by its authors as possible improvements. The point is made repeatedly that the document is intended merely as a feasibility evaluation and that substantial engineering development would have to precede practical implementation; one chapter is devoted to summarizing problem areas. In addition to a brief section on accountability, the report contains material on criticality control which provides some background for safeguards consłderations. All figures and tables are taken or adapted from ANL 7583.

The reference facility uses a mechanical head-end process to proride, from irradiated stainless steel-clad $\mathrm{UO}_{2}-\mathrm{Pu}_{2}$ fuel consisting of the combined core and blankets, a fluidizable oxide feed for continuous fluid-bed fluorinators. With appropriate temperature and reagent concentration in the fluorinators, first the uraniun and then the plutonium are converted to hexafluorides and separated from those fission products that remain with the alumina bed as nonvolatile fluorides. A continuous stream of granular alumina serves as a vehicle for moving these nonvolatile fission products through the fluorinators to waste receivers. The overhead $\mathrm{UF}_{6}$ and $\mathrm{PuF}_{6}$ streams are purified, using cold traps and selective sorption, thermai decomposition, and fractional distillation. The purified $\mathrm{UF}_{6}$ and $\mathrm{PuF}_{6}$ are recombined and converted to a mixed particulate oxide product. High-level wastes are stored in solid form on-site for the life of the plant, followed by shipment off-sil, possibly to a salt cavern. Intermediateand low-level solid wastes are converted to a form suitable for long-term storage on-site. Intermediate- and low-level liquid wastes are treated to the degree necessary so that a11 effluent discharged is within the applicable limits. Waste concentrates are solidified and handled as outlined above. Total containment of gaseous wastes is planned. In the reference process, off-gas and vent streams are so treated that the gases are converted to stable solid waste forms 
or compressed to relatively small volumes for storage. Gaseous waste discharges are held within the applicable limits set by regulations.

An overall diagram of the reference facility is shown in Figure III-3. The daily average feed postulated for the process is indicated in Table III-2. The plant processes core, axial blanket, and radial blanket material on a 300 daysper-year basis. The process is designed to give a highly decontaminated product of $409 \mathrm{~kg} 23 \mathrm{wt} . \% \mathrm{PuO}_{2}-\mathrm{UO}_{2}(\backsim 83 \mathrm{~kg} \mathrm{Pu})$ per day. The $\mathrm{UF}_{6}$ in excess over the amount required for conversion to this product ( $856 \mathrm{~kg} \mathrm{UF}_{6}$ per day) is stored for shipment off site. The process may be readily adapted to the production of pure $\mathrm{PuO}_{2}$ or varying degrees of coprocessing. There is also enough flexibility to provide for a degree of fission product retention.

Citicality considerations have had a major influence on design of the reference facility. Slab design is used for all process equipment exposed to significant amounts of $\mathrm{Pu}$. Both continuous-processing equipment and batchprocessing equipment have been specified for the reference plant. Much industrial experience is available on fluidized bed and distillation operations, and continuous processing equipment can be specified for these operations. On the other hand, relatively little or no information is available for continuouscold-trapping devices; therefore semi-continuous (batch) processing equipment had to be specified for the cold traps and most of the other components. This balanced design is useful from the criticality viewpoint.

The main process steps and their basic objectives are:

(1) Mechanical head-end; separate the fuel from the cladding.

(2) Continuous fluid-bed fluorination, using a continuous stream of granular alumina as the fluid bed medium. Separate first the uranium, then the plutonium as hexafluorides from the bulk of radioactive fission products (Groups I, II, III, and IV) that do not form volatile fluorides.

(3) Plutonium purification and separation from $\mathrm{UF}_{6}$. 
Figure III-3

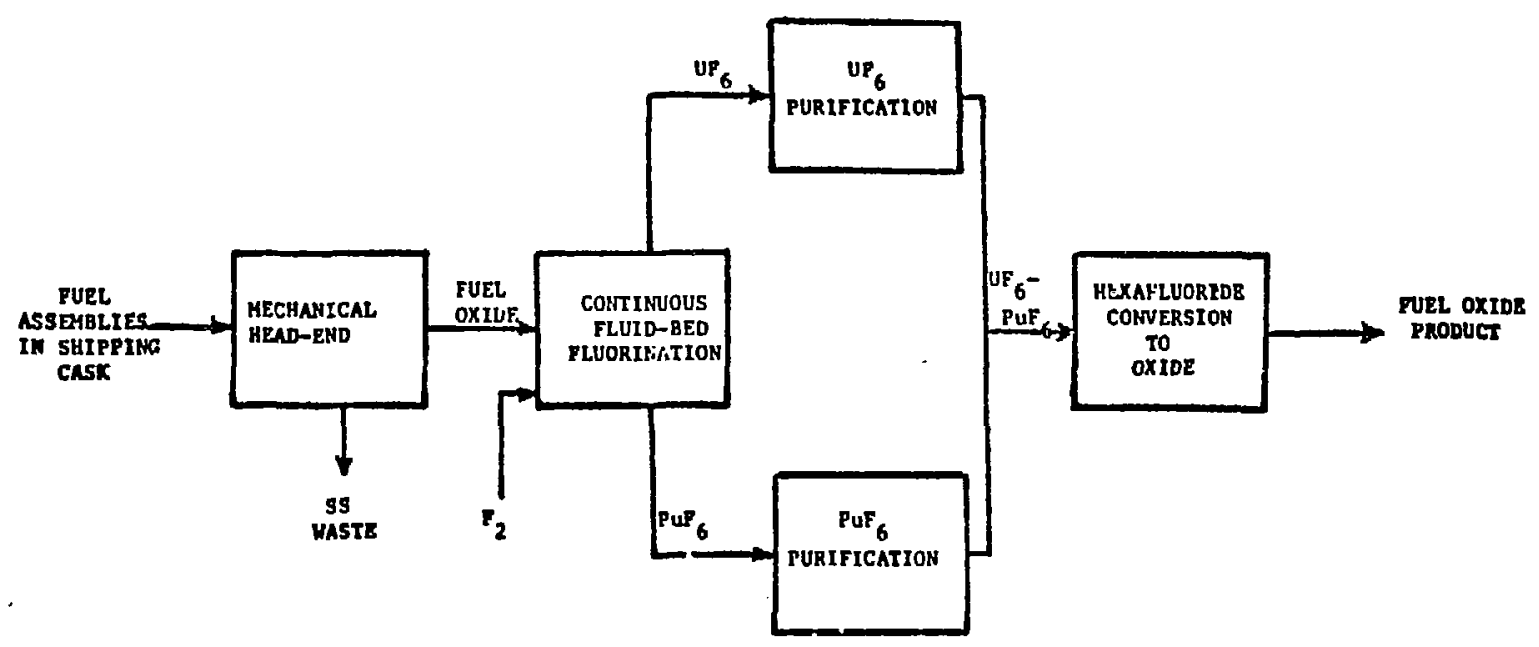

Conceptual Fluoride-volatility Process for LMFBR Fuels.

Reference fuel: $\mathrm{PuO}_{2}-\mathrm{UO}_{2}$ clad in staínlcss steel. 
Table III-2

Reference Daily Processing Load

\begin{tabular}{|c|c|c|c|c|c|}
\hline \multirow[b]{3}{*}{ Fuel Component } & \multicolumn{5}{|c|}{ Daily Discharge Rate, kg } \\
\hline & & & Core plus & & \\
\hline & Core & $\begin{array}{c}\text { Axial } \\
\text { Blanket }\end{array}$ & $\begin{array}{c}\text { Axial } \\
\text { Blanket }\end{array}$ & $\begin{array}{l}\text { Radial } \\
\text { Blanket }\end{array}$ & Total \\
\hline $\mathrm{u}$ & $223^{a}$ & 178 & 401 & 474 & 875 \\
\hline $\mathrm{Pu}$ & $72.3^{\mathrm{a}}$ & 1.6 & 73.9 & 9.6 & 83.5 \\
\hline $\mathrm{U}+\mathrm{Pu}$ & 295.3 & 179.6 & 474.9 & 483.6 & 958.5 \\
\hline F.P. & 35.06 & 1.08 & 36.14 & 2.84 & 38.98 \\
\hline
\end{tabular}

Fuel Elements Processed per Day

Core plus axial blanket: 6

Radial Blanket

Inner ring: 2.6

Outer ring: 1.5

aThese values, representing $22 \% \mathrm{PuO}_{2}-\mathrm{UO}_{2}$ corc fuel, were used for all calculations made in this study. 
(4) UF 6 purification.

(5) Conversion; convert a $\mathrm{UF}_{6}-\mathrm{PuF}_{6}$ product mixture to a particulate oxide solid for refabrication into core fuel.

It is assumed that the fuel will be transported to the reprocessing plant in sodium-filled containers inside shielded casks. After the fuel is removed from the containers, any sodium remaining on the fuel subassemblies will be removed by controlled oxidation and washing.

Each step will now be described in more detail.

(1) The mechanical head-end operations consist of the following sequence of steps:

(a) Unloading of fuel elements from shipping containers.

(b) Removal of sodium from external surfaces of the fuel elements in a cleaning vessel, by reacting with dry air followed by washing with water.

(c) Transfer of fuel elements into the storage pool.

(d) Underwater mechanical disassembly of fuel elements into individual fuel pins.

(e) Assay of fuel pins to identify sodium-logged pins, using an eddycurrent device (the ground rules in ANL -7583 postulate that an average of $1 \%$ of the fuel pins will be sodium-logged).

(f) Reassembling of intact fuel pins into 25-pin bundles for feeding to the pin chopper; logged pins are automatically deflected by the measuring device to a separate storage rack for later processing.

(g) Chopping of the fuel pins into short (s 1/2-in.) lengths.

(h) Continuous ball-milling of the fuel to separate powdered fuel from the hulls.

(i) Examination of separated stainless steel $\mathrm{f}_{1}$ i. 's by active delayed neutron measurement.

(j) Pneumatic conveyance of the fuel powder to three critically safe interim storage hoppers ( 2 " $\times 36^{\prime \prime} \times 120^{\prime \prime}$ or $2.2 \times 10^{4} \mathrm{~cm}^{3}$ ) preparatory to chemical processing. 
The storage hoppers are weighed continuously, during both filling and emptying operations. The weight change during filling serves as a check on the material flow rate through the ball mill. The full hopper is weighed for accountability; process feed-rate information is obtained as the hopper is emptied, and used for both monitoring and process control.

The fuel is discharged by gravity out of the bottom of the charge lisper and conveyed by a circulating oxygen stream to the fluorination system. Samples for further accountability and burnup measurements are taken out of the conveyor line. Sintered granular alumina is injected into the feed 1 ine downstream from the sampling point to give a ratio of fuel to alumina of 5 to 1 . This material serves as the major constituent of the fluidized bed used during the fluorination steps. It is assumed that complete mixing occurs in the fluorination reactors, so that the average fluidized bed composition in each reactor is the same as the corresponding solid effluent composition.

(2) Fluidized bed fluorination

Figure III-4 illustrates schematically the fluidized bed fluorination system used in the reference process.

Two fluorination reactors are operated continuously in series. Reactors $A$ and $B$ are designed to yield virtually all the $\mathrm{UF}_{6}$ and $\mathrm{PuF}_{6}$, respectively. Associated with each reactor are two cold traps (CTs; desublimators) in series. Those marked FP are fission product traps; the CTs are kept at lower temperatures to trap the more volatile solid $\mathrm{UF}_{6}$ and $\mathrm{PuF}_{6}$, respectively. The reactors and traps are of slab geometry as illustrated in Figure III-5 to promote criticality safety and temperature control by providing a high surface-to-mass ratio. In reactor $A$ the feed stream is subjected to a $23 \% \mathrm{~F}_{2}-\mathrm{O}_{2}$ gas mixture at $350^{\circ} \mathrm{C}$; the gas stream serves both as fluorinating agent and fluidizing medium. Under these conditions $99 \%$ of the $U$ is transformed into gaseous UF 6 ; the 
Figure III-4

$\therefore$

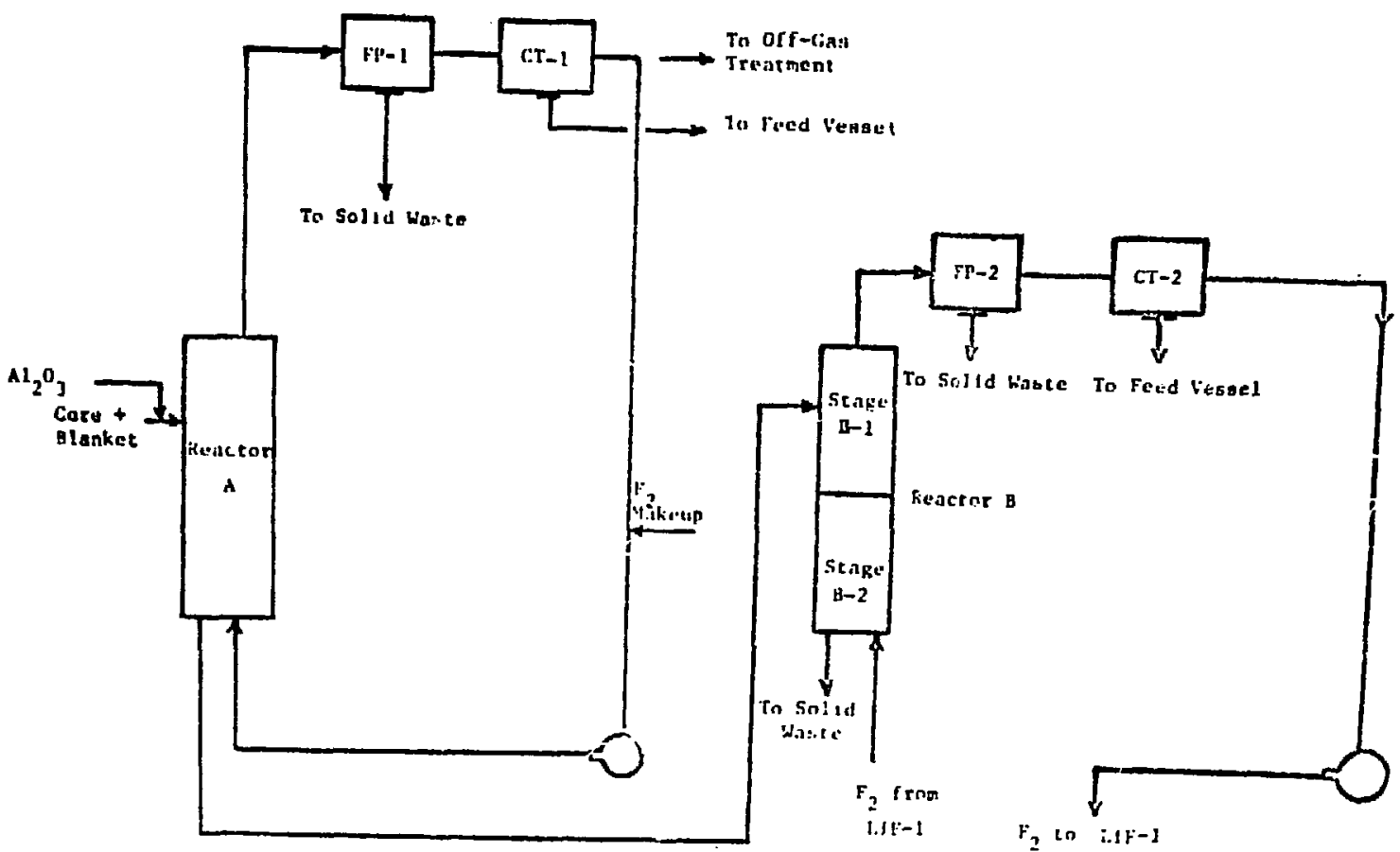

Fluorinarion of Actinides and Fission Products 


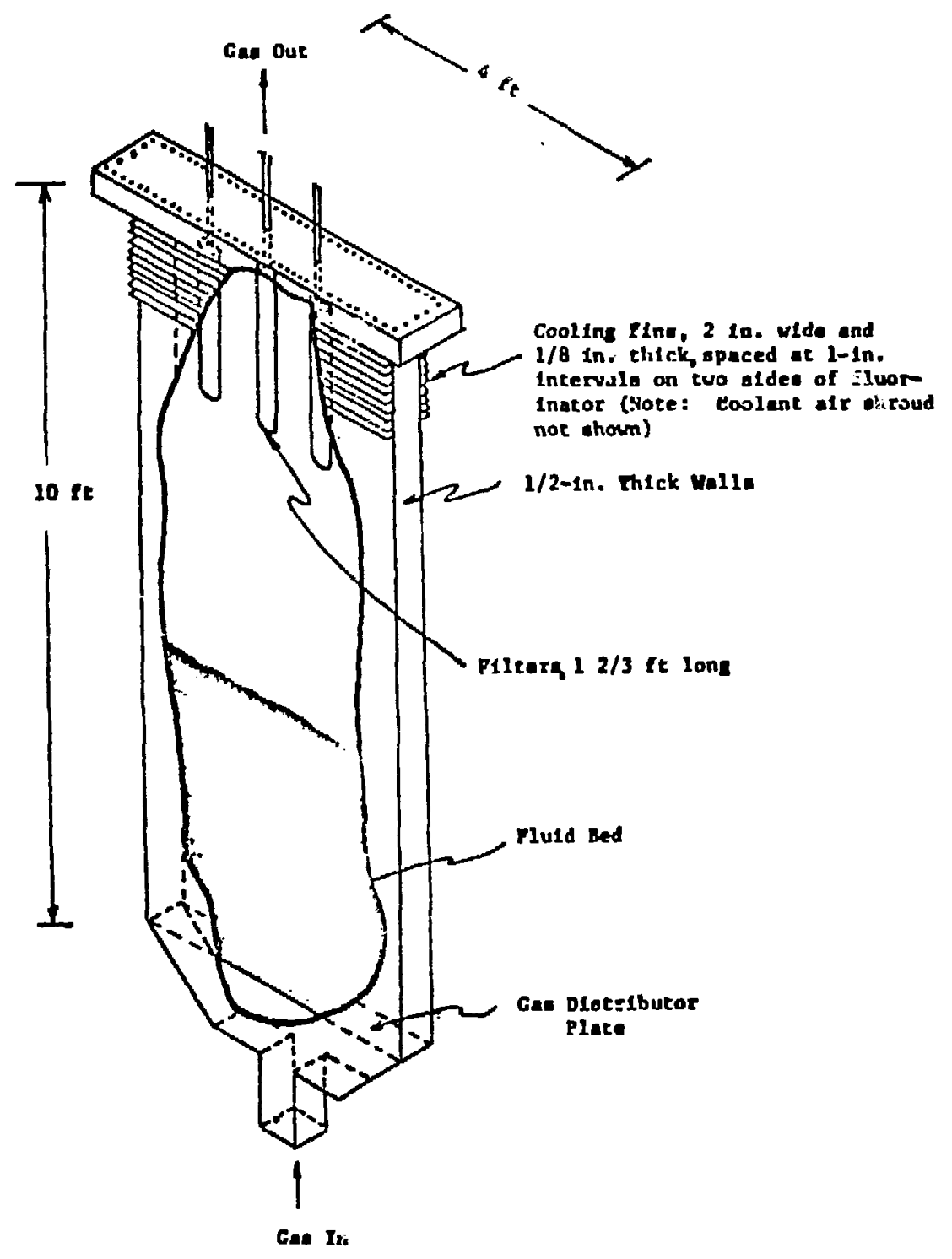

Schematic Diagram of Uranium Fluorinator (Reactor A) 
remaining $i \%$ leaves as ujk 4 in the solid effluent which is the feed for reactor B. Only a small fraction ( $4 \%$ or less) of the $\mathrm{Pu}$ accompanies the $\mathrm{UF}_{6}$ as $\mathrm{PuF}_{6}$; the remainder leaves as solid $\mathrm{PuF}_{4}$ in the aforementioned alumina effluent. Nominal residence time of solids in the reactor is 12 hours. Trap FP-1 is kept at $15^{\circ} \mathrm{C}$ and thus serves to remove most of the $\mathrm{NbF}_{5}$ and $\mathrm{RuF}_{5}$. The $\mathrm{UF}_{6}$ stream, accompanied by a small amount of $\mathrm{PuF}_{6}$, condenses in trap $\mathrm{CT}-1$, held at $-80^{\circ} \mathrm{C}$, over a 12-hr. cycle. Residual $\mathrm{F}_{2}$ in the remaining gas stream is recycled to reactor A; part of the gas stream which contains $\mathrm{Kr}$ and $\mathrm{Xe}$ is bled out to off-gaa treatment. During the next 12-hr. cycle a batch of condensed hexafluorides is removed from the trap by heating and draining the liquid thus obtained into the feed vessel for the next step; a duplicate trap is put on atream.

Fluorination of $\mathrm{Pu}$ in reactor $\mathrm{B}$ is accomplished using pure $\mathrm{F}_{2}$ gas at 500$550^{\circ} \mathrm{C}$. Re:actor $\mathrm{B}$ consists of two stages in which countercurrent flow of $\mathrm{F}_{2}$ and alumina is provided. Average solids residence time in each stage is about 9 hrs. Further operations are analogous to those in the reactor A system, except that FP-2 is kept at $-10^{\circ} \mathrm{C}$, a temperature appropriate for condensation of residual $\mathrm{NbF}_{5}$ and $\mathrm{RuF}_{5}$ from a product gas stream of relatively low actinide hexafluoride concentrations. Exit gas from trap CT-2 (which is kept at $-80^{\circ} \mathrm{C}$ ) is recycled to reactor $\mathrm{A}$. The $\mathrm{PuF}_{6}$ is removed from $\mathrm{CT}-2$ by heating and draining as described above for $\mathrm{UF}_{6}$. Total decontamination of $\mathrm{Pu}$ at this point is estimated to be about 400 .

(3) Plutonium purification and separation from $\mathrm{UF}_{6}$.

The overall schematic of this sequence is shown in Figure III-6. The partially decontaminated condensates from CT-1 and CT-2 are recombined in a feed vessel and distilled into the thermal decomposer (TD-1). Distillation is continued until there is a significant drop in production rate. The residue, 
Figure III-6

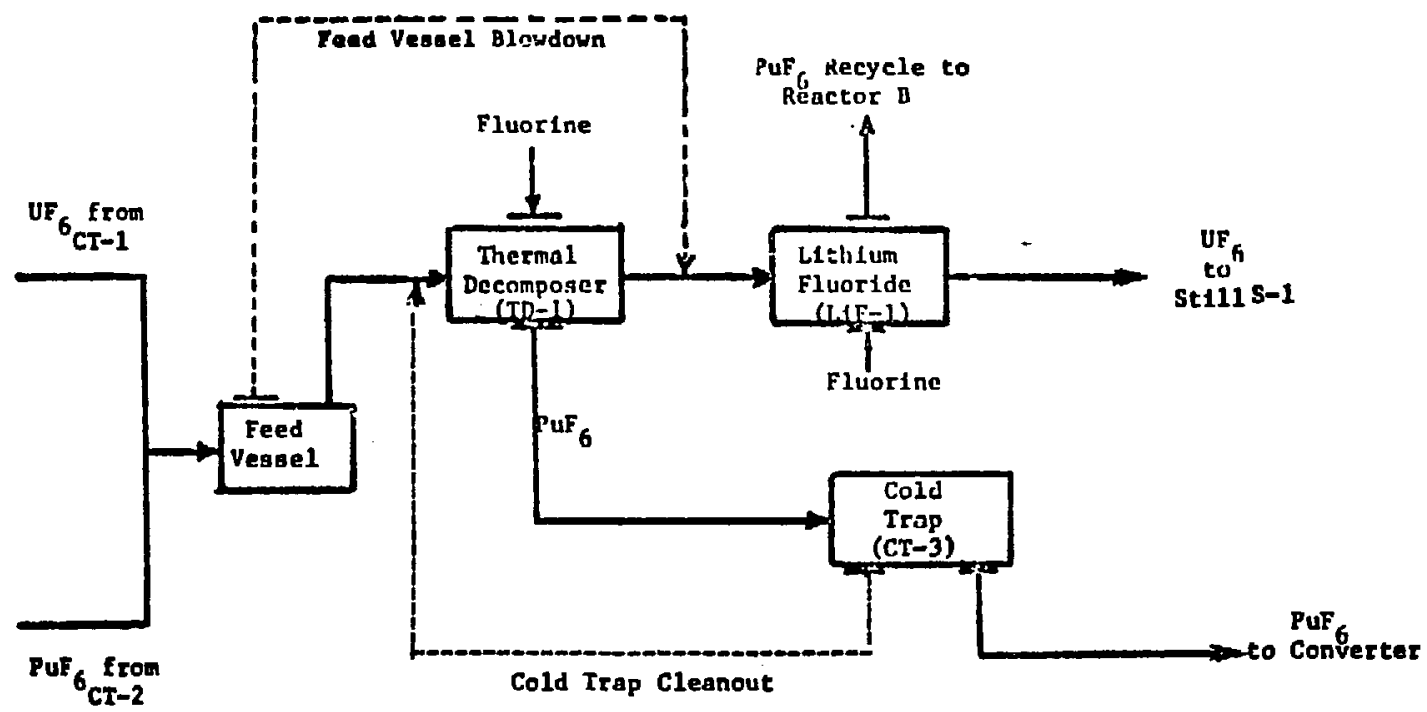

Plutonium Purification and Separation from $\mathrm{UF}_{6}$ 
containing mostly fission products, is flashed directly to the LiF trap (LiF-1, see broken line).

Pu is separated by decomposing the $\mathrm{PuF}_{6}$ at $350^{\circ} \mathrm{C}$ in $\mathrm{TD}-1$ according to the reaction $\mathrm{PuF}_{6}+\mathrm{PuF}_{4}+\mathrm{F}_{2}$. It is estimated that $99.6 \%$ of the $\mathrm{PuF}_{6}$ decomposes to $\mathrm{PuF}_{4}$ and deposits on the alumina; again, one batch is processed through TD-1 in 12 hours. Any remaining $\mathrm{PuF}_{6}$ which is carried in the $\mathrm{UF}_{6}$ stream is trapped in LiF-1, as a complex, probably $4 \mathrm{LiF}^{*} \mathrm{PuF}_{4}$; it is refluorinated at $450^{\circ} \mathrm{C}$ by the circulating $F_{2}$ stream, and recycled to the $B$ loop.

The pure $\mathrm{PuF}_{4}$ deposited in TD-1 is refluorinated using concentrated $F_{2}$ at $500^{\circ} \mathrm{C}$. The resulting $\mathrm{PuF}_{6}$ is collectec in cold trap CT-3 which is held at $-80^{\circ} \mathrm{C}$. The weight change of the latter is noted and the fluorination stopped when the rate of change drops, corresponding to about $95 \%$ recovery. The bed in TD-1 is reused in subsequent decomposition-refluorination cycles and finally fluorinated exhaustively before being discarded to waste.

After a batch of $\mathrm{PuF}_{6}$ has collected in CT-3, the trap is removed and heated to $80^{\circ} \mathrm{C}$ to liquify the $\mathrm{PuF}_{6}$, which is subsequently purified by distillation. About $90 \%$ of the purified $\mathrm{Pu}$ is recovered in this manner and ready for conversion. The heel is recycled to the thermal decomposer for processing with the batch next in line. The overall decontamination factor for Pu at this point is estimated to be $10^{6}-10^{7}$.

(4) UF 6 purification

The object of this step is to achieve further decontamination from Np and remaining volatile fission product fluorides. This is accomplished (Fig. III7) by two distillation stages and successive treatment in a $\mathrm{MgF}_{2}$ trap at $125^{\circ} \mathrm{C}$ and four stages of $\mathrm{NaF}-\mathrm{UO}_{2} \mathrm{~F}_{2}$ traps at $400^{\circ} \mathrm{C}$. About $32 \%$ of the purified $\mathrm{UF}_{6}$ is required for conversion to the mixed-oxide product of the reference process (see 


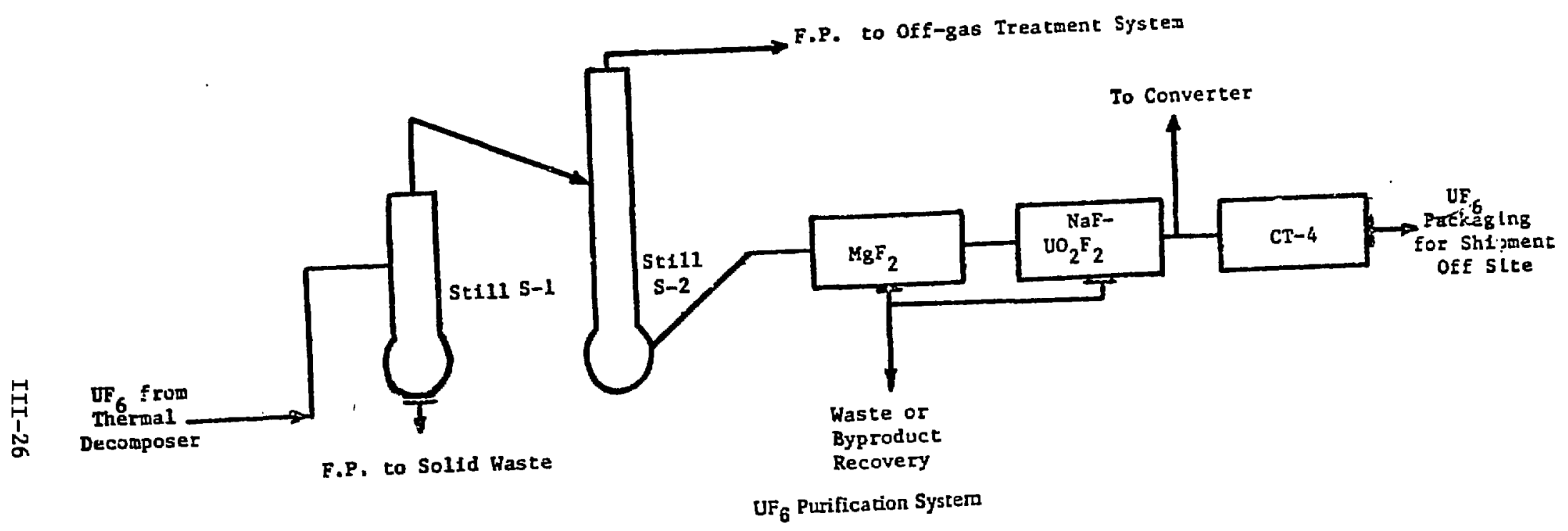


below); the remainder is bled to a side stream, separated by cold trapping and stored for shipment off-site.

\section{(5) Conversion}

The purpose of this step is to produce a suitable grade of 23 wt.\% $\mathrm{PuO}_{2}-$ $\mathrm{UO}_{2}$. It is an adaptation of a process developed for the preparation of $\mathrm{UO}_{2}$ and involves the simultaneous reaction of $\mathrm{UF}_{6}$ and $\mathrm{PuF}_{6}$ with a mixture of steam and hydrogen at $650^{\circ} \mathrm{C}$ in a fluidized bed. The process is semicontinuous in that a cyclic method of operation is used. In the first half of the cycle, hexafluorides, steam, and hydrogen are fed to the reactor to yield the expected products $\mathrm{PuO}_{2}-\mathrm{UO}_{2}$ and $\mathrm{HF}$. In the second half of the cycle steam and hydrogen on1y are fed to the converter to ensure conversion to $\mathrm{UO}_{2}$ of any $\mathrm{UF}_{4}$ and/or $\mathrm{U}_{3} \mathrm{O}_{8}$ intermediates. Excess reagents are used throughout the conversion cycle to ensure a high-density product with a minimum amount of residual fluoride. The design basis for the converter provides for a 2-hour cycle, with $34.1 \mathrm{~kg}$ of $\mathrm{PuO}_{2}-\mathrm{UO}_{2}$ withdrawn at the end of each cycle $(409 \mathrm{~kg}$. per day). The product is stored in two critically safe slab-shaped receivers (4" $\times 24^{\prime \prime} \times 24^{\prime \prime}$ or $5.4 \times 10^{3}$ $\mathrm{cm}^{3}$ ) and sampled for accountability and quality control before shipment.

III.2.2.3. Safeguards-Related Design Concepts

Compared to the corresponding material on the Sa1t Transport Process, ANL7583 contains a fair amount of safeguards-related process information, derived from process, criticality, and accountability considerations.

\section{IIf.2.2.3.1. Flows}

Feed was identified in Table III-2; the product stream is postulated to consist of $409 \mathrm{~kg}$ per day $23 \% \mathrm{PuO}_{2}-\mathrm{UO}_{2}$, or $83 \mathrm{~kg} \mathrm{Pu}$, and $856 \mathrm{~kg}$ per day $\mathrm{UF}_{6}$ - No estimates are given as to losses of fissile material in the waste strears. 


\section{III.2.2.3.2. Inventories}

The inventory values postulated in the reference design are to a large degree determined by criticality considerations. In-process Pu inventories are shown in Table III-3; they represent the maximium batch sizes during normal reference operation. The use of duplicate units for some of the components permits accumulation during a 12-hour on-stream period and discharge during a 12-hour off-stream period. This schedule allows coupling of continuous and semicontinuous (batch) processes, with an overall 24-avur time cycle of operations. The vessels are emptied completely by the end of each cycle, and a half-day batch is the maximum accumulated in normal operation. Regarding storage inventories, both the three feed hoppers and the two oxide product receivers have a total capacity of a one-day throughput ( $83 \mathrm{~kg}$. Pu) as a baseline case; no additional storage capacity is indicated.

ILI.2.2.3.3. Plant Layout Concept

Figure III-8 shows a conceptual layout of the main plant building. The main process cell and auxiliary cells are shown, along with other required facilities on the same floor, such as operation control rooms, laboratories, storage areas, the machine shop, and administration areas. The overall building area is approximately 150 by $260 \mathrm{ft}$. Additional facilities are below grade. These include a decontamination cel1, a hot-shop area, and a storage pool for fuel elements awaiting disassembly and processing.

The head-end and processing equipment must be located in heavily shielded cells designed for alpha containment as well as for beta-gamma radiation control. Ventilation must be controlled, with flows moving from the least contaminated to the most contaminated sections of the plant. Exhaust will be through one set of high-efficiency filters. A large circulating caustic 
Table III-3. Reference Values of Pu In-Process Inventory

$\begin{array}{cc}\begin{array}{cc}\text { Process Vessel } \\ \text { Fluorinator A }\end{array} & \mathrm{kg} \mathrm{Pu} \\ \text { Fluorinator B } & 45 \\ \text { CT-1 } & 4.5 \\ \text { CT-2 } & 1.7 \\ \text { CT-3 } & 40 \\ \text { Feed vessel for Pu purification } & 42 \\ \text { Thermal decomposer } & 42 \\ \text { Converter } & \end{array}$




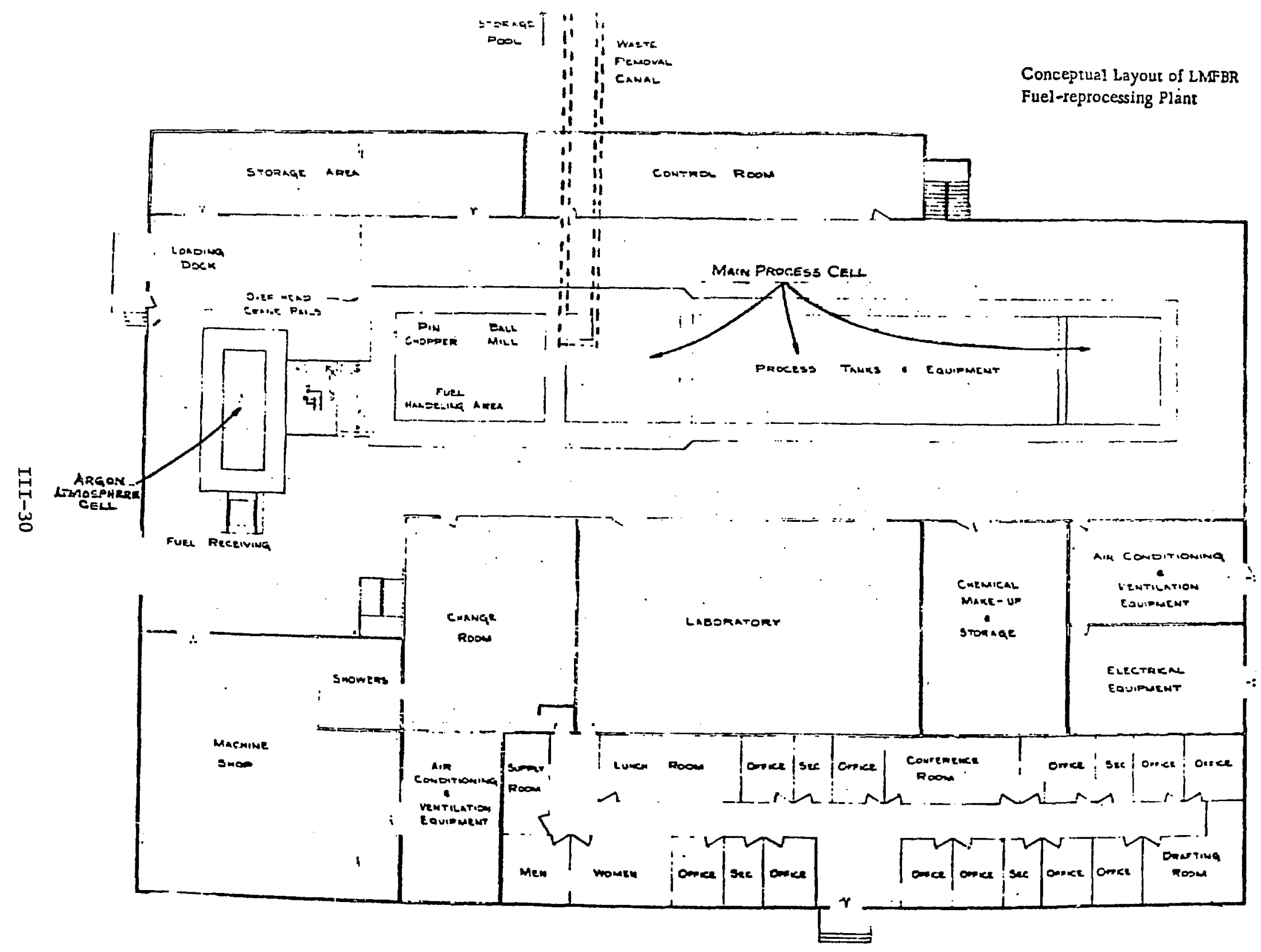


scrubber designed to accommodate the total ventilation flow will be located upstream of the first set of air filters. The sand-bed filter serves mainly as an emergency backup device. Ventilation air is finally exhausted through a 100-m stack.

In addition to a main process cell, two other cells are provided: (1) an argon-atmosphere cell for operations relating to fuel handling when sodium is present, and (2) an air-atmosphere cell for the mechanical head-end equipment. Intermediate partitions, which further subdivide the main cell into subcells, may be desirable from the standpoint of maintenance and accessibility, but cell design has not been analyzed to an extent to permit such delineation. Cell shielding thickness will comply with the regulations regarding personnel exposure.

\section{III.3. Safeguards Considerations}

III.3.1. General Discussion

Although the two non-aqueous processes discussed in the preceding pages are quite different in concept, they have certain safeguards-related features in common. A great deal of concerted effort must be expended and many questions answered if either of these technologies, or related ones, are to be commercially implemented within the next few decades. On the other hand, this long lead time affords a unique opportunity to start planning safeguards R\&D and incorporating desirable features into plant design at the :arliest stages of development .

One characteristic of non-aqueous processes which first made them appear attractive on grounds of economics and safety is the compactness of the equipment and thus the relatively amall plant size required. From the domestic safeguards point of view, this means that physical protection and containment/surveillance (c/s) measures would be particularly effective. With respect to international 
safeguards, the compactness of the plants would involve a relatively small inspection effort, aimed at monitoring appropriate accountancy and $\mathrm{C} / \mathrm{S}$ measures.(7) C/S measures carry particular promise, and their development and early integration into facility design would be a fruitful area for R\&D.

It is materials accountability and the need to close material balances which appear to pose the most important R\&D problems. Neither of the processes discussed here involve a homogeneous input solution which could be sampled and analyzed to provide a reliable accountability measurement, nor are other potential non-aqueous techniques likely to differ in that respect. Accountability in aqueous reprocessing technology-centers around the existence of such solutions, and much effort has gone into development of increasingly precise sampling and analytical measurement methods.

\section{III.3.2. The Salt Transport Process}

The Salt Transport Process is designed deliberately to minimize movement of solids within the process, by carrying out more than one unit operation in the same vessel. This approach intrinsically runs counter to the idea of producing a homogeneous input solution. The closest approximation to such a system occurs one step past the decladding process, at the conclusion of the reduction step. At that point the $P u$ and part of the $\mathrm{U}$ are dissolved in the reduction alloy, which could conceivably be sampled and analyzed for accountability. One byproduct of the pyrochemical studies carried out during the 1950's and 1960's has been interest in developing analytical measurement techniques for both molten salts and lizuid metals, including possible on-line and other non-destructive techniques. However, much of this effort was discontinued along with the rest of the work and became obsolete as interest in non-aqueous systems declined. Adaptation to commercial reprocessing techniques would require reassessment of the 
past work and extensive new R\&D based upon it. There would probably also have to be some R\&D for more specialized NDA instrumentation.

III.3.3. The Fluoride Volatility Process

The following excerpts form ANL-7583(8) illustrate the problems inherent in accountability measurements in the Fluoride Volatility Process and point to the R\&D areas which must be stressed,

"The accountability method proposed for the present plant uses automatic data processing; input is provided in part by automatic weighing systems. Verification of the input starts with the identification of a particular fuel element after its removal from the shipping cask. Information regarding weight and actinide content will be provided by the fuel manufacturer, and the radiation history of the fuel element also will be known. Fuel elements can best be weighed at the processing plant, if desired, after sodium removal from the exterior of the fuel element while the fuel element is in storage in the pool. Individual fuel pins have been assayed for any sodium log $\tilde{\xi}^{2}$. After decladding, the weight of the fuel alone is obtained by weighing the fuel storage hopper before the fuel oxide powder is fed to the process.

Sampling of the fuel powder while it is enroute to the first fluorinator (reactor A), followed by chemical analysis of the samples, will provide key information for accountability purposes. This nonhomogeneous powder will be sampled by pulsing small portions of the powder from the pneumatic conveyor line into a secondary vessel. If pulsing is done at regular intervals and if a statistically large number of portions are obtained, the sample will be representative. The material in the secondary vessel will be howogenized and sampled for analysis. This system of sampling will have to be demonstrated and tested in mockup studies.

Weighing of hexafluoride cold traps and the use of neutron survey meters as plutonium monitors will provide additional data for accountability. Necessary information on the plant output will consist of: (1) weight of the converter product, (2) plutonium content of the $\mathrm{PuO}_{2}-\mathrm{UO}_{2}$ product, and (3) the weight and analyses of the excess $\mathrm{UF}_{6}$. The plutonium content of waste streams (primarily that discharged from the plutonium fluorinator, reactor $B$, and the cladding hulls from the ball mill) will also be determined. Hopefuliy, other materials such as LiF sorption traps can be monitored for plutonium content by external means (neutron survey meters) with a go/no-go device, which would indicate when cleanupfluorination has accomplished its task. Development of a practical accountability method appears feasible...

...The analytical procedures that will be used to determine uranium and plutonium in the feed and product streams in this process are basically the same as those now being used for existing aqueous processing plants. A solid sample is weighed, then dissolved in a suitable acid or acid 
mixture; the solution is next diluted to a known volume and analyzed for the amounts of uranium and plutonium and their isotopic compositions.

The only sample in this process that can be considered unique is the feed. Since the fission-product content and the transplutonium element content of the feed will be significantly higher than for fuels now being processed, special consideration has been given to the problem of dissolving these samples and the choice of methods for analyzing the solutions obtained.

On the basis of existing information, it is anticipated that a mixture of hydrochloric, nitric, and hydrofluoric acids will effect complete solution of the uranium and plutonium in the high-burnup samples. However, it will be necessary to establish unequivocally that no acidinsoluble plutonium-fission product compounds have formed in the fuel.

Complete solution of all constituents of the feed will probably not be effected. The fission products (molybdenum, technetium, ruthenium, rhodium, and palladium) are known to precipitate as metallic inclusions within the fuel, and these inclusions are highly resistant to acid attack. Also, some precipatation of fission products may occur after dissolution has been effected. Precipitation of cesium chloropalladinate from solution of high-burnup fuels has been otserved.

of the various analytical techniques that have been used to determine uranium and plutonium in irradiated fuels, mass-spectrometric-isotope dilution (MSID) appears to be best suited to the analysis of the feed for this process. MSID has the advantage of requiring relatively small amounts of uranium and plutonium for the analysis ( 0.1 to $1 \mathrm{mg})$. Also, once the spikes $\left({ }^{233_{\mathrm{U}}}\right.$ and $\left.{ }^{242} \mathrm{Pu}\right)$ have been added and isotopic exchange effected, there is no need for quantitative recovery in the chemicalpurification steps. For chemically complex samples such as highly irradiated fuels, the reliability of MSID analytical results is superior to those from any other method of analysis. When properly executed, the relative standard deviation of this method is $\pm 0.2 \%$, witk no significant bias.

A relatively large concentration of fission products and transplutonium elements in a feed solution would seriously affect the accuracy of any chemical method of analysis. Each high-precision chemical method (e.g., controlled-potential coulometry) requires complete oxidation (or reduction) to a particular oxidation state, followed by reduction (or oxidation) with a standardized reagent to another oxidation state. Radiolysis within the solution due to the alpha, beta, and gamma activity will seriously interfere with both the oxidation and the reduction processes, and fission products such as molybdenum will be present in sufficient concentrations to interfere chemically in the analysis."

Again, it appears that the input accountability measurement poses the most difficult problem. The sampling procedure for the fuel powder identified in the second paragraph quoted above has not been tested experimentally and it appears 
doubtful that representative samples could be obtained. A more promising approach might be to sample the oxide input in reactor $A$ before starting the fluorination; the technology for obtaining homogeneous, representative fluidized bed samples appears to be well developed. Many of the other problems identified by the authors, including dissolution, are being pursued vigorously, especially by the LANL Analytical Chemistry Group.

The authors of ANL-7583 discuss three basic techniques for measuring ca. $500 \mathrm{ppm} \mathrm{Pu}$ in decontaminated $\mathrm{Al}_{2} \mathrm{O}_{3}$ (fluidized bed) waste streams. These are:

1. Active thermal neutron interrogation

a. delayed neutron counting;

b. detection of short-lived noble-gas fission products;

c. direct counting of fission product gammas.

2. X-ray Spectrometry.

3. Destructive radiochemical measurement (based on dissolution, extraction, and alpha measurement).

We do not believe that any of these techniques present a serious measurement problem, especially considering the progress in instrumentation which has been made in the interim and continues to be made in response to novel safeguards problems.

III.3.4. Conclusions

The reference facilities as described here are quite compact and designed to have relatively omall inventories, both in storage and in process. Given that other factors favor a decision to build such facilities, safeguards considerations may pose a relatively minor problem, especially if an effort is made to incorporate the pertinent features as the design process progresses. Adaptation of $\mathrm{C} / \mathrm{S}$ and (where applicable) physical protection measures to the types of facility in question would br in important R\&D area. 
Aside from the probable need for ad hoc development of specialized instrumentation, the problem of direct input measurement appears to be one that will require most attention and the greatest R\&D effort in the accountability area. Failure to develop a satisfactory procedure would make it necessary to rely on indirect measurement approaches, such as fuel fabricator measurements and irradiation history, which may fall short of leading to an adequate material balance closure. However, it should be noted that the reference facilities in question are envisioned to be part of regional central stations, so that reactor and reprocessing facilities would be closely coupled and shipment of strategic material over significant distances avoided. Institutional arrangements of this kind may create conditions where material balance closure not based completely on measured values could be accepted.

\section{III.4. Non-Proliferation Considerations}

It does not appear that the technologies considered in the present framework would raise novel problems regarding nuclear proliferation. Issues relating to non-proliferation are therefore unlikely to be a major factor in reaching a decision whether to adopt non-aqueous reprocessing technologies on a commercial scale. Proliferation in this context is assumed to involve either or both of the two general mechanisms of (1) diversion of Pu from declared streams, and (2) introduction and reprocessi $;$ Jf undeclared material. In addition, there is also the possibility of the construction and operation of a clandestine facility. However, in this last case, there is little or no advantage in building a clandestine, non-aqueous system when a small-scale plant, using proven Purex or other wel1-known current technology, will do as well.

The above conclusion is based first of all on the fact that any promising non-aqueous reprocessing technique can be adapted to coprocessing or "spiking" options (or both). Since implementation on a commercial scale of such tech- 
niques would in any case have to be preceded by major techrical and financial efforts, provision of capability for these options would represent a relatively small additional burden.

In addition, the following considerations are relevant to the type of system in question:

1. The equipment is compact and unencumbered by the extensive piping network which may facilitate access to a potential divertor in plants featuring aqueous solvent extraction systems.

2. In view of (1), the fasility itself can be made compact and designed with a minimum number of penetrations. As stated before, this factor would facilitate deployment of $\mathrm{C} / \mathrm{S}$ measures.

3. Non-aqueous processes based on high-temperature technology tend to be highly sensitive to traces of moisture and, in some cases, oxygen. This feature would tend to make any attempt at illicit use of materials or equipment a significant undertaking, and one which is potentially disruptive of the process. By the same token, a major incentive exists for providing optimum containment both for equipment areas and process buildings.

4. In view of the complexity and environmental sensitivity (see 3 above) of the processes, there appears to be little likelihood that facilities of substantially larger throughput or inventory than those discussed in this report would be attractive despite conventional economy-of-scale considerations. The reasoning advanced in points (1) and (2) is therefore unlikely to change in favor of bigger plants.

5. Indications are that the equipment and technology required are fairly unique. For example, there is little need in conventional industrial practice for fluidized bed components made from nickel, auxiliary equipment for carrying out solid-gas reactions, or massive amounts of pure $F_{2}$. Any nation 
demonstrating significant interest in purchasing such items, especially in combination, would therefore find it difficult to conceal its intention to build fluoride volatility reprocessing facilities. 


\section{References - Chapter III}

1. C.H. Bean, M.J. Steindler, "National Program for Pyrochemical and Dry Processing of Spent Reactor Fuel", in Actinide Separations, J.D. Navratil and W.W. Schulz, Eds., ACS Syaposium Series, pp. 177-189 (1980).

2. R.K. Steunenberg, R.D. Pierce, I. Johnson, "Status of the Salt Transport Process for FBR Fuel," in Symposium on Reprocessing of Nuclear Fuels, The Metallurgical Society of ATME, Ames, Iowa, August 1969, pp. 325-335 (Nuclear Metallurgy, Vol. 15).

3. J.B. Knighton, I. Johnson, R.K. Steunenberg, "U and Pu Purification by the Salt Transport Method", ibid. Pp. 337-362.

4. N.M. Levitz, L.J. Anastasia, E.L. Car1s, A.A. Chilenskas, J.A.E. Graae, A.A. Jonke, R.W. Ressie, R.P. Larsen, W.J. Mecham, D. Ramaswami, M.J. Steindler, and G.J. Vogel, "A Conceptual Design Study of a Fluoride Volatility Plant for Reprocessing LMFBR Fuel," ANL-7583, July 1969.

5. J.B. Knighton, C.E. Baldwin, "Pyrochemical Coprocessing of $\mathrm{UO}_{2}-\mathrm{PuO}_{2}$ LMFBR Fuel by the Salt Transport Method", Ref. 1, pp. 191-206.

6. C.J. Rodden, "Analysis of Essential Nuclear Reactor Materials," Division of Technical Information, US AEC, 1964; p. 456.

7. "The Structure and Content of Agreements Between the Agency and States Required in Connection with the Treaty on the Non-Proliferation of Nuclear Weapons," INFCIRC/153 (corrected), International Atomic Energy Agency, Vienna, Austria, 1972.

8. Ref. 4, pp. 199-201. 


\section{FUSION}

Certainly since the first detonation of a thermonuclear device in the early $1950^{\prime} \mathrm{s}^{(1)}$, and possibly even from the suggestion by Atkinson and Houtermans (2) in 1929 , refined by Bethe ${ }^{(3)}$ in the $1930^{\prime}$ s, that nuclear-fusion reactions power stars, scientists have thought about utilizing controlled fusion for peaceful purposes, notably the production of electric power. Serious experimental work began in the $1950^{\prime} \mathrm{s}$ and the atmosphere for conducting such work improved in 1958 when both the United States and the Soviet Union declassified their work. (4)

The problem for many years has remained the same: how to heat and confine a plasma (completely ionized gas) of light nuclei sufficiently long or sufficiently densely to cause significantly more energy to be released by nuclear fusion than was applied in the heating process. The situation is termed "breakeven" when these energies are equal, "ignition" when the fus in ultimately sustains itself without external heating, and "driven" when the fusion always requires external heating; the "gain" is the ratio of fusion energy produced to heating energy required.

The original approach, magnetic confinement, $(4,5)$ seems the most promising. A newer approach, inertial confinement, (6) also receives much attention, though a major impetus behind inertial confinement is its military applications. $(7,8,9)$

Neither approach has yet passed the scientific breakeven test though that goal is believed achievable in experiments soon to begin. Figure IV-1 illustrates recent experimental progress. (10) Fusion energy thus remains a future dream technologically, with many unresolved issues. (12) Its potential use by electical utilities depends on many factors. (13)

In both of the approaches, the current objective is to create by nuclear fusion a source of high-energy neutrons; the energy of these neutrons would then be used either to produce electricity by conventional thermal power cycles as in 


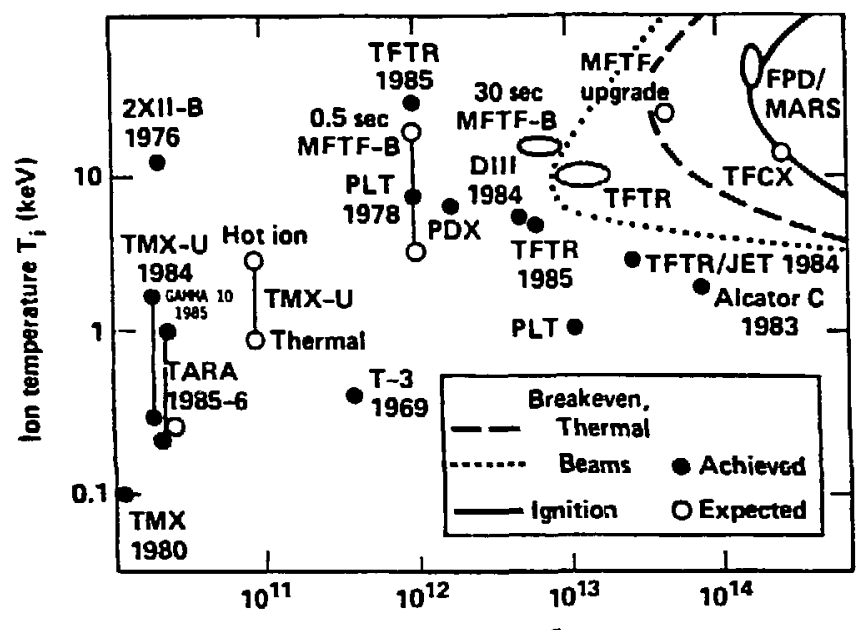

Lawson number $n T_{E}\left(\mathrm{~cm}^{-3}, \mathrm{sec}\right)$

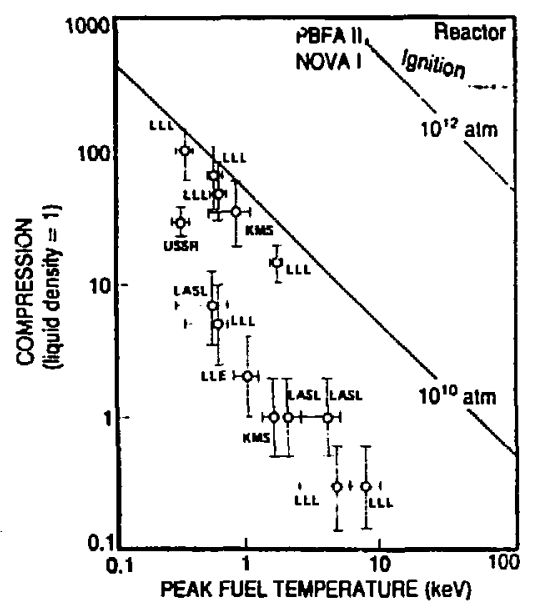

(b)

Figure IV-1. Thermonuclear conditions achieved in and projected for fusion experiments: (a) magnetic fusion experiments with some experiments shown no longer planned and with certain scale distortions (courtesy U.S. D.O.E.)

(b) inertial fusion experiments (from ref. 11).

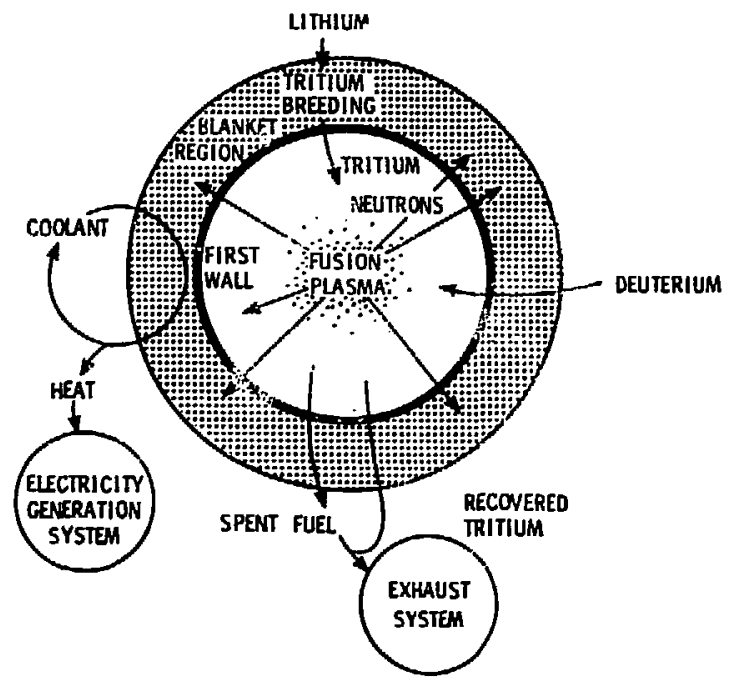

Figure IV-2. Principal features of a DT fusion reactor (from ref. 14). 
Figure IV-2 ("pure" fusion) or to produce electricity and fissile fuel ("hybrid" fusion-fission) for conventional fission reactors. Fusion could be employed in other ways; for example, it could produce electricity by direct conversion or electromagnetic coupling of the energy of the moving charged particles of plasma or be used as a source of heat for chemical processing.(15) These applications, which would employ different fuels or different reactor configurstions, will not be discussed further here since they pose no proliferation questions other than those that will be raised in conjunction with the more "prosaic" applications.

Specifically, we will fame our discussion in this chapter on magnetic and inertial-confinement pure fusion and hybrid fusion-fission through specific design studies $(16,17,18)$ for future commercial plants. Given that such plants exist, how could they be misused from a proliferation point of view? The choice of specific design studies is of course arbitrary in view of the present scientific and technological uncertainties and consequent remoteness of actual deployment -- after the year 2000. Another approach would involve a survey of many designs).

What are the proliferation concerns of fusion technologies? They are five: (1) the diversion of fusion materials for thermonuclear weapons; (2) the dissemination of classified information that is involved in certain aspects of inertial-confinement fusion (this existing concern transgresses conventional nuclear material safeguards); (3) the clandestine production in a declared facility of fissile material for fission weapons; $\mathrm{Pu}-239$ or $\mathrm{U}-233$, from undeclared fertile material by "neutron diversion"; (4) the diversion of declared fissile material. from hybrid systems; and (5) the production of fissile material or fusion materials in a clandestine, reactor or a misused fusion research facility. 
To set the matter in perspective, we believe that the diversion of fissile material from a declared hybrid is the most credible proliferation route of the five. Moreover, a country with the technological base to have any fusion system would be capable of producing weapons-grade fissile material in a dedicated and possibly clandestine fission reactor if it desired nuclear-fission weapons.

Very little published discussion exists regarding proliferation problems associated with nuclear-fusion technologies. The possible knowledge link between development of inertial confinement $(19,20,21,22,23,24)$ fusion and thermonuclear weapons has been noted as has been the possibility of neutron-diversion for surreptitious fissile-material production.(25) In the NASAP(26) studies, only the proliferation concerns of fusion hybrids were addressed. In other studies of this problem, $(27,28)$ hybrids were compared with conventional fission breeders to show, because of their relatively higher efficiency of fissile-fuel production, that hybrids in internationally safeguarded fuel service centers would be a better choice for a nuclear fuel cycle.

Finally, one group(29) did allude to all of the five concerns discussed here.

IV.1. Principles of Nuclear Fusion

At very high temperatures, certain ionized light nuclei (positively charged) can approach each other closely, fuse into a heavier nucleus plus another particle, and give off more energy than was required to initiate the reaction. If such fusion reactions can be made to occur under controlled conditions, then virtually limitless useful energy becomes available, for the reactants are abundant naturally or easy to breed and the process is fundamentally safer and less environmentally threatening than nuclear fission. 
Simple reviews of the basic scientific issues have been written and are excerpted here. $(5,30)$ The basic nuclear reaction involved in current efforts to achieve fusion power is

$$
\begin{aligned}
& \text { Deuterium }+ \text { Tritium } \rightarrow \text { Helium }+ \text { neutron }+ \text { energy } \\
& \text { or. } \quad D+T+\mathrm{He}^{4}+\mathrm{n}+17.6 \mathrm{MeV}
\end{aligned}
$$

The reactants are the relatively abundant (in seawater) and stable isotope of hydrogen, deulerium, and the very rare and relatively short-1ived (12.3 year half-life) isotope, tritium. This reaction is the immediate goal because it yields the largest thermonuclear power for a given temperature of the reactants. The energy $17.6 \mathrm{MeV}$ (million electron volts) ccrresponds to 94,000 kilowatt hours per gram of deuterium plus tritium, which is several times the energy release per gram in nuclear fission, about ten million times the energy release per gram in fossil-fuel conbustion, and about the energy released in the explosion of 0.08 kilotons of TNT (trinitrotoluene). (31) of this energy, $80 \%$ (14.1 MeV or 75,000 kilowatt hours per gram) is carried off by the neutron and can be exploited; the other $20 \%$ can be used to sustain the reaction.

The temperature of the reactants characterizes their speed of motion and consequent ability to approach each other closely and react in the face of their mutual electrostatic repulsion. For a deuterium-tritium (DT) plasma, the goal temperature is $3 \times 10^{8}$ or 300 million degrees Relvin. Heating the reactant plasma is one of the two key problems of fusion research.

For any fusion processes, a measure of the technological progress toward achieving practical amounts of energy from fusion is the Lawson criterion ${ }^{(32)}$, according to which the product of plasma density $n$ and plasma confinement time $\tau$ must exceed a value dependent upon the plasma temperature and the reacting species. For a DT plasma, the breakeven condition is roughly $\mathrm{n} \tau \geq 10^{14}$ particle-seconds per cubic centimeter 
at a temperature of $3 \times 10^{8}$ degrees Kelvin. The $n \tau$ goal was recently met, though at a lower temperature. (33) (The exact condition depends on the detailed distribution of particle energies in the plasma.)

A gas at such high temperatures exerts enormous pressures and would vaporize any material structure it contacts and be rapidly cooled. Thus, keeping the reacting plasma sufficiently dense for the requisite time but away from material structures is the second key problem for fusion research.

Finally, since tritium is very rare naturally, it mast be bred somewhere for the fusion reactions. This could occur in a tritium production fission reactor but is in fact planned to occur at the fusion facility itself. In either case, neutron capture by lithium would yield tritium via the two reactions

$$
\begin{gathered}
n+\mathrm{Li}^{6}+\mathrm{T}+\mathrm{He}^{4}+4.78 \mathrm{MeV} \\
\mathrm{n}+\mathrm{Li}^{7}+\mathrm{T}+\mathrm{He}^{4}+\mathrm{n}-2.47 \mathrm{MeV}
\end{gathered}
$$

Naturally occuring 1 ithium is $7 \% \mathrm{Li}^{6}$ and $93 \% \mathrm{Li}^{7}$; enrichment or depletion of the former may be necessary depending upon the details of the reactor. A neutron multiplier such as beryllium or lead may also be present to adjust the tritiumbreeding ratio. In equilibrium, a fusion facilitv would operate with a slightly growing tritium inventory to supply new facilities with startup inventories.

Three new ideas are under investigation. First, recent explorations $(34)$ of the notion of polarizing the spins of the reacting nuclei with respect to the magnetic field direction of a magnetically confined plasma have shown that a power production of 50 per cent more than was previously estimated is possible for otherwise similar plasma conditions. There is furthermore good experimental basis for producing the requisite polarized deuterium and tritium beams.

Second, experimental studies (35) have suggested than the formation of "meso-molecules" of D, T, and a muon (a heavy, electron-like elementary 
particle) catalyzes fusion in cold plasmas, bringing new life to an idea previously thought unworkable.

Third, theoretical studies suggest that magnetized fuel targets may drastically reduce the energy requirements of inertial-fusion drivers.(36)

IV.2. Nuclear-Fusion Reactor Systems

IV.2.1. Magnetic-Fusion Reactors

By confining a relatively diffuse (about $10^{14}$ ions per cubic centimeter) reacting plasma for a relatively long time (about 1 second), the Lawson criterion can be satisfied. This is the goal for plasmas confined by a magnetic fields in a vacuum chamber. Many different field configurations have been studied $(5,37)$ : among them are the tokamak, the mirror, and the E1mo Bumpy Torus. As a consequence of their field differences, the techniques for energy transfer, heating, and maintenance would differ too. We shall concentrate on one system in our analysis, the tokamak. The general problems relating to safeguards would be nearly the same for all pure magnetic-fusion systems.

The tokamak (from the Russian for toroidal magnetic chamber) concept was described independently in the 1950's by Sakharov and Tamm of the Soviet Union and $S_{p}$ itzer of the United States ${ }^{(38)}$. The essential point is that a plasma can be stably contained in a toroidal (doughnut) configuration by a magnetic field generated in part by external toroidal coils and in part by the bulk current of the moving plasma. The energy required to initiate the fusion arises both from magnetically induced plasma current and from incident beams of e $e^{1}$ ectromagnetic waves or particles. In a blanket outside of the plasma, the high-energy neutrons f-om the plasma breed tritium and deposit heat, which is transferred by coolants to an electricity-generating turbine. 


\section{IV.2.2. Inertial Confinement Reactors}

An inertial-confinement fusion system is one designed to compress reactant fuel pellets to extremely high densities (about $10^{26}$ ions per cubic centimeter) for very short times (about $10^{-11}$ seconds) to satisfy the Lawson criterion. Because of the inefficiencies of the driver and the implosion process, the requisite criterion is a factor of ten higher for practical inertial-fusion reactors than for magnetic fusion reactors.(11) Two "driver" methods have received the most attention for carrying out the compression, laser light and ion (or, conceivably, electron) beams incident on the pellets. $(7,39)$ For one type of target pellet, the incident beams heat the pellet surfaces, which then explode outward, while the remaining pellet material implodes in reaction to the surface motion. Figure IV-3 shows this. High temperatures result from the extreme compression. Thus, for inertial fusion, both confinement (such as it is) and heating are accomplished in one physical action.

Aside from the driver differences, the main differences among pure inertial-fusion power systems $(7,39)$ are in the energy capture or blanket designs. We shall concentrate here on the laser implosion technique; the safeguards questions are analogous for systems based on ion drivers.

\section{IV.2.3. Hybrid Fusion-Fission Systems}

In a "pure" fusion system, the energetic neutrons from a DT plasma impinge on a blanket wherein tritium is bred and a coolant is heated. The coolant carries energy to a heat exchanger, whence the energy powers a steam turbine.

It is also possible to include in the blanket fertile and fissile materials such as uranium-238 (or thorium-232) and uranium-235. Then the neutrons would induce some combination of fast fission of the former, slow fission of the latter, and breeding of the former into plutonium-239 (uranium-233). Either the 


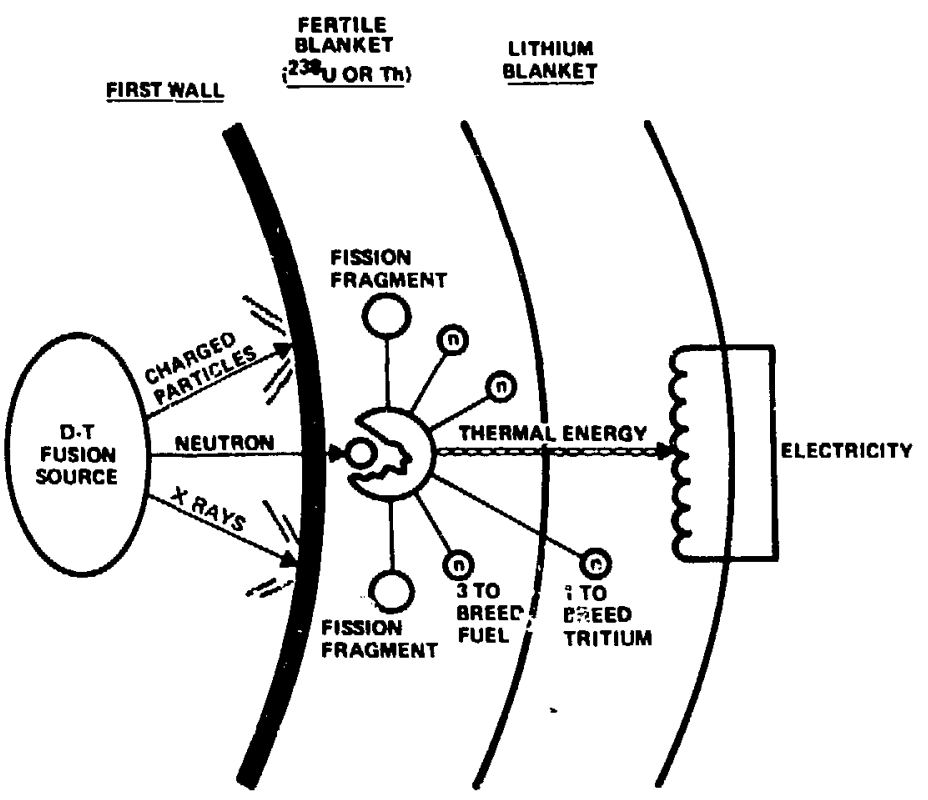

(a)

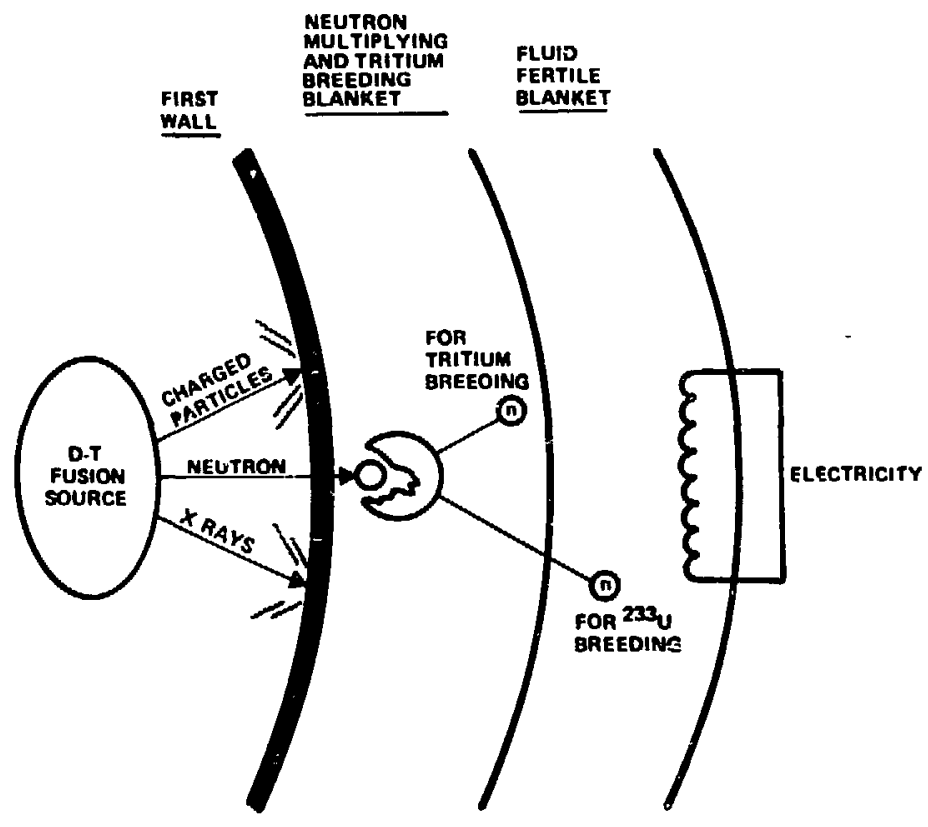

(b)

Figure IV-4. Fusion breeder concepts: (a) fast-fission blankets and (b) suppressed-fission blankets (from ref. 40). 


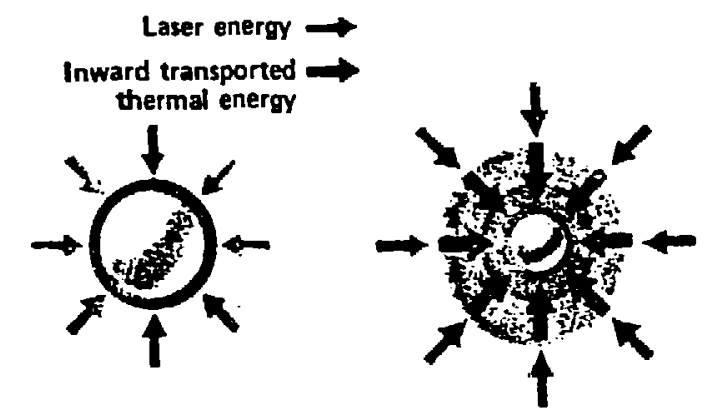

Atmosphere Formation

Laser or particle beams rapidly heat the wurface of the fusion target forming a surrounding plesm envelope.

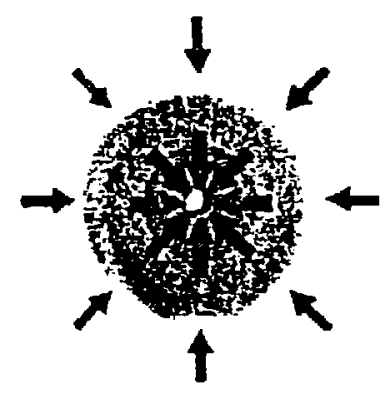

Ignition

With the final driver pulse, thy Fuel is compressed by rocket-like blowroff of the surfece material. full core reaches $1000-10,000$ times

liquid density and ignites at $100,000,000^{\circ} \mathrm{C}$.

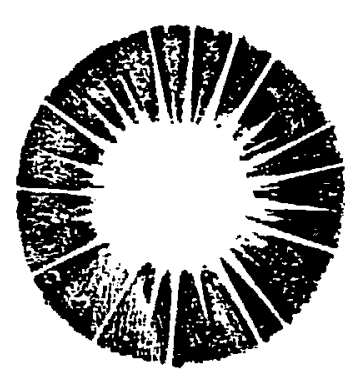

Burn

Thermonuclest burn spreads rapidly through the compressed fual, yislding many times the driver input enargy.

Figure IV-3. Inertial confinement fusion -- the concept (from ref. 7).

fissioning or the breeding could be emphasized in, respectively, a fast-fission or a suppressed-fission blanket; Figure IV-4 depicts them. Irrespectively, these processes could occur with either a magnetic or an inertial-fusion system operating at a lower gain $(40,41,42,43)$ than in a pure fusion system, though the technology would be more complex than pure fusion technology. Thus this "hybrid" approach could yield a valuable technology producing fuel for conventional fission reactors as well as serve as a pure fusion development milestone. Indeed, it was reported that hybrids are the main thrust of the fusion program in the U.S.S.R. (44)

In a review of the history of the hybrid idea, (45) it has also been noted that the technique could be used for the transmutation of fission wastes into less harmful species. In a suggested variation of this, used fuel rods from fission reactors could be reenriched or "refreshed" in a hybrid for still more 
use. $(46,47)$ In both of these schemes, fissile as well as fertile material would go into the hybrid blanket. These schemes necessitate safeguards at the "front end" of the hybrids doing the reenrichment.

Figure IV-5 is a general diagram showing the nuclear-material flows associated with a DT hybrid fusion-fission reactor. It is useful to study this figure because of its generality: nuclear-material flows applicable to purefusion as well as hybrid reactors are covered.

One other point concerning hybrids deserves emphasis. The fissile plutonium produced by hybrids with fast-fission blankets has a very high fissile content, $95 \%$ or higher depending inversely upon the duration of irradiation. $(48,49)$ Thus fission weapons constructed from such material would suffer much less from predetonation problems than would weapons constructed from plutonium recovered from light-water-reactor spent fuel. Hence, the reliability and explosive yield of the former would be higher. (50) In this sense, hybrid-produced plutonium would be similar to plutonium produced in the blanket of a liquid-metal fast-neutron breeder reactor. (48) Table IV-1 shows this.

IV.3. Proliferation of Fission and Fusion Weapons

The International Atomic Energy Agency (IAEA) $(51,52,53)$ carries out inspections of many nuclear facilities worldwide to account for nuclear material and to detect or deter any diversion from these facilities of fissile material, namely enriched uranium or plutonium. Other aspects of the international non-proliferation regime include national intelligence activities, export controls on sensitive technologies, (54) bilateral and multilateral supply agreements, and information classification. The last aspect notwithstanding, an underlying assumption is that the knowledge is needed to construct a fission weapon is so widespread that a determined state could, in time, fabricate a 


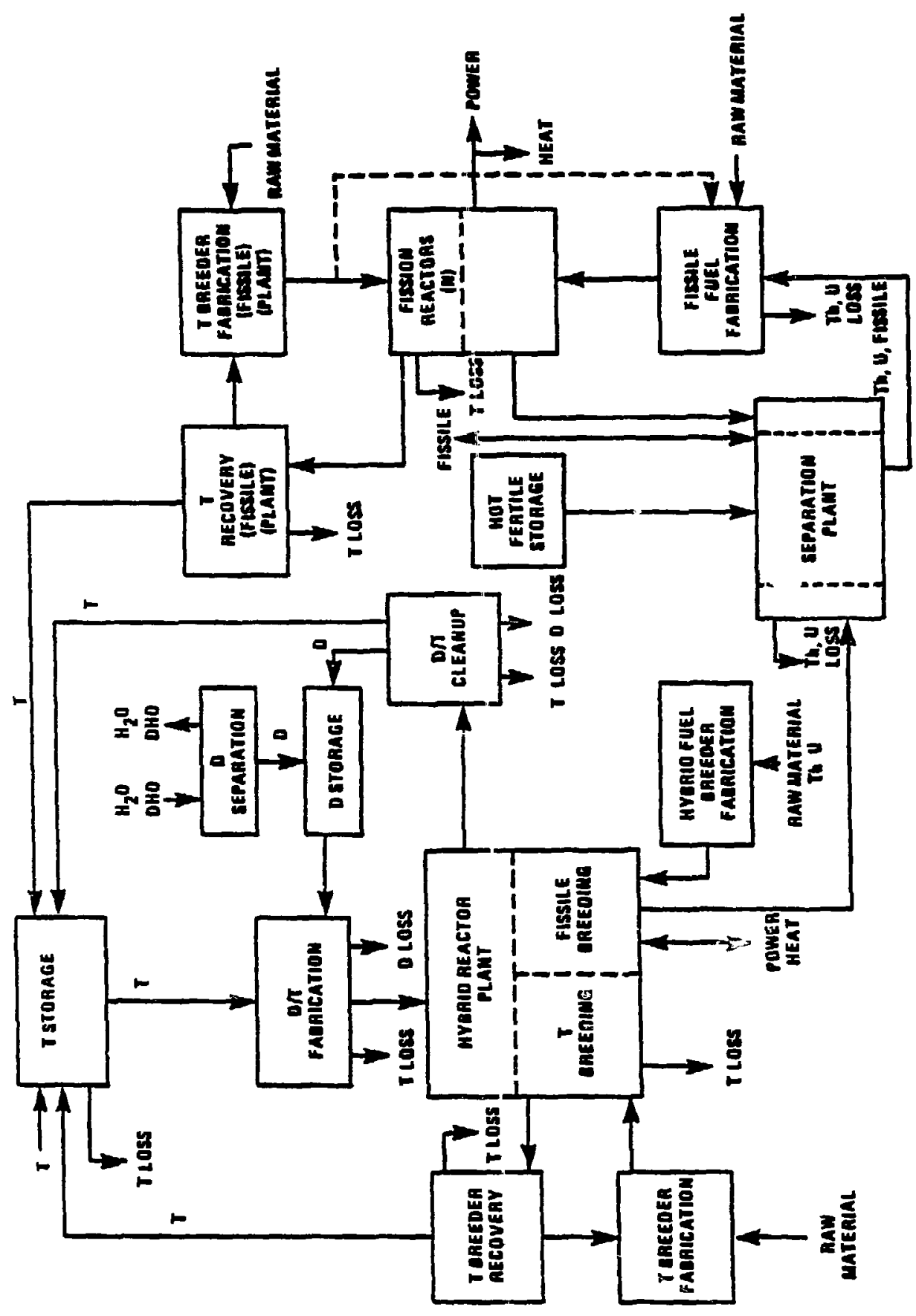

Figure IV-5. Nuclear-material fuel flows associated with hybrid fusion-fission reactors (from ref. 17). 


\section{Source}

Hybrid Fusion-Fission

Reactor Blanket

$\mathrm{LWR}^{a}$

$\mathrm{LMFBR}^{\mathrm{b}}$

B1anket

LMFBR $^{b}$

Reactor
A1pha Decays

(Curies/Kg)

202

393

70

256
Fissile

Percentage

98

75

a Light-water reactor

b Liquid-metal fast-neutron breeder reactor

weapon given the nuclear material.(24) This assumption has traditionally not been held regarding fusion (thermonuclear) weapons. Fusion-weapons technologv is highly classified and took years to develop in the countries that mounted sophisticated efforts to do so.(1) Furthermore, a fission weapon must initiate any fusion weapon $(1,25,55,56)$. Thus, possession of the requisite materials, tritium, deuterium, and lithium, that sustain fusion reactors does not have the same threehold value vis a vis fusion weapons that possession of fissile material has vis a vis fission weapons $(20,21)$.

For these reasons, vigilance over fusion materials is not maintained internationally by the IAEA. In the United States, however, these materials are controlled at varying levels, but less stringently than fissile materials.(57)

Were knowledge of fusion-weapon technology to become widespread, as may have happened to a limited extent during the Progressive incident, $(58,59,60,61)$ the present regime of internationally safeguarding only fissile materials and controlling exports of sensitive technologies might require serious revision. 
The possibility that knowledge about fusion weapons will become more widely known could be facilitated by current research and development into inertialconfinement fusion, aspects of which are classified, $(11,18,62)$ and subsequent deployment of inertial-fusion power plants, a distant possibility.

These arguments lead to the conclusion that international control of fusion materials should be considered. As by far the scarcest, essentially entirely synthetic, tritium would be the most likely candidate for such control.

Tritium is currently produced in production fission reactors by neutron bombardment of lithium-6. Canada is building plants to extract tritium from the heavy water used in its power reactors to enhance radiological safety. $(63,64)$ This tritium will be used for fusion power research(65).

Deuterium is a double-edged sword. In addition to its possible use in fusion weapons, it is also of proliferation significance hecause it can serve as the moderator in a small, clandestine fission reactor operated to produce plutorium. The strategically significant quantity is $\$ 3000$ kilograms of very pure (99.75 mole \%) deuterium, which is enough for a natural-uranium-fueled, heavywater-moderated reactor that can produce enough plutonium in one year to make a fission weapon. (66) In this sense, the IAEA plans to safeguard deuterium in the form of heavy water. (67) (See in this connection Chapter VII.)

\section{IV.4. Magnetic-Confinement Fusion Reactors}

IV.4.1. Physical Description of the Reactor and Power Plant

STARFIRE $(16)$ is a design for a tenth-of-a-kind commercial fusion power plant that would begin operation in about 2020. The design was created by a large team drawn from the scientific, engineering, and industrial communities. 
The STARFIRE plasma itself would satisfy the Lawson criterion with an average particle density $n=0.8 \times 10^{14}$ ions pèr cubic centimeter and a particle confinement time of $\tau=1.8$ seconds at an average ion temperature of $290 \mathrm{million}$ degrees Kelvin. The plasma would produce thermonuclear neutrons in a steady-state driven mode, heated by radio-frequency waves.

Figures IV -6 and IV -7 show respectively the reactor building lavout and an exploded view of the reactor. Table IV-2 lists the key features of STARFIRE. It is helpful to refer to Figure IV-2 to see how the components of the power plant fit together conceptually. Figure IV-8 nakes that conceptual picture explicit for the power flows in STARFIRE, while Figure IV-9 does so for the fuel flows. Actusl fueling of the reactor would be done by gas puffing.

Additional construction features of interest concern components subject to high neutron fluxes: the limiter, part of the exhaust and impurity control system; the first wall and blanket (Figure IV-10), where tritium breeding occurs and the coolant undergoes its predominant heating; and the shield, which reduces the neutron levels to values sufficiently low that the reactor building could be entered one day after a reactor shutdown.

Maintenance schedules would include one planned shutdown per year, averaging 37 days, and time for unplanned shutdowns, totaling 34 days. This yields an availability of $75 \%$. Completely remote maintenance procedures for reactor building components are central to the STARFIRE design. The maintenance philosophy would be to replace components rather than repair them in place. A hot cell would adjoin the reactor building, and any equipment needing repairs or processing before disposal would be handled there (see Figure IV-6). The remote maintenance procedures would be facilitated by giant machines and cranes on tracks capable of moving the very heavy, radioactive structures involved. A par- 


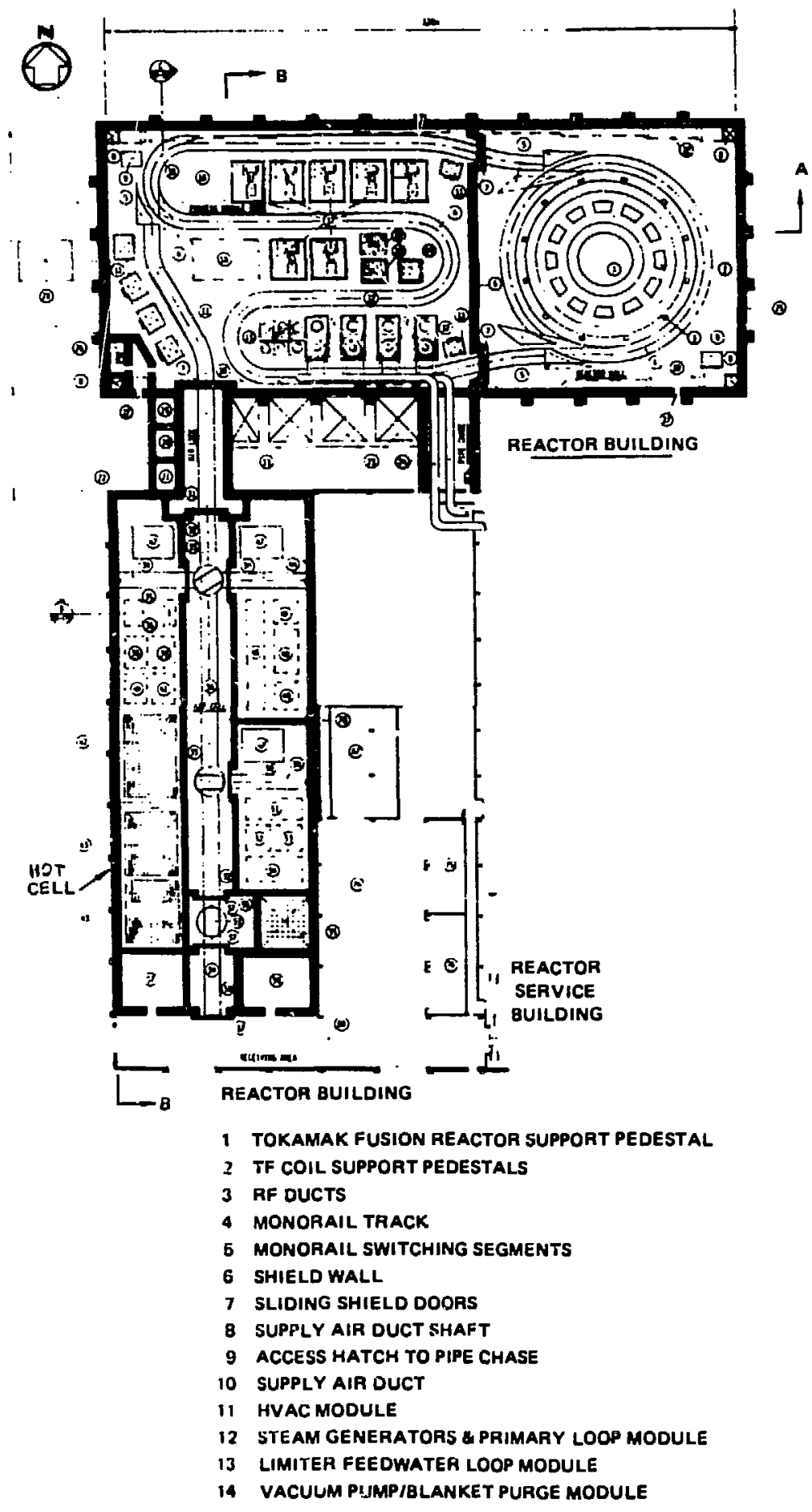

PRIMAARY LOOP MODULE

16 RF SYSTEM COOLING MODULE

17 ATMOSPHERIC TRITIUM PROCESSING SYSTEM

18 LAY-DOWN SPACE

19 ELEVATOR PIT (ABOVE)

20 PIPE SHAFT

21 DUCT SHAFT

22 TUNNEL TO STACK

23 AREAWAYS TO LOWER LEVEL

24 MAIN STEAM PIPE LINES

25 SEGHENTED REMOVABLE PANEL $32 \mathrm{~m}$ HIGH

26 EMERGENCY STAIR

27 EMERGENCY EXIT

28 ACCESS MATCH TO SUB-GRADE LEVEL

29 not used

30 not used

HOT CELL

31 SLIDING PRESSURE RESISTANT DOORS

32 CENTER CORRIDOR

33 MONORAIL TRACK TURNTABLE

34 MONORAIL TRACK

35 BLANKET MODULE I SOLID WASTE PROCESSING

36 BLANKET MODULE HOLDING AREA

37 SLIDING SHIELD DOORS

38 INSPECTION DISASSEMBLY a SEGREGATION AREA

39 TAEATING \& CUTTING AAEA

40 BAKING $\$$ OUTGASSING AREA

41 CleANing, COMPACTING, PACKAGING

12 DRY STORAGE CUEICLES

43 WET STORAGE TANKS

MACHINE SHOP

REACTOR SERVICE BUILDING

74 PREPARATION \& MAINTENANCE AREA

75 PARTS STORAGE

7 NEW BLANKET STORAGE

$8 B$ RAILROAD SPUA

Figure IV-6. STARFIRE reactor building and hot cell (from ref. 16). 


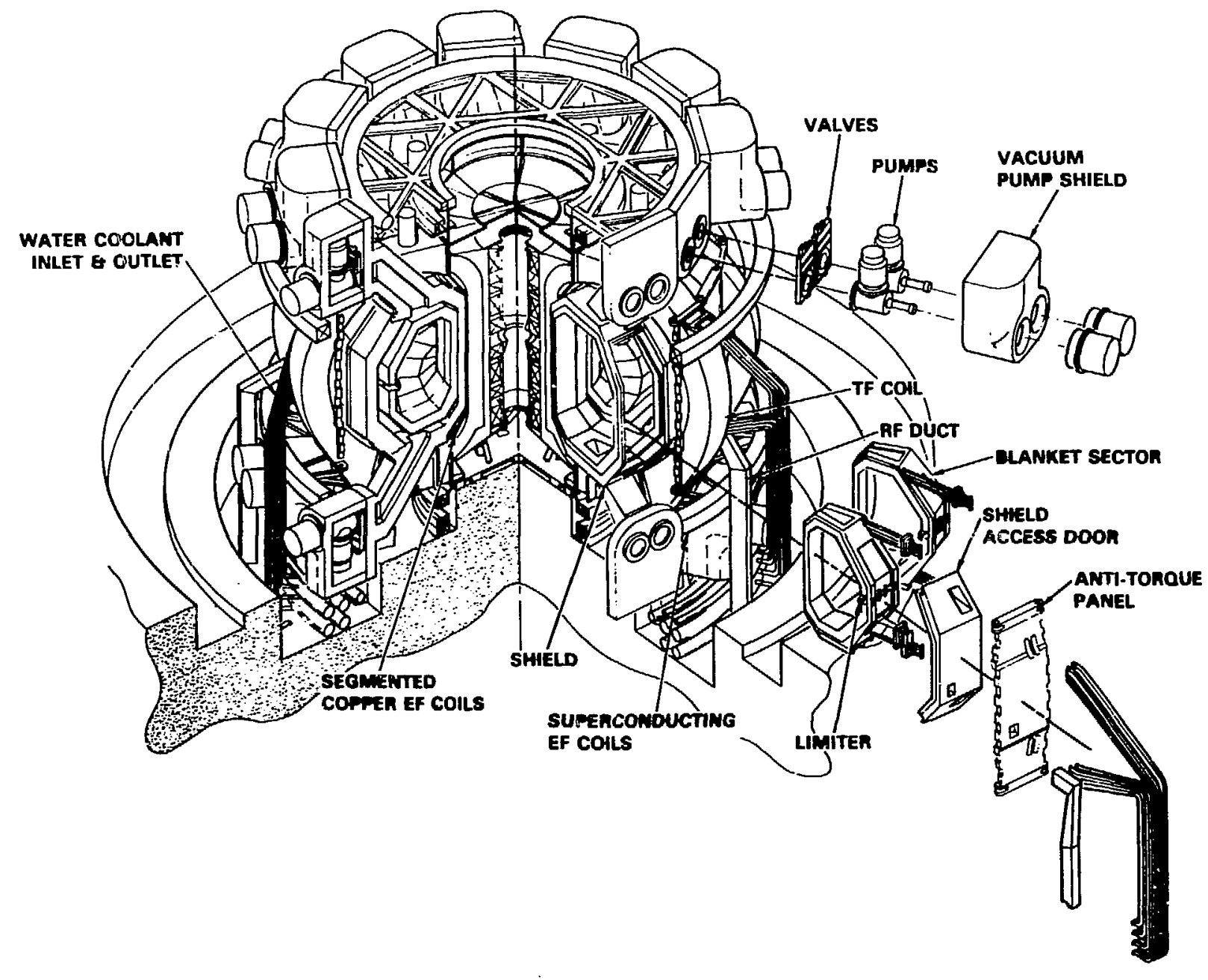

Figure IV-7. STARFIRE reactor design in an exploded view (from ref. 16). 
Table IV-2

Rey Features of STARFIRE (from ref. 16)

- Steady-state plasma operation

- Lower hybrid rf for plasma heating and current (10.1 million ampere) drive

- ECRH-assisted startup

- Limiter/vacuum system for plasma impurity control and exhaust

- All superconducting EF coils outside TF coils

- Vacuum boundary at the shield, mechanical seals

- Total remote maintenance with modular design

- Pressurized-water-cooled, solid tritium breeder blanket with stainless steel structure

- All materials outside the blanket are recyclable within 30 years

- Less than $0.5 \mathrm{~kg}$ of vulnerable tritium inventory

- Minimum radiation exposure to personnel

- Conventional water-steam power cycle with no intermediate coolant loop, no thermal energy storage, and $36 \%$ gross turbine-cycle efficiency

- Average neutron wall load of $3.6 \mathrm{MW} / \mathrm{m}^{2}$

- Major toroid radius of 7.0 meters and plasma half-width of 1.94 meters

" $r$ " means radio frequency

"ECRH" means electron cyclotron resonance heating

"EF" means equilibrium field

"TF" means toroidal field 


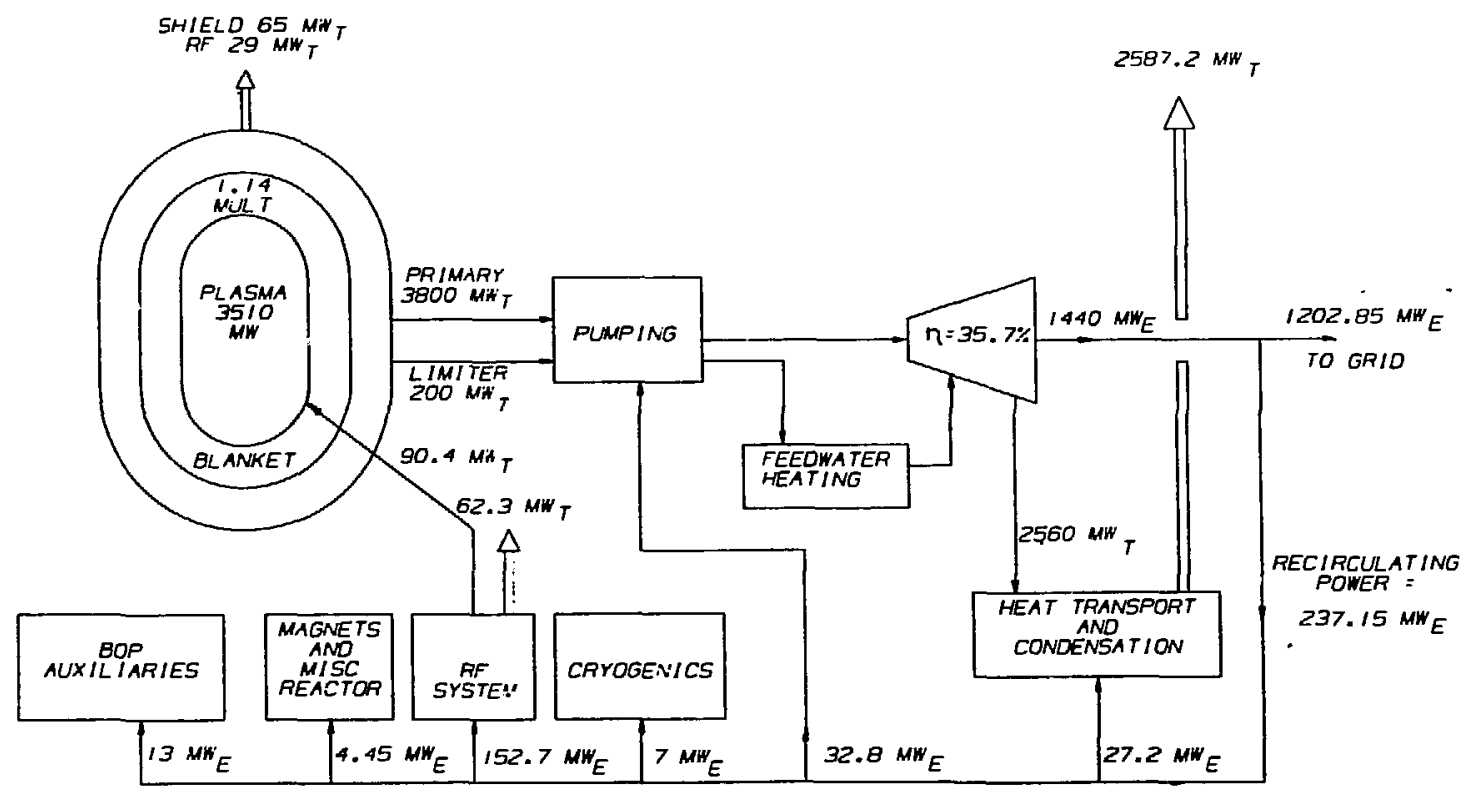

Figure IV-8. STARFIRE power-flow diagram (from ref. 16). 


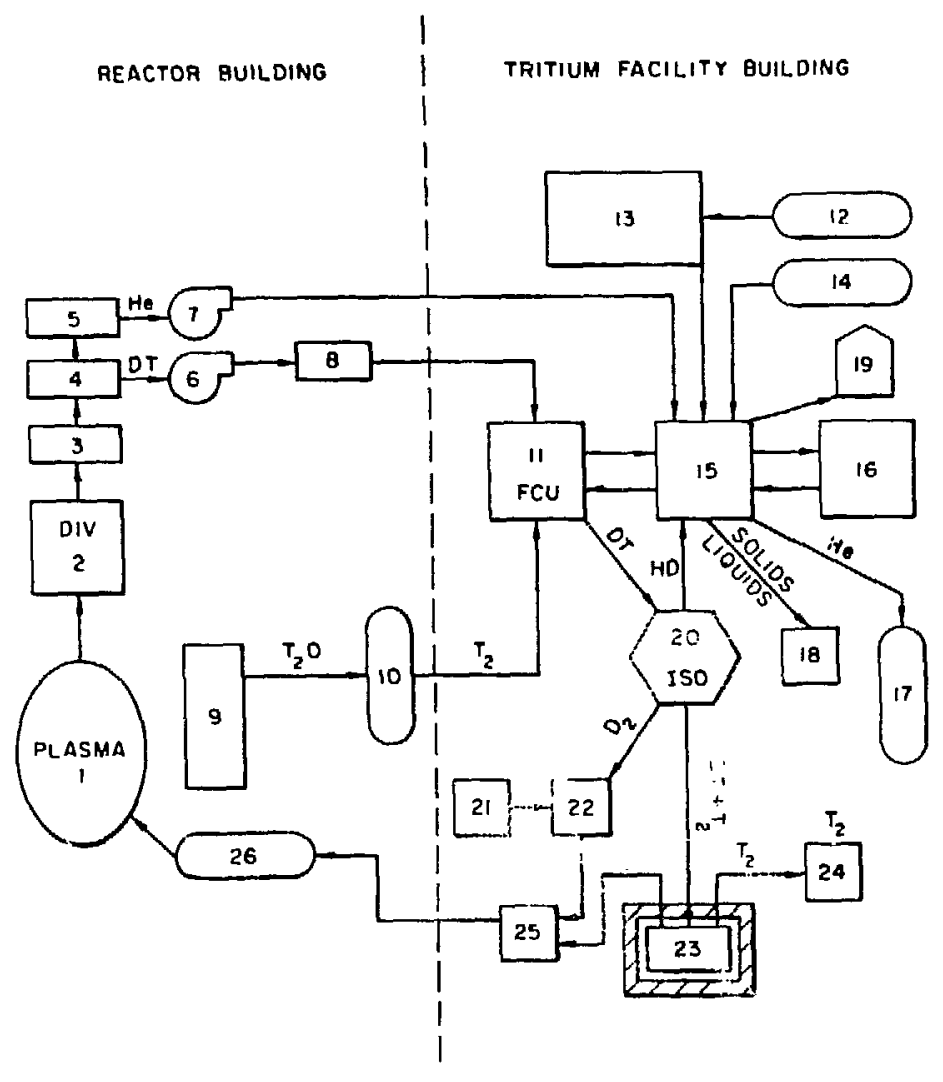

1. Plasma Chamber

15. Tritiated Waste Treatment

2. Limiter Plates

3. Debris Separator

4. D-T Cryocondensation Pump

5. Helium Pump

6,7. Regeneration Pumps

8. Metal Bellows Pumps

9. Breeder Blanket

10. Electrolysis Unit

11. Fuel Cleanup Unit

16. Tritiated Water Recovery Unit

17. Helium (tritium-Free)

18. Tritiated Waste -- liquids and Solids

19. Detritiated Gases: $\mathrm{N}_{2}, \mathrm{O}_{2}$, $\mathrm{CO}_{2}$, $\mathrm{Ar}$

20. Isotopic Separation Unit

21. $\mathrm{D}_{2}$ Supply

22. $\mathrm{D}_{2}$ Storage

23. $\mathrm{jT}$ and $\mathrm{T}_{2}$ Storage

12. Tertiary Enclosures

13. Atmospheric Tritium Recovery System

24. $\mathrm{T}_{2}$ Shipment/Receiving

25. Fuel Blender

14. Secondary Enclosures, Purge 26. Gas Fueling Streams

Figure IV-9. Fuel-cycle scenario for STARFIRE (from ref. 16). 

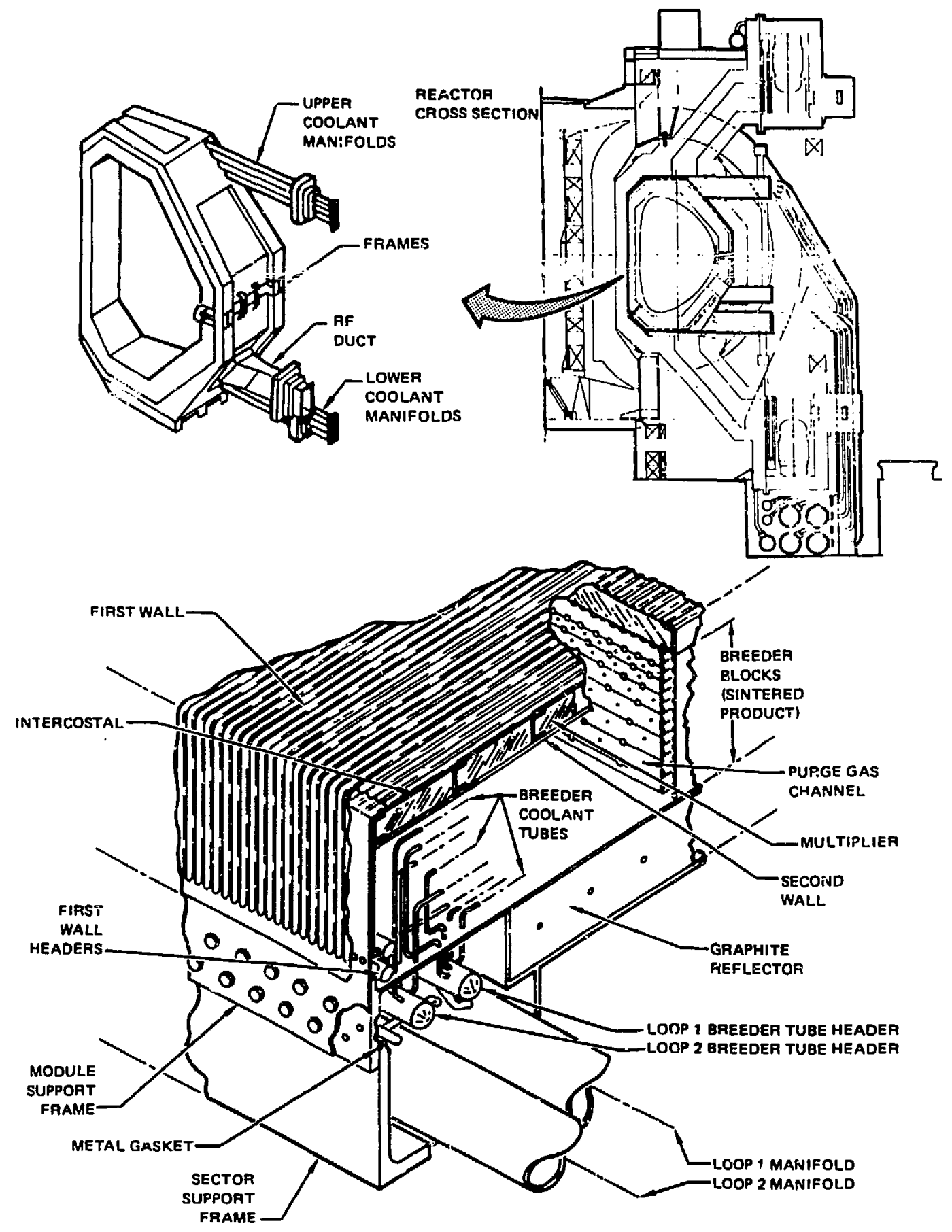

Figure IV-10. STARFIRE first-wall and blanket ccncept (from ref. 16). 
ticular maintenance operation involving access to material subject to high neutron flux would be the annual replacement of four of twenty-four blanket sectors.

\section{IV.4.2. Proliferative Materials}

According to the discussion in Section IV.3, the fusion fuel-cycle materials tritium, deuterium, and lithium may be of proliferation concern.

Deuterium fuel would be supplied continuously to the plant at a rate of about 500 grams per day in, let us say, monthly shipments.

About 10 kilograms of tritium would be initially supplied; thereafter normal breeding would suffice. Table IV-3 describes the normal flow characteristics. The excess of bred over burned tritium would represent a slow inventory buildup over four years for another fusion power plant requiring ten kilograms initially. Aside from the tritium in the solid blanket, a backup inventory of about one kilogram would be maintained in the form of uranium tritide (akin to a metal hydride) modules containing about twelve grams each. Such modules give off tritium when heated.(68) In Appendix IV.A we have calculated that about 30 kilograms of depleted uranium would be raquired to store the usable STARFIRE inventory. The entire tritium inventory is listed in Table $\mathrm{IV}-4$, in which the terms "vulnerable" and invulnerable" refer to safety -- to the potential for accidental escape because of the location and mobility of the tritium. (From a safeguards viewpoint, the tritium in storage is the most vulnerable.) The initial and standby inventory needed are strongly affected both by the breeding ratio and by the removal rate from the breeding blanket. (49)

Because of its radiological hazard, safe and secure handing of tritium is a major design goal of any LT fusion plant, and much research is focussed on attaining it. $(68,69)$ What this means practically for STARFIRE is that the tritium would be handled remotely, processed in doubly enclosed containments, 
Table IV-3

STARFIRE Fuel Flows (from ref. 16)

\begin{tabular}{|l|r|}
\hline Tritium Mass Flow Rates (g/d) & \\
\hline Tritium Burnup & 536 \\
Tritium Fueled & 1296 \\
Tritium Exhausted & 760 \\
Tritium Bred & 562 \\
Deuterium Mass Flow Rates (g/d) & \\
\hline Deuterium Burned & 360 \\
Deuterium Fueled & 865 \\
\hline
\end{tabular}

Table I $\nabla-4$

STARF IRE Tritium Inventory (from ref. 16)

\begin{tabular}{|l|c|c|}
\hline Tritium System & "Vulnerable" (g) & "Non-vulnerable" (g) \\
\hline Solid Breeder Blanket & - & $\sim 10,000$ \\
Blanket Purge Stream & 0.2 & - \\
Blanket Tritium Recovery & 281 & - \\
Vacuum Pumps & 63 & - \\
Fueling & 54 & 1071 \\
Fuel Processing & - & $\sim 11,225$ \\
Storage & - & 398 \\
\hline Total & & \\
\hline
\end{tabular}


and stored in a barricaded vault. Moreover the entire tritium building would have a negative pressure with respect to atmospheric pressure, contain atmospheric tritium recovery systems, and he sensitively monitored for large releases. The goal is that these measures would keep the inevitable routine tritium 1.osses to 5000 Curies or about one-half gram per year (see Appendix IV.A). The release of 50 grams of tritium inside the tritium building would be the largest conceivable release resulting from a processing-unit failure. Lithium would exist in the blanket structures as either unenriched or $60 \%$ enriched (in lithium-6) $\mathrm{LiAlO}_{2}$. Given enrichment, there would be an initial requirement of 550 metric tons of this solid, or about 8 metric tons of lithium. This amount would be distributed among 24 blanket segments of two different sizes, or about 330 kilograms each before irradiation and about 230 kilograms after six years of irradiation (assuming the Table IV-3 flows and that one atom of lithium would be lost for each atom of tritium gained). Table IV-4 indicates that about 417 grams of tritium would be entrained (as $T_{2} 0$ ) in each blanket segment during operation, so much of this would remain when the segment is replaced; it should be recovered during hot-cell recycling of the blanket sectors every six years. The lifetime 1 ithium requirement would be about twice that initially.

\section{IV.4.3. Time Scale of Development}

A strategy for U.S. magnetic-fusion research was recently propounded by the U.S. Department of Energy. (70) As Figure IV.1 shows, scientific breakeven has not yet been achieved. It is nevertheless confidently expected that this will be achieved with a DT.plasma in the latest generation of tokamak devices, for example the Tokamak Fusion Test Reactor (TFTR) at the Princeton Plasma Physics Laboratory. (71) The TFTR is the first U.S. system to require advanced tritium 
handling, development of a system for which is being carried out at the Mound Facility. (68) Developmert of tritium systems for subsequent reactors is centered at the Tritium Systems Test Assembly at the Los Alamos National

Laboratory. (69)

The latest experimental magnetic-fusion facilities will hopefully provide sufficient informaticn about the plasma physics, tritium handling, magnet technology, impurity control and, fueling systems to justify construction of a science-oriented burning plasma experiment. $(70,72)$ Thereafter, plans generally become very speculative tinewise but encompass a demonstration reactor before commercial plants. According to the Magnetic Fusion Engineering Act of 1980,(73) a Fusion Engineering Device should be constructed by about 1990 and commercial plants by 2000 , but this schedule has been superseded by budgetary constraints and programmatic changes. $(70,74)$

Internationally, Europe collectively, Japan, and the U.S.S.R. are conducting etrong magnetic-fusion programs comparable to that of the U.S. Each currently operates or is building a tokamak reactor similar to Princeton's TFTR. An IAEA panel ${ }^{(75)}$ has posed as a reasonable goal the demonstration of a fusion electric plant by about 2005. One U.S.S.R. plan presumed a fusion power station no sooner than 2010.(76) There has moreover been a significant international effort under the auspices of the IAEA to design an International Tokamak Reactor $(77)$, and there have been many bilateral projects.

\section{IV.4.4. Other Fuel Cycles}

Deuterium and tritium are the fuels of choice for fusion power plants because it is easier to induce energy-producing reactions between them than between other fusion fuels and because the energy gain per reaction is relatively large. In terms of the discussion in Section IV.1, higher temperatures would be 
required to ignite -- and higher energies to drive -- plasmas of other species, while not as much energy would be produced per unit of plasma mass. Indeed, the reduction is by a factor of ten to one hundred depending upon the operating temperature. The physics tradeoffs $(15,78)$ and the engineering constraints $(79)$ have both been studied.

There are basically two motives for employing fusion fuel cycles other than the DT cycle. The first is to eliminate the need to breed tritium in a blanket and the second is to eliminate high-energy neutrons, which cause hazardous radiological activation of structural materials in addition to transferring energy. Of course neut:rons would be necessary for hybrid systems. Tables IV5(a) and (b) 1ist possible fusion reactions.

Breeding tritium in a blanket could be obviated by employing the deuterium-deuterium (DD; the second and third of Table IV-5(b)) reactions. (80) The deuterium fuel is relatively plentiful, and the tritium produced would either imediately react via the basic DT reaction or be reinjected or could be stored to permit natural decay to helium-3. Thus this scheme would result in high-energy (DT) neutrons plus helium-3. The latter could serve as fuel for a different reactor operating on the basis of the fourth Table IV-5(b) reaction. Some neutrons would result but much energy would be extracted via direct elsctric conversion or electromagnetic coupling of the kinetic energy of the moving proton. (15) Some current magnetic fusion designs such as the tandem mirror, already embrace partial direct conversion of the energy of moving deuterium, tritium, and helium ions. (81) Thus, this scheme would eliminate the lithium blanket in both reactors and significantly reduce high-energy neutrons in one. Combining the first four reactions in Table IV-5(b) yields an overall DD reaction producing neutrons, protons, and helium-4. It eliminates the need for tritium breeding 
Table IV-5

(a)

Some Advanced-Fuel Reactions and Side Reactions (from ref. 82)

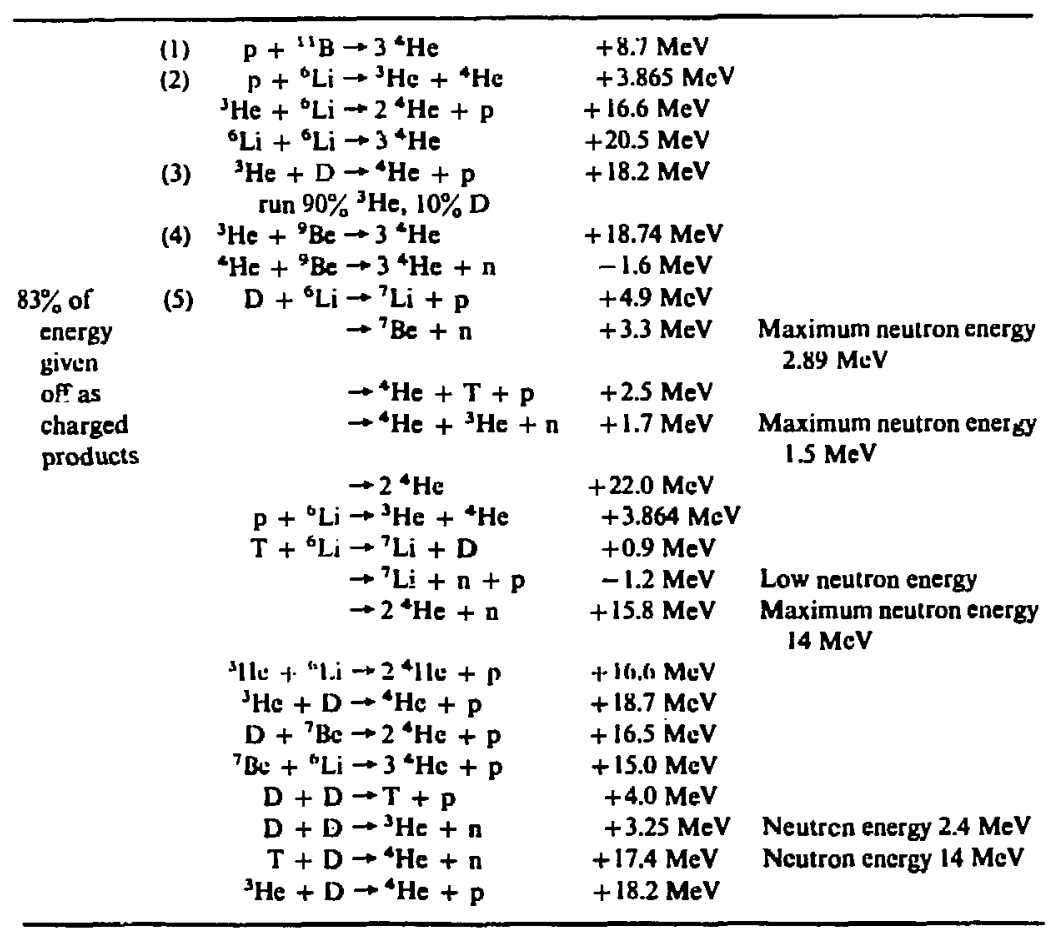

(b)

Data for Selected Fusion Reactions (from ref. 14)

\begin{tabular}{|c|c|c|c|c|}
\hline Reaction & $\begin{array}{l}\text { Shorthand } \\
\text { notation }\end{array}$ & $\begin{array}{l}\text { Renction } \\
\text { energy } \\
\text { (MeV) }\end{array}$ & $\begin{array}{l}\text { Threshold } \\
\text { plarma } \\
\text { temperature } \\
\text { (keV) }\end{array}$ & $\begin{array}{l}\text { Moximum } \\
\text { energy } \\
\text { gin per } \\
\text { fusion }\end{array}$ \\
\hline 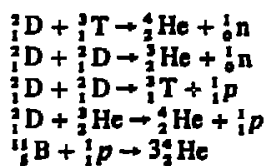 & $\begin{array}{l}\mathrm{D}-\mathbf{T} \\
\mathrm{D}-\mathrm{D} \\
\mathrm{D}-\mathrm{D} \\
\mathrm{D}-\mathbf{2} \mathrm{He} \\
{ }_{\mathrm{B}-\mathrm{P}}\end{array}$ & $\begin{array}{r}17.6 \\
3.2 \\
4.0 \\
18.3 \\
8.7\end{array}$ & $\begin{array}{r}10 \\
50 \\
50 \\
100 \\
300\end{array}$ & $\begin{array}{r}1800 \\
70 \\
80 \\
180 \\
30\end{array}$ \\
\hline
\end{tabular}


and is excellent for hybrid breeding but requires much better ignition conditions than do DT reactions alone.

By using the "exotic" boron-hydrogen cycle (the last reaction in Table IV-5(b)), neutrons could be almost completely eliminated. However, recent work $(83)$ calls into question the energy viability of this cycle for magnetic fusion. If workable, the energy would be recovered by direct conversion.

\section{IV.4.5. Proliferation Concerns}

Diversion of fusion materials and clandestine production of fissile materials are the proliferation concerns associated with magnetic-fusion plants.

\section{IV.4.5.1. Fusion Materials and Their Measurement}

Based upon the discussion in Section IV.4.2, we have collected in Table IV-6 the fusion materials that would exist at the STARFiRE plant and listed alongside the concomitant threshold quantity for current U.S. Department of Energy reporting requirements. (84) The nuclear materials depleted uranium, enriched lithium, deuterium, and tritium would be present in reportable quantities. Lithium and tritium inventories and tritium losses would be especially large. Cumulative tritium consumption and production would be enormous. Given the breeding excess of tritium, the inaccessible inventory, and the inevitable loss to the environment, material accounting would be especially dependent on plant process measurements.

Even if it were diverted, the depleted uranium in such a small amount could not be converted by irradiation to a significant quantity (85) (SQ) of plutonium ( 8 kilograms $)(17,48,86)$ during the 1 ife of the reactor.

Instituting some combination of strict material-accounting requirements and containment and surveillance of these fusion materials on the international 
level(19) would be the basic step necessary to deter simple diversion of them. The IAEA does not safeguard any of them yet, though it may soon play such a role for deuterium in the form of heavy water ${ }^{(67)}$. Containment and surveillance

Table IV-6

STARFIRE Nuclear Material Summary

STARF IRE

Material

Depleted Uranium

Lithium-6

Deuterium (Burned)

Tritium (Burned)

Tritium (Bred; net)

Tritium (Storage)
Quantity

r30 Kilograms

40,000 Kilograms ${ }^{a}$

$0.36 \mathrm{Kilogram} / \mathrm{day}$

$0.54 \mathrm{Kilogram} / \mathrm{day}$

$0.026 \mathrm{Ki}$ logram/day

1.07 Xilogram
DOE Reportable

Quantity ${ }^{b}$

Kilogram

Kilogram

Kilogram/tenth

Gram/hundredth

a Assuming 60\% enriched lithium is employed.

b From ref. 84 .

(in the safeguards sense), ordinarily complementary IAEA measures, may be applicable as monitoring measures for the tritium building and for the reactor building and hot cell (Fig. IV-6), where lithium components (plus residual tritium) would be in a relatively accessible state during maintenance. Extended containment and surveillance ${ }^{(87)}$ do not seem suitable for such a large facility. Finally, physical protection is a national, not an IAEA responsibility, so it could play no role in international safeguards as currently instituted.

Consideration has been given to carrying out tritium breeding away from the DT fusion reactor itself, at a dedicated fission reactor, say. This would simplify the fusion design by eliminating the lithium blanket. However, tritium would still have to be recovered from unburned reactor fuel, necessitating a 
processing system with its attendant losses; in addition, shipments of tritium would then be necessary. But for any fusion reactor designs where the fractional burnup of tritium would be very high (Table IV-3), remote tritium breeding would not even seem economically justified. (88) The additional transportation hazard would seem to make remote breeding undesirable from a safeguards as well as a safety standpoint.

I.t is important to realize that both deuterium and lithium-6 are stable, nonradioactive nuclei. Thus, passive nondestructive-assay (NDA) nuclear methosi:s are not suited to detecting them. If international inspectors were to perform confirmatory material accounting testa, active nuclear tests of some sort would be required. A variety have been examined for deuterium in the form of heavy water. (89) An acoustic measurement based on density differences also distinguishes between ordinary and heavy water. (90)

For lithium, nuclear assay methods consist of measuring alpha particles that result from neutron interrogation, which gives the lithium- 6 content, and of measuring the gamma rays that result from alpha interrogation, which gives the lithium-7 content. These methods have an accuracy of about $10 \%$.

Tritium emits beta particles and is radiologically dangerous. However, the beta emissions are not detectable directly if the tritium is inside a container. (Direct beta detection has been studied for NDA of tritium in laser-fusion targets. (91)) These emissions are indirectly detectable by the heat they generate. Indeed, calorimetry $(92)$ is a sensitive technique for material accounting, (93) accurate to about $0.15 \%$ for $10 \mathrm{gram}$ samples or larger. This could be the basis for safeguards inspections of shipments to fusion plants and annual plant inventory measurements. Other accounting $(92,94)$ techniques exist, but they require both mass-spectrometric analysis and pressure-temperaturevolume measurements; the overall accuracy is $0.25 \%$. These techniques could fit 
into safeguards inspections through reliance on process measurements as in a reprocessing plant. Nevertheless, the threshold for DOE reporting (Table VI-6) is certainly below the accuiutablility accuracy achievable in the processing equipment aseded for fusion reactors. (95)

The helium-3 daughter nucleus from the beta decay of tritium could be monitored as a surrogate for tritium, especially to determine the tritium gains and losses during plant operation. Carrying out this accounting would also necessitate assaying waste helium -4 and hydrogen. A direct physical inventory of tritium would be impossible without shutting down the reactor, difficult anyway, and of dubious value since the fuel-loop inventory-not including the blanket-would be a small fraction of the tritium burned and bred over $a$ few months (see Table IV-4).

\section{IV.4.5.2. Undeclared Production of Fissile Material}

Since a magnetic fusion reactor would be a prodigious source of neutrons, "diversion" of some of these neutrons to produce undeclared plutonium from uranium is conceivable.(25) In Appendices IV.B and IV.C, we have calculated crudely how much such plutonium could be produced for two possible placements, of the uranium, incorporated in the structure of the reactor and dissolved in the primary coolant. The calculations do not deal with the extra heat production and reprocessing that would be involved in any such scheme.

Appendix IV.B shows that 1.8 SQ of plutonium could be produced per year per square meter of STARFIRE wall if uranium carbide were substituted into the first wall and blanket structure (Fig. IV-10). This large quantity could occur because the neutron flux would be so high at that location, about $1.6 \times 10^{18}$ neutrons per square meter per second. 
This production rate would occur in the context of a wa11 area of about 780 square meters, thezeby allowing much room for clandestine plutonium production in any of the 24 first-wall sectors -- 58 SQ per replaceable sector per year -with a six-year replacement cycle. If the inside section of the radiation shield were the site of the uranium, where the flux would be lower, about six outboard shield sectors would have to be employed to Produce even one SQ of fissile material. Any such scheme would be further complicated by the 65 metricton sizes of the components involved.

Appendix IV.C indicates that about twenty SQ of fissile material could be produced per year by dissolving uranium in the reactor coolant. This relatively low rate makes this method less attractive than those involving emplacement in the structure, especially given the corrosive chemical environment required. These schemes for producing plutonium by neutron diversion could be prevented by ensuring that no illicit fertile material enters the reactor buipding (Fig. IV.6) and by monitoring the coolant. Whenever installed or replaced, all reactor components subject to fluxes higher than about $10^{16}$ neutrons per square meter per second should be scanned for the presence of uranium-238 (or thorium-232). Passive or active neutron nondestructive analysis would be possible techniques. In addition, a reactor power monitor could be employed to verify that no undeclared shutdown occurs during which fertile material is installed. The hot cell (Fig. IV.6) could also be monitored for fissile plutonium-239 (or uranium-233).

Finally, these neutron-diversion schemes, if possible to carry out without damage to the reactor, would likely have some detectable effect on ordinarily monitored reactor characteristics. (This is true for analogous schemes for light-water reactors ${ }^{(99)}$ ). Therefore, scritiny of the authentic operating records could provide another means for detecting neutron diversion. 
IV.5.1. Physical Description of the Reactor and Power Plant

The Westinghouse design study ${ }^{(18)}$ for an inertial-confinement fusion power plant was conducted under a contract with the Department of Energy to identify key design features for a utility-operated plant, to develop a cost-assessment methodology for such a plant, to study the effect of design variations on the cost of electricity produced, and to identify key research and development needs. The Westinghouse design team received significant help from Stone and Webster, Inc. in architectural engineering and from the Public Service Electric and Gas Research Corporation $(100)$ regarding utility views.

Though one does not conventionally speak of inertial fusion in this way, the DT plasma in this system would satisfy the Lawson criterion with a density of about $10^{26}$ ions per cubic centimeter ${ }^{(5)}$ for a time of about $10^{-11}$ seconds. The average ion temperature would be about 240 million degrees Kelvin. Such small explosions would occur ten times per second in the Westinghouse reactor. Figures IV-11 and 12 show respectively the laser-beam arrangement and the "dry-wa11" reactor chamber, the latter with the lithium-coolant flow path highlighted. The reactor chamber would be situated in a building about 100 meters by 64 meters in linear dimensions. The laser drivers would be located in other buildings. Table IV-7 gives the features of the design and several of its major design parameters. Figure IV-13 shows diagramatically the plant's power flows. Fueling of the reactor would be done by magnetically induced acceleration of the fuel pellets.

Because of the intense neutron and $X$-ray flux, procedures would be to replace remotely the first-wall assembly each year with a new or refurbished replacement, a task which would require thirty days of work under normal 


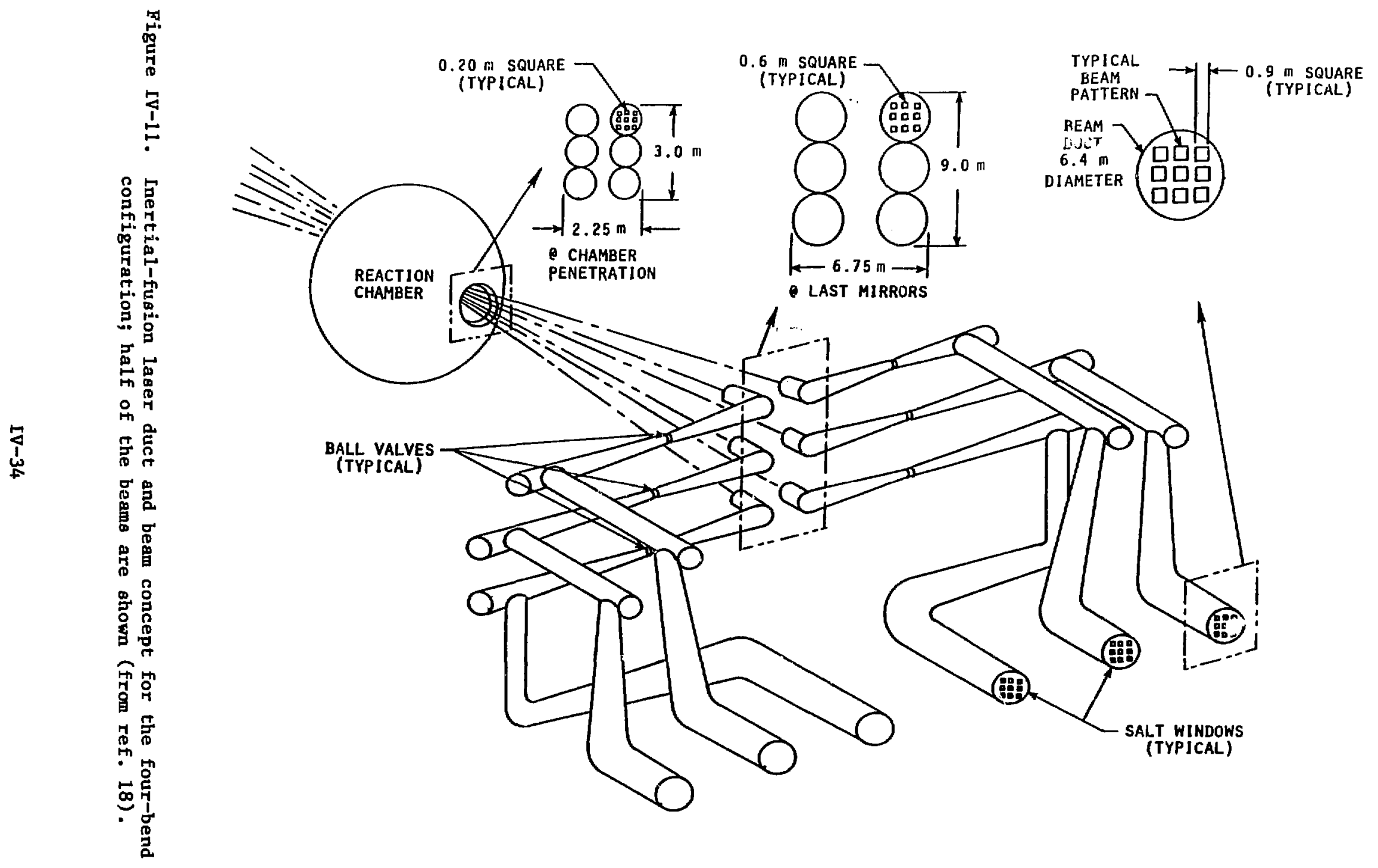



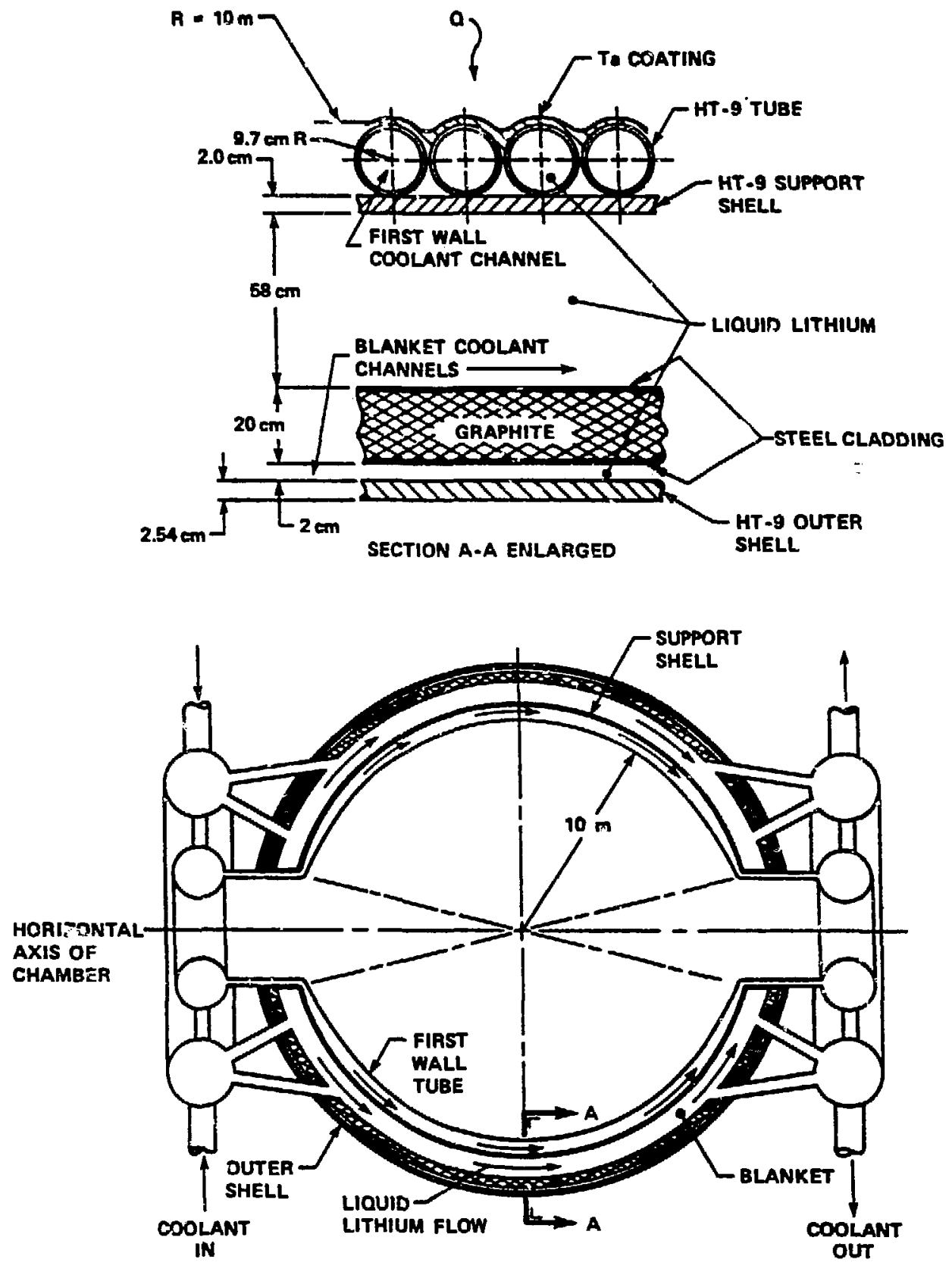

Figure [V-12. Reaction chamber concept for the laser-driven reactor (from ref. 18). 
Table IV-7

Key Features of the Westinghouse Inertial Fusion Power Plant

- Carbon-dioxide laser (and heavy-ion particle beam) examined as driver

- Laser energy of 2 megajoules, efficiency of $10 \%$, and repetition rate of 10 times per second

- Thermonuclear pellet yield of 350 megajoules and gain of 175

- Dry first wall with tantalum coating to minimize temperature fluctuations

- Liquid lithium as the primary coolant and tritium breeding medium

- DT fuel pellets with first-wal1-compatible tantalum layer manufactured at the plant site

- Magnetically induced acceleration of fuel pellets into the reactor chamber

- Liquid lithium, liquid sodium, water-steam heat-transfer loops

- Remote maintenance with removable first-wall structure

conditions. The plant would contain the hot-cell facilities necessary to permit servicing of this 1600 metric-ton assembly.

\section{EV.5.2. Proliferative Materials}

Given roughly equivalent gross electric power from magnetic and inertia1fusion power plants, we expect roughly equal fuel flow rates. Indeed, as we have shown in Appendix IV.D, the tritium requirement of the Westinghouse inertial-fusion plant would be 530 grams per day, virtually identical to that listed in Table IV-3 for the STARFIRE plant. Though the breeding ratio in the inertia1 plant would be 1.22 , the material summary given in Table IV-3 for deuterium and tritium would apply to the Westinghouse inertial-fusion plant as well. The 


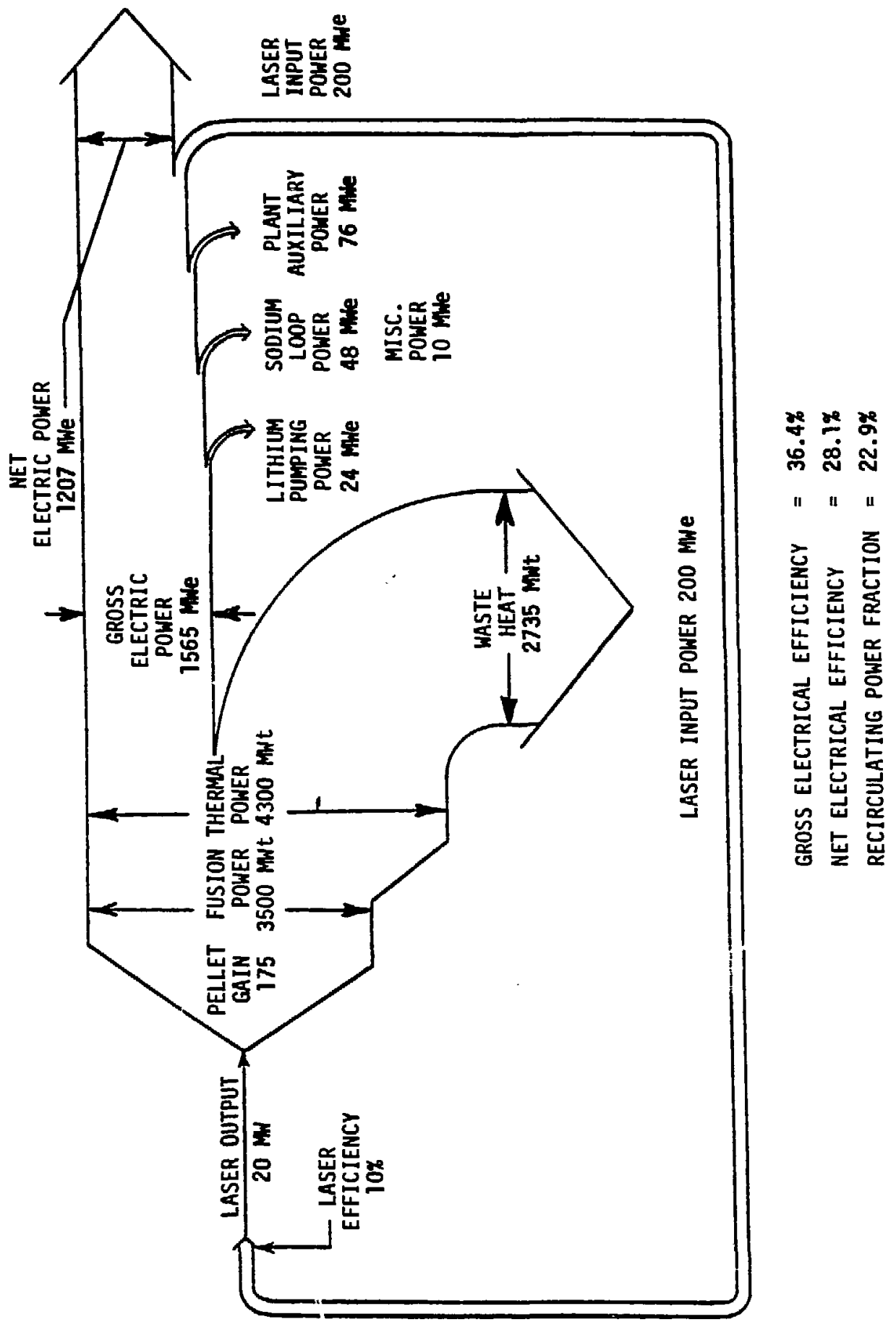

Figure IV-13. Power-flow diagram for the reference laser-fusion reactor (from ref. 18). 
lithium requirement is much greater than for STARFIRE because lithium would serve in liquid-metal form as the primary coolant as well as the tritium breeding medium for the inertial plant.

Processing of the reaction debris to recover unburned deuterium and tritium and of the blanket lithium to recover tritium would proceed in any DT fusion plant even though the chemistry and possibly accountability would depend on the exact materials in use. One major difference is that an inertial-fusion plant would house a pellet factory for fabricating laser fuel targets. (In some "wet-wa11" designs, (39) reaction debris would actually be trapped in a liquid lithium coolant, but it would have to be separated subsequently for reuse of the tritium along with the bred tritium.) Nevertheless, protection and storage of the radiologically dangerous tritium would involve the same quantities and storage methods. The deuterium would be bought periodically and stored until needed. The anticipated tritium losses to the environment would be about 365 Curies or 0.0365 grams per year at the inertial-fusion plant.

IV.5.3. Time Scale of Development

Inertial fusion research has, on the one hand, the added impetus from military applications, but on the other, the restrictions on information transfer and research interaction so implied. The military purpose is not to develop a weapon per se, but rather to provide a small-scale means for modeling the physical processes that occur in nuclear explosions or their effects, for studying materials properties under extreme thermodynamic conditions, and for studying weapons effects on diverse systems. $(7,8,9)$ In any event, electricity from inertial fusion seems further from realization than electricity from magnetic fusion. $(11,101,102)$ Given the status of development in the field,(103) scientific feasibility for inertial fusion is not expected to be demonstrated until 
the lace nineteen eighties, at the earliest. Very recent experiments with short-wavelength lasers have been encouraging(104) and a demonstration plant by 2010 is a plausible goal of successful agressive program of development. (105) The major 0.S. laser facility is the NOVA facility at the Lawrence Livermore National Laboratory. (106)

Administratively, the research programs for the two confinement methods are run by different management teams at the United States Department of Energy. Major foreign research programs in inertial-confinement fusion exist in Japan, Poland, the United Kingdom, and the U.S.S.R. $(107,108)$

\section{IV.5.4. Other Fuel Cycles}

Inertial-confinement fusion power plants could use the same fusion reactions as magnetic confinement plants. Fuel process loops would differ depending upon the design of breeding blankets and reaction-debris-handling systems. Another difference is that energy-conversion schemes employing direct or electromagnetic energy conversion are far less appropriate for inertial-confinement systems.

\section{IV.5.5. Proliferation Concerns}

Diversion of fusion materials, clandestine production of fissile materials, the spread of classified information, and the spread of sensitive technologies are the proliferation concerns for an inertial-fusion power plant. We have already discussed the first two matters in detail in Section IV.4.5 and Appendices IV.B and IV.C in connection with magnetic-fusion power plants. That discussion applies here too because of the qualitative similarity of the situations. The basic point is that significant clandestine production of fissile material by illicit placement of fertile material in structural members exposed to high neutron flux or in the primary coolant and tritium breeding medium is plausible. 
Roughly s: -rking, the clandestine production potential would scale linearly with fusion power from the Appendix IV.B and IV.C results. Of course quantitative estimates would depend on the detailed neutron flux distribution throughout the reactor.

One additional remark concerning the coolart-placement scenario is that there may be no compatible way to get fertile material into the liquid lithium coolant and tritium breeder of the inertial fusion reactor described here. However, for reactor engineering purposes the lithium-lead eutectic $\mathrm{Li}_{17} \mathrm{~Pb}_{83}$ has been suggested as a substitute for pure lithium in such situations. (109) Since thorium oxide $\left(\mathrm{ThO}_{2}\right)$ particles nearly match the lithium-lead eutectic in density, they could be put into suspension in the eutectic. Indeed, just this system is under study for a tandem-mirror hybrid reactor breeding blanket. (110) Thus, a basis does exist for considering illicitly breeding fissile material in a liquid metal coolant and breeding blanket of an inertial-confinement pure fusion reactor. (Experimentally, a uranium oxide suspension in the liquid sodium-potassium eutectic has been studied. (111) This remark should in no way be taken to imply that the coolant-placement scenario would be straightforward to accomplish in the absence of prior design considerations, for it would involve extra heat production, radioactivity, and reprocessing.

Consider now the questions of classified information and sensitive technologies, about which we made general remarks in section IV.3. of present concern is the classification of aspects of the technology. $(11,18,62)$ should this situation remain unchanged, then an inertial-fusion power plant might require classification at least in part, with all the attendant requirements such as access-authorization procedures. (112) Indeed, the classification problem exists now regarding research and development.

Should international safeguards be extended to fusion materials, then a 
future possible problem in this regard is that a domestic inertial-fusion plant for commercial power purposes would apparently be subject to the application of international safeguards under the voluntary U.S. - IAEA agreement $(113,114)$ (suitably amended) (see Section II.5.1) given that the plart would not have direct national-security significance. To protect sensitive technology, extra costs might have to be incurred in building such a plant or preparing for its inspection.

The laser (or ion) drivers for inertial-fusion plants are hugh installations themselves. Should technical breakthroughs in inertial fusion allow much smaller drivers, then the drivers of inertial-fusinn power plants would be very sensitive technology and would require control. Size would also be a factor in the use of high-energy drivers as directed-energy weapons, $(115,116,117,118,119)$ an application not considered here.

\section{IV.6. Hybrid Fusion-Fission Reactors}

IV.6.1. Physical Description of the Reactor and Power Plant

Westinghouse's Commercial Tokamak Hybrid Reactor (CTHR) ${ }^{(17)}$ design is intended for a first-generation fusion-fission plant. Its fusion design is more conservative than that of the pure fusion $\operatorname{STARFIRE}^{(16)}$ reactor, yet it represents a plausible marriage of fusion-driver and hybrid-blanket technologies.

The CTHR plasma itself would satisfy the Lawson criterion with an average particle density $n=0.89 \times 10^{14}$ ions per cubic centimeter and an energy confinement time of $\tau=1.3$ seconds at an average ion temperature of 240 million degrees Kelvin. The plasma would produce thermonuclear power in an ignited mode; a 1200 second burn period would alternate with a 5 second shutdown.

Figure IV-14 shows a trimetric view of the reactor and Table IV-8 1 ists its design guidelines. Figure IV-15 shows schematically the CTHR power flows. 


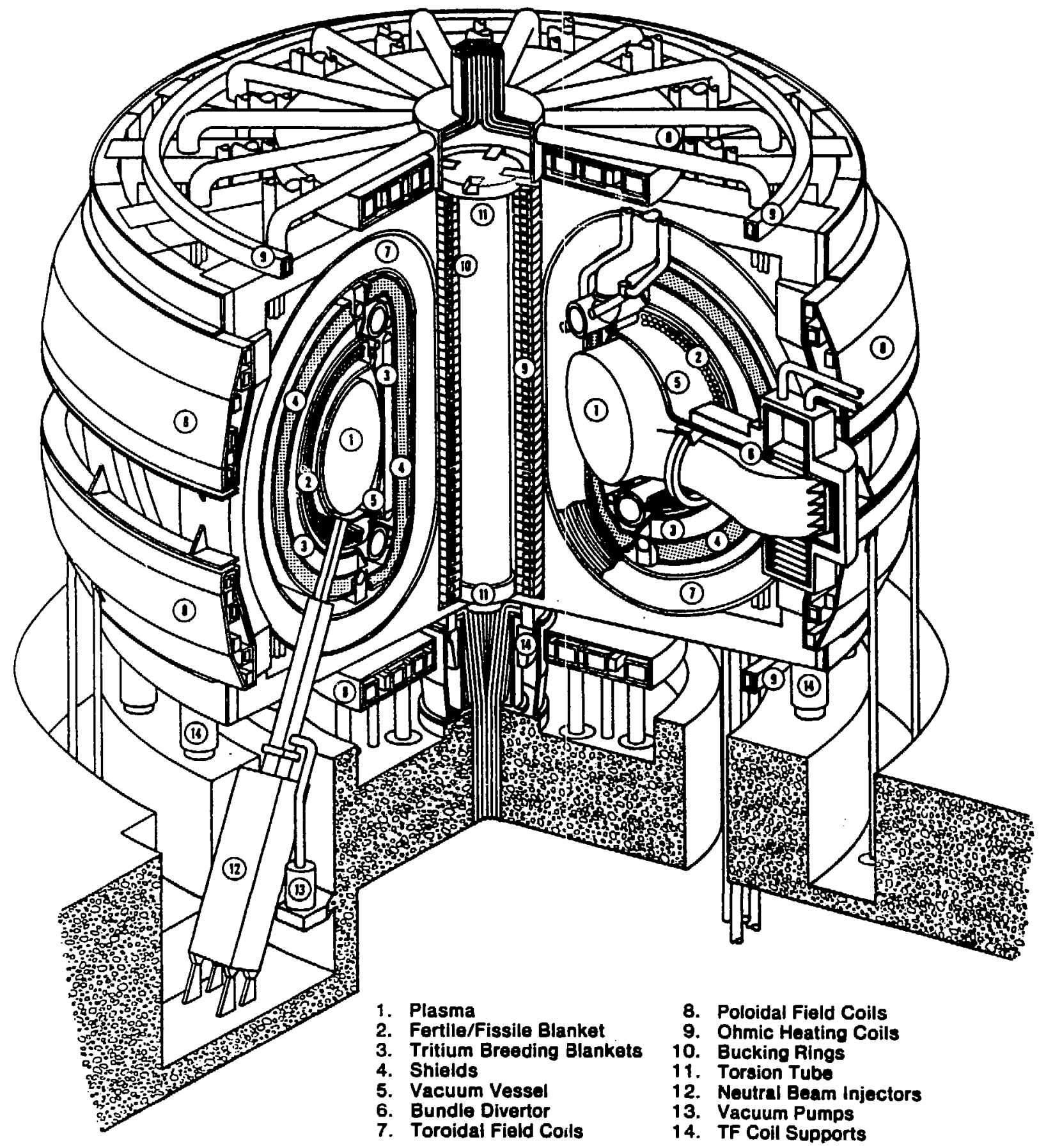

Figure IV-14. Trimetric view of the Westinghouse reference Commercial Tokamak Hybrid Reactor (CTHR; from ref. 17). 
Table IV-8

Design Guidelines of the CTHR (from ref. 17)

- Ignited plasma (near ignition option); $2 \mathrm{MW} / \mathrm{m}^{2}$ average neutron wall loading

- Superconducting $\mathrm{Nb}_{3} \mathrm{Sn}$ magnets: $12 \mathrm{~T}$ peak field

- Negative-ion neutra1 beams: for energies $\geq 200 \mathrm{keV}$

- Plasma duty cycle: $\geq 0.9$

- Bundle-divertor plasma exhaust system

- First-wall lifetime and magnet service requirements compatible with blanket refueling cycle

- Provision for full blanket coverage, if economically justified

- U-Pu fuel cycle with chemical reprocessing

- Fissile production maximized to about $2500 \mathrm{~kg}$ annually (goal: 3 weight per cent in 4 years residence time) based on a fundamental time-averaged rate of 0.86 net fissile atoms per fusion neutron

- Pressurized helium primary reactor coolant with a water-steam secondary circuit for heat removal and electrical generation.

- Electrical power production $\geq$ required operating power.

- Tritium self-sufficiency (goal: breeding ratio 1.05 at start of life).

- Reactor plant availability: 0.7 
HEAT TO ENVIRONYBNT

$\stackrel{ }{1}$

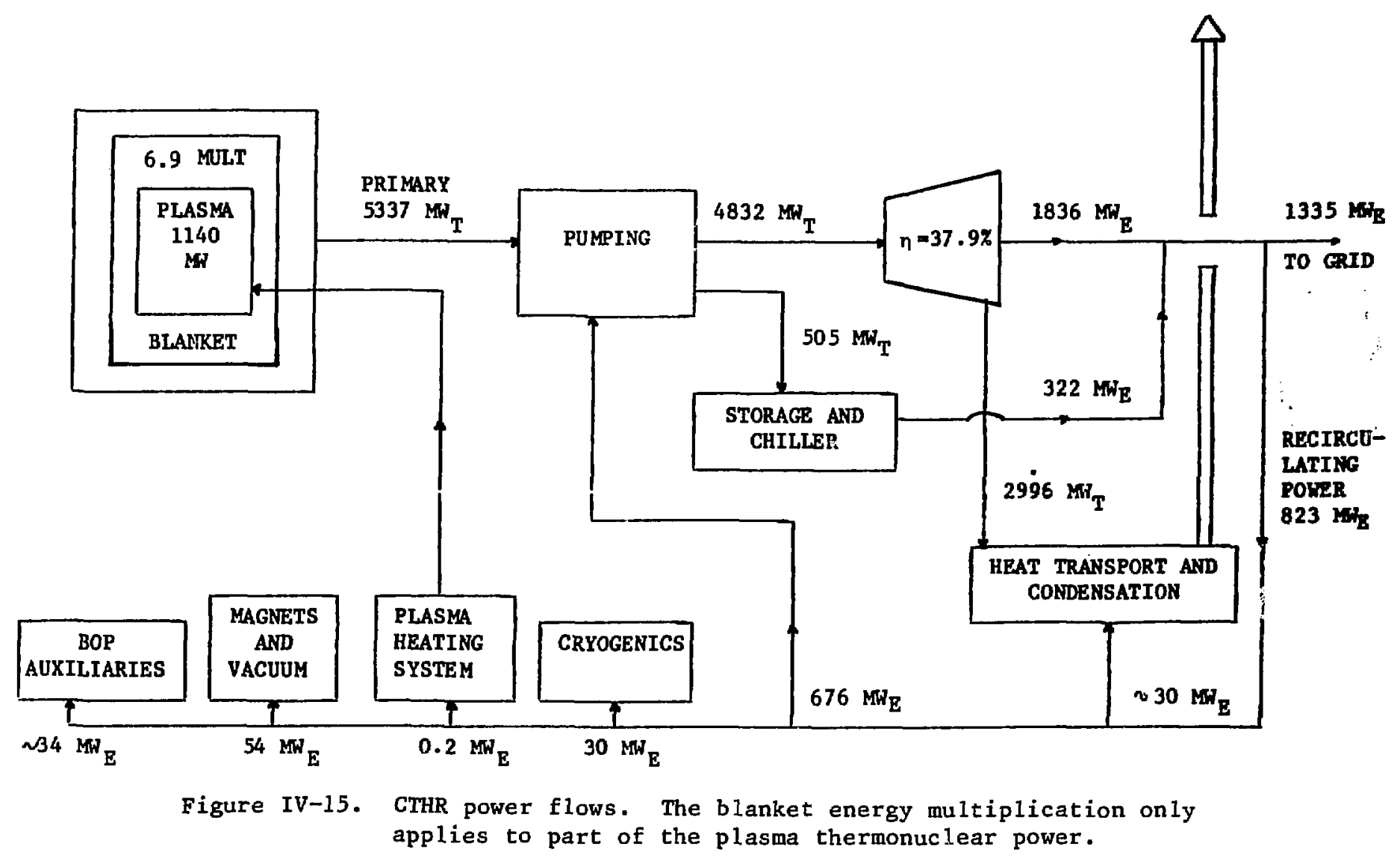


Of primary significance for a hybrid system is the breeding blanket. (Table IV-9 in Appendix IV.E presents detailed information about it. The data in Table IV-9 have been especially useful in formulations of the neutrondiversion scenarios discussed in the other appendices to this chapter.) Figures IV-16 and IV-17 illustrate the construction of the breeding blanket.

Helium gas would serve the CTHR both as the primary coolant and as the purge gas for the tritium breeding blanket. The latter helium application also applies to the STARFIRE pure fusion reactor, whereas water is the STARFIRE coolant. Hence the DT fuel cycle for the CTHR would be very similar to that depicted for STARF IRE in Figure IV-9. One difference is that fuelling for the CTHR is planned to be injection of 0.048 gram pellets of frozen deuterium and tritium about once every 1.7 seconds instead of gas puffing.

Annual maintenance procedures would be expected to occupy about 80 days per year. Of these, 28 days would be allocated to the annual replacement of onequarter of the 32 uranium-carbide fertile blanket sectors once the breeding reaches a steady-state equilibrium. This batch refuelling, though it would be done by machine, is one of the cumbersome aspects of the CTHR design.

Since the blanket sectors would be very radioactive, remote servicing by special machinery is planned. Figure IV-18 shows the temporary water storage area for fissile-fuel and tritium breeding blanket sectors, fuel canisters from the blankets, and other radioactive reactor components.

Facilities for reprocessing the blanket sectors to recover the fissile plutonium are not planned to be part of the hybrid power plant itself. Rather, the blanket would be reprocessed elsewhere, though both these facilities plus a fuel-fabrication plant for the "client" fission reactors of the hybrid could possibly be located together. (27) 


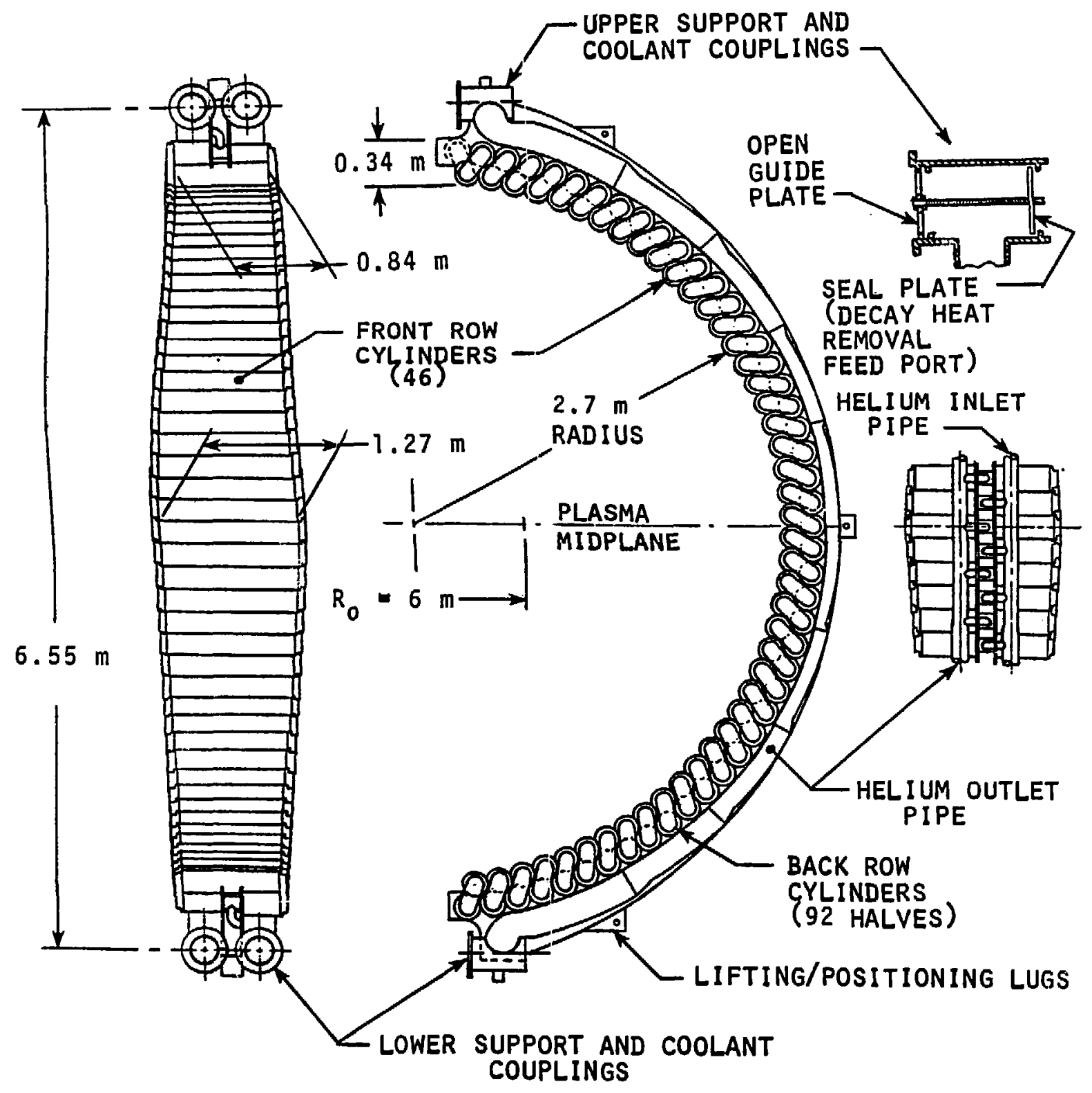

Figure IV-16. Cross section of a typical CTHR fertile-fuel blanket sector (from ref. 17). 

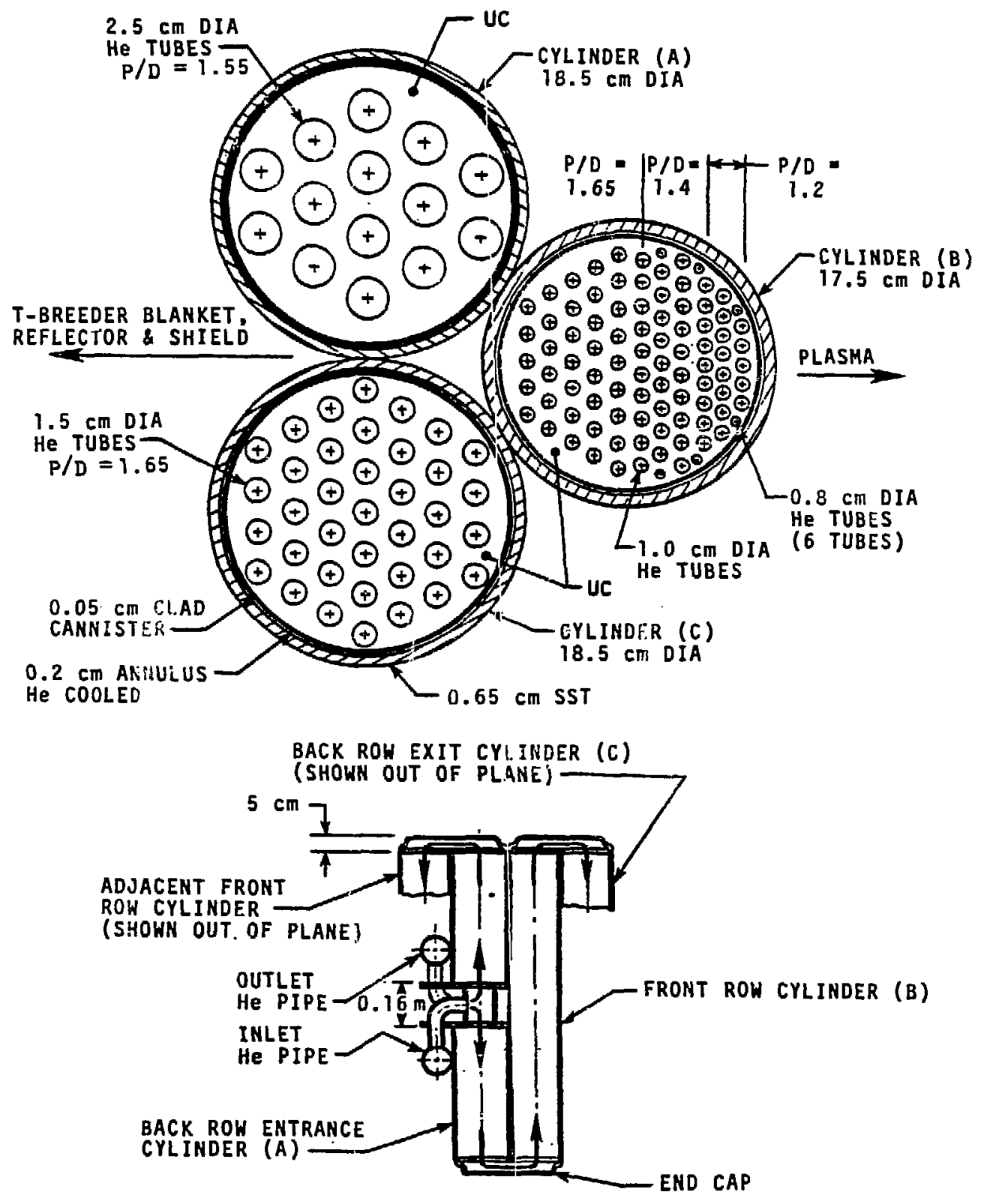

Figure IV-17. Cross section of the CTHR cylindrical fertile-fuel modules showing the coolant flow (from ref. 17). 


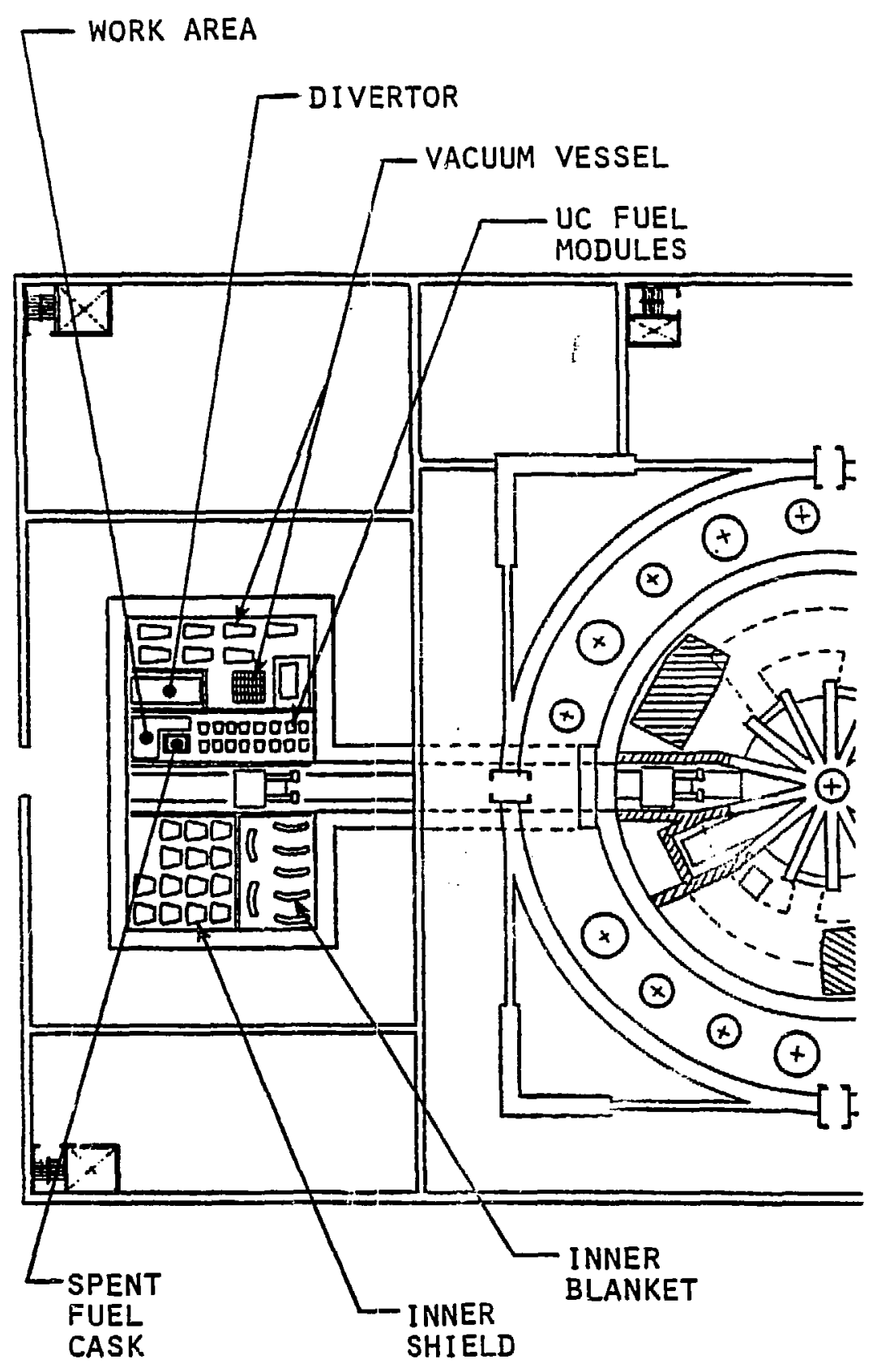

Figure IV-18. Arrangement of the CTHR water-pit storage area in the reactor building (from ref. 17). 


\section{IV.6.2. Proliferative Materials}

As far as the DT fuelling and tritium breeding are concerned, the fue 1 cycle of the CTHR would be similar to that for the STARFIRE pure-fusion reactor as depicted in Figure IV-9. The fusion power of the CTHR would be one-third that of STARFIRE, however, so that quantities of deuterium and tritium in the CTHR fuel cycle would be similarly smaller.

Lithium for tritium breeding would reside in 14 inner and 25 outer blanket sectors as solid lithium oxide $\mathrm{Li}_{2} \mathrm{O}$. There would be 157 metric tons of 1 ithium in all, and it would be expected to serve adequately for the plant's life. The outez sectors, also containing shielding, would weigh 136 metric tons each and two would be removed temporarily during annual fertile blanket replacements.

The raison d'etre of the CTHR would be its fertile-uranium breeding blanket. Described in Table IV-9 in Appendix IV.E, its structure is depicted in Figures $\mathrm{IV}-16$ and $\mathrm{IV}-17$. The cylindrical structures would contain the uranium carbide (UC) breeding material as disks perforated with holes for coolant flow and each disk would contain about 3.7 kilograms of natural uranium (see Appendix IV.E). Given an average fissile-enrichment increase of about 0.54 per cent per year, a long fuel cylinder would gain about 0.84 kilograms of plutonium per year. At the time of discharge, three cylinders would yie1d one SQ. The anriual replacemenc of eight sectors would involve 368 long and 736 short cylindere. It is the cylinders, weighing less than $200 \mathrm{~kg}$ each, that would be the basic transportable fue1 element.

An important aspect of this fissile plutonium production is that the plutonium would be very free of the nonfissile isotopes; Table IV-1 illustrates this. The essential point is that fast neutrons result in plutonium of higher quality than do slow neutrons. 
IV.6.3. Time Scale of Developicnt

Development of hybrid fusion-fiseion reactors depends mainly on development of the underlying fusion systems as discussed in Sections IV.4.3 and IV.5.3. The plasma physics requirements for a hybrid would be less demanding than for pure fusion though the entire system would be more complex. The authors of a hybrid assessment (102) forsaw demonstration of hybrid commercial feasibility by about 1995 and possible commercial introduction about 2010 given an agressive scenario for development that is not now likely. In any case hybrid development is many years behind the development of sodium fast breeder fission reactors, and the two systems would compete to supply fuel for light-water reactors. If successfully develuped, however, fusion breeders with suppressed-fission blankets (40) would be superior to fission breeders as fuel producers. (120) U.S. utilities could either rely on hybrids as fuel producers predominantly or as combined fuel and power producers. $(121,122)$

In the U.S.S.R. the development of a hybrid reactor is reportedly an important intermediate goal of the fusion program. $(44,76)$

\section{IV.6.4. O:her Fuel Cycles}

With respect to the fusion aspect, other hybrid fuel cycles are only those discussed in Section IV.4.4 for the STARFIRE magnetic-fusion reactor that produce an abundance of high-energy neutrons. The same proviso applies to hybrid designs(110) for inertial-confinement reactors. Practically speaking, the only other candidate is the "catalyzed" DD cycle encompassing the first four reactions in Table IV-5(3).

As a "transmutation plant" for converting fertile nuclear material to fissile nuclear material, the possibilities for hybrid fuel cycles are diverse. 
Figure IV-5 shows diagramatically how the hybrid would generically fit into the fission-reactor fuel cycle.

As a bulk fertile-to-fissile breeder, the hybrid could support any "client" reactor employing fissile plutonium produced from uranium-238 or fissile uranium-233 produced from thorium-232 (see Chapter VI). That is, the hybrid could support any fission fuel cycle, including denatured cycles, where breeding is required. (123) In fission-reactor rod or assembly refresh or fission-product transmutation schemes, $(45,46,47)$ fissile fuel would be in the hybrid blanket before any irradiation occurred. Though it would be extremely radioactive, the b'anket would then require safeguards at its "front end".

\section{IV .6.5. Proliferation Concerns}

Five different proliferation problems exist for fusion-fission hybrids: (1) diversion of nuclear-fusion materials; (2) the spread of classified information and, conceivably, sensitive technology if the facility employs inertialconfinement fusion; (3) clandestine production of fissile material in a known facility; (4) diversion of some of the facility's declared fissile material inventory; and (5) production of fissile material or fusion materials in a dedicated, clandestine facility or a misused fusion research facility. The last two problems must be discussed anew, while of the first three, discussed in connection with pure fusion reactors in Sections IV.4.5 and IV.5.5, only the third requires fur ther comment.

With regard to the third proliferation problem, consider first the reasonably plausible scenarios involving slight modification of a declared hybrid to increase fissile-fuel production. This could conceivably be done by controlling the amount of neutron multiplier such as beryllium, the lithium-6 enrichment, or the fertile material volume fraction. Production increases of a few percent 
would certainly be possible by such techniques and they would be hard to detect given the equivalent basic uncertainty in predictability of the amount of declared production using present-day methods. Even a $1 \%$ uncertainty in CTHR performance involves three SQ annually. Uncertainty exists now for conventional fission reactors: plutonium production is uncertain to about $5 \%$ until careful measurements can be made upon reprocessing. (124)

The current safeguards methods that mitigate this uncertainty are item accountability of the fuel bundles, which becomes increasingly difficult as the size of the fuel items decreases, and facility containment and surverilance. The problem would be more severe at a hybrid fusion-fission plant producing ten times more fissile material than does a conventional fission reactor. Indeed, depending upon the detailed breeding-blanket design, 1ithium charge and discharge and fertile-material charge and fissile-material discharge could occur in large batches over intervals of years, in mobile fluid form continuously with on-1ine reprocessing, or in small batches over intermediate time periods. Designs for all of these cases exist. $(40,102)$

Safeguards at a hybrid plant to deter diversion of declared production or undeclared production within the declared plutonium zones would thus vary from safeguards applied at light-water reactors with off-1ine refuelling of large fuel assemblies, (125) to safeguards applied at CANDU (Canadian deuterium uranium) reactors with on-line refueling of small fuel assemblies, (126) to safeguards at reprocessing plants. $(127,128)$ This variation would depend upon the form of the hybrid-reactor breeding blanket.

Location of hybrids at internationally safeguarded fuel service centers (27) would be a possible further meisure to alleviate this safeguards concern.

Again with regard to the third proliferation problem listed above, consider next scenarios involving simple emplacement of fertile material where it should 
not be. Because the most "likely" locations would already be occupied by the declared breeding blanket, no other locations would offer a large illicit breeding potential. Only emplacement in the outer tritium breeding zone would yield enough to avoid implausibly misusing huge parts of reactor subsystems in this scenario. For that one zone, 0.84 SQ per replaceable module per year would be possible based on a calculation analogous to that in Appendix IV.B. Putting gaseous uranium hexafluoride $(26,97,129)$ in the helium coolant would be extremely unlikely for reasons of corrosion, paucity of tests, and plutonium recovery, among other things.

While it would be relatively easy to check for illicit nuclear material built into a pure fusion reactor, doing so for a hybrid reactor would be difficult because of the legitimate presence of such materials. Presumably those reactor components subject to high neutron fluxes would undergo careful scrutiny by NDA techniques when replaced or installed to detect illicit materials or deter such emplacement. NDA examination of irradiated components would have to take account of activation and fission products.

With respect to the fourth proliferation problem listed earlier, declared-material diversion, the legitimate fertile and fissile material from a hybrid reactor such as the Westinghouse CTHR should undergo the same item accounting as do the fuel assemblies from a fission reactor. The fresh blanket structures would contain fertile material of little strategic value. The eight irradiated blanket structures discharged each year would contain 736 transportable (1ong-equivalent) cylinders with about $0.4 \mathrm{SQ}$ each but would be highly radioactive. Thus the water-pit storage area depicted in Figure IV-18 should be treated for safeguards purposes just like the spent-fuel pools of fission reactors. Reprocessing would occur at another facility. The transportable 
spent-fuel cylinders would weigh less than $200 \mathrm{~kg}$ each and would be similar to fuel bundles from CANDU reactors. Some safeguards problems would be similar.(126)

Finally, there is the possibility of construction of a complete clandestine hybrid fusion-fission reactor or misuse of a fusion research facility to produce fissile material or fusion materials. Such a scenario seems very implausible because a divertor who could construct a clandestine hybrid system or misuse a fusion research facility to breed fissile material or fusion materials would certainly be able to construct a clandestine fission reactor to do the same (if not a uranium-enrichment facility for enriched uranium only). The fertile material is a requirement in all cases, though the hybrid would not require fissile material. The concept of a clandestine dedicated hybrid reactor has been discussed $e^{1}$ sewhere,(130) but it is worthwhile to emphasize here that small hybrid reactors are conceivable, based on the dense plasma focus concept for example. (131) Furthermore, designs for compact pure fusion plants with high power levels(132) as well as with power levels as low as 44 megawatts (thermal) do exist. (37) Prevention or detection of clandestine facilities is only related to the IAEA nonproliferation regime in the sense that nuclear materials diverted from safeguarded facilities might be used in the clandestine facility. Otherwise, intelligence methods and export controls ${ }^{(54)}$ would be the ways to detect and prevent, respectively, clandestine facilities. For fusion reactors, the relevant components are large and probably superconducting magnets; cryogenic equipment; vacuum pumps; ion-beam and electron-beam accelerators; high-power electromagnetic-wave sources; high-power lasers; plasma diagnostic instruments; highcapacity electrical power supplies, switching mechanisms, and conversion and storage devices; large capacity pumps, pipes, and heat exchangers; and the nuclear materials tritium, deuterium, and lithium, possibly enriched in lithium- 
6. Additionally, analytical techniques for the design of a reactor system including computer programs and data files for neutronic analysis would be necessary. Finally, a hybrid system would also require attendant fertile-fuelfabrication and spent-fuel reprocessing.

A variation on a completely clandestine facility would be a clandestine hybrid reactor chamber plus blanket associated with a declared inertial-confinement hybrid reactor. There has been discussion of purposely using a single driver for several inertial-fusion reactors.(11) one could then imagine diverting the laser or ion driver beams to the clandestine reactor chamber and blanket. Such "beam diversion" would require a large sophisticated optical or magnetic system to bend the laser or ion beam from its intended path (or the disabling of a design bending system) plus the construction of an undeclared hybrid target system to facilitate breeding of undeclared fertile material. Given. the complicated nature of a reactor chamber and breeding blanket system, it is not credible that such a clandestine system could be built and not be detected by inspectors during periodic visits. A further safeguards measure against such a diversion strategy would be a tamper-proof beam monitor that would indicate, among other things, if the beam were operating during purported maintenance periods and conceivably irradiating an undeclared target system. This would be especially important if the laser or ion beam driver part of a facility were a so-called "nonaccess area" in the same way that the laser area of a laser isotope-enrichment plant would probably be a nonaccess area. This is not thought to be a serious problem because of the very great difficulty of carrying out a beam-diversion scenario.

It would also be possible for a hybrid research facility (or, indeed, an altered pure fusion facility) to be misused for illicit fissile material produc- 
tion. Presumably, facilities with a significant production potential would be safeguarded as are fission research reactors now.

Appendix IV.A

Calculation of the Uranium Content of Tritium Generators (Storage Beds)

Tritium would be stored for backup purposes in fusion plants as uranium titride (similar to metal-hydride storage of hydrogen). When tritium is needed, the beds would be heated. Depleted uranium would be the bed medium and we shall calculate here the amount of uranium that would be needed in the STARFIRE plant.

Data from development work for the Tritium Storage and Delivery System ${ }^{(68)}$ are that a bed containing 145 grams of uranium has a design storago capacity of 50,000 Curies of tritium. We shall convert this to grams of uranium required per gram of tritium stored. To do this conversion we need the following additional data: the half-iife $t_{1 / 2}$ of tritium, 12.3 years; Avogadro's number, $A_{0}$ $=6.03 \times 10^{23}$ atoms per gram-atom, the definition of a Curie, $c=3.7 \times 10^{10} \mathrm{dis}^{-}$ integrations per second; and the mass per gram-atom for tritium, $q=3$ grams.

Let $\mathrm{t}=$ time;

$\lambda=$ probability per unit time of a disintegration;

$a=$ activity of the stored tritium;

$N(t)=$ number of stored tritium atoms as a function of time; and

$M=$ mass of the stored tritium.

Then the radioactive decay law

$$
N(t)=N(0) e^{-\lambda t}
$$

yields, at the half-life, when $N(t)=N(0) / 2$,

$$
\lambda=\ln 2 / t_{1 / 2} \text {. }
$$

Since $a=\Lambda \lambda$, we have 


$$
\begin{aligned}
& M=\frac{G}{A} N=\frac{q}{A} \frac{a}{\lambda} \\
& =\frac{3 \mathrm{~g} \cdot 5 \times 10^{4} \cdot 3.7 \times 10^{10} \mathrm{dis} / \mathrm{s} \cdot 12.3 \mathrm{y} \cdot 3.16 \times 10^{7} \mathrm{~s} / \mathrm{y}}{6.03 \times 10^{23} \text { atoms } \cdot \ln 2} \\
& =5.16 \text { grams }
\end{aligned}
$$

ihus 5.16 grams of tritium require 145 grams of uranium for storage or, inversely, 28.1 grams of uranium are required per gram of tritium.

For the STARFIRE storage, 1071 grams of tritium, this translates to 30 kilograms of depleted uranium. This would mean 207 units of the size being built for the Princeton Tokamak Fusion Test Reactor(68) or 90 units of the STARE IRE size, (16), which would each contain 335 grams of uranium.

\section{Appendix IV.B}

Calculation of the Possible Clandestine Plutonium Production From a Tokamak

Pure Fusion Reactor by Emplacing Uranium in the Structure

Calculating the possible production of plutonium in a pure-fusion reactor such as STARFIRE involves a difficult neutronic analysis that depends on the detailed configuration of fertile material illicitly installed in the structure. Such an analysis need not be done if we extrapolate from the production estimate for a genuine hybrid fusion-fission reactor and recognize that the result will be approximate. We shall consider blanket and shield locations.

We take the conversion ratio for a depleted-uranium blanket of 0.34 meter thickness (of which the uranium occupies $44 \%$, or 0.150 effective meters) to vary from 0.96 net fissile atoms bred per fusion neutron at zero dose to 0.77 after four years of dose at 2 megawatts of neutron energy per square meter (17) (see Table IV-9 in Appendix IV.E). We shall simplify this further and assume conservatively a conversion ratio of 0.96 for one year's exposure. This conver- 
sion ratio would occur in a well-designed hybrid blanket subject to a wall load of high-energy neutrons of $2 \mathrm{MH} / \mathrm{m}^{2}$. What would the flux $f$ be?

$$
\begin{aligned}
& \text { Flux }\left(\frac{\text { neutrons }}{\mathrm{m}^{2} \mathrm{~s}}\right)=\text { Wall Load }\left(\frac{\text { Watts }}{\mathrm{m}^{2}}\right) / \text { Neution Energy }\left(\frac{\text { Joules }}{\text { neutron }}\right) \\
& \begin{aligned}
\mathrm{f}_{\text {hybrid }} & =\frac{2 \times 10^{6} \mathrm{~W} / \mathrm{m}^{2}}{14.1 \times 10^{6} \mathrm{eV} / \mathrm{n} \cdot 1.6 \times 10^{-19} \mathrm{~J} / \mathrm{eV}} \\
& =8.9 \times 10^{17} \mathrm{n} / \mathrm{m}^{2} \mathrm{~s}
\end{aligned}
\end{aligned}
$$

The STARFIRE first-wall flux would be

$$
\mathrm{f}_{\text {STARF IRE }}=\frac{3.6 \mathrm{MW} / \mathrm{m}^{2}}{2 \mathrm{MW} / \mathrm{m}^{2}} \cdot \mathrm{f}_{\text {hybrid }}=1.6 \times 10^{18} \frac{\mathrm{n}}{\mathrm{m}^{2} \mathrm{~s}}
$$

The plutonium atomic production rate per unit of blanketed wall area, $N$, is the product of the flux $f$, conversion ratio $c_{b}$, time $t$, and plant availability $p$. The rate in mass units $R$ is obtained by dividing $N$ by the number of atoms of plutonium per kilogram, which is in turn Avogadro's number $A_{0}$ divided by $q$, the mass per gram-atom. We shall compute $R$ for one year:

$$
\mathrm{R}=\mathrm{f} \cdot \mathrm{c}_{\mathrm{b}} \cdot \mathrm{t} \cdot \mathrm{p} /\left(\mathrm{A}_{\mathrm{o}} / \mathrm{q}\right)
$$

$\underset{\text { B lanket }}{R_{\text {STARFIRE }}}=\frac{1.6 \times 10^{18} \mathrm{n} / \mathrm{m}^{2} \mathrm{~s} \cdot 0.96 \mathrm{atoms} / \mathrm{n} \cdot 3.16 \times 10^{7} \mathrm{~s} / \mathrm{year} \cdot 0.75}{6 \times 10^{23} \mathrm{atoms} / .239 \mathrm{~kg}}$

$$
=14.5 \mathrm{~kg} / \mathrm{m}^{2} \text { year }
$$

Given the IAEA definition of $8 \mathrm{~kg}$ of plutonium per strategically significant quantity ( $\mathrm{SQ}$ ) for fission-weapon manufacture ${ }^{(85)}$, this rate is

$$
\mathrm{R}_{\text {STARFIRE }}=1.8 \mathrm{sQ} / \mathrm{m}^{2} \text { year }
$$

We can further compute an enrichment of fissile material if we assume that the 0.15 meter thick breeding layer is composed of fertile uranium carbide, in which the effective uranium density is $13.0 \mathrm{~g} / \mathrm{cm}^{3} .(96)$ Assuming irradiation of 1 square meter of wall, we find that the increased enrichment $\varepsilon$ is

$$
\begin{aligned}
\varepsilon & =\frac{14.5 \mathrm{~kg} / \mathrm{m}^{2} \text { year } 1 \mathrm{~m}^{2} \text { year }}{0.013 \mathrm{~kg} / \mathrm{cm}^{3} \cdot 0.15 \mathrm{~m}^{3} \cdot 10^{6} \mathrm{~cm}^{3} / \mathrm{m}^{3}} \\
& =7.4 \times 10^{-3}=0.0074
\end{aligned}
$$


The STARFIRE first wall and blanket (see Fig. IV-10) would have an area of $780 \mathrm{~m}^{2}$ (exclusive of openings) divided into 24 sectors. Even one sector would have sufficient area to allow breeding of one SQ per year. (Two caveats are in order. First, incorporating fertile material in only a small section of the reactor wall would create a wall with nonuniform neutron scattering and absorption coefficients. This could increase the neutron flux in the wall sections with fertile material to several times the value calculated above. Second, formally allowing production over the entire STARFIRE wall would yield a production greater than that of the reference hybrid given equivalent fusion power. This happens because we are here considering breeding in the STARFIRE inner and outer blankets; only the latter is the site of fissile breeding in the hybrid.)

We have not studied carefully the important questions of heat production from uranium fast fission, radiation damage, and the ability of the uranium (as a carbide, e.g.) to be incorporated structurally without otherwise negatively affecting the fusion reactor. Concerning the heat production, the hybrid study(17) whose conversion ratio was used in the calculation gives a fastfission uranium-blanket energy multiplication of 5.1 to 8.6 over the four-year exposure life. On the other hand, the volume of material required to breed one $\mathrm{SQ}$ in a year is a small fraction of the tritium-breeding volume of a blanket segment. $\quad\left(0.083 \mathrm{~m}^{3}=0.55 \mathrm{~m}^{2} \cdot 0.15 \mathrm{~m}\right.$ versus an average sector tritium-breeding volume of $7.4 \mathrm{~m}^{3}=178 \mathrm{~m}^{3} / 24$ ) This suggests that the additional local heat load can probably be handled without modifying the coolant flow if only a small amount of plutonium were bred. Finally, the blanket segments involved weigh about sixty metric tons. Modifying them to incorporate illicit fertile material would be a formidable task. 
As the distance from the plasma increases, the neutron flux decreases. Figure IV-19 shows the flux in the STARFIRE outer bulk radiation shield as a function of position. (The total shield thickness would be $1.1 \mathrm{m.}$ ) The energy spectrum of the neutrons, which depends strongly on position, significantly affects the conversion of uranium to plutonium, and relying on the conversion ratio from the hybrid-reactor design ${ }^{(17)}$ to do a shield calculation becomes more speculative. We shall nevertheless use it to make crude estimates based on the Figure IV-19 fluxes and on a linear scaling of our previous result:

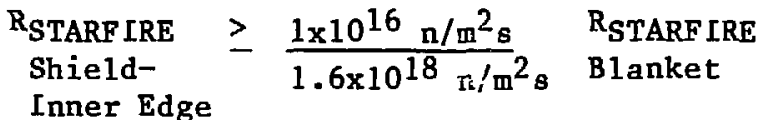

$$
\begin{aligned}
& =0.091 \frac{\mathrm{kg}}{\mathrm{m}^{2} \text { year }} \\
& \begin{array}{l}
\mathrm{R}_{\text {STARF IRE }} \\
\begin{array}{l}
\text { Shield- } \\
\text { Outer Edge }
\end{array}
\end{array} \frac{10^{11} \mathrm{n} / \mathrm{m}^{2} \mathrm{~s}}{1.6 \times 10^{18} \mathrm{n} / \mathrm{m}^{2} \mathrm{~s}} \quad \begin{array}{l}
\mathrm{R}_{\mathrm{STARF} \text { IRE }} \\
\text { Blanket }
\end{array} \\
& =9.1 \times 10^{-7} \frac{\mathrm{kg}}{\mathrm{m}^{2} \text { year }}
\end{aligned}
$$

Approximately $100 \mathrm{~m}^{2}$ of the inner section of the shield -- more than one sector - would require uranium incorporation to yield one $S Q$, while outside the shield the flux would simply be too low to yield much plutonium at all.

Though the numbers will differ, all of these remarks apply qualitatively to the production of fissile uranium-233 from a thorium blanket.

Appendix IV.C

Calculation of the Possible Clandestine Plutonium Production From a

Pure Fusion Tokamak Reactor by Dissolving Uranium in the Primary Coolant

By dissolving some uranium compound in the STARFIRE coolant, one could conceivably breed plutonium. Indeed, reactor systems based on dissolved uranium compounds were studied and even built in the $1950^{\prime} \mathrm{s}^{(97)}$. Some included breeding blanket regions. These fluid-fuel or homogeneous reactors did not stand the 


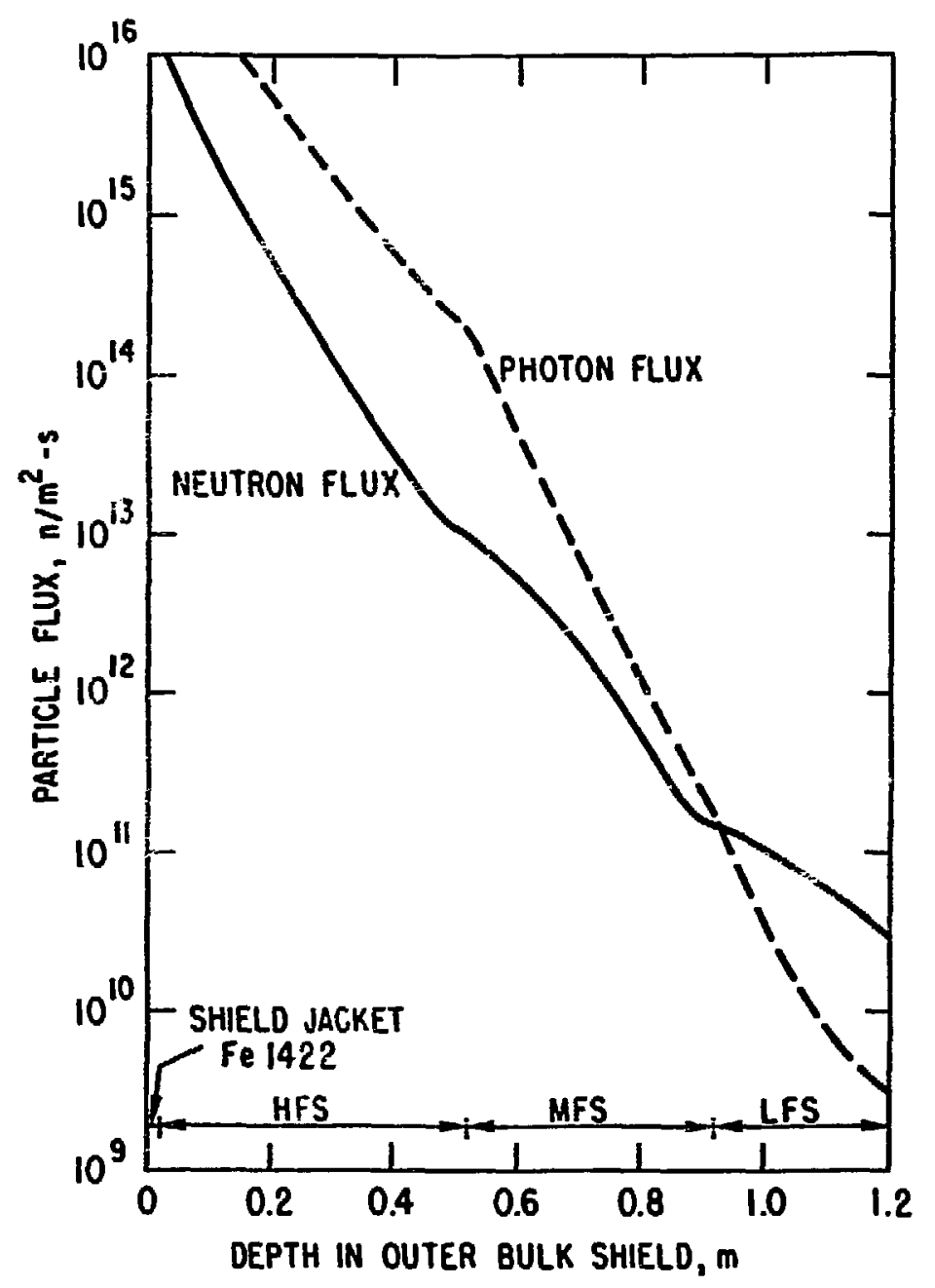

Figure IV-19. Neutron anr photon fluxes in the STARFIRE outer bulk shield (from ref. 16). 
test of time, apparently aue to corrosion problems. Indeed, the coolant would have to be maintained as sulfuric acid and periodic or continuous reprocessing it would be required. Given the hostile solvents required and the present-day difficulties with steam generators (which are part of the STARFIRE design), a diversion based on this scenario seems most unlikely. We shall nevertheless estimate its plutonium production potential.

The key point for our pu purposes is that a solution of uranium as uranyl sulfate $\left(\mathrm{UO}_{2} \mathrm{SO}_{4}\right)$ can be made with a uranium concentration of 250 grams per liter. (97) Plutonium would be produced upon neutron irradiation of the dissolved uranium. (Other solution chemistries as well as thorium-uranium slurries may work, but none would alter the essential aspects of the scenario. Indeed, a fusion reactor that breeds fissile fuel in a thoriun oxide slurry coolant has been seriously proposed.(98)).

The key result upon which the Appendix IV.B result was based is a hybridreactor conversion ratio of 0.96 fissile atom per fusion neutron given a fertile blanket of definite thickness. We then assumed that the plutonium production rate is linearly dependent on the high-energy neutron flux. Here we shall further assume that the conversion ratio itself is linearly dependent on the effective area density of fertile uranium upon which the neutrons are incident. From the STARFIRE study, (16) we find that at most one-sixth of the ordinary-water coolant volume of about 500 cubic meters would be in the blanket at any given time. For simplicity, we shall assume that the coolent in the blanket, though flowing through a maze of piping, effectively forms a uniformly thick layer over the blanket area of about 780 square meters. We can now compute the area density of dissolved fertile uranium as follows: 
$\mathrm{d}_{\mathrm{A} ; \underset{\text { Coolant }}{\text { STARFIRE }}}=\frac{(1 / 6) \cdot 500 \mathrm{~m}^{3} \cdot 250 \mathrm{gU} / \mathrm{l} \cdot 10^{3} \mathrm{\ell} / \mathrm{m}^{3}}{780 \mathrm{~m}^{2} \cdot 10^{4} \mathrm{~cm}^{2} / \mathrm{m}^{2}}$

$=\quad 2.67 \mathrm{gU} / \mathrm{cm}^{2}$

The analogous result for the hybrid (17) blanket (Table IV-9 in Appendix IV.E), consisting of 0.15 effective meters thick of solid uranium carbide (UC), depends on its uranium density $(96)$ :

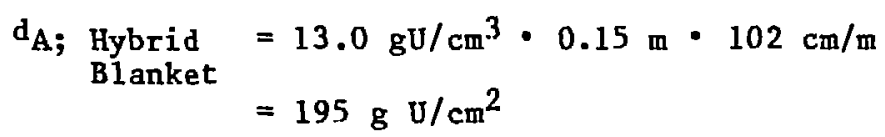

Thus an effective conversion ratio for uranium in the STARFIRE water coolant is that for the hybrid as linearly scaled by these area densities:

$$
\begin{aligned}
c_{w} & =c_{b} \cdot\left(d_{A} ; \underset{\text { STARF IRE }}{\text { Soolant }} / d_{A} ; \begin{array}{l}
\text { Hybrid } \\
\text { Blanket }
\end{array}\right. \\
& =0.96(\text { atoms } / \mathrm{n}) \cdot\left(2.67 \mathrm{gU} / \mathrm{cm}^{2}\right) /\left(195 \mathrm{gU} / \mathrm{cm}^{2}\right) \\
& =1.31 \times 10^{-2} \text { atoms } / \mathrm{n}
\end{aligned}
$$

We shall now proceed as in Appendix IV.B, assuming that the flow rate of the coolant has no bearing on the result other than through the one-sixth factor used above. Two more important distinctions we are ignoring in this preliminary calculation are the differences in neutronics and the heat production the coolant by fast fission of the uranium.

The area-specific production rate is (given 0.75 plant availability)

$$
\begin{aligned}
\begin{array}{r}
\text { STARF IRE } \\
\text { Coolant }
\end{array} & =\frac{1.6 \times 10^{18} \mathrm{n} / \mathrm{m}^{2} \mathrm{~s} \cdot 1.31 \times 10^{-2} \text { atoms } / \mathrm{n} \cdot 3.16 \times 10^{7} \mathrm{~s} / \text { year } \cdot 0.75}{6 \times 10^{23} \text { atoms } / 0.239 \mathrm{~kg}} \\
& =0.20 \mathrm{~kg} / \mathrm{m}^{2} \text { year }
\end{aligned}
$$

But here the enire wall area serves for breeding. We obtain

$$
\begin{aligned}
\underset{\text { Coolant }}{\mathrm{R}_{\text {CARF IRE }} \cdot(\text { Wall art2 })} & =0.20 \mathrm{~kg} / \mathrm{m}^{2} \text { year } \cdot 780 \mathrm{~m}^{2} \\
& =156 \mathrm{~kg} / \text { year },
\end{aligned}
$$


which is about twenty strategically significant quantities of plutonium per year. This number may be high because the coolant in the reactor is not all exposed to the high neutron flux assumed.

Finally, since STARFIRE would include two separate coolant loops, one of them could be used exclusively or both could be used in alternating sequence to facilitate reprocessing or deceit. This would halve the production rate.

Appendix IV.D

Calculation of the Tritium and Deuterium Flows in an Inertial-Fusion Plant According to the Westinghouse study, (18) the inertial-confinement fusion power plant would yield 350 megajoules of fusion energy per pellet microexplosion at the rate of ten microexplosions per second. We shall translate these numbers into mass fuel flow rates.

First let us compute the daily energy consumption:

$$
\begin{aligned}
\text { Energy/day } & =350 \mathrm{MJ} / \text { fusion } 10 \text { fusions } / \mathrm{sec}=3600 \mathrm{sec} / \mathrm{hr} \cdot 24 \mathrm{hr} / \text { day } \\
& =3.0 \times 10^{14} \mathrm{~J} / \text { day }
\end{aligned}
$$

The basic datum needed to compute the fuel requirement is that $17.6 \mathrm{MeV}$ of energy is released per fusion event (see Section IV.1). Thus

$$
\begin{aligned}
\frac{\text { Mass tritium }}{\text { day }} & =\frac{\text { Energy }}{\text { day }} \times \frac{\text { Tritium mass }}{\text { Tritium energy }} \\
& =3.0 \times 10^{14} \frac{\mathrm{J}}{\text { day }} \cdot \frac{3 \mathrm{gT}}{6 \times 10^{23} \text { atoms } \mathrm{T}} \cdot \frac{1 \text { atom } \mathrm{T}}{17.6 \times 10^{6} \mathrm{eV}} \cdot \frac{1 \mathrm{eV}}{1.6 \times 10^{-19} \mathrm{~J}} \\
& =5.3 \times 10^{2} \frac{\text { grams } \mathrm{T}}{\text { day }}
\end{aligned}
$$

The deuterium atom flow would equal that of tritium; its mass flow would be 350 grams per day. 


\section{Appendix IV.E}

Calculation of the Uranium and Plutonium Content in a Hybrid Blanket

Figures IV-16 and IV-17 illustrate the construction of the CTHR(17) fertile blanket. Table IV-9 lists its parameters. (We have used in Appendices IV.B and IV.C the conversion ratio for fusion neutrons to fissile atoms.) We compute the uranium content from the uranium density of UC, $\rho_{U}=13 \mathrm{~g} / \mathrm{cm}^{3}$, and from an estimate of the volume $V_{d i s k}$ occupied by the disks of UC, about $17 \mathrm{~cm}$ in diameter, $2.5 \mathrm{~cm}$ thick, and perforated with holes for coolant flow through half their volume. The uranium mass per disk would thus be

$$
\begin{aligned}
\mathrm{M}_{\mathrm{U} ; \text { disk }} & =\rho_{\mathrm{U}} \cdot 1 / 2 \cdot \nabla_{\text {disk }}=\rho_{\mathrm{U}} \cdot 1 / 2 \cdot \pi \mathrm{r}^{2} \mathrm{~h} \\
& =1.3 \mathrm{~g} / \mathrm{cm}^{3} \cdot 1 / 2 \cdot \pi \cdot(8.5 \mathrm{~cm})^{2} \cdot 2.5 \mathrm{~cm} \cdot 10^{-3} \mathrm{~kg} / \mathrm{g} \\
& =3.7 \mathrm{~kg} \cdot
\end{aligned}
$$

With $1.05 \mathrm{~m}$ long front-row cylinders containing disks (see Fig. IV-17), each such cylinder would contain

$$
\begin{aligned}
\mathrm{M}_{\mathrm{U} ; \text { cylinder }} & =\frac{1.05 \mathrm{~m}}{0.025 \mathrm{~m} / \mathrm{disk}} \cdot 3.7 \frac{\mathrm{kg}}{\mathrm{disk}} \cdot 10^{-3} \frac{\text { metric tons }}{\mathrm{kg}} \\
& =155 \mathrm{kilograms}
\end{aligned}
$$

The short or back-row cylinders would contain about half as much. With 46 long and 92 short cylinders for each of 32 blanket sectors, there would be

$$
\begin{aligned}
& \mathrm{M}_{\mathrm{U} ; \text { sector }}=14.3 \text { metric tons } \\
& \mathrm{M}_{\mathrm{U} ; \text { Hybrid }}=458 \text { metric tons }
\end{aligned}
$$

If the average increase in fissile-enrichment percentage over the planned four year breeding period were $(2.4-0.25) / 4=0.54$, then the average annual fissile production would be (compare with the number in Table IV-9)

$$
M_{\text {Fissile; hybrid }}=4.58 \times 10^{5} \mathrm{~kg} \cdot 0.0054 / \text { year }=2473 \mathrm{~kg} / \text { year }
$$


Table IV-9

Summary of the Features of the CTHR Breeding Blanket

(from ref. 17)

\begin{tabular}{|c|c|}
\hline \multicolumn{2}{|l|}{ Fertile Fuel Zone } \\
\hline Coverage & Outer Torus \\
\hline Fuel Thickness, m & 0.34 \\
\hline Fuel/Structure/Coolant, $\mathrm{X}$ Volume & $44 / 15 / 41$ \\
\hline Tube/Structural Material & $316 \mathrm{SST}$ \\
\hline $\begin{array}{l}\text { Pitch/Dianeter Ratios (Plasma side to } \\
\text { Dack side) }\end{array}$ & $1.2 / 1.4 / 1.65$ \\
\hline Max. Coolant Channel Length, m & 23 \\
\hline Width of Blanket Sector, m & 1.37 \\
\hline Thickness of Blanket Sector, $\mathrm{m}$ & 0.43 \\
\hline Overall Height of Blanket Sector, m & 7.0 \\
\hline Radius of Sector Curvature, m & 2.7 \\
\hline \multicolumn{2}{|l|}{ Iritium Breeding fuel Zone } \\
\hline Inner Blanket $L i_{2} 0$ Thickness, m & 0.46 \\
\hline Outer Bianket Li, 0 Thickness, m & 0.47 \\
\hline Fue $1 /$ Structure/Coolant, $x$ Volume & $70 / 10 / 20$ \\
\hline [ube/Structural Material & $316 \mathrm{SST}$ \\
\hline Reflector Material & Pb \\
\hline Ref lector Locations (Inner/Outer) & Front Zone \\
\hline Ref lector Thickness, m & 0.04 \\
\hline
\end{tabular}

BLAKKET OPERATING CONDITIONS

\begin{tabular}{|c|c|}
\hline & Value $^{(a)}$ \\
\hline Average Blanket Power Density, $\mathrm{W/ \textrm {cm } ^ { 3 }}$ & $40-70$ \\
\hline Average Fuel Power Dens'ty, H/Cm & $115-203$ \\
\hline Peak fuel Power Denstty, $\mathrm{H} / \mathrm{cm}^{2}$ & $340-460$ \\
\hline Inlet Coolant Pressure, MPa (Dsia) & $8.96(1300)$ \\
\hline In let Coolant Temperature. "C & $280-257$ \\
\hline Outlet Coolant Temperature, $\bullet$ & $447-416$ \\
\hline Average Coolant Temperature, ${ }^{\circ} \mathrm{C}$ & $410-407$ \\
\hline Heliun Flow Rate, $\mathrm{kg} / \mathrm{s}$ & $1459-2122$ \\
\hline Maximum Structural Temperature, ${ }^{\circ} \mathrm{C}$ & 500 \\
\hline Maximum Fuel Canister Temperature, "C & 550 \\
\hline $\begin{array}{l}\text { Coolant Pumping Power to } 8 \text { lanket } \\
\text { Thermal Power, } x\end{array}$ & $\dot{B}^{(0)}$ \\
\hline
\end{tabular}

glanket perfoqmance Characteristics

Neutron Exposure, HL-yr/n't

Tritons/Fusion Neutron

Net Fissile Atoms/Fusion Neutron

Blanket Energy Hultiplication

Tritiun Breeding Rat io ${ }^{(b)}$

Heavy Metal Inventory. THA (c)

Heavy Metal Discharge, THW/yr $(c)$

Average Fissile Enrichment, w/o

Net Fissile Production, kg Fissile/yr

Cunulative Burnup, Mud7Th

Average Thermal Power, Mut

Net Electric Power, kW hr/yr (d)

Design Power Rating, HAle ${ }^{\text {(d) }}$

\begin{tabular}{|c|c|c|}
\hline BOL & $2 \mathrm{yr}^{(\mathrm{a})}$ & 4 yr. \\
\hline-- & 2.66 & 5.32 \\
\hline 1.05 & 1.15 & 1.26 \\
\hline 0.96 & 0.86 & 0.17 \\
\hline 5.1 & 6.9 & 8.6 \\
\hline 0.79 & 0.88 & 0.96 \\
\hline-- & -. & 472 \\
\hline-- & - & 118 \\
\hline 0.25 & 1.6 & 2.4 \\
\hline 2800 & 2520 & 7250 \\
\hline-- & -- & 13.270 \\
\hline 4000 & 5380 & 6640 \\
\hline-- & $8.185 \times 10^{\circ}$ & -- \\
\hline -- & 1335 & -. \\
\hline
\end{tabular}

(a) The 2 year performance parameters are approximately blanket equtlibrium conditions.

(b) Does not include special tritium breeding blankets above and below bundle divertor.

(c) Average values for 4 year irradiation period based on the merhantcal design.

(d) At equilibrium, af ter hybrid plant power requirenents are met, i.e., net power to utility grid.

TURBIHE PARAMETERS

Stean cycle

Pressure at SG-Superheater Exit, MPa (psia)

INDIRECT

Superheat, "C

$8.96(1300)$

Feedwalier Temperature, ${ }^{\circ} \mathrm{C} \quad 150$

Rating, Hile 1000

Munber of Parallel Units (Tandem Compound) 2

Gross Thermal Efficiency, $\$ \quad 38$

Estimated Net Cycle Effictency, $x \quad 26$

(a) First quadrant - fourth quadrant

(b) Average value at equilibrium conditions 
At the time of discharge, each long cylinder, which would weigh less than $200 \mathrm{~kg}$ totally, would thus contain about $3.4 \mathrm{~kg}$ of fissile plutonium. Three such cylinders would yield one SQ. 


\section{References - Chapter IV}

1. H. York, The Advisors: Oppenheimer, Teller and the Superbomb, Freeman, San Francisco, 1976.

2. R. d'E. Atkinson and F.G. Houtermans, Z. Phys., 54, 656, 1929; as cited in reference 4 .

3. H. Bethe, "Energy Production in Stars," Phys. Rev., 55, 434, 1939; as cited in reference 4.

4. E. Teller, "Introduction," p. 1, in E. Teller, editor, Fusion, 1A, Academic Press, New York, 1981.

5. R.F. Post, "Nuclear Fusion," Ann. Rev. Energy, 1, 213, 1976.

6. D. Keefe, "Inertial Confinement Fusion," Ann. Rev. Nuc. Part. Sci., $\underline{32}$, 391,1982 .

7. J.A. Maniscalco, "Inertial Gonfinement Fusion," Ann. Rev. Energy, 5, 33, 1980 .

8. S.L. Kahalas, "Inertial Fusion Program-Present Status," Nuc. Tech./Fusion, 4 (2), Part 2, 3, 1983.

9. A.J. Teopfer and L.D. Posey, "The Application of Inertial Confinement Fusion to Weapon Technology," SAND 77-0913, Sandia Laboratories, Albuquerque, N.M. 1978.

10. The September, 1985 issue (Vo1. 25, No. 9) of the journal Nuclear Fusion includes progress reports and review articles for facilities around the world.

11. J.N. Nuckolls, "The Feasibility of Inertial-Confinement Fusion," Physics Today, 35 (9), p. 25, 1982.

12. M. Tillack, M. Abdou, D. Berwald, J. Davis, G. Deis, P. Gierszewski, G. Hollenberg, K. Kleefeldt, Y. Liu, D. Morgan, S. Piet, Y. Seki, W. Steele, and $J$. Straalsund, "Identification and Characterization of the Rey Issues of Fusion Nuclear Technology," Fus. Tech., ㅁ (1), Part 2B, 1985.

13. B.R. Jensen, N.E. Nour and T.M. Piascik, "Utility Evaluation of FusionFission Hybrids," Nuc. Tech./Fusion, $\underline{5}$ (2), 224, 1984.

14. R.A. Knief, Nuclear Energy Technology, McGraw-Hi11, New York, 1981.

15. G.H. Miley, Fusion Energy Conversion, American Nuclear Society, 1976.

16. Argonne National Laboratory, MeDonnel1 Douglas Astronautics Co, - East, General Atomic Company and the Ralph M. Parsons Company, STARFIPE - A Commercial Tokamak Fusion Power Plant Study, Volumes $I$ and II, ANL/FPP-80-1, Argonne National Laboratory, Argonne, Illinois, September 1980. 
17. J.L. Kelly and R.E. Gold, editors, Conceptual Design of a Commercial Tokamak Hybrid Reactor, WFPS-THS-80-012, Westinghouse Electric Corp., Pittsburgh, Pennsylvania, December 1980.

18. E.W. Sucov, editor, Inertial Confinement Fusion Central Station Electric Power Generating Plant, Volumes I and II, WFPS-TME-81-001, Westinghouse Electric Corporation, Pittsburgh, Pennsylvania, 1981.

19. A. Stefanescu, "Thermonuclear Weapons Triggered by Lasers and the Impact on the Agency Safeguards System Under NPT Conditions," IAEA/STR-19, International Atomic Energy Agency, Vienna, Austria, 1970.

20. J. Holdren, "Fusion Power and Nuclear Weapons: Significant Link?," Bul1. At. Scientists, 34, No. 3, 4, March 1978.

21. J. Holdren, "Fusion-Fission Hybrids: Enviromental Aspects and Their Role in Hybrid Rationale," J. Fusion Energy, 1, 197, 1981.

22. D. Westervelt and R. Pollock, "Laser Fusion and Fusion Hybrid Breeders: Proliferation Implications," Nuclear Energy and Nuclear Weapon Proliferation, Crane Russak, New York, 1979.

23. W.A. Smit and P. Boksma, "Laser Fusion," Bull. At. Scientists, 36, No. 10, 34, Dec., 1980.

24. M. Willrich and T.B. Taylor, Nuclear Theft: Risk and Safeguards, Ballinger, Cambridge, Mass., 1974.

25. L.M. Lidsky, "The Trouble With Fusion," Technology Review, p. 32, October 1983.

26. Nonproliferation Alternative Systems Assessment Program (NASAP), Nuclear Proliferation and Civilian Nuclear Power, DOE/NE-0001, Volumes VIII and IX, U.S. Department of Energy, Washington, D.C., 1979, draft.

27. R. Liner and S. Locke Bogart, "Nonproliferation Implications of FusionFission Hybrid Energy Systems," Science Applications, Inc., SAI Working Paper No. 46, 1978.

28. E. Greenspan, "Fusion-Fisson Hybrid Reactors and Nonproliferation," NRCN-555, Israel Atomic Energy Commission, Nuclear Research Center-Negev, 1984.

29. A. Gsponer, B. Jasani, and S. Sahin, "Energing Nuclear Energy Systems and Nuclear Weapon Proliferation," Atomenergie" Kerntechnik , 43 (3), 169 , 1983.

30. M.O. Hagler and M. Kristiansen, An Introduction to Controlled Thermonuclear Fusion, Lexington Books, Lexington, Massachusetts, 1977.

31. S. Glasstone and P. Dolan, eds., The Effects of Nuclear Weapons, U.S. Departments of Defense and Energy, Washington, D.C., 1977, 3rd ed. 
32. L.D. Lawson, Proc. Phys. Soc. (London), B70, 6, 1957; as cited in reference 4 .

33. B.M. Schwarzschild, "MIT Tokamak Alcator C Exceeds Lawson Criterion," Physics Today, 37 (2), 20, February, 1984.

34. R.M. Kulsrud, H.P. Furth, E.J. Valeo and M. Goldhaber, "Fusion Reactor Plasmas with Polarized Nuclei," Phys. Rev. Let., 49, 1248, 1982.

35. S.E. Jones, "Engineering Issues in Muon-Catalyzed Fusion," Fus. Tech., $\underline{8}$ (1), Part 2B, 1511, 1983.

36. I.R. Lindemuth and R.C. Kirkpatrick, "The Promise of Magnetized Fue1: Inertial Confinement Fusion With Existing Driver Technology," Atomkernenergie - Kerntechnik, 45 (1), 9, 1984.

37. C.C. Baker, G.A. Carlson, and R.A. Krakowski, "Trends and Developments in Magnetic Fusion Reactor Concepts," Nuc. Tech./Fus., 1, 5, 1981.

38. H.P. Furth, "The Tokamak," p. 123, in E. Teller, editor, Fusion, 1A, Academic Press, New York, 1981.

39. M.J. Monsler, J. Hovingh, D.L. Cook, T.G. Frank, and G.A. Moses, "An Overview of Inertial Fusion Reactor Design," Nuc. Tech./Fus., 1, 302, 1981 .

40. J. Maniscalco, D. Berwa1d, B. Campbe11, R. Moir, and J. Lee, "Recent Progress in Fusion-Fission Hybrid Reactor Design Studies," Nuc. Tech./Fus., 1 , 419,1981 .

41. C.E. Willingham and W.E. Bickford, "Evaluation of Fusion-Fission Energy Systems," in F.H. Tenney and C.C. Hopkins, editors, Proceedings of the Fourth Topical Meeting on the Technology of Controlled Nuclear Fusion, CONF-801011, U.S. Department of Energy, Washington, D.C., 1981, Vo1. III, p. 1583 .

42. B.R. Leonard, "A Review of Fusion-Fission (Hybrid) Concepts," Nuc. Tech., 20, 161,1973 .

43. J.D. Lee, "U.S. DOE Fusion Breeder Program-Blanket Design and System Performance," Atomkernenergie - Kerntechnik, 44, (1), 35, 1984.

44. F.E. Coffman, J.E. Baublitz, D.S. Bear, M.M. Cohen, E.N.C. Dalder, C.R. Finfgeld, G.M. Haas, C.R. Head, M.R. Murphy, G.R. Nardella, R.N. Ng, T.C. Reuther, H.S. Staten, and K.M. Zwilsky, "An Overview of International Fusion Technology Programs," in C.K. McGregor and T.H. Batzer, editors, Proceedings of the 8th Symposium on Engineering Problems of Fusion Research, IEEE 79CH1441-5 NPS, Institute of Electrical and Electronic Engineers Inc., New York, 1979, p. 18 .

45. L. Lidsky, "Fission-Fusion Systems; Hybrid, Symbiotic and Augean," Nuc. Fus., 15, 151, 1975. 
46. J.W. Miller, E.M. Iwinski, A.Y. Lee, and T.V. Prevenslik, "A Study of Reenriching PWR Fuel Rods in an Inertial Confinement Fusion Reactor," in C.K. McGregor and T.H. Batzer, editors, Proceedings of the 8th Symposium on Engineering Problems of Fusion Research, IEEE 79CHI441-5 NPS, Institute of Electrical and Electronic Engineers Inc., New York, 1979, p. 1528.

47. D.L. Chapin, "Nuclear Analysis on the Enrichment of PWR Fuel in a Fusion Hybrid Reactor," WFPS-TME-101, Westinghouse Electric Corporation, Pittsburgh, Pa., 1978.

48. B.R. Leonard, Jr. and U.P. Jenquin, "The Quality of Fissile Fuel Bred in a Fusion Reactor Blanket," Proceedings of the Second Topical Meeting on the Technology of Controlled Nuclear Fusion, CONF-760935, Sept., 1976, Richland, Washington, Vol. II, p. 711.

49. J.W. Miller, L. Green, A.Y. Lee, G.W. Ruck, M.E. Culbert, D.L. Chapin, and J.L. Kelly, "Uranium Carbide Blanket Design Concept for a Commercial Tokamak Hybrid Reactor (CTHR)," WFPS:TME-80-010, Westinghouse Electric Corporation, Pittsburgh, Pennsylvania, 1980.

50. A. DeVolpi, Proliferation, Plutonium, and Policy, Pergamon Press, New York, 1979.

51. Stanford Arms Control Group, J.H. Barton and L.D. Weiler, editors, International Arms Control, Stanford University Press, Stanford, Ca., 1976; the Non-Proliferation Treaty is in Appendix C.

52. "The Agency's Safeguards System (1965, as Provisionally Extended in 1966 and 1968)," INFCIRC/66/Rev.2, International Atomic Energy Agency, Vienna, Austria, 1968 .

53. "The Structure and Content of Agreements Between the Agency and States Required in Connection with the Treaty on the Non-Proliferation of Nuclear Weapons," INFCIRC/153 (corrected), International Atomic Energy Agency, Vienna, Austria, 1972.

54. "Communications Received from Certain Member States Regarding Guidelines for the Export of Nuclear Material, Equipment or Technology," INFCIRC/254, International Atomic Energy Agency, Vienna, Austria, 1978.

55. E. Te1ler, "Hydrogen Bomb," in Encyclopedia Americana, Americana Corporation, Danbury, Conn., 1979, Volume 14, p. 654 .

56. C.M. Stickey, "Laser Fusion," Physics Today, 31 (5), 50, 1978.

57. B. Keisch and A. Fainberg, "Differences in DOE and NRC Safeguards and Security Requirements and Their Potential Impacts on Comparability of DOE and NRC Systems," BNL-29272, Brookhaven Nationa1 Laboratory, Upton, N.Y., 1981 , the relevant DOE and NRC rules are analyzed and reproduced or cited herein. 
58. A. DeVolpi, G.E. Marsh, T.A. Postol, and G.S. Stanford, Born Secret - The H-Bomb, the "Progressive" Case, and National Security, Pergamon Press, New York, 1981.

59. H. Morland, The Secret That Exploded, Random House, New York, 1981.

60. H. DeWitt, "Has U.S. Government Disclosed the Secret of the H-Bomb?" Bul1. At. Scientists, 35, April, 1979, p. 60 .

61. L. Sobota, "The Unexploded Bomb: The Progressive and Prior Restraint," Southern I11. Univ. Law J., 1980, No. 2, 199.

62. R.J. Harrach, "Perspectives and Some Recent Developments Concerning Declassification of the Inertial Confinement Fusion(ICF) Program," Energy Communications, 6 (3), 223, 1980 .

63. W.J. Holtslander, T.E. Harrison, V. Goyette, and J.M. Miller, "Recovery and Packaging of Tritium from Canadian Heavy Water Reactors," Fus- Tech., 8 (2), Part 2, 2473, 1985.

64. S.K. Sood, R.A.P. Sissingh, and 0.K. Rveton, "Removal and Immobilization of Tritium from Ontario Hydro's Nuclear Generating Stations," Fus. Tech., $\underline{8}$ (2), Part 2, 2478, 1985.

65. "CFFTP Mission Synopsis," Fusion Fuels Technology, 2 (1), 1984; the newsletter of the Canadian Fusion Fuels Technology Project, Mississauga, Ontario, Canada.

66. C. Auerbach, J.R. Lemley, and W.P. Bebbington, "Heavy Water Accountability," BNL-24941, Brookhaven National Laboratory, Upton, N.Y., 1978.

67. E.g., "The Text of the Agreement of 14 October 1981 Between Argentina and the Agency for the Application of Safeguards to Heavy Water Supplied from the Union of Soviet Socialist Republics," INFCIRC/297, International Atomic Energy Agency, Vienna, Austria, 1982.

68. F.C. Capuder, R.L. Reece, R.L. Stephenson, W.A. Slusher, and W.R. Wilkes, "Valves and Tritium Generators (U Beds) for the TSDS," in L.J. Wittenberg, compilator, Proceedings: Tritium Technology in Fission, Fusion, and Isotopic Applications, U.S. D.0.E. CONF-800427, American Nuclear Society (Southwestern Ohio Section) La Grange Park, Ill.

69. J.L. Anderson and W.R. Wilkes, "The Development of Tritium Technology for the United States Magnetic Fusion Program," in F.H. Tenney and C.C. Hopkins, editors, Proceedings of the Fourth Topical Meeting on Controlled Nuclear Fusion, coNF-801011, Vo1. I, p. 491, U.S. Department of Energy, Washington, D.C., 1981.

70. U.S. Department of Energy, Office of Energy Research, "Magnetic Fusion Program Plan," DOE/ER-0214, Washington, D.C., 1985; see also K.I. Thomassen, "Progress and Directions in Magnetic Fusion Energy," Ann. Rev. Energy, 9, $281,1984$. 
71. B.M. Schwarzschild, "First Plasma at Princeton's Tokamak Fusion Test Reactor," Physics. Today, 36 (3), 17, March, 1983.

72. H.P. Furth, "Reaching Ignition in the Tokamak," Physics Today, 38 (3), 53, 1985.

73. Subcommittee on Energy Research and Production of the Comm. on Science and Technology of the U.S. House of Representatives, Ninety-Sixth Congress, Second Session, Fusion Energy: An Overview of the Magnetic Confinement Approach, Its Objectives, and Pace, U.S. Government Printing Office, Washington, D.C., 1980; including Public Law 96-386, the "Magnetic Fusion Energy Engineering Act of 1980."

74. M. Crawford, "Hard Times in Magnetic Fusion," Science, 228, 1069, 1985.

75. International Fusion Research Council, "Status Report on Controlled Thermonuclear Fusion," Nuc. Fus., 18, 137, 1978.

76. "Soviet Minister of Electrification Pyotr Neporozhny Has Announced...,," Nucleonics Week, McGraw-Hill, New York, 15 July 1982, p. 6.

77. Intor Group, "International Tokamak Reactor," Nuc. Fus., 20, 349, 1980. Intor Group, International Tokamak Reactor-Phase One, IAEA/STI/PUB/619, 1982; and Intor Group, International Tokamak Reactor-Phase Two A, Par I, IAEA/STI/PUB/638, (both) International Atomic Energy Agency, Vienna, Austria, 1983.

78. J. Rand McNally, "Physics of Fusion Fuel Cycles," Nuc. Tech./Fusion, 2 (1), 9, 1982 .

79. J.R. Roth, "The Impact of Engineering Constraints on the Feasibility of Advanced Fuel Fusion Reactors," Nuc. Tech./Fusion, 2 (1), 29, 1982.

80. K. Evans, Jr., C.C. Baker, J.N. Brooks, R.C. Clemmer, D.A. Ehst, P.A. Finn, H. Herman, J. Jung, R. Mattas, B. Misra, D.L. Smith, H.C. Stevens, L.R. Turner, R.B. Wehrle, K.M. Barry, A.E. Bolon, R.T. McGrath, and L.M. Waganer, "WILDCAT: A Commercial Deuterium-Deuterium Tokamak Reactor," Nuc. Tech./Fusion, 4 (2), Part 1, 2261983.

81. B. Badger, K. Audenaerde, J.B. Beyer, D. Braun, J.D. Callen, G.A. Emmert, J.M. Gilmore, N. Hoffman, J. Kesner, G.L. Kulcinski, D.C. Larbalestier, E. Larsen, Xingzhong Li, W. Maurer, C.W. Maynard, I. Ojalvo, M. Ortman, R. Perry, M. Ragheb, J. Santarius, J. Scharer, D. Schluderberg, R. Shaing, I. Sviatoslavsky, D.K. Sze, W.F. Vogelsang, A. White, P. Wilkes, and T. Yang, Witamir-I: A University of Wisconsin Tandem Mirror Reactor Design, UWFDM-400, University of Wisconsin, Madison, Wisconsin, 1980.

82. J.M. Dawson, "Advanced Fusion Reactors," p. 453, in E. Teller, editor, Fusion, 1B, Academic Press, New York, 1981.

83. J.D. Gordon, T.R. Samec, S.A. Freije and B.I. Hauss, "Viability of the $11_{B}(p, \alpha) 2 \alpha$ Cycle," Nuc. Tech./Fusion, 4 (2), Part 2, 348, 1983. 
84. Order DOE 5630.2, U.S. Department of Energy, Washington, D.C., August 21, 1980 .

85. IAEA Safeguards Glossary, IAEA/SG/INF/1, International Atomic Energy Agency, Vienna, Austria, 1980.

86. M. Benedict, R.T. Shanstrom, S.L. Amberg, N.B. McLeod, and P.T. Steranka, Nucl. Sci. Eng., 11, 386, 1961.

87. C.C. Cameron and M.E. Black, "International Safeguards for a Light-Water Reactor Fuels Reprocessing Plant: Containment and Surveillance Concepts," SAND80-0160, Sandia National Laboratories, Albuquerque, New Mexico, 1980.

88. M.S. Ortman, E.M. Larsen, and S.I. Abdel-Khailik, "Characteristics of Unburned Tritium Exhaust, Recovery, and Reprocessing Systems in Magnetic and Inertial Confinement Reactors," in L.J. Wittenberg, compilator, Proceedings: Tritium Technology in Fission, Fusion, and Isotopic Applications, U.S. D.0.E. CONF-800427, American Nuclear Society (Southwestern Ohio Section), La Grange Park, I11.

89. A. Fainberg, M.S. Zucker, J.R. Lemley, and E.V. Weinstock, "Assay of Heavy Water in Barrels for Safeguards Purposes" L. Stanchi, editor, in Proceedings of the 3rd Annual Symposium on Safeguards and Nuclear Material Management, European Safeguards Research and Development Association, Joint Research Centre, Ispra, Italy, 1981.

90. M.S. Zucker, "Current Status of $\mathrm{D}_{2} \mathrm{O}$ Assay Using U1trasonics," Proceedings of the 7 th Annual Symposium on Safeguards and Nuclear Material Management, ESARDA 19, European Safeguards Research and Development Administration, Ispra, Italy.

91. G.M. Halpern, "An Improved Method for the Nondestructive Assay of the Tritium Content of Glass Microballoon Laser Fusion Targets," J. Fus. Energy, 2 (6), 419, 1982 .

92. P.W. Sebaugh, D.E. Sellers, H.A. Woltermann, D.R. Boh, J.C. Miles, and F.C. Fushimi, "A Controllable Unit Concept as Applied to a Hypothetical Tritium Process," Nuc. Mat. Management, v. V, No. 4, p. 39, Winter, 1976-1977.

93. As opposed to low-level detection methods for health and safety monitoring. See J.H. McGlesky, Literature Survey of Tritium: Safety, Handling, and Equipment, EI-77-3, Energy Incorporated, Idaho Falls, Idaho, 1977.

94. W.R. Wall and S.I. Cruz, "Tritium Control and Accountability Instructions," SAND85-8227, Sandia National Laboratories, Livermore, California, 1985.

95. J.L. Anderson and J.R. Bartlit, "Unresolved Tritium Issues in the Magnetic Fusion Energy Program," Fus. Tech., 8 (2), Part 2, 2027, 1985. 
96. H. Etherington, editor, Nuclear Engineering Handbook, McGraw-Hil1, New York, 1958 .

97. J.A. Lane, H.G. MacPherson, and F. Maslan, editors, Fluid Fuel Reacters, Addison-Wesley, Reading, Massachusetts, 1958.

98. T.C. Geer and T.A. Parish, "Thorium Oxide Slurries as Blankets for Fissile Producing Fusion Reactors," Nuc. Tech./Fusion, 4 (2), Part 2, $161,1983$.

99. L. Goldstein, L. Geller, Q.Z. Dahodwala, "Diversion Hazards for Light Water Reactor8," ISP0-69, The S.M. Stoller Corporation, New York, 1979.

100. R.D. Endicott, B.K. Jensen, and C.R. Guerra, "A Utility Perspective on Inertial Confinement Fusion Electric Power Generating Plants," in F.H. Tenney and C.C. Hopkins, editors, Proceedings of the Fourth Topical Meeting on Controlled Nuclear Fusion, CONF-801011, U.S. Department of Energy, Washington, D.C., July, 1981, Vo1. III, p. 1265.

101. W.D. Metz, "Ambitious Energy Project Loses Luster," Science, 212, 517, 1981 .

102. D.L. Chapin, ed., Preliminary Feasibility Assessment of Fusion-Fission Hybrids, WFPS :TME-81-003, Hestinghouse Electric Corporation, Pittsburgh, Pennsylvania, 1980.

103. G. Yonas, "Advances in Inertial Confinement Fusion Research," Nuc. Fus., 24 (4), 505, 1984.

104. J.2. Holzrichter, E.M. Campbe11, J.D. Lindle, and E. Storm, "Research with High-Power Short-Wavelength Lasers," Science, 229, 1045, 1985.

105. W. Steele, J. Maniscalco, J. Gordon, S. Salem, T. McCarville, and D. Berwald, "A Success Oriented ICF R\&D Plan for Commercial Demonstration by 2010," Nuc. Tech./Fusion, 4 (2), Part 3, 985, 1983.

106. Energy and Technology Review, Lawrence Livermore National Laboratory, Livermore, California, February, 1985.

107. International Atomic Energy Agency, "World Survey of Major Facilities in Inertial Confinement Experiments," Fuc. Fus., i8, 557, 1973.

108. B.H. Ripin, "Inertial Confinement Fusion," Physics Today, 38 (1), 548, January, 1985.

109. H.I. Avci and G.L. Rulcingki, "The Effect of Liquid-Metal Production Schemes in Inertial Confinement Fusion Reactors," Nuc. Tech., 44, 333, 1979. 
11C. R. Moir, J.D. Lee, W. Neef, T. Ogdon, D. Berwald, B. Campbe1l, S.C. Mortenson, J.R. Ogren, Y. Saito, R. Rose, J.S. Rarbowski, K. Schultz, C.P.C. Wong, R. Creedon, I. Maya, J. De Van, D. Jassby, and N. Hoffman, "Fusion Breeder Program Interim Report--December 1981-February 1982," UCID-19406-1, Lawrence Livermore Laboratory, Livermore, California, 1982.

111. B.M. Abraham, H.E. Flotow, and R.D. Carlson, "UO ${ }_{2}-\mathrm{NaK}$ slurry studies in Loops to $600^{\circ} \mathrm{C}, "$ Nuc. Sci. Eng. , 2, 501, 1957.

112. Code of Federal Regulations, The National Archives of the U.S., Washington, D.C., Jan. 1, 1982, Title 10, Chapt. 1, Parts 10 and 11, p. 179 and 193.

113. Environmental and Natural Resources Policy Division, Library of Congress, The International Atomic Energy Agency: Application of Safeguards in the United States," prepared for the committee on Foreign Relations, United States Senate, 96th Congress, 1st Session U.S. Government Printing Office, Washington, D.C., 1979.

114. Order DOE 1270.2, U.S. Department of Energy, Washington, D.C., December 30,1982 .

115. J. Parmentola and K. Tsipis, "Particle-Beam Weapons," Scientific American, 240 (4), 54, April, 1979.

116. K. Tsipis, "Laser Weapons," Scientific American, 245 (6), 51, December, 1981 .

117. B.G. Levi, "Directed Energy Weapons-Where Are They Headed? " Physics Today, 36 , (8), 17, August, 1983.

118. G. Yonas, "Strategic Defense Initiative: The Politics and Science of Weapons in Space," Physics Today, 36 (8), 241985.

119. J.C. Fletcher, "The Technologies for Ballistic Missile Defense," Issues in Sci. and Tech., p. 15, Fall, 1984.

120. J.A. Maniscalco, D.H. Berwald, R.W. Moir, J.D. Lee, and E. Teller, "The Fusion Breeder-An Early Application of Nuclear Fusion," Fusion Tech., 6 (3), $596,1984$.

121. W.C. Gough, "The EPRI Viewpoint on Fusion-Fission," Proceedings of the USUSSR Symposium on Fusion-Fission Reactors. CONF $\rightarrow 7607 \overline{33 \text {, Lawrence Livermore }}$ Laboratory, Livermore, California, 1976, . 9 .

122. B.R. Jensen N.E. Nour, and T.M. Piascik, "ltility Evaluation of Fusion Fission Hybrids," Nuc. Tech./Fusion, 5 (2), _c4, 1984.

123. E.V. Weinstock and B. Reisch, "Technical Safeguards Issues for Alternative Fuel Cycles," NUREG/CR-1048 and BNL-NUREG-51182, Brookhaven National Laboratory, Upton, New York, 1980. 
124. C.C. Thomas, Jr., D.D. Cobb, and C.A. Ostenak, "Spent Fuel Composition: A Comparison of Predicted and Measured Data," LA-8764-MS, Los Alamos Scientific Laboratory, Los Alamos, N.M., 1981.

125. E.g., J. Lovett and D. Tolchenkov, "Safeguarding Light Water Reactors," IAEA/STR-80 (draft), International Atomic Energy Agency, Vienna, Austria, 1978.

126. M. Honami and D. Jung, "General Considerations in Safeguarding CANDU Reactors by Item Accounting and Containment/Surveillance," IAEA/STR-83, International Atomic Energy Agency, Vienna, Austria, 1979.

127. V. Sukhoruchkin, "Safeguarding of Reprocessing Facilities," IAEA/STR-77 (draft), International Atomic Energy, Vienna, Austria, 1979.

128. J. Lovett, $K$. Ikawa, and M. Tsutstmi, "An Advanced Safeguards Approach for a Model 200 t/a Reprocessing Facility," IAEA/STR-220 (draft 3), International Atomic Energy Agency, Vienna, Austria, 1982.

129. D.E. Hul1, "Possible Applications of $\mathrm{UF}_{6}, "$ U.S. A.E.C. Report Mon N-336, Oak Ridge National Laboratory, Oak Ridge, Tennessee, 1947.

130. Office of Technology, Nuclear Proliferation and Safeguards, Vo1. I, OTAE-48, Congress of the United States, Washington, D.C., 1977; see also, the accompanying Appendix VI in Part Two V01. II, OTA-E-50.

131. V.N. Gribkov and H.G. Tyagunov, "Possible Applications of a Hybrid Thermonuclear Energy Source Based on a DPF Device in Modern Energy Complexes," in G.S. Bauer and A. McDonald, eds., Nuclear Technologies in a Sustainable Energy System, Springer-Verlag, Berlin, 1983.

132. R.A. Gross, "Survey of Reactor Aspects of Compact Fusion Concepts," Nuc. Tech./Fusion, 4 (2), Part 1, 305, 1983. 


\section{v. ACCELERATOR-DRIVEN REACTOR SYSTEMS}

With the development of particle accelerators for fundamental studies in physics to higher and higher energies has come the recognition that these devices can serve as prodigious sources of neutrons. Through so-called spallation reactions, protons or deuterons incident at high energy on suitable targets can cause the production of such significant numbers of neutrons that these neutrons can then be utilized to convert fertile uranium-238 or thorium-232 into fissile plutonium-239 or uranium-233 in practical quantities. (1) The idea was first conceived by Lawrence (2) and Lewis $(3)$ and has received continuing study in Canada $(4,5)$ and the Soviet Union ${ }^{(6)}$ in addition to the American work summarized below.

If desired, the system can be optimized to produce power ${ }^{(7)}$ instead of fissile fuel, but the incentives for so doing seen fewer: why add an accelerator system to a reactor when the latter is capable of operating alone? (8) There is even an "Augean" form of the accelerator system designed to transmute highly radioactive fission products to less harmful forms $(9)$.

Conceptually, accelerator-driven systems are similar to fusion-fission hybrid systems (see Chapter IV) in that both involve large sources of neutrons. (5) The differences are, first, that accelerators, as opposed to fusion systems, have a technologically demonstrated basis, and second, that accelerators and fusion systems would be energy consumers and producers, respectively. In the latter sense, the accelerators would be analogous to the laser or ion driver part of inertial-fusion systems.

We shall frame our discussion here around specific designs for accelerator-driven systems, those performed at Brookhaven National Laboratory $(7,9,10,11)$. Some of these systems were previously analyzed for proliferation concerns in the MASAP studies(12) and by Outlaw, (13) and very briefly by Gsponer, Jasani, and 
Sahin.(14) Oak Ridge National Laboratory designs based on a liquid-metal target and coolant were also subjects of the NASAP studies.

Three proliferation concerns would exist for these systems: (1) diversion of some of a facility's declared material production; (2) clandestine production of fissile material in a declared facility; and (3) production of fissile material in a dedicated, clandestine facility or a misused research facility. Diversion of fissile material from a declared facility is the most credible diversion scenario of the three. Moreover, a country with the technological base to possess such a system would certainly be capable of producing fissile material in a dedicated and possibly clandestine fission reactor if the country had the desire to possess nuclear-fission weapons.

v.1. Principles of Accelerator Drivers

The heart of accelerator-driven reactor systems is a high-energy particle accelerator of the kind used in fundamental physics research. It is an experimental fact that when high-energy protons or deuterons are incident on heavymetal primary targets, large numbers of neutrons are liberated -- "spalled", to use the technical term. Figure v-1 illustrates the neutron yield from a proton beam incident on various targets. Although a linear function of proton energy at high energies, the neutron yield drops nonlinearly at lower energies. Other calculations extend the neutron yields depicted to energies as high as 2000 million electron volts (MeV); roughly 190 neutrons per proton are expected.(15) If such neutron production could be sustained reliably at a sufficiently high rate, then the neutron's could be used to drive a subcritical lattice of uranium or thorium to emphasize either power production or the conversion of fertile material into fissile material to fuel other reactor systems. The lattice of fissile and fertile fuel is called the secondary target. The primary and secondary targets are actually unified in the latest design.(11) 


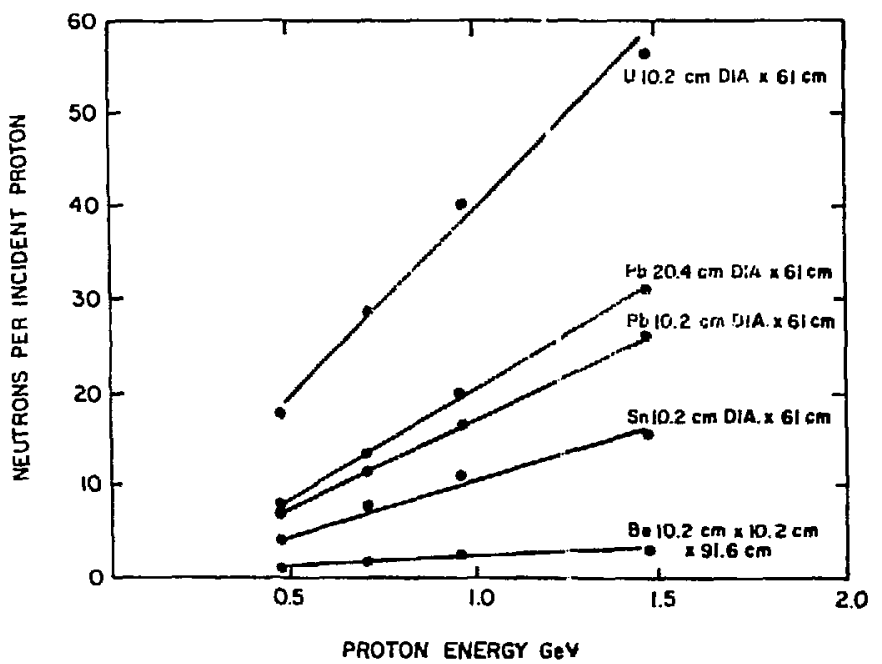

(a) Yield measırement of neutrons ohtained by bombardment of a heavymetal target with high-energy protons (from ref. 10).

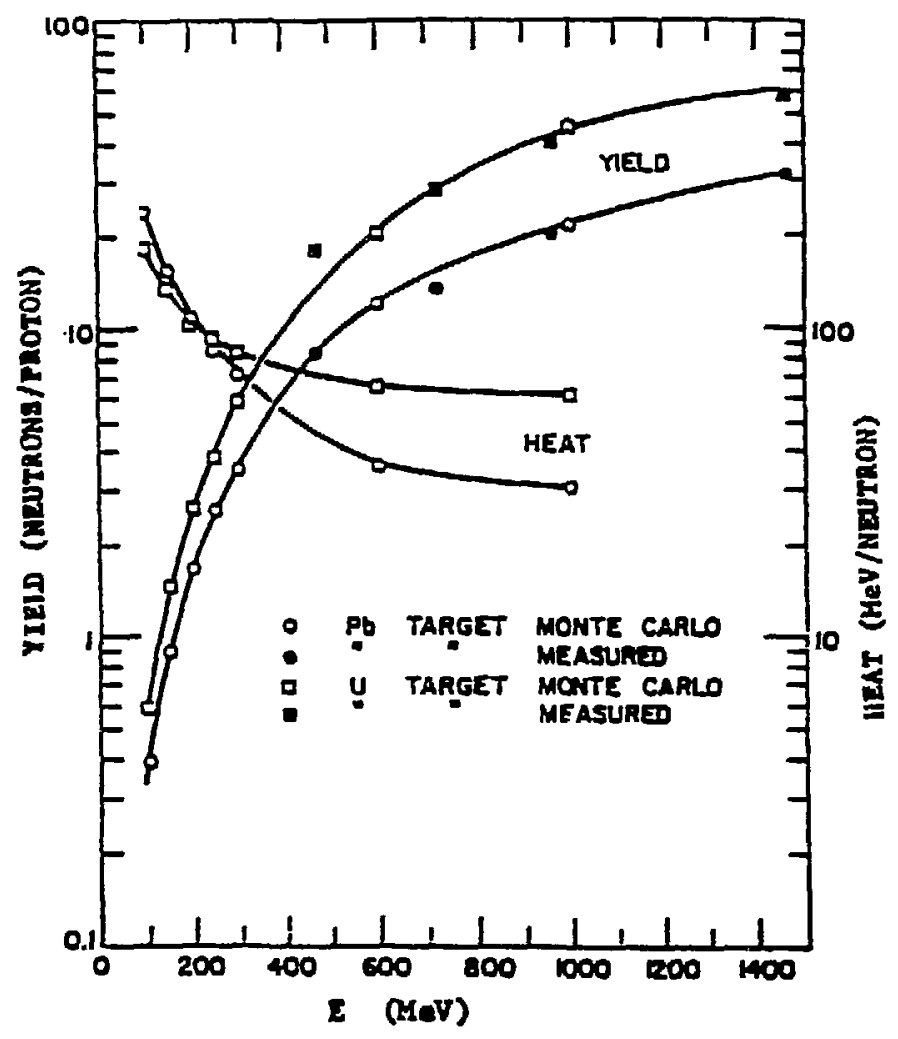

(b) Neutron-yield and heat-production measurements and theoretical predictions for $20 \mathrm{~cm}$ lead $(\mathrm{Pb})$ and uranium (U) targets showing the nonlinear low-energy region (from ref. 15).

Figure $\mathrm{V}-1$. 
Table V-1 lists the published parameters of several operating and proposed linear particle accelerators. Machine upgrades or atypical operating regimes permit these parameters to be exceeded. Although none has the exact characteristics of the proton linear accelerator needed for a commercial-scale accelerator-driven reactor system $(10)$, several important characteristics are or would be achieved in at least one of these existing or proposed facilities, namely, a current of 0.3 amperes and a duty factor of $80 \%$. Achieving a beam energy of 2000 $\mathrm{MeV}$ is not thought to be an insuperable problem given much higher energies achieved in other types of particle accelerators such as proton synchrotrons.

The Los Alamos Meson Physics Facility already operates a linearaccelerator-based neutron spallation source, (17) and there are a number of other operating neutron spallation sources for research purposes based upon final acceleration of protons in synchrotrons and neutron production in uranium or tungsten. $(18,19)$

\section{V.2. Linear-Accelerator-Driven Systems}

Three different accelerator-driven reactor systems have been proposed: the linear-accelerator driven reactor (LADR), linear-accelerator fuel enricher and regenerator (LAFER), and linear-accelerator fuel producer (LAFP).

Figures $v-2, v-3$, and $v-4$ illustrate respectively how the LADR, LAFER, and LAFP would fit into an energy system. The captions for these figures 1 ist the respective system advantages and disadvantages compared to existing 1 ightwater-reactor systems. We sha11 focus in our subsequent discussion on the latest design for the LAFP, also called the "Spallator"(i1), because it is the likeliest candidate for development. 


\section{Table v-1}

Parameters of Selected Linear Accelerators

(from refs. 10 and 20 )

\begin{tabular}{|c|c|c|c|c|c|}
\hline Laboratory & $\begin{array}{l}\text { Ion } \\
\text { Type }\end{array}$ & $\begin{array}{c}\text { Energy, } \\
\mathrm{MeV}\end{array}$ & $\begin{array}{l}\text { Current, } \\
\text { Amperes }\end{array}$ & $\begin{array}{l}\text { Duty } \\
\text { Factor, } \\
\%\end{array}$ & Status \\
\hline LANL-LAMPF 1 & Proton & 800 & 0.014 & 11 & Operational \\
\hline LLNL - MTA 2 & Deuteron & 500 & 0.320 & 100 & Proposed \\
\hline$B N L-A G S^{3}$ & Proton & 200 & 0.1 & 0.1 & Operational \\
\hline $\mathrm{FNAL}^{4}$ & Proton & 200 & 0.3 & 0.06 & Operational \\
\hline HEDL-FMIT 5 & Deuteron & 35 & 0.1 & 100 & Proposed \\
\hline \multicolumn{3}{|c|}{$\begin{array}{l}1 \text { Los Alamos National Laboratory } \\
\text { Meson Physics Facility }\end{array}$} & \multicolumn{3}{|c|}{$\begin{array}{l}4 \text { Fermi National Accelerator } \\
\text { Laboratory }\end{array}$} \\
\hline \multicolumn{3}{|c|}{$\begin{array}{l}2 \text { Lawrence Livermore National Labor- } \\
\text { atory Materials Testing Accelerator }\end{array}$} & \multicolumn{3}{|c|}{$\begin{array}{l}5 \text { Hanford Engineering Development } \\
\text { Laboratory Fusion Materials } \\
\text { Irradiation Test Facility }\end{array}$} \\
\hline
\end{tabular}

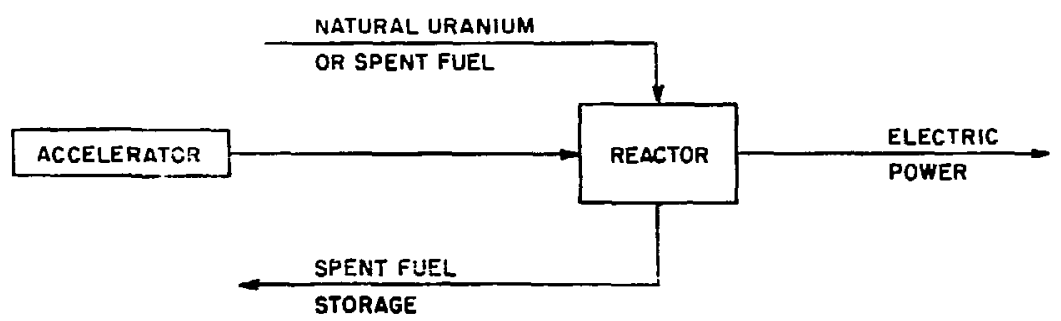

Figure V-2. Linear-accelerator-driven reactor (LADR). Advantages: (1) once through, no reprocessing; (2) power from natural uranium fuel in a $\mathrm{H}_{2} \mathrm{O}$-or $\mathrm{D}_{2} \mathrm{O}$-moderated subcritical assembly; (3) subcritical = safety advantages; (4) uranium resources stretched; (5) enriched fuel not required. Digadvantages: (1) an accelerator required by each power reactor; (2) increased complexity; (3) long burnup. (This figure is from ref. 10). 


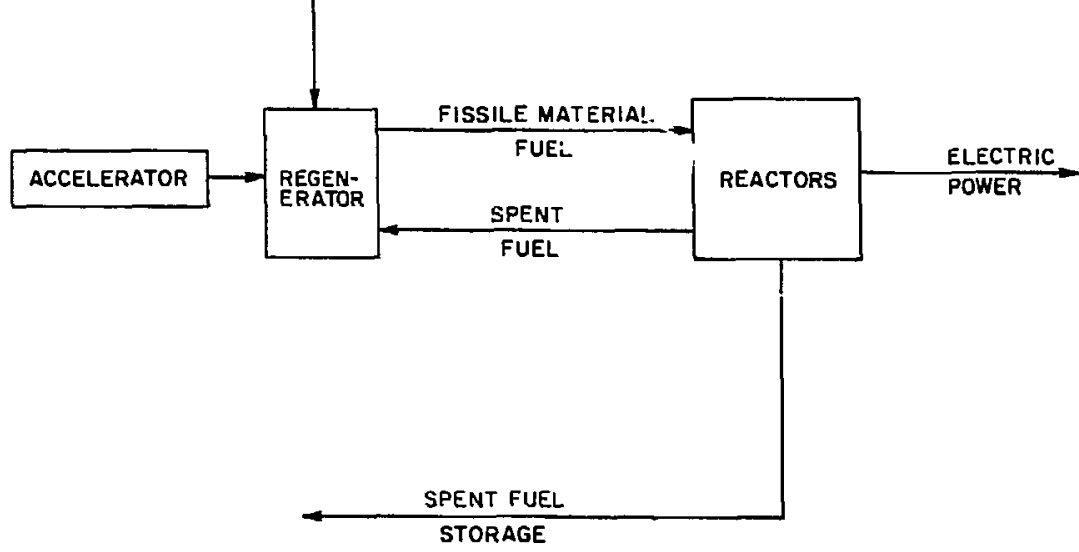

Figure V-3. Linear-accelerator fuel enricher and regenerator (LAFER). Advantages: (1) no reprocessing; (2) no departure from existing power-reactor practice; (3) provision of means of ${ }^{233} \mathrm{U}$ denatured production; (4) several reactors can be supplied by one accelerator; (5) uranium resources stretched; (6) fuel producer and power reactor kept separate, with resulting reliability benefit; (7) enrichment facilities' requirement reduced; (8) relatively little extrapolation required by technology in target and power reactors. Disadvantages: long burnup options $(>60,000 \mathrm{MWD} /$ ton) may be 1 imited by fission-product buildup and radiation damage to cladding and structural materials. (This figure is from ref. 10.)

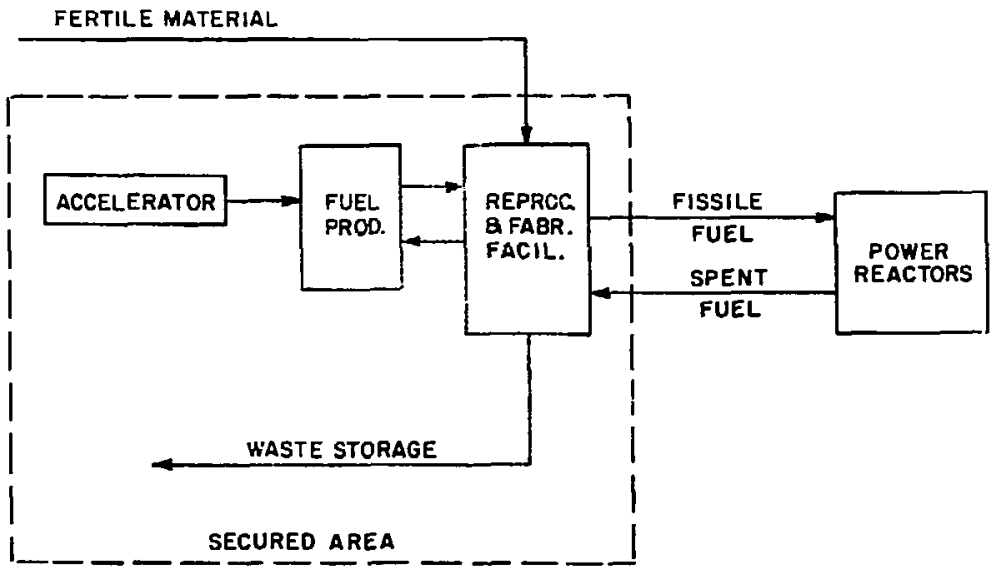

Figure V-4. Linear-accelerator fuel producer (LAFP) or "Spallator".

Advantages: (1) no departure from existing reactor technology; (2) provision of means of 233 production; ( 3 ) several reactors can be supplied by one accelerator; (4) full use made of fuel resources as breeders. Disadvantages: reprocessing required. (This figure is from ref. 10.) 


\section{V.3. Linear-Accele rator Reactors and Fuel Breeders}

V.3.1. Physical Description of the Facility

The three linear-accelerator-driven systems, the LAFER, LADR, and LAFP, would consist of a linear-accelerator building about 1 kilometer long with its associated auxiliary services. It would be connected to a containment building similar to the containment of an existing fission reactor and housing the reactor or breeder system. Figure V-5 shows this containment for the LAFP and its connection to the linear accelerator.

Target structure is specific to the particular system, and Figure V-6 gives views of it for the latest design(11) of the LAFP for making bulk fissile fuel. It would consist of a Calandria of the sort found in Canadian deuterium-uranium (CANDU) reactors with fertile target material inside pressure tubes and fueled on-1ine. (21)

Table V-2 presents key features of the LAFP and Table V-3 gives some of its important quantitative parameters.

Sufficient heat would be produced in the fertile target and be extracted via a pressurized-water coolant for transfer to the plant's thermal-electric generator that the LAFP would not be a net consumer of electricity. (This fact, and indeed, the energy efficiency of the entire accelerator-breeder concept, depend strongly on the linear-accelerator efficiency.) Figure $\nabla-7$ depicts the LAFP power flows. 


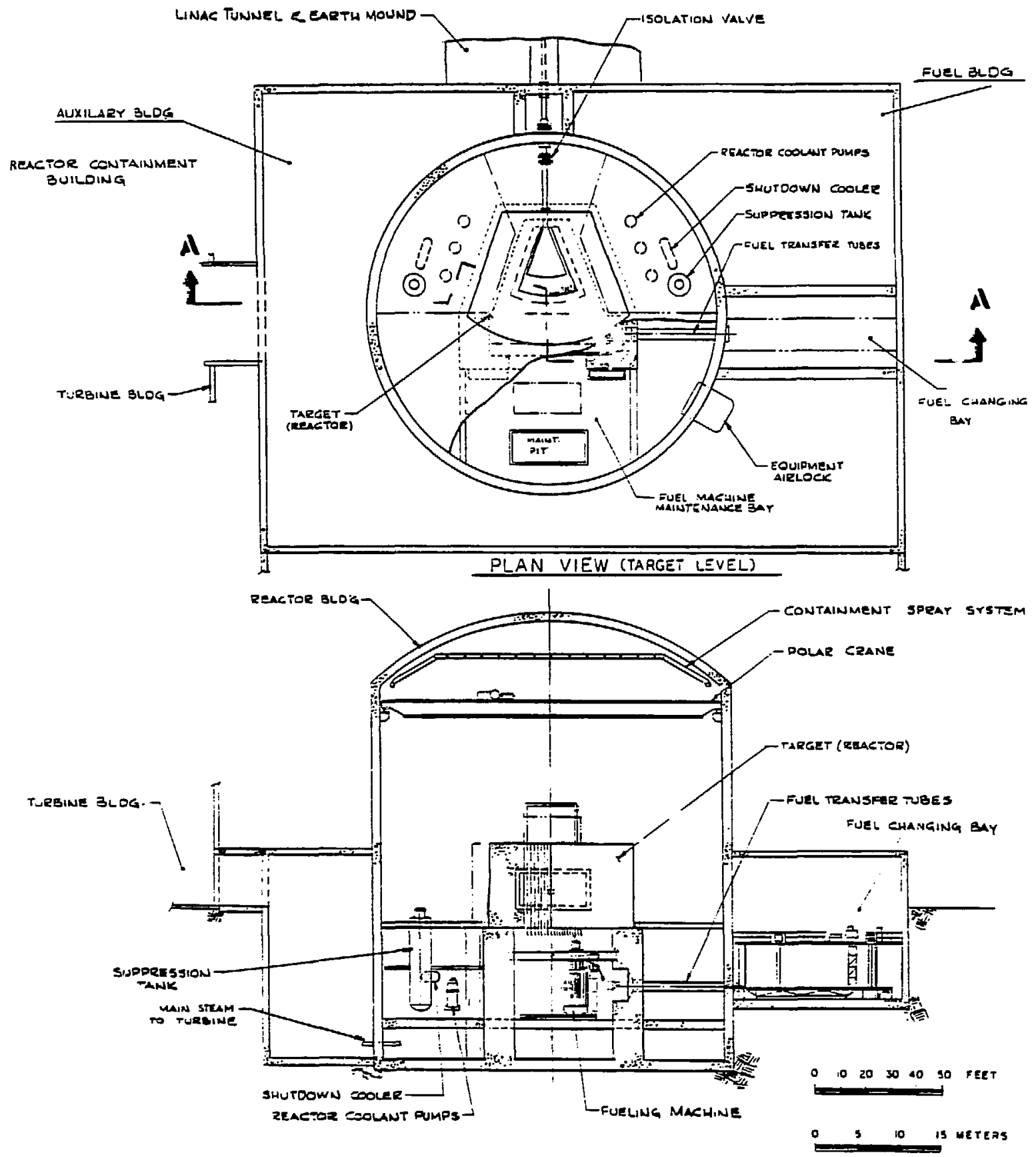

Figure V-5. LAFP (Spallator) target system and containment building. 


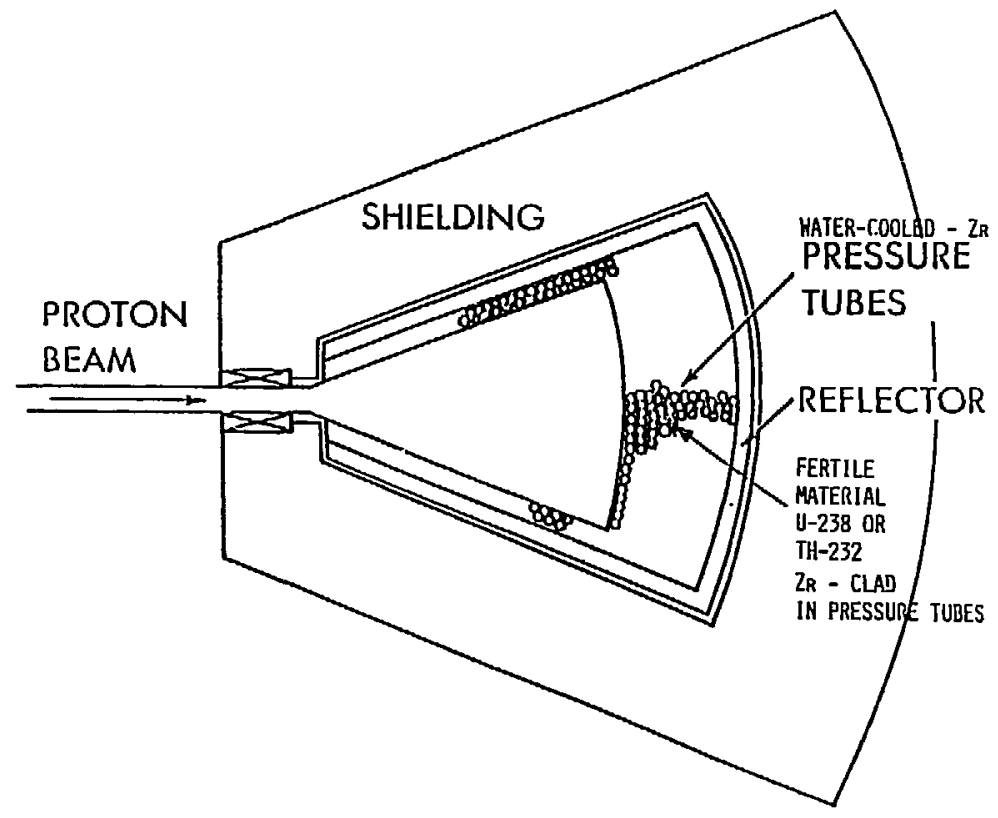

Figure V-6. LAFP (Spallator) target-blanket configuration (fxom ref. 11).

Table V-2

Key Features of the Linear-Accelerator Fuel Producer (Spallator)

- Single-purpose fuel producer that only requires external power for startup.

- Linear-accelerator driver based on existing radio-frequency methods.

- Hohlraum target for accelerator beam.

- Subcritical target lattice of fissile material in the form of fuel bundles within pressure tubes.

- Target cooled by a conventional pressurized-water heat-transfer system that produces power for the accelerator.

- Nine client light-water reactors supported by fissile material production. 


\section{Table V-3}

Parameters of the Linear-Accelerator Fuel Producer

Ascelerated primary particle

proton

Particle energy, million electron-volts 2000

Accelerator length, meters $\checkmark 1000$

Accelerator current, amperes 0.3

Accelerator delivered power, megawatts 600

Accelerator efficiency, per cent s5

Accelerator required power, megawatts $s 1200$

Target neutron-production rate, $\mathrm{n} /$ second ง.5 $\times 10^{20}$

Initial neutron yield per proton, including those from fission ง 188

Breeding ratio, $\mathrm{Pu}$ atoms/neutron

Target thermal power, megawatts

Plant thermal electric generating efficiency

Plant thermal electric production, megawatts

Plant net electric-power requirement, megawatts

Target annual fissile-fuel ( $\mathrm{Pu}$ ) production, kilograms per year $\checkmark 3300$

Plant availability, per cent 75 


\section{V.3.2. Proliferative Materials}

As Table V-3 indicates, the LAFP would produce about $3300 \mathrm{~kg}$ of fissile plutonium per year, which is enough for nine 1 ight-water reactors (LWRs) of 1000 megawatts (electric). Given an LAFP core configuration with CANDU-1ike bundles(21) of fertile fuel and an enrichment increase of $1.0 \%$, the production rate corresponds to the flow of about 18,000 fuel bundles annually. Forty-five such bundles would contain one significant quantity (SQ) of plutonium (22) (Appendix V.A).

Figure V-8 displays the isotopic quality of the bred plutonium for the LAFER cycle. What is noteworthy is that after the first cycle in the LAFER but before being burned in a reactor, the assemblies would contain plutonium that is rich in the fissile isotope plutonium-239 and virtually free of the spontaneously fissioning isotope plutonium 240.(13) This material would be very reliable for weapons use ${ }^{(23)}$ even though the assemblies would be radioactive, having undergone a burnup of 3000 megawatt days per metric ton (MWD/ton) of heavy metal. These same statements apply generally to the LAFP cycle, which would a1-

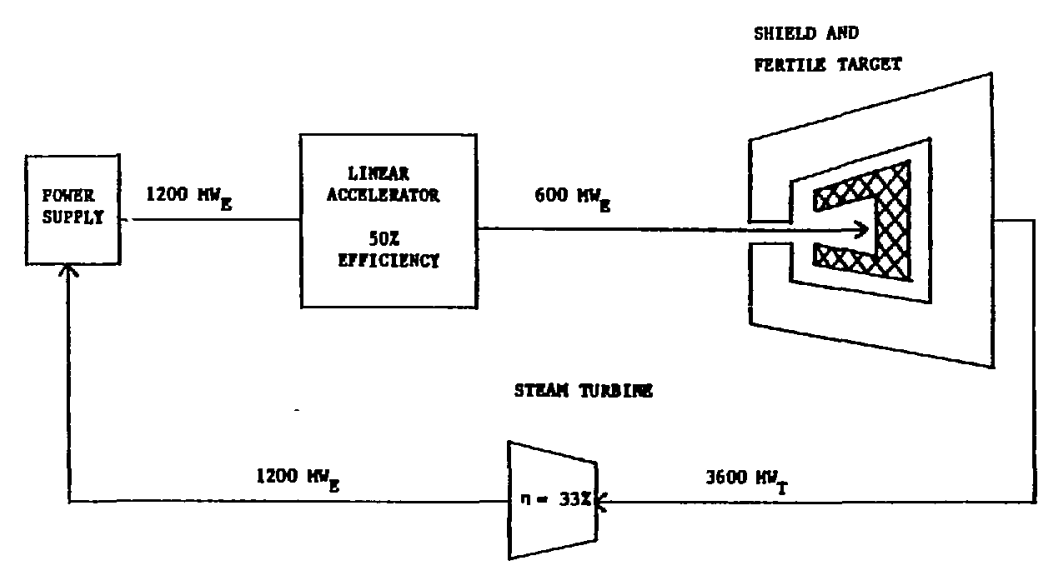

Figure V-7. LAFP power flows. 
ways be supplying bulk fuel of the character of LAFER fuel at the end of the LAFER's first "enrichment" cycle in Figure V-8. (On the other hand, at the end of the two reactor burn cycles, the LAFER-LWR fuel would contain more plutonium-240 and plutonium-242 than would conventional LWR fuel, making it less reliable for weapons use than the conventional fuel(10)). Table V-4 summarizes the character of the fuel at various points in the LAFER cycle.

This plutonium vulnerability would not be as great for the LADR, in which the fuel would remain until having undergone a large burnup and having become highly radioactive(18) (see Fig. V-2). However, if the fuel were shuffled in position at shorter intervals, fuel with relatively low burnup would become temporarily accessible.(13)

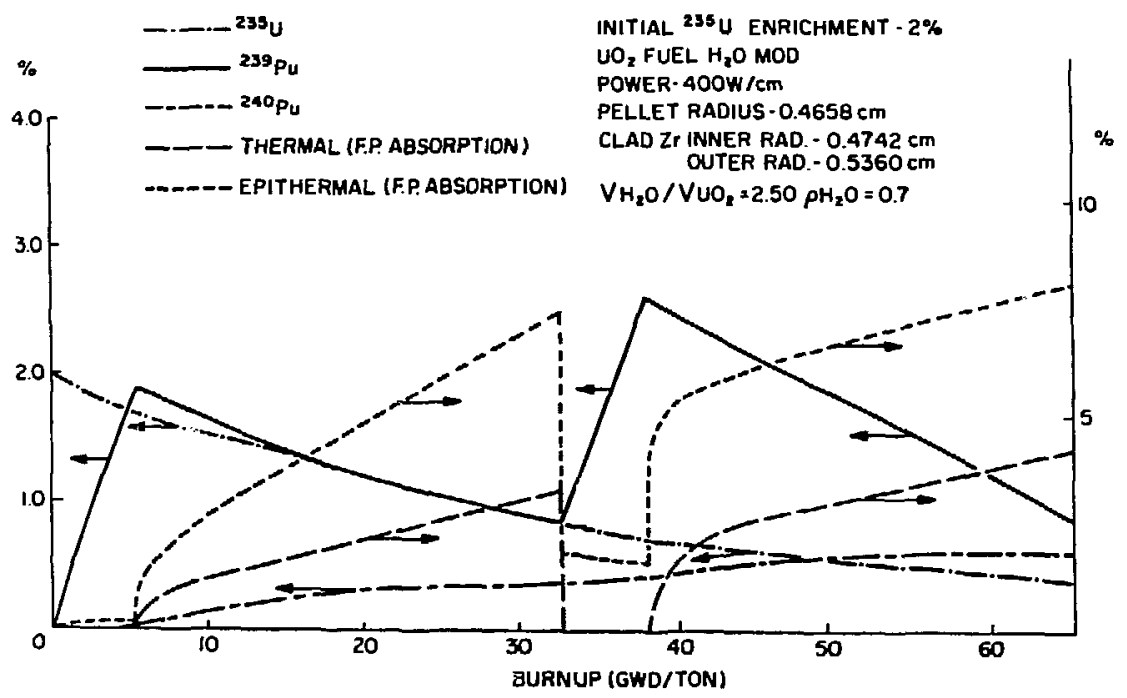

Figure V-8. Fissile-material buildup and neutron absorption due to fission products during IAFER enrichment and LWR burn cycle (from ref. 10). 
Table V-4

Nuclear Materials Available in the Once-Through Fuel Cycle for the LinearAccelerator Fuel Enricher and Regenerator (LAFER) with Dispersed Reactors

(from ref. 13).

\begin{tabular}{|c|c|c|c|c|}
\hline $\begin{array}{l}\text { Fue! } \\
\text { Type }\end{array}$ & $\begin{array}{c}\begin{array}{c}\text { Diversion } \\
\text { Poine }\end{array} \\
\end{array}$ & Mazezial & $\begin{array}{l}\text { Number of Assemblies } \\
\text { for } 100 \mathrm{~kg} \text { of } \\
\text { Pu or U-233 or } \\
300 \mathrm{~KB} U-235 \\
\end{array}$ & $\begin{array}{c}\text { Sceps co Produce } \\
\text { Weapons Usable } \\
\text { Material }\end{array}$ \\
\hline \multirow[t]{5}{*}{$\mathbf{U}-\mathbf{P u}$} & $\begin{array}{l}\text { Enrithment plant } \\
\text { or LAFK fresh fuel } \\
\text { storage }\end{array}$ & Assemblies $2.0 \%$ U-235 & Abouc 45 LWR assemblies & $\begin{array}{l}\text { Isocopic enrichment } \\
\text { and conversion to } \\
\text { uranium oreal }\end{array}$ \\
\hline & $\begin{array}{l}\text { LAFR or dispersed } \\
\text { reactor storage }\end{array}$ & $\begin{array}{l}\text { LAFR initial output } \\
\text { assemblies } \\
3.27 \text { Fissile } \\
q 1.57 \mathrm{PU} \\
\text { q1.7\% U-235 } \\
\text { (nigoo WWD/MT } \\
\text { burnup) }\end{array}$ & $\begin{array}{l}\text { About } 20 \text { LUR-type } \\
\text { assemb lies }\end{array}$ & $\begin{array}{l}\text { Hot separation } \\
\text { and conversion to } \\
\text { Pu metal }\end{array}$ \\
\hline & $\begin{array}{l}\text { LAFR or dispersed } \\
\text { renctors }\end{array}$ & $\begin{array}{l}\text { Once burnt asseablies } \\
227 \text { Fissile } \\
217 \mathrm{Pu}\end{array}$ & $\begin{array}{l}\text { About } 30 \text { LWR-type } \\
\text { assemblies }\end{array}$ & $\begin{array}{l}\text { Hor separaiton and } \\
\text { converaton to Pu } \\
\text { metal }\end{array}$ \\
\hline & $\begin{array}{l}\text { LAFR or dispersed } \\
\text { reactor }\end{array}$ & $\begin{array}{l}\text { Once burnc - reenriched } \\
1 \mathrm{n} \text { LAFR } \\
23.25 \mathrm{Fissile} \\
32.22 \mathrm{Pu}\end{array}$ & $\begin{array}{l}\text { 10-15 LWR-cype } \\
\text { assembliea }\end{array}$ & $\begin{array}{l}\text { Hot meparation and } \\
\text { converaion to Pu } \\
\text { aetal }\end{array}$ \\
\hline & $\begin{array}{l}\text { Disperaed reactors } \\
\text { or away froo reac- } \\
\text { tor opent fuel } \\
\text { otorage }\end{array}$ & $\begin{array}{l}\text { Twice burnt spent } \\
\text { fuel } \\
\eta l=1.57 \mathrm{Pu}\end{array}$ & $\begin{array}{l}\text { About } 30 \text { LUR-type } \\
\text { assemblies }\end{array}$ & $\begin{array}{l}\text { Hot eeparation and } \\
\text { converaion to Pu } \\
\text { metal }\end{array}$ \\
\hline \multirow[t]{3}{*}{$\begin{array}{l}\text { Denatured } \\
\text { U-Th } \\
\text { Euels }\end{array}$} & $\begin{array}{l}\text { Enrlchment, fuel } \\
\text { fab, plant or } \\
\text { LAFR }\end{array}$ & 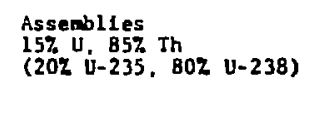 & $\begin{array}{l}\text { About } 30 \text { LWR-type } \\
\text { assemblies }\end{array}$ & $\begin{array}{l}\text { Cold eeparacion plus } \\
\text { isotopic enzichment } \\
\text { and conversion to } \\
\text { uranium mecal }\end{array}$ \\
\hline & $\begin{array}{l}\text { LAFR or dispersed } \\
\text { reactor }\end{array}$ & 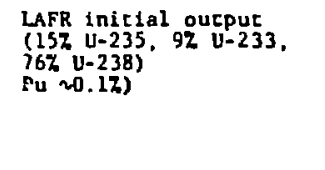 & $\begin{array}{l}\text { 230-40 LWR-cype. } \\
\text { several hundred } \\
\text { assemblies for Pu }\end{array}$ & $\begin{array}{l}\text { Hot separation plus } \\
\text { isotopic enrichment } \\
\text { and conversion to } \\
\text { uranium metal- or } \\
\text { possible direct use } \\
\text { in a very crude de- } \\
\text { vice }\end{array}$ \\
\hline & $\begin{array}{l}\text { Dispersed reactors } \\
\text { or away from re- } \\
\text { actor spent fuel } \\
\text { srorage }\end{array}$ & $\begin{array}{l}\text { Dispersed reactor } \\
\text { spent fuel } \\
\text { ( } 60.000 \text { HD/MT) } \\
\text { denatured U-233, U-235, } \\
U-238 \text { in thorium }\end{array}$ & $\begin{array}{l}\text { For U-233 or U-235, } \\
250-100 \text { : for pluco- } \\
\text { nium. several hundred }\end{array}$ & $\begin{array}{l}\text { Hor separacion plus } \\
\text { isoropie enrichment } \\
\text { for U-233 and/or } \\
\text { U-235 - or hot seps- } \\
\text { ration of Pu and con- } \\
\text { version to metal }\end{array}$ \\
\hline
\end{tabular}




\section{v.3.3. Time Scale for Development}

Accelerator-driven systems have not progressed beyond the conceptual-design stage even though there are no untested scientific principles involved and most of the subsystems involved exist. This is in great contrast to the situation regarding nuclear fusion, for which the problems and promise are great and the scientific program is widespread and vast (see Section IV.4.3).

The most recent designs for accelerator-driven systems employ the Hohlraum target design (see Fig. V-6) with direct incidence of the proton beam on the uranium targets. (11) 0lder designs $(4,7,9,10)$ were based on the use of a primary liquid lead-bismuth target upon which the proton beam would be incident. The neutrons produced there would then be incident on a surrounding secondary fertile target. The Hohl raum target design would lead to a simpler system.

Figure V-9 shows a possible LAFER development schedule based upcn a decision to proceed in 1980 . The most important points of that schedule are that a

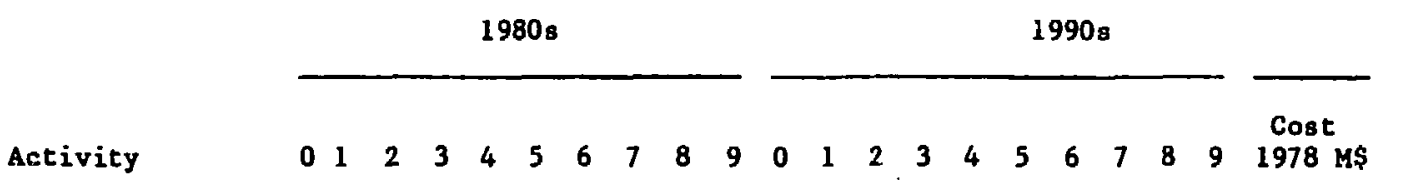

\footnotetext{
LAFER physics

Reactor physics

Yieìd exper.

Eng. design study

Lattice exper.

Accel. devel.

Target devel.

Materials devel.

Demo. plant design construction operation

Safety, 1icensing

Proto. plant design construction operation
}

$\operatorname{CosT} 1978 \mathrm{M \$} \times 10$

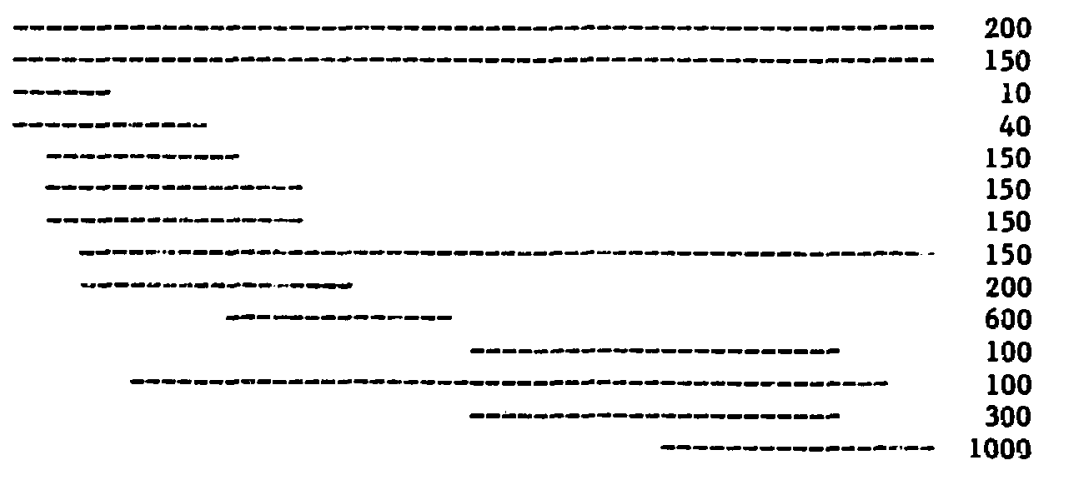

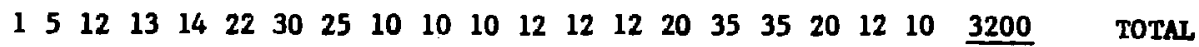

Figure 8-9. Research, development, and demonstration cost and time schedule For the LAFER given a 1980 starting date (from ref. 10). 
demonstration plant could be operating within about ten years of a decision to proceed and a prototype commercial plant, within about twenty years.

Canada and the United States are the countries whose scientists and engineers have had the greatest interest in accelerator-driven systems.

\section{V.3.4. Other Fue 1 Cycles}

The accelerator-driven systems could operate as well on a uranium-233 and thorium-232 cycle as on a uranium-238 and plutonium-239 cycle (see Chapter VI). That is, the accelerator systems could support any fission-fuel breeding cycle. More important, the other modes of accelerator system would pose different proliferation hazards than would the LAFP cycle upon which we have focussed. The LADR and LAFER (see Figs, V-2 and V-3) could operate either with fresh fuel assemblies or with partially burned (30,000 MWD/ton) spent-fuel assemblies from a light-water reactor. In the former case, except for the possibility of beam diversion (see Section V.3.5), the LADR or LAFER would pose the same proliferation hazards as does a conventional light-water reactor. In the latter case, the "front end" of the LADR or LAFER cycle would involve plutonium-bearing but very radioactive fuel assemblies that would require the same safeguards as are applied to spent fuel from light-water reactors, which sf course these particular as semblies actually would be.

The LAFP also plays a role in the Augean or fission-product-transmuting (APEX) fuel cycle, wherein selective and partial reprocessing occurs (see Fig. v-10). The reprocessing product would contain many transuranic elements (e.g. Am, Cm, and Np) and long-1ived fission products (e.g., Cs, Sr, $\mathrm{Kr}$, and I) along with plutonium. From the point of view of proliferative materials, in this fuel cycle even the feed into the LAFP, though it would be radioactive, could be further processed into weapons materisl. 


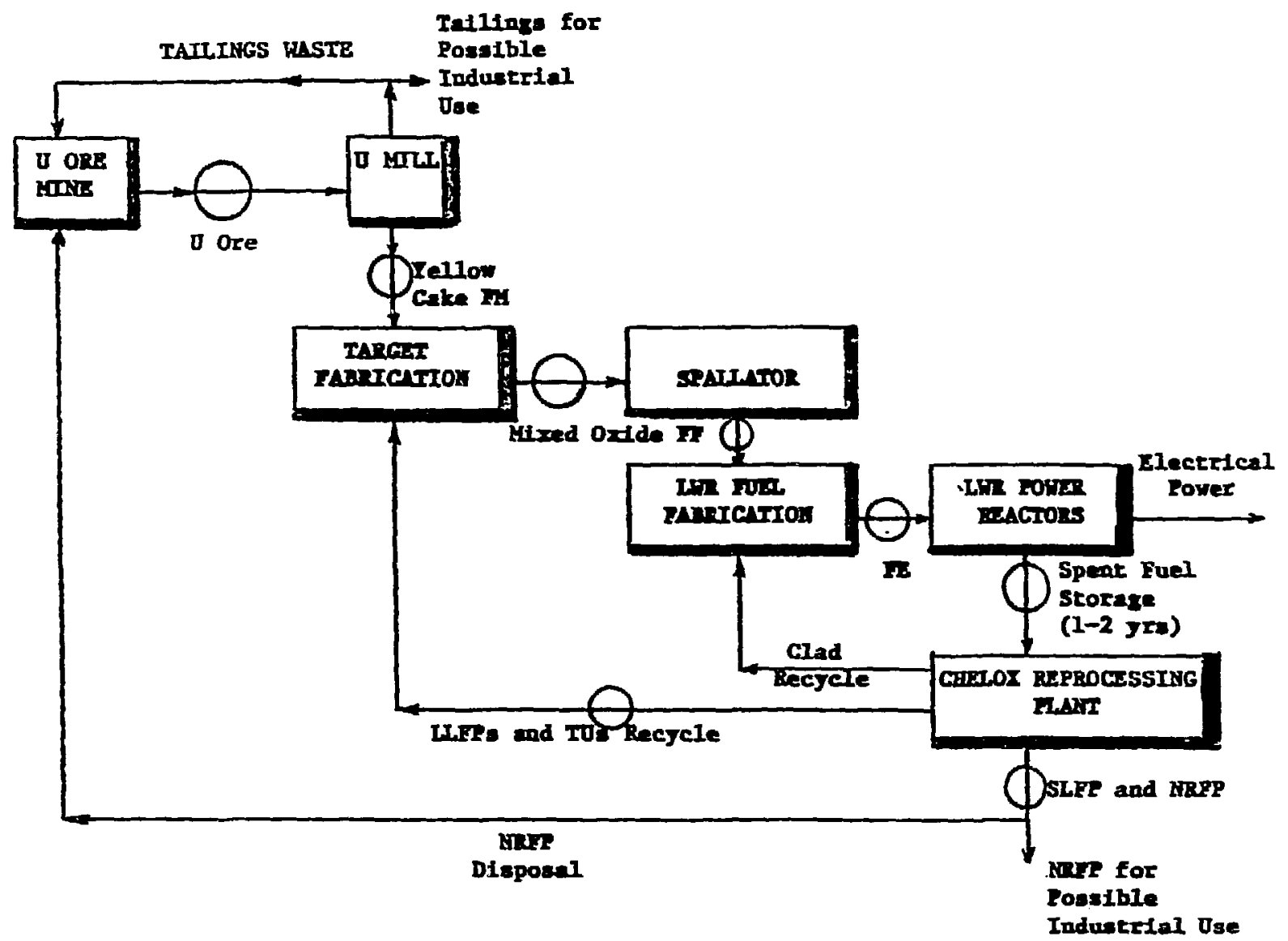

Figure V-10. APEX nuclear fuel cycle for uranium and plutonium. It includes a Spallator (LAFP), chelox reprocessing for recycling radioactive wastes, and light-water reactors for generating power. This fuel cycle has no need for enrichment or for the long-term geologicalage storage of long-lived nuclear wastes. The aystem can be modified for application to the fuel cycle involving thorium and uranium-233. In this figure, FM means fertile material; FF, fissile fuel; NRFP, nonradioactive fission products; SLFP, shortlived fission products; LLFP, long-lived fission producta, Ti, transuranics; and FE, LWR fuel elements. (This figure is from ref. 11). 


\section{V.3.5. Proliferation Concerns}

Three different proliferation problems would exist for accelerator-driven reactor systems: (1) diversion of some of a facility's declared fissilematerial production (or, if applicable, feed); (2) clandestine production of fissile material in a declared facility; and (3) production of fissile material in a dedicated, clandestine facility or a misused research facility. Except for the neutron-diversion aspect of the second point, these concerns have generally speaking been discussed previously. $(10,13,24)$

The first proliferation concern is the diversion of some of a facility's declared fissile material production or, in the case of the LAFP in the APEX fuel cycle (see Fig. V-10) or of the LAFER or LADR when using spent fuel, of some of the facility's feed. All of this declared material would undergo strict item accounting and surveillance, which periodic fuel shuffling would complicate.

The conventional fuel assemblies envisioned for the LAFER and LADR would undergo the same item verification and accounting that is used now for LWRs. For the LAFER, Table V-4 gives the fuel cycle locations and strategically significant number of fuel assemblies. The fuel for the LAFP would presumably be treated much as would that for CANDU reactors, with all the attendant difficulties regarding remote on-line refueling, the huge numbers of fuel bundles, and their lack of identfiability. (25) This is a crucial design choice which would markedly affect the safeguards system and its potential efficiency. For the same reasons that the production of plutonium in conventional LWRs is uncertain to within about $5 \% .{ }^{(26)}$ production of fissile material in the LAFP could be just as uncertainly known unless predictive methods improve. For this reason, item accountability of LAFP fuel would be especially important. 
The second proliferation concern is the clandestine production of fissile material in a declared facility. This could occur at an accelerator-driven system either by diversion of the accelerator beam to a clandestine target area or by diversion of neutrons from the primary target.

Beam diversion would require a large, sophisticated magnetic system to bend the beam from its intended path (or the disabling of a design bending magnet) plus the construction of an undeclared target system to facilitate breeding of undeclared fertile material. Given the evident nature of a beamtransport system, evacuated piping, it is not credible that such a system could be built and not be detected by inspectors during periodic visits to reverify design information. Moreover, any auxiliary beam piping could be sealed or monitored in such a way to indicate beam passage. A further safeguard against such a diversion strategy would be a tamper-proof beam monitor that would indicate, among other things, if the beam were operating during purported maintenance periods and conceivably irradiating an undeclared target system. In this connection, power monitors that record neutron flux for fission reactors exist ${ }^{(27)}$ but are not in routine use as safeguard devices. It is possible that the linear accelerator part of a facility might be a so-called "nonaccess area" in the same way that the laser area of a laser isotope-enrichment plant would probably be a nonaccess area. This should not be a serious problem if the aforementioned design verifications could be carried out.

Diversion of neutrons to breed fissile material from undeclared fertile material is conceivable in two ways. They are emplacement of fertile material, say uranium, as a solid in the structure of the accelerator-driven system and dissolution of a uranium salt in the target coolant. Calculations (Appendix V.B) for these scenarios show that the first could yield about 19 SQ of fissile material in cne year if the entire shield of the system structure were involved 
while the second could yield about $10 \mathrm{SQ}$ if the coolant were used for an entire year. This is aside from their unstudied problems relating to matters of corrosion, reprocessing requirements, and cooling requirements. In any case, safeguards to deter or detect these scenarios would be straightforward: checks by nondestructive-assay instruments for the presence of fertile and fissile material in system locations where such materials should not be, as well as design checks for undeclared piping and chemical processing apparatus. These checks would presumably occur at the times of component installation and replacement. Related to the diversion scenario of emplacing undeclared fertile material in the structure or coolant is that of altering the production of fissile material in the declared fuel bundles by such strategems as introducing or altering the amount of neutron multiplier and reflector materials or by altering the energy of the accelerator beam. Both of these strategies could be masked by the aforementioned production uncertainty. Safeguarding against the former would requires careful design checks of the facility, surveillance, and checks of the fresh fuel. Safeguarding against the latter would require tamper-proof monitoring of the accelerator beam.

The third proliferation concern is the possibility of construction of a complete clandestine accelerator breeder dedicated to the production of fissile material. This is an implausible scenario for a divertor because the construction of a clandestine fission reactor or even a uranium-enrichment facility is easier. The fertile material is a requirement in all cases.

The concept of a clandestine dedicated accelerator breeder has been discussed elsewhere, (24) but we emphasize here that accelerator breeders with a small breeding capacity could be built based on existing technology (see Appendix C). Moreover research facilities to produce neutrons at high intensity by proton bombardment of uranium targets already exist. $(18,19)$ Other facilities 
are planned, $(30,31)$ including one as part of a project specifically designed for accelerator breeding. (32)

One technical development -- collective-effect accelerators $(33,34,35)$ could significantly change the size of the linear accelerator part of accelerator-driven reactor systems. Conventional linear accelerators employ external electric and anagnetic fields to accelerate and guide the proton beams; these external fields are generated in huge structures. Collective-effect accelerators would employ the fields of other charged particles and currents to effect the beam acceleration and in theory would do so in much smaller structuris. Laser acceleration is also conceivable. (36) Thus, instead of the $\sim 10 \mathrm{Mel} / \mathrm{meter}$ acce1eration gradienc of conventional linear accelerators, collective-effect accelerators promise gradients of $\sim 100 \mathrm{MeV} /$ meter. (37) If achieved in a practical way, the concept would markedly decrease the size and cost of accelerator drivers, possibly facilitating the construction of clandestine accelerator-breeder systems. Caution dictates reexamination of such a possibility periodically. Prevention or detection of clandestine facilities is only related to the IAEA nonproliferation regime in the sense that nuclear materials diverted from safeguarded facilities might be used in the clandestine facility. Otherwise, intelligence methods and export controls $(38)$ would be the ways to detect and prevent clandestine facilities. For accelerator-driven systems, the relevant components are radio-frequency power tubes, i.e., megawatt-rated tetrodes, triodes, and klystrons, which are manufactured by very few concerns; the copper-clad steel cavities in wich the particle acceleration occurs; ion sources; high-capacity electrical power supplies and switching mechanisms; ion-beam bending magnets; the piping, pumps, and heat exchangers needed for cooling the target; 
the analytical techniques and data necessary for neutronic analysis; and the technology for fertile-fuel fabrication and spent-fuel reprocessing.

Related to this concern of a clandestine facility would be the misuse of a research facility for the clandestine production of fissile material (akin to the misuse of an ordinary research reactor). There is little reason for serious concern here. We have shown in Appendix V.C that the most powerful such existing facility, the Los Alamos Meson Physics Facility (LAMPF), could only produce one SQ ( $8 \mathrm{~kg}$ ) of plutonium in two years if it were continuously misused at its design duty factor. Misuse at a greater duty factor would yield as many as four SQ per year, but this would require significant enhancements in the power supply and cooling capability of the accelerating cavities.

As a close kin of a breeder reactor, the LAFP would present similar proliferation problems; namely it would produce large quantities of high-quality plutonium or uranium-233 requiring reprocessing. Location of the LAFP with a fuel fabrication facility in a secure fuel center would eliminate some proliferation problems. $(10,13)$ A more extreme proposal would be to require some burnup of the LAFP fuel in an ordinary reactor first, thereby degrading the weapons quality of the LAFP product. (13) 


\section{Appendix V.A}

Calculation of Some Fuel Characteristics of the LAFP Core

Given the LAFP production rate of $3300 \mathrm{~kg}$ of plutonium per year and a pressure-tube target configuration, how much plutonium exists in a target unit? We must assume a structure for the target unit because of the paucity of published detail. We take it to be the fuel bundle of the heavy-water CANDU (Canadian deuterium-uranium) 600 megawatt (electric) reactor.(21)

A CANDU reactor core contains $95,000 \mathrm{~kg}$ of uranium dioxide in 4560 bundles or about $18.3 \mathrm{~kg} U$ per bundle. If the LAFP irradiation causes a fissile material increase of $1.0 \%$ (see Figure $\mathrm{V}-8$ ), then each bundle at discharge would contain $0.18 \mathrm{~kg}$ of plutonium. To divert one $S Q$ of plutonium would mean diverting 45 bundles. This must be compared to the roughly 18,000 that would be discharged from the LAFP annually and probably continuously (i.e., on-line refueling would occur).

\section{Appendix V.B}

Calculation of Possible Clandestine Plutonium Production from Neutron

\section{Diversion in Accelerator-Driven Reactor Systems}

Two neutron-diversion scenarios are conceivable based upon the design in this chapter for accelerator-driven reactor systems. The general method is to secretly place fertile material, say uranium-238, someplace in the reactor system where it would undergo sufficient neutron irradiation to breed fissile material, say plutonium-239. The two scenarios are emplacement of solid uranium in the structure of the system; and dissolution of a uranium salt in the target coolant, if it bo water.

Analogous scenarios have been studied in the appendices to Chapter IV in connection wich neutron diversion at fusion reactors. We shall therefore merely 
sketch the calculations here. We emphasize again that these scenarios are bizarre and unlikely because they have not been tested and involve, among others, problems of heat removal, corrosion, and reprocessing.

The basic datum we shall use is that one fusion (14.1 MeV) neutron could give rise to 0.96 uranium-to-plutonium conversions in a we11-designed hybrid fusion-fission reactor blanket consisting of 0.15 effective meters thick of uranium as uranium carbide(28) (see Table IV-9 in Appendix IV.E). We sha11 assume that this conversion rate scales 1 inearly as the neutron energy, about $6 \mathrm{MeV}(8)$ for $1500 \mathrm{MeV}$ accelerator-driven systems (for the secondary neutron spectrum from protons incident on liquiá lead-bismuth; we shall assume that the leakageneutron spectrum from $2000 \mathrm{MeV}$ protons incident directly on uranium peaks at 8 $\mathrm{MeV}$ ). In addition, there are the more obvious linear dependences on neutron flux, blanket effective thickness, exposed blanket area, and plant avaiiability. Consider first solid emplacement. The possible location would be the thick shield surrounding the target (see Fig. V-6), whose shape we take to be five sides of a five-meter cube and into wh.ch we assume a leakage neutron flux of 10 per cent of the production rate (see Table $\mathrm{v}-3$ ) in the uranium target. Our results follow analogously from the formulae in Appendix IV.B. Emplacement in the shield would yield $1.2 \mathrm{~kg}$ per square meter per year or $150 \mathrm{~kg}$ per year if a layer in the entire shield were involved.

Consider next dissolution of a uranium salt in the target coolant. Our calculation follows that in Appendix IV.C, particularly with regard to the uranium concentration of 250 grams per liter. (29) We shall further assume that the amount of coolant exposed to the neutron flux scales linearly as the thermal power extracted by the coolant loop. The result is that the plutonium production rate would be $80 \mathrm{~kg}$ per year. 
Appendix V.C

Calculation of the Plutonium Production Cafability of Existing and Proposed Linear Acce lerators

We wish to calculate the potential plutonium production from the linear accelerators listed in Table $\mathrm{V}-1$. While the neutron yield as a function of incident proton energy is linear for relatively high energies, the yield falls steeply at lower energies. Figure $\mathrm{V}-1(\mathrm{~b})$ depicts the yield over low as well as high energies.

We can estimate possible plutonium production by a linear scaling of the production for the LAFP as described in Table V-3. The annual production $N$ would be proportional to the average beam current I; the neutron-per-proton yield $Y(E)$, a function of beam energy $E$; the plant availability $P$; and the incident particle type $i$, with incident deuterons yielding about $20 \%$ more neutrons than do incident protons. The relation is

$$
\frac{\mathrm{N}}{3300 \mathrm{~kg}}=\frac{\mathrm{I}}{0.3 \mathrm{amp}} \cdot \frac{\mathrm{p}}{0.75} \cdot \frac{\mathrm{i}}{1} \cdot \frac{\mathrm{Y}}{188 \mathrm{n} / \mathrm{p}}
$$

Thus,

$$
\mathbf{N}=78 \cdot(\mathrm{I} / \mathrm{amp}) \cdot \mathrm{p} \cdot \mathrm{Y} \cdot \mathbf{i} \mathbf{k g}
$$

Table V-5 gives the results of this calculation for the design plant duty factor, which we take as the availability, and for a duty factor of $100 \%$. Only in the case of systems designed for production, the LAFP and MTA, would the plutonium amounts be large. Of the experimental facilities, the LAMPF accelerator could produce one SQ in two years at its design duty factor. For an unrealistic duty factor of unity, several SQ could be produced at the experimental facilities. 
Table V-5

Conceivable Plutonium Production from Existing or Proposed Accelerators

\begin{tabular}{|c|c|c|c|c|c|c|}
\hline Accelerator & $\begin{array}{l}\text { Ion } \\
\text { Type }\end{array}$ & $\begin{array}{c}\text { Energy, } \\
\mathrm{MeV}\end{array}$ & $\begin{array}{l}\text { Neutron } \\
\text { Yield }\end{array}$ & $\begin{array}{l}\text { Current, } \\
\text { Amperes }\end{array}$ & $\begin{array}{l}\text { Duty } \\
\text { Factor }\end{array}$ & $\begin{array}{l}\text { Annual Pu } \\
\text { Production, kg }\end{array}$ \\
\hline $\mathrm{LAFP}^{\dagger}$ & Proton & 2000 & 188 & 0.3 & 0.75 & 3300 \\
\hline LANL-IAMPF & Proton & 800 & 35 & 0.014 & 0.11 & 4.2 \\
\hline LANL-LAMPF & Proton & 800 & 35 & 0.014 & $1.0 *$ & 38 . \\
\hline LLNL-MTA $^{\dagger}$ & Deut. & 500 & 19 & 0.32 & 1.0 & 569 \\
\hline BNL-AGS & Proton & 200 & 2.7 & 0.1 & 0.001 & 0.02 \\
\hline BNL-AGS & Proton & 200 & 2.7 & 0.1 & $1.0 *$ & 21 \\
\hline FNAL & Proton & 200 & 2.7 & 0.3 & 0.0006 & 0.04 \\
\hline FNAL & Proton & 200 & 2.7 & 0.3 & $1.0 *$ & 63. \\
\hline HEDL-FMIT $^{\dagger}$ & Deut. & 35 & $s 0.1$ & 0.1 & 1.0 & 0.94 \\
\hline $\begin{array}{l}\text { * Unrealisti } \\
+ \text { Proposed }\end{array}$ & factor & for calcul & tion only & & & \\
\hline
\end{tabular}




\section{References - Chapter V}

1. C.M. Van Atta, I.D. Lee, and W. Heckrotte, "Electronuclear Conversion of Fertile to Fissile Material", UCRL 52144, Lawrence Livermore Laboratory, Livermore, California, 1976.

2. C.M. Van Atta, "A Brief History of the MTA Project", Proceedings of an Information Meeting on Accelerator Breeding, CONF-770107, Brookhaven National Laboratory, Upton, New York, 1977.

3. W.B. Lewis, untitled, 1944, as cited in R.F. Taschek and W.G. Davey, "Accelerator Breeder Concepts and Applications", Proceedings of an Information Meeting on Accelerator Breeding, CONF-770107, Brookhaven National Laboratory, Upton, N.Y., 1977.

4. P.R. Tunnicliffe, "High Current Proton Linear Accelerators and Nuclear Power," Proceedings of an Information Meeting on Accelerator Breeding, CONF-770107, Brookhaven National Laboratory, Upton, N.Y., 1977; and J.B. Fraser, C.R. Hoffmann, S.0. Schriber, P.M. Garvey, and B.M. Townes, "A Review of Prospects for an Accelerator Breeder," AECL-7260, Chalk River Nuclear Laboratories, Chalk River, Ontario, Canada, 1981.

5. A.A. Harms and C.W. Gordon, "A Parametric Analysis of the Spallation Breeder", Nuc. Sci. Eng., 63, 336, 1977; see also a unified exposition of fusion, fission, and accelerator breeders in A.A. Harms and M. Heindler, "Nuclear Energy Synergetics, Plenum, New York, 1982.

6. R.G. Vasil'kov, V.I. Gol'danskii and V.V. Orlov, "Electrical Breeding," Sov. Phys. Usp., 26 (3), 228, 1983.

7. J.R. Powe11, M. Steinberg, H. Takahashi, H.J.C. Kouts, and P. Grand, "Linear Accelerator Reactors," BNL 50766, Brookhaven National Laboratory, Upton, New York, 1978.

8. R. Scott, "The Utility Point of View," Proceedings of an Information Meeting on Accelerator Breeding, CONF-770107, Brookhaven National Laboratory, Upton, N.Y., 1977.

9. M. Steinberg, J.R. Powel1, H. Takahashi, P. Grand, and H.J.C. Routs, "The Linear Accelerator Fuel Enricher (LAFER) and Fission Product Transmutor (APEX)," BNL-26951, Brookhaven National Laboratory, Upton, N.Y., 1980.

10. P. Grand, H.J. Routs, J.R. Powe11, M. Steinberg, and H. Takahashi, "Conceptual Design and Ecconomíc Ánalysís of a Light Water Reactor Fue1 Enricher/Regenerator," BNL-50838, Brookhaven National Laboratery, Upton, New York, 1979.

11. M. Steinberg, J.R. Powe11, and H. Takahashi, "APEX Nuclear Fuel Cycle for Production of LWR Fuel and Elimination of Radioactive Waste," BNL 31004 , Brookhaven National Laboratory, Upton, N.Y., 1982; see also H. Takahashi, P. Grand, J.R. Powell, M. Steinberg, and H.J.C. Kouts, "Fissile Fuel Production by Linear Accelerators," Trans. Amer. Nuc. Soc., 43, p. 138, 1982. 
12. Nonproliferation Alternative Systems Assessment Program (NASAP), Nuclear Proliferation and Civilian Nuclear Power, DOE/NE-0001, Volumes VIII and IX, U.S. Department of Energy, Washington, D.C., 1979, draft.

13. D. Outlaw, "Proliferation Resistance Assessment of Linear Acceleratnr Drir: 2 Reactors, Fuel Regenerators, and Fuel Producers," Science Applications, Inc., McLean, Virginia, SAI Working Paper No. 47, 1978.

14. A. Gsponer, B. Jasani, and S. Sahin, "Emerging Nuclear Energy Systems and Nuclear Weapon Proliferation," Atomkernenergie " Kerntechnik, 43 (3), 169, 1983.

15. M. Steinberg, "Linear Accelerator Breeder for Energy Security," Proceedings of an Information Meeting on Accelerator Breeding, CONF-770107, Brookhaven National Laboratory, Upton, N.Y., 1977.

16. R.G. Alsmiller, Jr., T.A. Gabriel, J. Barish, and F.S. Alsmiller, "Neutror: Production by Medium-Energy ( $(1.5 \mathrm{GeV})$ Protons in Thick Uranium Targets," ORNL/TM-7527, Oak Ridge National Laboratory, Oak Ridge, Tenn., 198i.

17. "Los Alamos Neutron Source Meets First Test," Science, 228, 1417, 1985.

18. G.H. Lander and D.L. Price, "Neutron Scattering and Spallation Sources," Physics Today, 38 (1), 38, January, 1985.

19. D.A. Gray, "Initial Operation of the SNS, "IEEE Trans. Nuc. Sci., NS-32 (5) , 2638, 1985 and C. Potts, F. Brumwel1, J. Norem, A. Rauchas, v. Stipp, and G. Volk, "Beam Intensity Increases at the Intense Pulsed Neutron Source Accelerator," ibid., 3107.

20. H. Haseroth, "Survey on the Performance and Development of Existing Proton Linacs," in N. Angert, ed., Proceedings of the 1984 Linear Accelerator Conference, GSI-84-11, p. 3, Gesel1schaft für Schwerionenforschung, Darmstadt, Federal Republic of Germany.

21. A.V. Nero, Jr., A Guidebook to Nuclear Reactors, University of California Press, Berkeley and Los Angeles, California, 1979.

22. IAEA Safeguards-Glossary, IAEA/SG/INF/1, Internationa1 Atomic Energy Agency, Vienna, Austria, 1980.

23. A. DeVolpi, Proliferation, Plutonium, and Policy, Pergamon Press, New York, 1979.

24. Office of Technology Assesment, Nuclear Proliferation and Safeguards Vo1. I, OTA-E-48, Congress of the United States, Washington, D.C., 1977; see also the accompanying Appendix VI in Part Two of Vol. II, OTA-E-50.

25. M. Honami and D. Jung, "General Considerations in Safeguarding CANDU Reactors By Item Accounting and Contairment/Surveillance," IAEA/STR-83, International Atomic Energy Agency, Vienna, Austria, 1979. 
26. C.C. Thomas, Jr., D.D. Cobb, and C.A. Ostenak, "Spent Fuel Composition: A Comparison of Predicted and Measured Data," IA-8764-MS, Los Alamos Scientific Laboratory, Los Alamos, New Mexico, 1981.

27. E.J. Dowdy, A.A. Robba, R.D. Hastings, and S.W. France, "A New Instrument for the Confirmation of Declared Power Histories of Central Station Nuclear Power P1ants," Nuc. Mat. Management, V. VIII, Proceedings Issue, 679, 1979.

28. Fusion Power Systems Dept., Conceptual Design of a Commercial Tokamak Hybrid Reactor, WFPS-TMS-80-012, Westinghouse Electric Corp., Pit Pennsylvania, Dec., 1980.

29. J.A. Lane, H.G. MacPherson, and F. Maslan, editors, Fluid Fuel Reactors, Addison-Wesley, Reading, Massachuset:s, 1958.

30. R.L. Kustam, T.R. Khoe, and E.A. Crosbie, "A 1500-MeV Fixed Field Alternating-Gradient Synchrontron for a Pulsed-Spallatian Neutron Source," IEEE Trans. Nuc. Sci.: NS-32 (5), 2672, 1985.

31. H. Lustfeld and J.E. MGiller, "Beam Dynamics in a High Current Proton Linac," IEEE Trans. Nuc. Sci., NS-32 (5), $2468,1985$.

32. 5.0. Schriber, "The ZEBRA Project - Past and Present," in $\mathrm{N}$. Angert, ed., Proceedings of the 1984 Linear Accelerator Conference, ESI-84-11, p.501 Gesellschaft fur Schwerionenforschung, Darmstadt, Federal Republic of Germany.

33. J.D. Lawson and M. Tigner, "The Physics of Particle Accelerators," Ann. Rev. Nuc. Part. Sci., 34, 99, 1984.

34. D. Keefe, "Collective-Effect Accelerator," Scientific American, 226 (4), 22, Apri1, 1972.

35. C.L. Olson, "Collecive-Effect Accelerator," Proceedinss of an Information Meeting on Accelerator Breeding, CONF-770107, Brookhaven National Laboratory, Upton, N.Y., 1977.

36. T. Katsouleas, J.M. Dawson, D. Sultana, and Y.T. Yan, "A Side-InjectedLaser Plasma Accelerator," IEEE Trans. Nuc. Sci., NS-32 (5), 3554, 1985; D. Larson, "A. Modified Two Beam Accelerator Driven By a D.C. Pelletron Free Electron Laser," ibid., 3548; and N. Ebrahim, P. Lavigne, and S, AithaI," Experiments on the Plasma Beat-Wave Accelerator," ibid., 3539.

37. C.L. Olson, C.A. Frost, E.L. Patterson, J.P. Anthes, and J.W. Poukey, "1FA-2 Collective Ion Acclerator Experiments" IEEE Trans. Nuc. Sci., NS-32 (5), 3530, 1985 .

38. "Commnications Received from Certain Member States Regarding Guidelines for the Export of Nuclear Material, Eruipment, or Technology," INFCIRC/254, International Atomic Energy Agency, Vienna, Austria, 1978. 


\section{NEW REACTOR TYPES}

A variety of new reactor types is proposed from time to time. Sucí proposals are usually motivated by a conceived weakness in existing types. The NASAP study (see Chapter I, Appendix), for example, generated a fair number of new concepts (or modifications of old concepts) in order to alleviate inherent proliferation-prone weaknesses in relatively established systems such as the LWR, HWR, LMFBR, etc. The results of the NASAP study did not, and probably will not, initiate any massive switch to an inherently proliferation-proof system because none was found. However, some of the more advanced types that were proposed were not as seriously considered because many additional years of research and development were needed to explore their qualities. In addition, some new types have been proposed because of possible safety-oriented or economic improvements. It is not our intention to go over the same ground as the NASAP study, but rather to further explore new concepts for some of the advanced typer. which involve radically different fuel cycles, applications, or new processing technologies (see Chapter III).

The discussion begins with a review of a fairly complete list of unconventional reactor types. "Unconventional" pertains loosely to those types that are not already in full-scale use. Most of the reactor types on the list are excluded from further consideration for one reason or another, as will be mentioned. Three types are selected for further discussion of safeguards and proliferation issues because (a) they represent some reasonable chance of becoming fully operational at some time in the future, and (b) they involve issues that are representative of potentially unusual kinds of safeguards and proliferation problems. 


\section{VI.l Types of Reactors}

A number of these were discussed in the NASAP study(1). The remainder are referenced elsewhere.

\section{VI.1.1 Water-Cooled Breeder Reactors (2)}

Those discussed in NASAP include both light water (LWBR) and heavy water (HWBR) types. These types are largely designed to take advantage of existing PWR technology and are ultimately based upon the Thorium-U-233 breeding cycle. Indeed, one of the proposals is a "back-fit" system using an existing PWR design (Combustior Engineering System 80) for a pre-breeder plant. All of the LWBR systems include some sort of pre-breeder, fueled with U-235, to produce enough fuel (U-233) for the breeder itself. The HWBR is also based on PWR technology. There are advantages and disadvantages for all of these -- both economic and safety related -- which are fully discussed in NASAP. In any case, technical safeguards issues for them are discussed elsewhere ${ }^{(3)}$ and the problems are considered to be either within current capabilities or, at worst, solvable with relatively modest development effort on short notice. Hence, water-cooled breeder reactors will not be considered in the present study.

\section{VI.1.2 Gas-Cooled Fast Breeder Reactors (GCFRs) (2)}

The gas-cooled fast-breeder reactor design developed for NASAP uses a homogeneous plutonium-uranium mixed-oxide core and thorium oxide axial and radial blankets. U-233 recovered from the blanket is denatured by the addition of depleted uranium and stored for use in other reactors. Plutonium and uranium from the core are coprocessed, mixed with makeup plutonium and uranium from "secure" storage, pre-irradiated after fabrication in assemblies, and recycled into the reactor. Recovereú thorium is stored for 10 years before reuse, and new or decayed thorium is fabricated into fresh blanket elements. 
The GCFR borrows heavily from both HTGR and LMFBR technology in that the development of the HTGR will provide the cooling and fuel-handling expertise while the LMFBR embodies a similar fuel design. There are, however, a number of additional problems unique to the BSFR. From the point of view of safeguards and proliferation, the issues are most similar to those of the LMFBR. Since the latter is well ahead (in development) of the GCFR, it is assumed that most, if not all, safeguards problems will have been handled by the time that they are needed. Hence the GCFR will not be considered in the present study.

VI.1.3 Liquid Metal Fast Breeder Reactors (LMFBRs) (2)

LMFBRs use liquid metal to transfer useful heat from the core with little neutron moderation. The resulting flux of high-energy neutrons makes the breeding process more efficient. LMFBRs create from 10 to $40 \%$ more fissile material than is consumed. Plutonium or U-233 is the fissile fuel with U-238 or Th-232 as fertile materials.

Anti-proliferat on concerns led to design studies in which variations of core loadings, fuel and fertile materials, and special proliferation-resistant features (e.g., coprocessing, denaturing, etc.) were incorporated. Most of these turn out not to be panaceas and often merely raise safeguards and proliferation issues that are different, if not worse, than those of the reference design. (3)

Unlike many of the other reactor types discussed by NASAP(1), LMFBRs have been operated as demonstrations in a number of countries and, indeed, full-scale operating plants are either planned or under construction (e.g., France's SuperPhenix). The issues have been thoroughly discussed elsewhere $(3,4)$, appear to be well understood, and solutions to the problems raised are not very different than those raised by LWR-based cycles with reprocessing. Hence, LMFBRs will not be considered in the present study. 


\section{VI.1.4 Spectral-Shift-Controlled Reactors (SSCRs)(2)}

The SSCR is based on PWR technology. The soluble-boron reactivity control system of a typical PWR would be replaced by varying heavy water concentration instead. This shifts the neutron spectrum to higher energies, thus leading to a greater degree of absorption in fertile materials. As the reactor ages, the $\mathrm{D}_{2} \mathrm{O}$ concentration is gradually reduced to compensate for fissile-material depletion and fission-product buildup. The net effect is to improve the utilization of the fuel; e.g., for a once-through cycle, the $\mathrm{U}_{3} \mathrm{O}_{8}$ requirement would be about $90 \%$ of that of a conventional PWR. The latter savings does not pay for the $\mathrm{D}_{2} \mathrm{O}$ required, however. Except for the additional requirement for heavy water safeguards (as for HWRs) the safeguards and proliferation issues for SSCRs and any associated reprocessing would be the same for a PWR. Hence SSCRs will not be discussed further in this work.

\section{VI.1.5 Accelerator-Driven Reactors}

This topic is discussed in another chapter ( $V$ ) of this study. There were two such reactors described in the $\operatorname{NASAP}^{(2,5)}$, the Linear Accelerator Fuel Regenerator and the Ternary Metal-Fueled Electronuclear Fuel Producer.

\section{VI.1.6 Fission-Fusion Hybrid Reactors}

This topic is discussed in another chapter (IV) of this study. The NASAP described a Tokamak Fission-Fusion Hybrid Reactor $(2,5)$.

\section{VI.1.7 Fast Mixed Spectrum Reactor $8(2,5)$ (FMSRs)}

The NASAP considered an FMSR that was then under study by Brookhaven National Laboratory (BNL). While based on fast breeder technology, it departs from LMFBR designs by establishing 3 different zones with in the core which are characterized by different neutron spectra. The version described in the NASAP is based on a once-through fuel cycle but with fuel remaining in the reactor for a very long time (17 years) with very high burnups. In that version there were 
a number of drawbacks including the requirement for a fuel shuffling operation every 6 months.

Later versions of FMSRs, conceived at BNL, include an improvement that would extend the shuffling to a 2-year cycle (the Centrally Moderated FMSR or (CM)FMSR) and a design with a 10-year, ultimately, 30-year, single cycle (the Extended-Cycle FMSR or (EC)FMSR). $(9,10)$

While all of these are only in the conceptual stage, many of the problems of R\&D are closely related to the sane technological base as the LMFBRs currently under study or construction. Therefore, while development is well in the future, this type is sufficiently attractive, because of inherent advantages such as resource utilization and proliferation resistance, as to be further considered in this work.

\section{VI.1.8 Gaseous-Core Reactors $(2,5)$}

The Mixed-Flow Gaseous Core Reactor (MFGCR) is one example of a gaseouscore reactor which has been studied by NASAP. In this concept, a circulating fuel gas also serves as the primary heat-transport system. A molten-salt blanket, which requires reprocessing, supplies make-up fuel (U-233) for the fuel gas -- UF 6 which contains some proportion of fissile uranium (and plutonium as the process proceeds). There are R\&D problems to be solved and it is not clear the system will ever be practical. Of all the NASAP concepts, this one is probably least likely to be pursued. The NASAP study estimates at least 50 years for development if possible at all. Hence, we exclude this type from further consideration in this study.

VI.1.9 Molten Salt Reactors $(2,5)$

Holten salt reactors are characterized by the use of a molten mixture of salts which can contain fissile material, fertile material, or both. The salts are usually fluorides of lithium, beryllium, uranium, and thorium and are 
circulated through a graphite-moderated nore and, thence, to a heat exchanger. The latter transfers heat to a secondary molten salt coolant which, in turn, is circulated through a steam generator. An additional loop may be added for continuous reprocessing (making the system a true breeder) although, in the design considered by the NASAP, this loop is not present. The NASAP concept is the Denatured Molten Salt Reactor (DMSR) which is a very-long cycle ( $\backsim 30$ years), once-through, system.

The Molten-Salt Reactor Experiment (MSRE), an 8-MW (thermal) reactor, was successfully operated more than 10 years ago and so the basic technology is known (but not fully developed).

Despite the requirement for significant further developmeni=, there are a number of attractive aspects of MSRs and a number of countries are interested in the concept. France, for example, is exploring the development of a Molten Salt Breeder Reactor (MSBR) $(6,7)$. A Japanese patent $(8)$ has been issued for an Actinide Molten-Salt-Fueled Fast Reactor (AMSFFR) which combines the concept of a molten salt reactor with that of an accelerator breeder. The advantages of MSRs are generally based upon the high level of neutronic performance achievable. In the case of the DMSR, the lifetime $\mathrm{U}_{3} \mathrm{O}_{8}$ resource requirement is estimated at only about $1 / 3$ that of an equivalent LWR. Further, most of the plutonium produced is consumed in the reactor and the remainder becomes at risk only at the end of the reactor life.

While comercialization is not likely within a 40-year horizon, demonstration plants could be built well within this period. Hence, concepts based on the MSR are considered in the present study in greater detail.

VI.1.10 High Temperature Gas-Cooled Reactors $\left(H_{T H}\right)^{(2,11)}$

HTGR are helium-cooled, graphite-moderated and reflected, and fueled with uranium with or without fertile thorium. There have been a number of different 
fuel cycles proposed ranging from those utilizing high-enriched uranium to medium-enriched with various portions of fertile material and either once-through or reprocessing systems. In addition, there are two general fuel types, prismatic and pebble-bed. Thus far, the former is preferred in the U.S. and has been demonstrated most recently at Ft. St. Vrain. The pebble-bed reactor is under developmene in the Federal Republic of Germany (FRG) with a small model operating and a somewhat larger demonstration unit under conetruction. In addition, there are two alternative power cycles under consideration: the steam cycle and the direct cycle. Also proposed is the use of HTGR for furnishing process heat for industries such as stee1-making(12) and coal gasification(11). Such applications are possible because of the high temperatures available from HTGRs of appropriate design. Other advantageous characteristics $(11,13)$ of the HTGR, including safety and efficiency, make it a viable alternative for future development. While a good deal of the technical safeguards issues have been discussed already for some HTCR systems, (3) not all of the possible variations have been covered. Therefore, some discussions of HTGR, particularly those systems involving pebble beds and process heat applications, is warranted in the present study.

VI.2. Molten Salt Reactors

The original goal of R\&D in molten salt reactors was directed toward the Molten Salt Breeder Reactor (MSBR) as a high-performance breeder. For the purposes of the present discussion, we consider here a Denatured Molten Salt Reactor (DMSR) such as that described in the NASAP(5). Most of the information that follows is derived from a more recent reference ${ }^{(14)}$, however. Physically, the MSBR and DMSR differ mainly in that the former includes a continuous reprocessing loop which serves to remove fission products and surplus bred spe- 
cial nuclear material (SNM). The SNM so produced constitutes a proliferation risk, and hence, the concept of the DMSR was developed.

VI.2.1. Physical Description of the Reactor

Figure VI-l is a simplified diagram of a once-through DMSR. The reactor is graphite-moderated and reflected, having a graphite-log lattice through the interstices of which the molten fuel salt can flow freely. In the reference design, the fuel salt has a nominal composition of

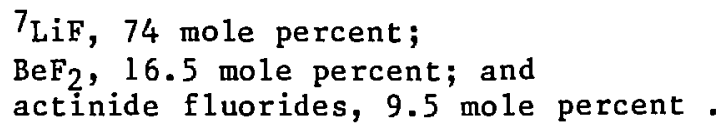

Initially, the actinide elements present would be $87 \%$ thorium and the balance medium-enriched uranium $(20 \% \mathrm{U}-235)$. The reactor is conceived to have a 30-year operating period. During that time, no (or very little) fuel is to be removed. Additions of $\sqrt{20 \%}$ enriched $U-235$ would be made as needed to maintain reactivity (mainly in the later years). However, since U-233 and fissionable plutonium are produced with a breeding ratio of nearly 1.0 , such additions would be minimized. During the early years, the $\mathrm{U}-235$ is largeiy replaced by bred U-233. Later on, however, enriched-uranium additions are required to override fission-product buildup. Plutonium content remains relatively low because of its high fission cross-section in this spectrum. Table VI-1 shows the actinide inventories at the beginning, middie, and end of $1 \mathrm{ife}$. One of the important advantages this design has over currently operating reactors is an estimated resource utilization that is better by a factor of three.

VI.2.2. Proliferative Materials

As far as proliferation-sensitive materials are concerned, there are the following considerations. At the beginning, of course, there is only the denatured uranium. This material is somewhat sensitive because, although not directly usable in weapons (only $20 \%$ enriched), further enrichment is relatively 


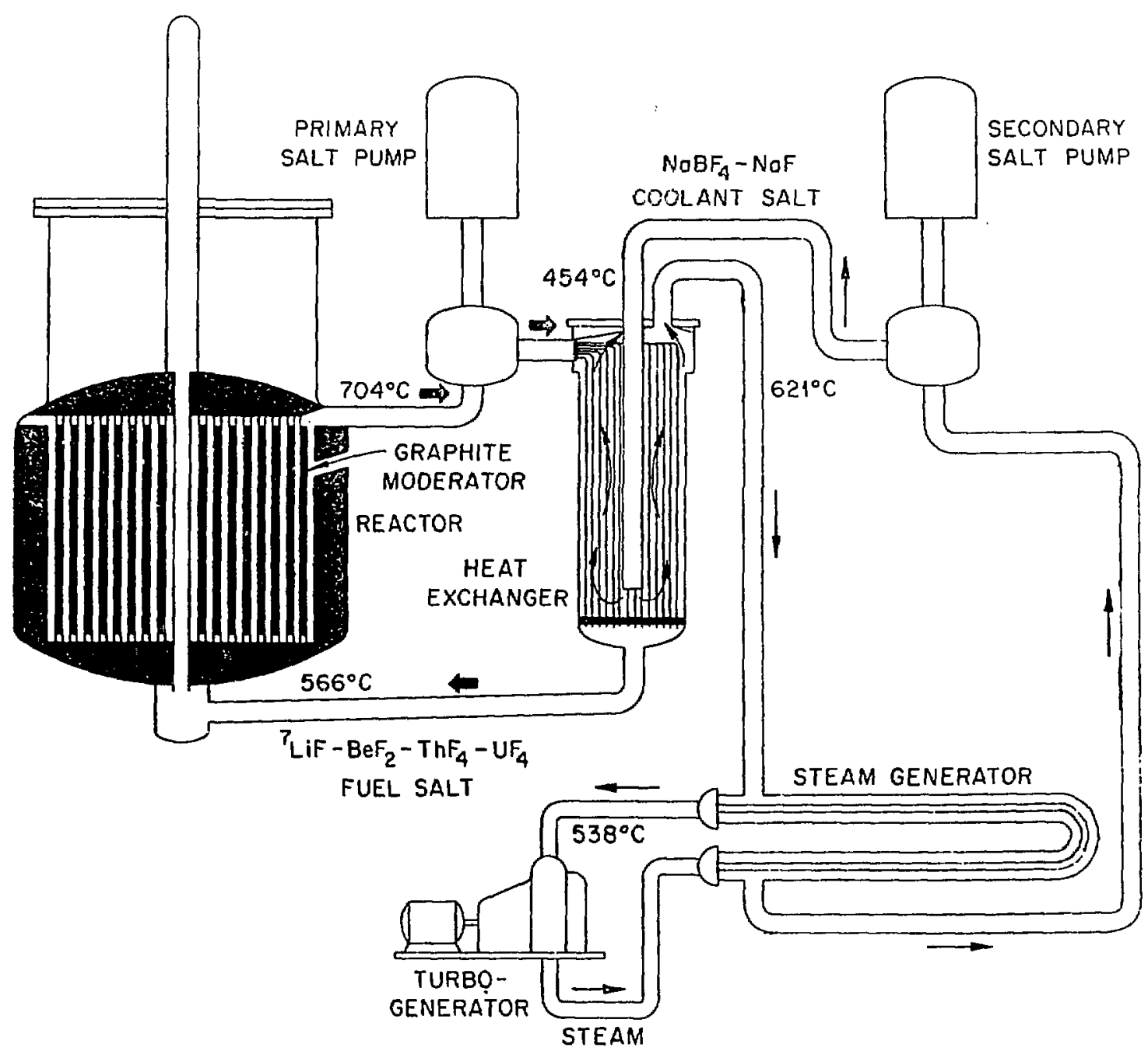

Figure VI-1. Simplified Diagram for Once-Through DMSR (Ref. 5). 
Table VI-1. Actinide inventories in DMSR fuel salt (1 GWe reference design)

\begin{tabular}{|c|c|c|c|}
\hline & \multicolumn{3}{|c|}{ Inventory $(\mathrm{kg})$} \\
\hline & $\mathrm{BOL}^{\mathrm{a}}$ & $\mathrm{MOL}^{\mathrm{b}}$ & $\mathrm{EOL}^{\mathrm{C}}$ \\
\hline $232 \mathrm{Th}$ & 110,000 & 103,000 & 92,900 \\
\hline${ }^{233} \mathrm{~Pa}$ & 0 & 45 & 38 \\
\hline $233_{U^{d}}^{d}$ & 0 & 1,970 & 1,910 \\
\hline${ }^{234} \mathrm{U}$ & 0 & 372 & 596 \\
\hline $235_{U}$ & 3,450 & 1,020 & 1,250 \\
\hline${ }^{236} \mathrm{U}$ & 0 & 661 & 978 \\
\hline $237_{\mathrm{NP}}$ & 0 & 75 & 136 \\
\hline שU & 14,000 & 19,600 & 28,600 \\
\hline${ }^{238} \mathrm{Pu}^{\mathrm{d}}$ & 0 & 36 & 93 \\
\hline${ }^{239} \mathrm{Pu}^{\mathrm{d}}$ & 0 & 179 & 231 \\
\hline $240 \mathrm{Pu}$ & 0 & 102 & 133 \\
\hline $241_{\mathrm{Pu}} \mathrm{d}$ & 0 & 76 & 100 \\
\hline${ }^{242} \mathrm{Pu}$ & 0 & 99 & 179 \\
\hline $\begin{array}{l}\text { Total actinides } \\
\text { Fissile uranium } \\
\text { Total fissile }\end{array}$ & $\begin{array}{r}127,000 \\
3,450 \\
3,450\end{array}$ & $\begin{array}{r}127,000 \\
2,990 \\
3,440\end{array}$ & $\begin{array}{r}127,000 \\
3,160 \\
3,490\end{array}$ \\
\hline
\end{tabular}

${ }^{a}$ Beginning of life

$b_{\text {Middle of life }}$

${ }^{c_{\text {End }}}$ of life

$\mathrm{d}_{\text {Nuclide }}$ reated as fissile in inventory calculation 
easy compared to starting with natural or low-enriched material. As the reactor ages, U-233 is produced which, during the middle years, reaches concentrations of approximately $8 \%$ of the total uranium. Again, this is not directly usable for weapons but potentially easier to enrich further than is LEU. Plutonium also becomes a constituent of the molten salt circulating in the system. However the total quantity is not yery large, $736 \mathrm{~kg}$ at the end of 1 ife as compared to LWRs where $300 \mathrm{~kg}$ is produced during each annual cycle. It is also not very attractive for weapons use. Only $45 \%$ of it consists of the fissile nuclides, Pu-239 and Pu-241, while a relatively high concentration of heat-producing Pu238 is present. Finally, there is a sma11, but significant amount of Pa-233, up to $45 \mathrm{~kg}$, which could be separated and allowed to decay to pure U-233. There are a number of self-protecting attributes of the fuel salt which place constraints on the potential divertor of these various materials. Further discussion of the materials and the constraints can be found below.

\section{VI.2.3. System Configuration}

As can be seen in Figure VI-1, the molten fuel salt exits the reactor at $704^{\circ} \mathrm{C}$, is pumped through a heat exchanger, and returns at $566^{\circ} \mathrm{C}$. In a secondary loop, a conlant salt is circulated through the heat exchanger where its temperature is raised from $454^{\circ} \mathrm{C}$ to $621^{\circ} \mathrm{C}$. The coolant salt, a mixture of $\mathrm{NaBF}_{4}$ and NaF, transfers energy to a steam generator. Most of the fisaion products remain with the fuel salt. However, the noble-gas fission products and tritium, produced by interaction of neutrons on the Li-7 in the salt, are removed by sparging with helium. The noble and semi-noble fission products tend to precipitate out of the salt or plate out on reactor or other surfaces (or both) in a currently unpredictable manner. While there are data available from the MSRE, there is a good deal of further work necessary to define and control fissionproduct behavior. 
The preparation and maintenance of the fuel salt composition is not a trivial matter. Careful attention is required in order to be certain that the chemical ferm of the uranium, thorium, plutonium, and other actinides is correct so thar they remain in solution. Also, the corrosive properties of the salt must be considexed. For example, the fission Fazduct tollurium must ie cortailed with raspect to chemical form or it produces excessive grain boundary embrittlement in metal surfaces. A number of fuel maintenance options have been proposed. It is not known, however, which ones will be necessary because some of the potential problems envisioned may not, in fact, actually be problems. For example, it is not known whether treatment to remove inadvertent oxide concentrations will be needed, in what chenical form uranium will be added as makeup fuel, what the quantitative oxidative effect of fission will be, or whether noble or semi-noble fission products need be removed.

\section{VI.2.4. Time Scale of Engineering and Other Developments}

The MSRE provided much valuable information on the behavior of structural metals and graphite moderating material under appropriate conditions. In particular, the use of Hastelloy-N, which-was developed and eventually further modified for use with this system, found considerable success. This preferred material, which is mostly nickel plus 11-13\% molybdenum, 6-8\% chromium, and 1$2 \%$ niobium, has yet to be produced in large heats (although difficulties are not anticipated). Also larger radiation exposure times and other long-period tests will be needed. It is also believed that currently available graphites are likely to be adequate but further testing is indicated and improvements are like1y.

All in all, $\varepsilon$ large number of engineering development problems remain to be solved. These problems range from the basic technoiogy (shutdown mechanisms, further alloy development, optimization of fuel-salt chemistry, transient behav- 
ior, etc.) through safety analysis and design and long-term testing of components (such as pumps and valves) to licensability and scale-up to commercial size. It has been predicted (1) that, before a standard commercial plant can be designed, there would have to be a demonstration plant and a lead commercial plant plus a number of specialized facilities for testing various components and other concepts. It is believed (1) that a decision to build a small DMSR demonstration plant could be made in 1990 if technology development is undertaken soon. This could lead to commercial deployment in approximately 40 years.

VI.2.5. Other Fuel Cycle Choices

There are a number of variations for the DMSR which ostulate some variations in the fuel cycle as compared with that described above. For example, the most favorable, from the economics point of view, is to attempt to obtain break-even breeding. This might be possible to achieve with full-scale fission-product removal. Reference 14 suggests using a reductive-extractive/ metal-transfer process. Down the performance scale somewhat is partial fission-product rewioval and, even further along, no chemical removal at all. In the latter case, a small quantity of fuel salt would be periodically replaced with fresh material in order to keep fission-product concentrations within tolerable limits.

The best of these alternatives, toward break-even breeding, could conceivably make a batch of fuel last hundreds of years. The fuel salt would be transferred to a new reactor each time the end of plant life was reached. of course, the closer one comes to break-even operation, the closer one comes to giving up the non-proliferation advantages of the DMSR.

VI.2.6. Proliferation Problems

The DMSR has some "built-in" non-proliferation features. Most noticeably these include: 
(a) The denaturing of all uranium, both fresh and spent fuel.

(b) The lack of reprocessing, transport, and fuel fabrication facilities in which there exists strategic special nuclear material (SSNM).

(c) The small inventory of plutonium over the reactor's total life, its relatively high dilution, and its low accessibility.

(d) The fact that large quantities of opent fuel (if any) are not removed over very long periods of time.

On the other hand, by comparison with the more familiar facilities associated with LWRs, there are problems requiring sateguards of a different nature.

Unlike currently used reactor types, the fuel is not amenable to item accountability. LWR safeguards include the counting and measurement of attributes of individual fuel assemblies. The assemblies are then sealed into a reactor vessel and cannot be removed without reopening the vessel, an obviously observable event. For a molten salt reactor, the containment could be breached by hidden pipes, installed during construction, through which a part of the fuel could be removed and replaced covertly. Thus more attention must be paid to the design and construction plans of such a reactor. Verification of the fact that no such removal/substitution has taken place requires a whole new gamut of instrumentation. Such instrumentation might include means of remotely and independently monitoring the quantity of salt in the system as well as the concentrations of SNM in the salt. It might be noted, however, that there is also one advantage in not having individual units of fuel; homogeneity precludes concentrating a particular target material, for clandestine purposes, in a retrievable manner.

For designs incorporating partial removal of fission products, there conceivably could be ways in which system alterations would remove SNM as well. For 
example, if hydrofluorination equipment, used to maintain salt composition, could be altered to fluorinate uranium or plutonium, volatile $\mathrm{UF}_{6}$ or $\mathrm{PuF}_{6}$ could be removed with the gaseous fission products, $\mathrm{Xe}$ and $\mathrm{Kr}$. Even if $\mathrm{UF}_{6}$ so removed were denatured, subsequent further enrichment of $20 \% \mathrm{U}-233$ or U-235 might be a viable prospect. Another route for separating SSNM from the system is described in reference 11. There appears to be the possibility that columns of cerium fluoride or lanthanium fluoride could be used to remove rare-earth fission products from the molten salt by ion exchange along with plutonium as well.

While these prospects may not be particularly attractive because of the dilute nature of the molten salt with respect to SNM, the possibility should be considered in the design of the system. One way is to limit the size and capacity of any accessory equipment, but verification instrumentation would also be desirable.

The ideal fuel salt composition requires the use of lithium containing a minimum amount of Li-6 to minimize tritium (T) production. An operator wishing to deliberately produce $\mathrm{T}$ could easily increase the concentration of $\mathrm{Li}-6$ in the salt. (The value of $T$ to a potential divertor is not clear, however. This aspect of the problem is discussed elsewhere in this report (See Chapter IV).) It may, therefore, be desirable to devise a tritium monitoring system, or better, a method of verifying lithium isotopic composition, perhaps by measuring neutron absorption characteristics.

There would also be economic pressures, once molten salt reactors are in use, to upgrade their performance by achieving break-even breeding or better or by using uranium makeup of higher enrichment. Such potential "improvements", though, are quite speculative at this time because of the calculational uncertainties in the behavior of a DMSR. 
Another big difference between the concept of a reactor with unitary fuel assemblies and one with one homogeneous fluid involves the procedure to be followed during an emergency shutdown. With the former, the emergency core cooling system brings a cooling fluid to the fuel. In the case of the molten salt reactor, the design calls for a dumping of the fuel out of the reactor and into a cooled receptable or receptacles. This pathway for removal of material would also require a medsurement/monitoring system. Such a system should be capable of detecting the passage of even a small amount of material such as might represent a long-term diversion at a low rate. It also should be capable of measuring total content of the receptacle in the event of an emergency dump.

VI.2.7. Perceived Safeguards Development Requirements

The application of safeguards to a molten salt reactor appears to be more like that of a reprocessing plant than a typical, present-day reactor. Thus a safeguards plan would be composed of devices and techniques analogous to that of a reprocessing plant. Design and construction would have to be closely monitored to ensure that no covert piping were installed. Valves, piping, flows, etc. would have to be monitored and volumes, densities, and concentration measured and verified. Measurement devices would have to be periodically calibrated and re-calibrated.

The problem, for developmental purposes, is that the instrumentation developed for reprocessing plants would not be compatible with that required for an MSR and its accessory system. For example, the industry standard for level, and thus volume, measurements in reprocessing plant accountability tanks is the bubbler probe. One would have to develop a substitute technique, perhaps based on ultrasonics, infrared, or conductivity, that would be more compatible with the molten salt, high-radiation environment. 
For concentration determinations, it would be ideal if on-line methods were available. However, as in present-day reprocessing plants, it is likely that samples would have to be removed periodically to verify compositions (actually for process control purposes as we11). Methods for doing so, comparable to the highly developed methods for aqueous solutions, would have to be developed. Actually, the development and operation of MSRs requires a significant amount of analytical chemistry, sampling methods, and even on-1ine analytical methods.(15) Much of this work, some of which is already well along $(15)$, would be directly applicable to the measurements required for safeguards applications. Methods that show promise include voltammetry and spectrophotometry. Much more development is required, however. Pipe monitors and flow meters might be quite similar to those used in reprocessing plants but perhaps improvements could be realized by taking advantage of the special properties of the molten salt such as electrical conductivity and high density. While much of this new instrumentation might be required for operation purposes anyway, the need for higher accuracy instrumentation which might be required for safeguards would probably require a special development program. The nature of this new instrumentation may well require fitting to the system and calibration before the reactor is operational. Hence, these devslopments should be resolved well before the design of the reactor is completed.

VI.3. HTGRs and Process Heat

\section{VI.3.1. Prismatic and Pebble-Bed Reactors}

As mentioned above, HTGR may be divided into two general types. In the U.S., all of the effort has been directed toward development of a prismatic fuel shape. In such fuel, individual particles of fuel, which consist of grains multiply coated with pyrolytic graphite or silicon carbide or both, are formed into rods which are contained in bulky, graphite blocks having the shape of hexagonal 
prisms with drilled coolant channels. These prismatic fuel elements, some 3000 in a large HTGR, ( $N$ GWe) are not amenable to mechanical fuel separation. (16) In effect, graphite moderator and fuel are combined into a unit that must be reprocessed together. Proposed reprocessing schemes involve crushing the blocks and burning of the carbon to expose the fuel grains. (17) The latter must be crushed again to crack the protective layers so that the fuel particles are finally exposed. While this procedure would add complications to the head end of a reprocessing plant, at the same time this fuel system does have desirable anti-proliferation characteristics.

With pebble-bed reactors, such as those being developed in West Germany, individual fuel elements are relatively small (6 cm diameter balls), and there would be $3 \times 10^{6}$ of them in a 1 GWe reactor. (18) Item accountability, if possible at all, is a problem at all points in the fuel cycle. Each ball in the THTR-300 (Thorium Hochtemperatur Prototyp Reaktor) contains $\Omega$ gram of $93 \%$ enriched U-235, $\Omega 10 \mathrm{~g}$ of thorium, and $192 \mathrm{~g}$ of carbon. (19) The individual fuel particles in the ball are similar to those in the prismatic block of the U.S. design. Reprocessing of the balls requires a similar crush-burn procedure as for block fuel.

For both types, the reactors built or being built thus far have contained high-enriched uranium. This is the main safeguards problem since very little plutonium is produced and it is in a very dilute form.

HTGRs have a number of positive attractions that may eventually lead to their use on a larger scale. They are inherently safer than light water reactors, there being virtually no melt-down problem and very long time intervals between malfunctions and reactor damage. $(11,13)$ The latter results from the great bulk and high temperature capabilities of the material used. In addition, they are more efficient than water-cooled reactors because of the higher temperature 
capabilities and, for the same reason, more useful as a source of process heat. $(11,12,13)$

Thus far, however, there have only been a few demonstrations. In the U.S., the first substantial HTGR was the Peach Bottom reactor, which was quite successful as a power producer at 40 MWe. This unit operated at $88 \%$ lifetime availability and excellent maintenance access. It was shut down in 1974 (and decommissioned) after 7 years of commercial operation. (18)

The larger, Fort St. Vrain demonstration plant began operating in 1976 and has recently operated at full power ( $f u l l$ power $=330 \mathrm{MWe}$ ). This overcomes a limitation imposed by the Nuclear Regulatory Commission (NRC) which depended upon resolution of local temperature fluctuations in the core. Further development led to a design fix which has now been successfully installed. $(18,20)$

In the United Kingdom, a sma11 (20 MWt) reactor called Dragon was operated from 1965 at full power for about 2000 days. The purpose was to study fuel and graphite performance. This was also prismatic-type fue1. (18)

Pebble-bed reactor experience has been limited to the AVR (Arbeitsgemeinschaft Versuchs-Regktor) in West Germany, which began operating in 1967. It is a $40 \mathrm{MWt}$ ( $15 \mathrm{MWe}$ ) test reactor with on-line refueling and had a lifetime availability of over $80 \%$ (until a water ingress incident in 1978). One feature central to a larger pebble-bed reactor and not tested in the AVR is the insertion of control rods directly into the pebble bed.(18) The THTR-300, under construction, will include this feature. Startup of the THTR-300 is projected for 1985.

In Japan, there is some research and development in progress and plans for an experimental reactor with an output of 50 MWt. The Japanese interest is directed to a large extent toward the use of nuclear heat for steel-making. Hence their design calls for an output helium temperature of $1000^{\circ} \mathrm{C}$ (12) It is 
based upon a prismatic fuel similar to the U.S. design. Reprocessing concepts using fluorination and catalytic combustion are under consideration.

\section{VI.3.2. Low Temperature Heat Applications}

The prospect of using low temperature nuclear heat has been discussed in various contexts worldwide. The suggested uses of low temperature heat include district heating, process heat, desalination ${ }^{(21)}$, pisciculture(22), and agriculture(23). Proposed sources of heat include normal power reactor waste heat ${ }^{(24)}$, a dedicated portion of power reactor heat $(24)$, small dual-purpose heat and electricity reactors $(25)$, small heat-only reactors $(26)$, and the use of spent fuel as a heat source. (27) These reactors and related equipment may be indigenously produced or imported from suppliers. Indeed, an international market for such facilities may exist in the foreseeable future.(28)

Proliferation concerns stem from the potential these systems present for nations using them to divert, either covertly or overtly, some form of weapons grade material. As a result, the major factors of concern are the reactor type and fuel composition. Concerns such as safety and physical security are not considered important to non-proliferation and are not addressed kere, nor are institutional concerns such as licensing or risk assessment.

Three types of nuclear reactors are contemplated as sources of lowtemperature heat. They are normal power reactors, small dual-purpose electricity and heat reactors, and sma!1 heat-only reactors.

Power reactors may use either normal waste heat or a dedicated portion of the nuclear steam supply system output. Heat is drawn off either between the high and low pressure sections of the generator turbine, from a separate heating turbine attached to the main turbine shaft, or from a separate, independently switchable, heating turbine. (29) Only three types of reactors have received serious attention for this application. The light water reactor (LWR), the high 
temperature gas-cooled reactor (HTR) and the CANDU reactor have been scrutinized technically and economically. $(29,30,31)$ LWRs have been safeguarded by the IAEA for many years and turbine modification would have no affect on their non-proliferation potential. HTGRs, on the other hand, have not been subject to international safeguards long enough to fully assess their non-proliferation impacts. The CANDU reactor uses heavy water and continuous refueling, both ố which are proliferation concerns because of accounting weaknesses.

These reactor types present no new safeguards issues since their use has aiready been scrutinized under international safeguards. (32) Their use in generating low temperature heat does not alter the present non-pioliferation concerns surrounding each reactor type.

Small dual-purpose reactors to supply both electricity and heat have been proposed in the literature and used in Sweden and Northern Siberia. The Swedish $80 \mathrm{MW}(\mathrm{t})$ Agesta reactor supplied $12 \mathrm{MW}(\mathrm{e})$ of electricity and $55 \mathrm{MW}(\mathrm{t})$ to heat a suburb of Stockholm for ten years before it was decommissioned in 1974 for economic reasons. The Soviet-built Bilibino and Bieloyarsk dual-purpose reactors have supplied heat and electricity since 1973.(33) The General Atomic Company has proposed a $840 \mathrm{MW}(t)$ HTGR for use as an industrial steam briler cogenerating $46 \mathrm{MW}(\mathrm{e}) .(34)$

Future production of dual-purpose reactors will probably involve LWR and HTGR technologies. There may be a need to examine the impact of small, rurally distributed reactors on international safeguards.

Small heat-on1y, low temperature reactors have been proposed by both the French and Swedes. The French THERMOS reactor is a 100-i50 MW(th) pool-type reactor using reactivity control rods. It uses low-enriched uranium ( $\curvearrowright 3.5 \% \mathrm{U}-$ 235). Spent fuel is stored inside the reactor containment, which cannot be opened while the reactor operates. ${ }^{(35)}$ The SECURE reactor, designed by Sweden 
in cooperation with Finland, is a pool-type reactor rated at $200 \mathrm{MW}(t)$. It uses a lower enrichment than the THERMOS reactor $(\sqrt{2.6 \%})$ and does not utilize control rods. It instead empry s ciemical moderation to control radioactivity. Spent fuel from rite SECURE reactor is also stored in the reactor containment. (36) Both are refueled every one to two years.

Neither the SECURE or THERMOS reactor seem to present novel safeguards problems except that they may be deployed in different contexts than normal power reactors.

The use of spent fuel as a heat source has been proposed.(37) This concept, known as a nuclear waste boiler (NWB), can be used to supply either steam or hot water. It utilizes multiple spent fuel storage chambers with separate "cooling" circuits called heat-supply-removal (HSR) systems. The HSR is a closed-loop water supply with a heat exchanger. The NWB, as proposed, would house over 300 fuel elements in four separate chambers with spent fuel moved into a chamber just subsequent to irradiation and out when the residual heat has decreased sufficiently. Each chamber is to hold its spent fuel load for three years, so that every year one chamber is "refueled".

The NWB concept does present proliferation problems similar to an awayfrom-reactor spent fuel storage facility. (See Chapter VIII.) Diversion paths include all those associated with the movement and storage of spent fuel.

VI.3.3. High Temperature Heat Applications

Some energy-using industrial processes require large energy inputs at fairly high temperatures. Many of these which have been relying on gas or oil are encountering shortages and escalating costs. Because of the high temperatures required, only HTGRs are viable nuclear alternatives. These applications include petrochemical manufacturing(38), petroleum refining $(38)$, hydrogen production( 39$)$, methane reforming $(40)$, steel making $(12)$, and coal gasification 
and liquefication(41). Some of these applications require large HTGRs, but some require relatively small units (a few hundred megawatts, thermal).

The versatility of the HTGR, whether the prismatic or pebble-bed type, is such that applications such as those listed above would have little or no effect on reactor design, except, perhaps, for changes required to reach very high temperatures. Therefore the end use would have little effect on safeguards and non-proliferation problems. Just as in the case of low temperature process heat applications, the only additional safeguards concerns would be an increase in the numbers of small reactors in use at a large variety of locations.

\section{VI.3.4. Proliferation Concerns}

Since, as it has already been noted, the particular application of a reactor does not really affect the safeguards issues, there remain two questions to consider. The first involves the potential for a large growth in the numbers of relatively small reactors which would require international safeguards. The reactor types involved may not be unusual in the sense that pany of these same types are already under safeguards or under study for safeguards application.' However, it is conceivable that large numbers of small reactors migh overwhelm ! the manpower available to inspect and verify all reactors with sufficient rigor to ensure an effective safeguards system. It may therefore become necessary to improve, modify, and, perhaps, automate the inspection system to enable the more efficient use of the inspectorate under such conditions. Perhaps an "automatic verification system" can be designed into such small reactors, although at this time it is difficult to envision what that would be like. $(42,43)$ It would seem that the entire subject of seals, tamper-proofing, and tamper-resistance could be further upgraded so as to include future state-of-the-art technology. This would have to be done periodically so that svstems do not become obsolete as the 
potential divertor finds increasingly advanced and sophisticated tools at his conmand.

The second safeguards question involves the use of HTGRs as a type of reactor for which there has not been much safeguards experience. The HTGRs thus far demonstrated or under construction have all been fueled with highly enriched uranium (HEU). These, of course, do not produce plutonium of any proliferation concern. However, the presence of HEU in all parts of the fuel cycle is an important consideration for non-proliferation. Largely because of this, there have been several proliferation-resistant alternatives proposed in which mediumenriched uranium (MEU; $\sqrt{20 \%} \mathrm{U}-235$ or less) is used instead. In that case sma11 amounts of $\mathrm{Pu}$ are produced and the MEU is something of a target because little additional separative work is required to produce weapons-useable material. It has been estimated that, for example, the enrichment of $30 \% \mathrm{U}-235$ to $90 \%$ requires a factor of 3.6 less separative work than does the enrichment of $3 \%$ U-235 in LWR fuel to $90 \%$ (same tails assay). All this means, of course, that strict accounting of the fuel must be maintained. For the prismatic fuel types, this is not any more difficult than it is for typical light water reactors. In fact, the situation is somewhat mitigated by the fact that the fuel and the moderator are essentially combined in a large, heavy unit. A typical assembly is a hexagonal prism $36 \mathrm{~cm}$ across the flats and $79 \mathrm{~cm}$ high and weighs $100 \mathrm{~kg}$. This typically contains $1.7 \mathrm{~kg}$ of uranium with $20 \% \mathrm{U}-235$ and $6 \mathrm{~kg}$ of thorium in fresh fue1. Spent fiel, once equilibrium conditions were reached, would contain only $2-3 \%$ U-235 and $10 \%$ U-233 (bred from $T h$ ) in the uranium and also approximately 40 $\mathrm{g}$ of plutonium (of very poor quality, high in Pu-238)(16). Thus the SNM would be highly dilute in a (mostly) carbon matrix. For the pebble-bed reactor, similar dilutions would be encountered. For example, THTR-300 fuel balls weigh $\sqrt{200}$ grams and contain (fresh fuel) approximately $1 \mathrm{~g}$ of uranium. A disadvantage for 
proliferation resistance is the fact that there are an enormous number of balls in the reactor. Individual balls are not identifiable. Nevertheless, a method has been devised to safeguard the THTR-300(19) which includes special measuring equipment and relies a great deal on containment and surveillance.

The reprocessing of HTGR fuel involves some unfamiliar methods, as mentioned ab re. The head-end crush-burn treatment required complicates accountability as compared to the relatively simple shearing procedure for LWR fuel. As already noted, this need for such a complicated system also works against the divertor and, thus, might be an an advantage on the whole. The bal-ance of the reprocessing system (after fuel is in solution) need be no different from conventional reprocessing plants. There exists the possibility, as suggested by the Japanese(12), that following the exposure of the fuel by cr"sh-burn procedures, separation based on a fluoride volatility process might be used (see Chapter III). In any case, it is likely that new measuring or monitoring systems might need to be developed for accounting and surveillance of the head-end treatment at least. The problems may include one or more of the following: NDA of the large, unprocessed elements, hold-up determinations for the crushing and burning equipment, measurements of hold-up associated with leached SiC particles, etc. There seems to be little if any work being done on the problems; most of the effort relative to the head end at this time appears to involve the process itself. VI.4. Fast Mixed Spectrum Reactors (FMSRs) $(9,10)$

As noted above, there are two general versions of FMSRs that are in conceptual stages, the Centrally Moderated FMSR ((CM)FMSR) and the Extended-Cycle FMSR ((EC)FMSR). Within these classifications a number of different arrangements, fuel loadings, etc. have been considered. 
These reactors are designed to use metal fuel like that of the Experimental Breeder Reactor-II (EBR-II) with either liquid sodium or helium cooling. Beryllium oxide is used as a moderator and is arranged to provide three zones, within the core, each having a different neutron spectrum.

\section{VI.4.1. (CM)FMSR}

In the most recently described version of the (CM)FMSR, an innermost zone has the lowest-energy neutron spectrum and includes moderator subassemblies. The effect is to enhance safety and prevent large changes in power. The outermost zone contains fuel with relatively low quantities of fissile isotopes and has a low power density. Here, fissile material is bred. The fast zone (physical1y located between the other two), has no moderator, a very "hard" spectrum, and provides most of the power. The designs considered included proliferation resistance as an important goal. Initial fueling could be limited to U-235 at an enrichment of approximately $10 \%$ in that case. A mora vulnerable alternative is to use $\checkmark 7 \%$ plutonium (in natural uranium) that had been produced in LVks. In either case, plutonium is bred in the reactor as time passes but is also mcstly burned up. Limitations in the metallurgical characteristics of the fuel and cladding determines the peak burnup allowed. It was found that, with proper design, the reactor could be operated for 10 to 15 years without fuel shuffling and in a single batch. Then, either the core would have to be replaced, or it could be increased in size to operate for the 30-year lifetime of the reactor. With fuel shuffling* allowed, natural uranium would be introduced to the low-power-density regions to build up plutonium and then moved to the high-power-density region, shere plutonium is burned, after which it would be discharged. Any of these mocies of operation would give far better design of such a system is still highly tentative. 
resource utilization than LWRs, but the cycle mentioned last would be best. The net uranium resource requirement in that case would be 1838 tons over the 30year life of the reactor as compared to 6000 tons for an LWR of similar size. If shuffling takes place, safeguards to be applied should not be very different from the kind of item accountability and surveillance that takes place during ordinary LWR refueling operations. The main danger is that the shuffling operation might be a period of confusion during which some high Pu-bearing fuel could be diverted out of the reactor instead of being moved from a Pu-producing area to a Pu-burning one. Fortunately, such shuffling procedures would take place relatively infrequently so that more intensive surveillance could be maintained during this time. It may be worthwhile to develop special methods and equipment for precise measurement of plutonium in the fuel being shuffled or removed. Long-term reactor sealing arrangements should also be studied for possible improvements in tamper-proofing characteristics in order to relieve inspectorate resource requirements by taking advantage of the long cycle time expected (640 full power days).

VI.4.2. (EC)FMSR

A major objective of the current design studies of the extended cycle FMSR is to obtain a very long, stable fuel cycle. It is believed that ultimately the cycle could be as long as the life of the reactor, 30 years. The current (theoretical) design involves a 10-year cycle. Since the design is still under study, there is no point in describing details here. Fuel type and arrangement is similar to that for the (CM)FMSR described above but with a different arrangement of the various neutronic zones. The design is such that it could be fitted as a replacement core in a typical $1000 \mathrm{MW}(\mathrm{e})$ LMFBR.

With such a long fuel cycle, many safeguards problems would be relieved, provided the reactor could be reliably sealed for a long time. The initial 
fueling, one or two refuelings, and one, two, or three unloadings during the 30-year period would require very close inspec-ion. In particular, very high quality Pu-239 would be produced in the breeding blankets of this design and, a1though most of the bred material would be burned, at the end of the proposed 10-year cycle, $1200 \mathrm{~kg}$ of such material would be present.

VI.4.3. Anti-Proliferation Development Requirements

For both of the FMSRs, there are some inherent anti-proliferation features. Especially for the extended cycle version, the amount of fuel handing would be reduced to some very intense activity for widely separated, brief periods. During these periods, very strict accounting, containment, and surveillance methods would be required. Perhaps the related activities, such as fuel preparation, reprocessing, storage, etc., could be accomplished at centers under international control. It is clear, however, that the actual operation of such a reactor is many decades away. Hence it is likely, given current progress in safeguards development, that the necessary techniques, institutional arrangements, and equipment ould be available in time. 
1. Nucl :ar Proliferation and Civilian Nuclear Power, Report of the NASAP, US $\mathrm{DOE}, \mathrm{NE}-0001,12 / 79$.

2 Ref. 1, Vol. IX, Reactor and Fuel Cycle Descriptions.

3. E.V. Weinstock and B. Keisch, "Technical Safeguards Issues for Alternative Fuel Cycles", NUREG/CR-1048, January 1980.

4. International Fuel Cycle Evaluation Working Group 5, "Fast Breeders," International Atomic Energy Agency, Vienna, Austria, 1980.

5. Ref. 1, Vol. VIII, Advanced Concepts.

6. Bienvenu, P. Faugeras, M. Hery, M. Israel, Lheureux, "Molten Salt Reactors", Revu General Nucleaire, 3, 290 (1979).

7. M. Hery, M. Israe1, P. Faugeras, A. Lecocq, "Status of Research in France in the Field of Molten Salt Nuclear Reactors", CEA-CONF-3980 (Brusse1s, May 1977).

8. Furukawa, K. and Kuroi, H., "Actinide Molten Salt Fueled Fast Reactor", Jap. Pat. No. 54-120399 (1979).

9. G.J. Fisher, A. Galperin, S. Shenoy, B. Atefi, "The Fast-Mixed Spectrum Reactor, Prog. Rprt. for 1980", October 1980.

10. G.J. Fisher, H.J.C. Kouts, R.J. Cerbone, B. Atefi, and C...Durstan, "LMFBR Design for Safety and Proliferation Resistance, with Excellent Performance," (to be published).

11. US/FRG Joint Pebble Bed Reactor Evaluation Report No. GA-A14611, October, 1977.

12. K. Shimokawa, "Present Status of Research and Development of Nuclear Steelmaking in Japan", Trans. of the Iron and Steel Institute of Japan, 19, 291300, (1979), and S. Nomura, et a1., "Present Status of Fuel Resterches for VHTR in Japan", IAEA-CN-36/168, May 1977.

13. H. Agnew, "Gas Cooled Nuclear Power Reactors", Scient. Amer., 244 (6), 5563 , June 1981 .

14. J.R. Enge1, H.F. Bauman, J.F. Dearing, W.R. Grimes, E.H. McCoy, and W.A. Rhoades, "Conceptual Design Characteristics of a Denatured Molten-Salt Reactor with Once-Through Fueling", ORNL/TM-/207, July 1980.

15. J.R. Enge1, H.F. Bauman, J.F. Dearing, W.R. Grimes, H.E. McCoy, Jr. , "Development Status and Potential Program for Development of Proliferation-Resistant Molten-Salt Reactors", ORNL/TM-6415, March 1979.

16. PSEID Thume IV, High-Temperature Gas-Cooled Reactor, DOE/NE-0003/4, Dept. of Energy, Washington, D.C., January 1980. 
17. E.J. Cook and J.M. McNair, "Solids Transport System for HTGR Fuel Reprocessing: Interim Development Report," GA-A14958, General Atomic Co., Oct., 1980.

18. Pebble Bed Reactor, Fiscal Year 1980, Review Summary Report GA-A15956, General Atomic Co., July 1980.

19. H. Büker and H. Engelhardt, "The Nuclear Materials Control System in the THTR-300 High-Temperature Pebble-Bed Reactor", IAEA-SM-231/41, H. Engelhardt, "Development of a Safeguards System for the THTR Pebble Bed Reactor," IAEA-R-1877-F, August 1978.

20. Energy Daily, $\underline{9}$ (222), Nov. 19, 1981 .

21. Risto Tarjanne, "Prospects for Using Low Temperature Nuclear Heat", 22 Nuc1. Eng. Int. 261 (1977), $\overline{\mathrm{P}}$. 5 .

22. P. Balligand, P. Le Gouellec, M. Dumont, and A. Grauby, "Experience Gained in France on Heat Recovery from Nuclear Plants, for Agriculture and Pisciculture", 38 Nucl. Tech. 1, 1978, p. 90.

23. D. Dewalle and A. Chapura, "Soil Warming for Utilization and Dissipation of Waste Heat in Pennsylvania", 38 Nucl. Tech. 1, 1978, p. 83.

24. M. Timm, "The Economics of Nuclear District Heating from a Utilities Point of View", 38 Nuc1. Tech. 1, 1978, p. 281.

25. T. Beresovski, I. Spiewak, and I. Oliker, "Urban District Heating Using Nuclear Heat -- A Survey", 17 Atomic Energy Rev. 4, 1979, p. 917.

26. L. Nilsson and M. Hannus, "Secure Nuclear District Heating", 38 Nuc1. Tech. 2, 1978, P. 225; M. Labrousse, B. Lerouge, G. Dupoy, and J.P. Schwartz, "Thermos Reactors", 38 Nucl. Tech. 2, 1978, p. 242.

27. W. Witzig and M. Foster, "Nuclear Waste as a Heat Source", 38 Nucl. Tech. 2, 1978, p. 258 .

28. P. Margen, "Summary-Low Temperature Nuclear Heat," 38 Nuc1. Tech. 2, 1978 , Pp. 321-325.

29. H. Muhlhauser, "Steam Turbines for District Heating in Nuclear Power Plants," 38 Nuc1. Tech. 1, 1978, PP. 113-119.

30. D. Vreeland, "Use of Power Plant Waste Heat in District Heating," 33 Trans. Am. Nuc1. Soc., 1979, p. 9-10.

31. CANDU reactors have received some attention, but have not received serious consideration. See, for example, J. Rogeus, et al., "CANDU Reactor Operation for Electricity Production and District Heating," 38 Nucl. Tech. 1 , 1978, p. 165; "District Heating in Canada", 73 Mod. Power Eng. 11, Nov. 1979 , PP. 35-46. 
32. The Annual Report for 1980, International Atomic Energy Agency, Austria, Juiy 1981, table 148 .

33. Beresovski, Ref. 25, p. 917.

34. A. McMain and F. Blok, "An Energy Alternative for Industry -- the High Temperature Gas Cooled Steamer," 38 Nucl. Tech. 2, 1978, p. 271.

35. M. Labrossie, Ref. 26, pp. 242-246.

36. L. Nilsson, Ref. 26, pp. 225-230.

37. Witzig, Ref. 27 8; J. Renzetti, "Process Steam Generation by Reactor Wastes," (Thesis) Nuclear Engineering Department, Pennsylvania State University, March 1973; D. Urbani, "Nuclear Waste Utilization," (Thesis) Nuclear Engineering Department, Pennsylvania State University, March 1974.

38. "An Assessment of Industrial Energy Options Based on Coal and Nuclear Systems," ORNL-4995, Oak Ridge National Laboratory, Ju1y 1975.

39. R. Fort, "French Research on the Production of Hydrogen using Nuclear Energy," Gas Today, February 1976, p. 77.

40. "Eva trifft Adam", Energie, 31, (6) 178, June 1979.

41. V.G. Hirschfelder, "Stand der Entwicklung des Hochtemperaturreaktors," VGB Kraftsverkstecknik 60 (6), June 1980 .

42. E.V. Weinstock and J.B. Sanborn, "An Evaluation of a Remote Continual Verification System, RECOVER, for Internation Safeguards," ISP0-198, Brookhaven Nationa1 Laboratory, 1983.

43. B. Keisch, "Safeguards Application of Remote Monitoring, Phase A - Light Water Reactors," ISPO-228, Brookhaven National Laboratory, 1984. 
VII. HEAVY WATER AND DEUTERIUM PRODUCTION

VII.1. Introduction

A heavy-water-(HW) moderated reactor can be designed to operate on uranium fuel of natural enrichment $(0.711 \% \mathrm{U}-235)$. Since plutonium is produced in its fuel, such a HW-moderated reactor provides a route to acquisition of weaponsusable nuclear material which does not require enriched uranium either for the weapon itself or for reactor fuel. Natural uranium is indigenous to many parts of the world whereas supplies of enriched uranium are carefully controlled internationally and domestically. Thus a HW-moderated reactor may offer a simpler means to acquire weapons-usable nuclear material than those requiring enriched uranium, provided that a sufficient amount of HW can 'se obtained.

The only application which requires ton quantities of deuterium-enriched materials is the use of $\mathrm{HW}$ as the moderator or coolant in a nuclear-fission reactor. (Use of deuterium in fusion reactors is discussed in Chapter IV although deuterium requirements for fusion will not be significant until well into the next century at the earliest.)

The reasons for application of safeguards to HW are to prevent, deter, or detect its diversion from declared applications to use in a program for production of materials for nuclear explosives and to ensure that all nuclear materials used with or produced as the result of use of HW are covered by appropriate safeguards agreements. The direct use of deuterium in fission and thermonuclear explosives is not relevant to safeguards for HW since the quantities required are much smaller and since there are other materials essential for nuclear explosives whose availability is much more easily controlled in the quantities required. 


\section{VII.1.1. Domestic Safeguards}

Heavy-water-moderated reactors are not deployed commercially in the lnited States, and there are no other large-scale commercial uses of HW. Therefore HW is not licensed by the NRC.

There are several large HW-moderated reactors at DOE's Savannah River Plant which are used for production of special materials for military programs. There are also a number of HW-moderated research reactors in the U.S. The last operating HW production plant in the U.S. has been "mothballed," although the water-distillation portion of that plant remains operational for upgrading HW. The toxic, flammable, and explosive inventory of hundreds of tons of hydrogen sulfide used in the production plant has been disposed of.

Heavy water under government control is subject to DOE regulations for physical security and for accountability. Heavy water which has been irradiated in a nuclear reactor contains tritium and is therefore subject to government regulations for health and safety in use, transportation, and handing. For the foreseeable future the high cost (presently about $\$ 230 / \mathrm{kg}$ ) of HW will determine the stringency of DOE safeguards regulations rather than the risks of use of HW by subnational groups for production of nuclear explosives or for dispersal.

Since the heavy-water-based nuclear-fission fuel cycle is not commercially deployed in the U.S., the NRC has not issued regulations for HW. In addition to the once-through natural uranium fuel cycle, which is typified by the CANDU reactor but is not deployed in the U.S., several advanced fuel cycles requiring heavy water have been considered. These include use of slightly enriched uranium in a once-through fuel cycle in CANDJ reactors to improve uranium utilization(1) and the so-called spectral-shift-controlled reactor(2). Any new large-scale commercial uses of deuterium-enriched material would, of course, mean that the NRC would have to issue appropriate regulations for its control. 
A 1000 MWe fusion reactor will consume about $0.3 \mathrm{~kg}$ of deuterium per day; however fusion reactors are not expected to be deployed until well into the next century (Chapter IV).

\section{VII.1.2. International Safeguards}

The objective of applying international safeguards directly to heavy water is to bring under safeguards all nuclear material which is produced as a result of its use and which would not otherwise be subject to appropriate safeguards agreements. For example, some states which are not party to the NonProliferation Treaty (NPT) possess, or are building, HW-moderated reactors which are not covered by safeguards agreements. Natural uranium fuel for such reactors may be produced indigenously or otherwise acquired out side the scope of international safeguards. It may be possible to bring the plutoniun produced in such reactors under safeguards through agreements for supply of HW or HW production technology. In any situation where all the nuclear material in a state is not subject to safeguards, it may be necessary to apply safeguards directly to $\mathrm{HW}$ in order to verify that the HW is not diverted from the purposes authorized in the agreements for supply of the HW or the HW production technology •

HW and production technology have been designated as sensitive material and technologies by a group of nuclear-supplier nations. (3) Therefore it may be expected that supply agreements will require some form of safeguards. The IAEA has negotiated an agreement with Argentina to apply safeguarda at a HW production plant being built by a Swiss Company. (The U.S. has approved export 1icenses for certain components of that plant. (4)) However the IAEA has not developed a safeguards approach for HW production plants. 
Work at Brookhaven National Laboratory has suggested that the quantity of $\mathrm{HW}$ of safeguards significance is $10-20 \mathrm{Mg} *$ (2-4 $\mathrm{Mg}$ of contained deuterium). (5) Work by the Lummus Company $(6)$ and by BNL(7) suggests that it would be feasible for the IAEA to achieve a detection sensitivity within this range and with reasonable inspection effort even for relatively large HW production plants using the safeguards measure of material accountancy supplemented by containment and surveillance measures. Work is in progress at BNL to further define an IAEA safeguards approach for HW production plants and to analyze suggested approaches in terms of the IAEA's safeguards effectiveness as sessment methodology. All of the work mentioned above is applicable primarily to HW production plants which use water as the source of deuterium.

Safeguards measures for HW in reactors have been studied in Canada(8). Basically the proposed approach involves measurement of the amount of HW required to fill the moderator and coolant systems at the time of commissioning and monitoring the level of $\mathrm{HW}$ in expansion tanks during operation. Additions of HW as well as retovered losses would also be verified by the IAEA.

When the nuclear material in a reactor is under safeguards, the question of safeguards for the heavy water in that reactor may be of less importance. However, a situation which may deserve further analysis would arise if there are other unsafeguarded HW-moderated reactors containing unsafeguarded nuclear material in a state where at least some of the HW in the state is subject to safeguards agreements.

Application of the IAEA's standard two-level attributes-variables measurement procedure for verification of inventories of HW stored in drums has been investigated at BNL. Various methods for performing attributes measurements

$\star \mathrm{Mg}=$ Megagrams $=10^{6}$ grams 
without the need to remove samples from drums were investigated experimentally. (9)

Since the IAEA has not yet developed a safeguards approach and has no experience in safeguarding HW production plants (HWPPs), it is likely that the IAEA will require assistance in this area. For example, the IAEA may convene a working group on safeguards for HW production plants. It also seems reasonable to expect that the IAEA will encounter technical and practical problems in implementing whatever safeguards approach it adopts and that assistance with such problems would be helpful.

The remainder of this chapter is devoted to safeguards considerations involving HW which are not being addressed at present either in the U.S. or at the IAEA. Since most of the present work on safeguards for HW production plants has been concerned with plants which extract deuterium from water, discussion will be concentrated on plants which extract deuterium from various sources of hydrogen. It will be necessary to consider future growth in demand for hydrogen and potential sources of supply. Some implications for HW safeguards of a socalled "hydrogen economy" will be examined.

\section{VII.2. Extraction of Deuterium from Hydrogen Sources}

VII.2.1. Material Accountancy for Hydrogen-Fed HWPPs of Types Now in Service

Studies by the Lummus Company $(6)$ and by BNL $(7)$ suggest that an IAEA safeguards appreach based on material accountancy and supplemented by containment and surveillance measures potentially could be effective for any $\mathrm{HW}$ production plant using water as the source of deuterium. In this approach the deuterium material balance could be based on measurements of the water feed, effluent, and product streams entering and leaving the plant. In principle mate- 
rial accountaniy could also be based on measurements of internal process streams, for example, between stages where the deuterium concentration is not higher than about $0.5-1 \%$ but where the flows are much smaller than the external feed and effluent streams. However, for the water-fed ammonia-hydrogen process such internal measurements appear less attractive compared to measurements of the external streams because of the number of internal streams to be measured, the process conditions, and the phases and chemical compositions of these streams. Measurements of internal streams in the water, hydrogen sulfide exchange process would also be less attractive than measurement of the external streams. Nevertheless, a safeguards approach for plants using the ammoniahydrogen process may require measurements of the flows and deuterium concentrations in process streams in order to account for the effects of normal leakage of deuterium-containing materials from the process equipment.

HW production plants using hydrogen as the source of deuterium are always parasitic to the process which produces the hydrogen because the cost of producing the hydrogen in a stand-alone process would make the HW more expensive than HW prođuced by the weīl-known water-fed water, hydrogen sulfide exchange process (the GS or Girdler-Sulfide process).(10) Hydrogen-fed HW production plants have an upper limit on their capacity determined by the size of the hydrogen source.

Two hydrogen-fed processes have been deployed on a commercial scale -- the ammonia-hydrogen exchange process and the cryogenic hydrogen-distillation process. $(10,11)$ Both monothermal and bi-thermal versions of the anmonia-hydrogen process have been developed to commercial scale. Special transfer stages have been designed so that the ammonia-hydrogen process can be used with water feed; however the ammonia-hydrogen process is most attractive economically when a hydrogen source of deuterium is available. (10) Other hydrogen-based processes 
have been investigated $(10,11,12)$; they are not discussed here since the purpose of this section is to consider requirements for safeguarding processes which currently are or will be deployed on a commercial scale (capacity > $20 \mathrm{Mg} / \mathrm{year}$ $D_{2} 0$ ) in the near future.

A safeguards approach for any HW production plant should be able to detect diversion of any deuterium-enriched material in which the deuterium concentration is greater than about 0.5-1 mole percent deuterium because materials with greater deuterium concentration can be upgraded to reactor-grade HW with relatively simple and readily available equipment. For example, deuteriumcontaining intermediate materials can be burned to water, and the water can be concentrated to reactor-grade HW with distillation equipment such as upgraders, which are standard peripheral equipment for HW-moderated power reactors, and which generally are not safeguarded by the IAEA. Surveillance measures to detect removal of materials of intermediate deuterium concentration are likely to be unacceptably costly in terms of equipment or inspection effort. If material accountancy can be used to measure the amount of deuterium extracted by the plant (or by the portion of the plant where the deuterium concentration is greater than about $0.5-1 \%$ ), the removal of intermediate materials would result in a detectable shortage of deuterium in the product stream (assuming that no undeclared feed has been introduced). This is a major strength of safeguards approaches based on material accountancy. We now consider problems which would require further 'investigation if international safeguards based on material accountancy were to be applied to hydrogen-fed HW production plants.

First, the interconnections between the parasitic HW plant and the hydrogen source may not be simple. That is, there may be a number of connections where hydrogen feed is supplied to the HW plant and where deuterium-depleted material is returned from the HW plant to the host plant.(10) The deuterium content of 
each of these flows would have to be measured in order to determine the amount of deuterium extracted in the HW plant. Various ways to integrate an ammoniahydrogen HW plant with an ammonia production plant, the most common large-scale source of hydrogen, are described in Ref. 10. Ways to measure the flows and deuterium contents of these streams should be investigated if it is necessary to safeguard this type of HW production plant.

Second, some of the process streams which it might be desiratle to measure for safeguards in a hydrogen-based HW plant are likely to be vapor phase. Flows of gas or vapor apparently cannot be measured as accurately as flows of liquids such as water. Consideration of safeguards for hydrogen-based plants probably would requirie evaluation of the uncertainties associated with vapor-phase flow measurements and their effects on the safeguards detection sensitivity which might be achieved.

The ammonia-hydrogen exchange process uses a catalyst in some of the streams which might be measured for purposes of accountancy. The catalyst is potassium amide (dissolved in liquid ammonia), which is corrosive and can form solid deposits or explode on contact with oxides of carbon or with water, air, or oxygen. This catalyst might complicate accountability measurements.

Material accountancy around only the higher stages of a hydrogen-fed ammonia-hydrogen HW production plant would require measurements of several highpressure liquid or vapor process streams as well as a catalyst recycle stream. As noted above, measuring the hydrogen feed and return for the entire HW production plant is not obviously a feasible or simple alternative in this case.

In summary, safeguards considerations for hydrogen-fed HW production plants have received little attention, and further study would be necessary to develop a feasible safeguards approach for such plants. 


\section{VII.2.2. HW Safeguards Implications of Future Hydrogen Usage}

Hydrogen is used today as a chemical intermediate, as a reducing agent, and in specialty applications.(13) The greatest single usage today is for fixation of atmospheric nitrogen through production of ammonia. (14) A growing usage is in refineries to increase the yield of light hydrocarbon product s from increasingly less volatile feedstocks. (14) Refinery-produced hydrogen which was formerly simply burned as fuel is more and more commonly recovered and purified for use as a process chemical. Thus growth in the use of hydrogen as a process chemical seems a certainty.

Over the longer term, as natural gas and petroleum feed stocks become depleted, hydrogen will be produced from coal for distribution and used directly as a gaseous fuel or for the production of other fluid fuels from coal. The time scale on which coal gasification and liquefaction become economical is more speculative but could eventually involve very large quantities of process hydrogen.

Over the very long term, hydrogen may be used as a carrier for storage and distribution of energy from sources such as nuclear fission, solar energy, or fusion energy. $(13,15)$ In addition to development of these primary energy sources, use of .hydrogen as an energy carrier also would benefit from development of more efficient methods of elect rolysis or thermal decomposition of water. $(13,15)$ However, it is uncertain whether the primary sources of energy mentioned above, even nuclear fission reactors, will be deployed sufficient?y that large fractions of their output would be used for massive-scale production of hydrogen within the rime period of interest in this study (25-50 years).

In a study for the National Aeronautics and Space Administration (NASA), (16) it has been estimated that if hydrogen were produced and liquefied in a plant with the capacity $(2270 \mathrm{Mg} / \mathrm{d})$ to supply the fuel needs of a large airport, then deuterium could be extracted at very low cost by hydrogen distilla- 
tion. The low cost compared to present methods arisey partly from suggested improvement $s$ in hydrogen-liquefaction technology but primarily because the HW production would bear neither the hydrogen-production nor the liquefaction costs. (For comparison, it is noted that the capacity of the largest hydrogen liquefaction plant in the U.S. operating in 1980 was $55 \mathrm{Mg} / \mathrm{d}$ and that the total installed and imminently planned capacity of the U.S. and Canada was $144 \mathrm{Mg} / \mathrm{d}$. This latter capacity would support production of about $60 \mathrm{Mg} / \mathrm{yr} \mathrm{D}_{2} \mathrm{O}$ if $80 \%$ of the deuterium were recovered from hydrogen originally containing 140 ppm deuterium.) (17)

VII.3. Conclusions

In conclusion it seems virtually certain that the production of hydrogen will increase at least because of its increasing use as an industrial process chemical. The time scales for greatly increased production of hydrogen as result of production of fluid fuel from coal and for use as an energy carrier with non-fossil primary energy sources are more uncertain. Regardless of the reasons for increasing production of hydrogen, deuterium may be extracted from large hydrogen sources for reasons such as economical production or to obtain indigenous or reliable supply. Since it is desirable that deuterium or heavy-water production facilities be subject to appropriate non-proliferation undertakings, it may be necessary to develop safeguards approaches which would be applicable to deuterium or HW production plants which use hydrogen as the source of deuterium. Since there are several alternative HW production processes and various possibilities for connecting the deuterium extraction facility with the source of hydrogen, the saf cuards approaches probably would have to be quite plantspecific. However, it might be useful to study safeguards approaches for HWPPs associated with emmonia plants since several HWPPs of this type already have been constructed. 
1. Nuclear Proliferation and Civilian Nuclear Power: Report of the Nonproliferation Alternative Systems Assessment Program, Volume IX:

"Reactor and Fuel Cycle Descriptions," Report DOE/NE-0001, U.S. Department of Energy, December 1979 (Draft), p. $65 f$.

2. Reference 1, p. $193 \mathrm{f}$.

3. "Communications Received from Certain Member States Regarding Guidelines for the Export of Nuclear Material, Equipment or Technology", INFCIRC/254, Vienna, IAEA, February 1978.

4. See, for example, The Washington Post, $19 \mathrm{July} 1982$.

5. C. Auerbach, J.R. Lemley, and W.P. Bebbington, "Heavy Water Accountability", Report BNL-24941, Revised 20 September 1978.

6. A.G. Baum, F.C. Boroughs, and R.C. Johnson, "The Design of Heavy Water Production Plants to Facilitate the Application of International Safeguards", Report AC8NC125, The Lummus Company, 14 December 1979.

7. J.R. Lemley, "IAEA Safeguards for Heavy Water Production Plants Using Verified Material Accountancy", Report BNL-29347, 12 March 1981.

8. R.M. Smith, D. Amundrud and D.A. Head, "'Safeguarding Heavy Water in Power Reactors," Report WNRE-446, October 1980.

9. A. Fainberg, M.S. Zucker, J.R. Lemley, and E.V. Weinstock, "Assay of Heavy Water in Barrels for Safeguards Purposes," Proceedings of the 3rd Annual Symposium on Safeguards and Nuclear Material Management, ESARDA 13, p. 177, European Safeguards Research and Development Administration, Ispra, Italy, 1981 .

10. See, for example, Separation of Hydrogen Isotopes, ed. by H.K. Rae, ACS Symposium Series No. 68, Washington, D.C., American Chemical Society, 1978.

11. M. Benedict, T.H. Pigford and H.W. Levi, Nuclear Chemical Engineering, New York, McGraw-Hi11 Book Company, 2nd Ed., 1981 .

12. J.A. Ayres, "Production of Heavy Water - Status Report," Report BNWL-884, March 1969.

13. Hydrogen: Production and Marketing, ed. by W.N. Smith and J.G. Santangelo, ACS Symposium Series No. 116, Washington, D.C., American Chemical Society, 1980.

14. Reference 13, P. $67 \mathrm{f}$.

15. Hydrogen as an Energy Vector, ed. by A.A. Strub and G. Imarisio, Dordrecht, D. Reidel Publishing Co., 1980. 
16. C.R. Baker, "Study of the Potential for Improving the Economics of Hydrogen Liquification through the Use of Centrifugal Compressors and the Addition of a Heavy Water Plant," NASA Contractor Report 145282, December 1979.

17. Reference 13, p. 253. 
VIII. LONG-TERM STORAGE OF SPENT FUEL

VIII.1. Introduction

World-wide spent fuel accumulation over the next several decades wilı

soon outstrip the capacity of many reactor spent fuel storage pools (SFSPs).( 1 ) These pools with high densicy storage racks hold only about 10 years' worth of spent fuel. Beyond that, the utilities must either reprocess the fuel or transfer the fuel to a long-term spent fuel storage facility. Because of the general delay in construction of reprocessing facilities or because of the decision to forego, for the time being, the reprocessing route, utilities around the world are now considering which of several long-term storage schemes they should pursue. The choices most often discussed* are:

1. Wet storage at additional SFSPs either at-reactor (AR) or away-fromreactor (AFR),

2. Dry storage at an on-site AR storage facility,

3. Dry storage at a large AFR central facility,

4. Dry storage in casks stored on-site,

5. Dry storage in sealed canisters placed in a concrete silo,

6. Dry storase of canisters placed underground,

7. Dry storage of canisters in water, and

8. Dry storage at a waste repository with limited retrievability.

In any of these schemes, the material stored can be either full assemblies or sealed containers of consolidated spent fuel rods taken from assemblies.

*For an excellent review article, see reference 12 . 
These consolidated containers would almost double the capacity of SFSPs. In all cases, the storage period could be 30 years or greater.*

It is the purpose of this report to consider, in general, the impact of new long-term storage facilities on the U.S. and IAEA safeguards programs. In particular, the following two questions have been addressed. What new safeguards systems or devices should be developed to maintain the same level of safeguards at fuel storage schemes 2-7 above as is present in SFSPs? What new diversion scenarios arise from storage schemes 2-7 above considering advanced technology?

These questions naturally arise from the principle of "same material, same safeguards", and the fact that spent fuel with its large plutonium content cooled beyond 10 years is an even better target for diversion than the more radioactive spent fuel that is stored in reactor SFSPs (see Figure VIII-1). VIII.2. Safeguards Guidelines

IAEA safeguards at SFSPs currently use a combination of material accountancy in the form of item identification (assembly serial number) and containment/surveillance using TV or movie cameras ( 2 movie cameras per installation). In addition, there has been and continues to be a considerable amount of research and development work on new devices and systems. A very successful DOE development project at Los Alamos produced a Cerenkov glow detector capable of seeing the blue glow in the water due to radiation emitted by the assemblies as old as 10 years.(2) Los Alamos has also developed non-destructive assay (NDA) devices for gama and neutron fast scanning of assemblies.(3) Sandia has developed improved TV çameras, fuel assembly identification devices (FAIDs),

\footnotetext{
*The DOE Interim Spent Fuel Management program and the Electric Power Research Institute are sponsoring demonstrations of spent fuel storage which are to be held in the next few years for licensing review. Emphasis will be placed on demonstration for fuel bundle consolidation, fuel storage casks and near-surface dry wells. Concrete site demonstrations are presently being done in Canada for CANDU fuel.
} 
in-pool radiation and acoustic detectors, crane use monitors, etc.(4) The European research laboratory at Ispra. Italy and Brookhaven National Laboratory have been working on ultrasonic and laser beam surveillance of pools, respectively. $(5,6)$ The Ispra lab also develops ultrasonic seals for spent fue1.(5)

These activities, and others not mentioned, reflect the concern of the safeguards community over diversion of fuel from reactors where so much of the world's plutonium is and will be stored.

Given that the level of safeguards at long-term storage facilities should be comparable to that present at reactor SFSPs, it is necessary to qualify in some meaningful way what that level of safeguards is. Although this approach is problematic, it is essential for determining what new safeguards system may be needed for these new facility types. Furthermore, it would be overly optimistic to presume that whatever safeguards system is recommended for these long-term storage facilities is already available at one of the other facility types in the nuclear fuel cycle. By analogy, one would be wrong to believe that the safeguards systems and devices at enrichment plants can be used at fabrication plants simply because both work with low-enriched fuel. The safeguards system at each new facility type must be tailored to the form or container (or both) in which the SNM is found.

The current safeguards level at reactor SFSPs can be stated thusly:

(a) There is active surveillance (the cameras);

(b) There is item counting and item identification (of the serial number on the top plate of the assembly).

The Cerenkov glow detector can be classified as a

(c) detector of radiation from the radioactive assembly, i.e., a type of NDA device. Others could serve the same function. 
The other safeguards systems being developed may fall into one of the above categories but could also be considered

(d) a redundant system to ensure inventory continuity in case of one system failure.

It is reasonable to argue that items (a) and (b), and when introduced, (c) and (d), should also be present at long-term storage facilities in order to maintain a comparable level of safeguards.

An example of a safeguards practice that does not encompass both items (a) and (b) and therefore does not maintain a comparable level of safeguards is the placing of a seal on a concrete silo with no sure means of verifying the silo's integrity between inspections. This example will be discussed again in the next section.

VIII.3. Safeguards Systems Recommended for Long Term Storage Facilities

VIII.3.1. Spent Fuel Storage Pools

For the most part, the safeguards systems at reactors SFSPs can be transferred to AFR pools. However, there has been some discussion of double-tiering at AFR pools. (7) (Double-tiering is in place at the LaCrosse, Wisconsin reactor SFSP and is being planned for the Yankee Rowe, Maine reactor SFSP). If this becomes widespread, materializes, routine inspection of lower-leve1 individual assemblies may be impractical. To compensate for this constraint, the safeguards agency might consider strengthening its surveillance system by installing either redundant cameras or different active surveillance systems (see the discussion above and Appendices VIII-A-I and II for some examples of proposed new active surveillance systems for spent fuel storage schemes). The combination of consolidation of rods in a sealed container and double-tiering would probably exceed the structural 1imits of the current designs of SFSPs but maybe not of future SFSP designs. Given the cost-effectiveness of consolida- 
tion versus other interim storage schemes, consolidation may well be the first step toward any of the interim long-term storage methods considered by utilities. With consolidation of spent fuel rods, continuity of assembly identification is lost (also, the Cerenkov glow is considerably reduced and is not a good measure for the number of rods in a container). Therefore, a new method of identification of these sealed containers will be needed. If the safeguards community takes an active role in the design specification for these containers now, while they are not yet in full production, considerable savings in inspector manpower and effectiveness could be realized in the future.

Even before consolidation becomes accepted as a means for increasing storage capacity, the larger number of canned failed fuel rods at an AFR compared to the relatively fewer numbers at a single reactor will require a new method of monitoring the contents of these cans of rods, verifying the contents, or both.

The increased poolside activity at large AFR pools may make correlations between camera surveillance recordings and facility records of fuel movement difficult. New, more automated surveillance techniques that perform some of the correlations directly may be preferable, e.g., recording the location in the pool of each fuel transfer.

VIII.3.2. Dry Storage at an AR Ștorage Facility

An example of this type of storage for Magnox fuel elements is the Wylfa dry storage facilities at the Wylfa Nuclear Power Station in Great Britain. (8) The original reactor store facility was a $\mathrm{CO}_{2}$-cooled dry store. Two new aircooled dry storage facilities* adjacent to the old store have been constructed

\footnotetext{
*Each of the new facilities has a capacity of $350 t$ of uranium - 28,992 fuel elements. Twelve elements load one tube, 192 tubes make up a storing unit - a skip - and there are 151 skips. The fuel transfer machine can hold up to 64 tubes (see Figure 2). Fuel from the $\mathrm{CO}_{2}$ store is transferred to a skip at the transfer station and then the skip is moved to its store position.
} 
with the associated transfer machinery to transfer 150-day-old or older fuel from the $\mathrm{CO}_{2}$ store to the new air-cooled facility.

Based on their experience, the British engineers have designed a LWR dry storage facility of modular construction for AR siting. (9) Cooling would be passive, natural circulation using air (see Figure VIII-3). This type of storage is sometimes referred to as canyon storage.

From the safeguards viewpoint, this dry storage design may be quite secure if certain precautions are taken. The spent fuel in each module is entirely enclosed by thick biological shields resembling a secure container. The inspector should verify this design when the module is empty. The fuel transfer machine moves assemblies in and out of the store area.

Safeguards at this proposed dry storage design which are comparable to SFSP safeguards should include the following:

(a) Active surveillance to ensure that no other fuel transfer device is brought into the store and to ensure that the biological shield is not tampered with.

(b) Because assemblies cannot be viewed by the inspector without moving them, the movements of the fue1-transfer machine should be monitored for every transfer of spent fuel. The monitoring should record if the assembly is being transferred in or out of the store and the location of each new arrival. (Camera surveillance supplemented with a radiation detector fitted into the fuel transfer machine may suffice to supply this information to the inspector. Alternatively, a laser surveillance system ${ }^{(6)}$ could do both a and b.)

(c) During routine inspections, NDA devices would be diracted at a sample of the new arrivals to detect substitution of dumm assemblies. 
Just installing a camera (a) without both (b) and (c) would not constitute "comparable safeguards" since no substitute for item counting and item identification would have been made.

A general safeguards concern for any type of additional AR storage is the new diversion scenario of rapid shuffling between the reactor SFSP and the dry store to conceal a missing assembly (see Figure VIII-4).

VIII.3.3. Dry Storage at an AFR Storage Facility

The above design of dry storage would also apply to an AFR site. However, the large number of truck or train shipments each year* could cause a safeguards problem. A diversion scenario that conceals the loss of an assembly by always claiming it is en route to an AFR site would be difficult to detect unless each assembly had a unique signature. Several methods of installing a unique signature on the top plate of a spent fuel as sembly have been proposed and some testing has been completed. (10) However, the top plate can be transferred to a dummy assembly. U1timately, a sealing system that associates a unique signature with the fuel in a spent fuel assembly will be needed.(11) An AFR dry storage facility will house many more modules than an AR facility. Since each module may be self-contained, each may require its own set of safeguards systems. Therefore, if a module design is chosen for AFR storage, then safeguards costs could grow as the facility grows and be inversely proportional to the size of each module, i.e., many smaller modules would require more surveillance systems.

VIII.3.4. Dry Storage in Casks Stored On-Site or Off-Site

The main advantage of dry storage in casks is that it obviates the need for constructing a new hardened facility. (However, a strong enclosure may be required for national-security reasons.) Also, cask "farms" can expand ₹If an AFR site serves the needs of 5 LWR reactors, then several hundred as semblies are being transferred each year. For a nation to claim that 10 or more assemblies are in transit on any one day is not unreasonable. 
uniformly with the shipments. The cost of the casks decreases when only aged spent fuel is being shipped, and if on-site storage is selected, the cost per cask drops dramatically because the casks do not have to meet stringent transport safety requirements. West Germany is planning a facility for cask storage at Ahaus. (12) The Tennessee Valley Authority (TVA) plans to demonstrate cask storage and other dry storage schemes as part of DOE's Interim Spent Fuel Storage Program.

Safeguarding casks containing spent fuel will be difficult and will almost certainly require one or more new safeguard systems to estabilish comparable safeguards as at SFSPs.

Camera coverage would probably be prohibitively expensive because of the limited number of casks that would be within the view of each camera. Item counting or identification of assemblies would not be possible for routine inspections. Information from standard NDA measurements would be 1 imited and probably could not determine the number of assemblies in a cask.

Generally, shipping containers of SNM are safeguarded with seals. Whereas this method may be considered adequate for low-enriched $\mathrm{UF}_{6}$, the present state of seal/container safeguards does not match the level of safeguards at SFSPs. Regardless of the safeguards integrity of the seal itself, cask integrity veri-fication has been inadequately developed. To date, no passive verification system of cask integrity is available, and, absent such a passive system, the only recourse would be to install a new active surveillance system, one that does not rely on visual information. Any one of several electronic monitoring devices selected from commercially available systems, e.g., load cells, vibration sensors, movement sensors, etc., could probably be installed on individual casks and be incorporated in a safeguards system similar to the safeguards system installed at plutonium vaults (see Appendix A-II for 
a system that uses a proposed modificat $\_$n of the electronic seal(13)). Even if such a system were developed and installed, it is not clear if it alone would constitute "comparable safeguards"; a second active surveillance system may be needed.

VIII.3.5. Dry Storage in Concrete Silos

Some CANDU fuel is currently being stored in concrete silos in Manitoba, Canada as part of a pilot study on spent fuel storage. (14) Each silo contains 216 fuel bundles, about two significant quantities of SNM. At present, the only safeguards systems installed are seals: a fiber optics seal and a Type E seal strung between the silo's Iid and body (see Figure VIII-5). There is neither active surveillance nor the possibility of NDA of the fuel. No method of detecting tampering with the silos is employed or planned.

Other schemes of dry storage of spent fuel in concrete cylinders have been proposed. In particular, the Pacific Basin countries have considered storage of their spent fuel assemblies on a Pacific Island. One proposed scheme calls for placing a LWR assembly in a canister and placing one or several of these canisters in a concrete cask located above ground.

Active surveillance should constitute part of the safeguards system for concrete silos. Camera surveillance may be impractical due to the low density of storage or due to the effects of weather on the camera, film or field of view. Active surveillance using some form of temperature or radiation detection could be developed (see Appendix A-III). Again, two active surveillance systems may be necessary.

VIII.3.6. Dry Storage of Canisters Placed Underground

This underground storage scheme (see Figure VIII-6), sometimes called caisson has many of the same safeguards concerns as silo storage along with the added concern of diversion by underground tunnelling. The tunnelling and 
diversion could be accomplished with remote-controlled drilling rigs attached to specially designed robots to handle the radioactive fuel. This is an example of a new diversion scenario using advanced technologies. Chapter IX of this report includes a special section on robotics.) Active surveillance of the radiation field around the canisters is quite feasible and is proposed as one possible safeguards technique.

Tunnelling is also feasible, albeit wore difficult, through concrete silos; perhaps it should be considered a likely diversion scenario in that case too.

\section{VIII.3.7. Dry Storage of Canisters in Water}

This scheme has been proposed for HTGR fuel.(15) (See Figure VIII-7.) Although similar to SFSPs, a top biological shield prevents direct surveillance of the fuel assembly or canisters. On the other hand, the same comments $(a-c)$ about safeguards surveillance on the fuel transfer machine mentioned in Section VIII.3.2 apply here too.

\section{VIII.3.8. Waste Repository}

Storage of spent fuel at a waste repository is being incorporated in the plans for a U.S. repository. (16) If the underground repository is considered a secure tamper-proof container and the shaft its only "valve", then safeguards need only be applied to the shaft in order to detect if any fuel is leaving the repository. For example, shipping casks entering full should be monitored to ensure that they leave empty. Camera surveillance and weight and radiation monitoring are probably sufficient.

Periodic inspections of the repository would be required to ensure that no other shaft has been sunk and to ensure that no reprocessing of spent fuel takes place in the repository. 


\section{VIII.4. Conclusions}

It is clear that several quite distinct storage facilities for spent fuel will soon exist, each requiring its own individual safeguards systems. Based on the principle of "same material - same safeguards" and given the two current safeguards systems at SFSPs, e.g., cameras and item identification, we have envisioned the development of comparable active surveillance systems for the new storage schemes. (A standard type-E passive seal does not constitute comparable safeguards). These active surveillance systems may not always be camera systems but may be sealed electronic monitoring units made from currently available off-the-shelf components that sense radiation, temperature, vibration, weight, motion, etc. Such surveillance would be similar to the monitoring of safeguarded plutonium storage vaults. (17) These active surveillance systems will have to be rugged, long-lived and perhaps capable of remote interrogation (via remote verification). $(18,19,20)$ Appendices VIII-A-I and II describe suggested preliminary designs for safeguards systems for interim spent fuel storage schemes discussed in this report.

For those storage systems that emplace the assemblies in closed canisters, continuity of assembly identification is lost and its prompt replacement by another item identification safeguards system is required. However, for the other storage systems, a method of fuel identification is desirable that goes beyond the serial number or the FAID and obtains the signature from the fuel itself. NDA of spent fuel assemblies should be employed when a system becomes available, but NDA, in general, does not provide a unique signature. For some fuel, a signature may be obtained from a scan of the unique magnetic properties of each as sembly. (11)

With these new sturage systems, some AF and others AFR, new diversion scenarios appear. These include the possibility of rapid shuffling of assemblies 
between AR storage basins or the possibility of tunnelling into canisters or silos by intelligent robots. To detect these new scenarios, new safeguard systems may be needed (see Ghapter IX concerning the latter).

Finally, it is entirely possible that still another interim storage scheme for assemblies would arise, one not discussed here. Any such scheme will need to be scrutinized for the best appropriate safeguards systems, but at least one active surveillance system would most certainly be required. 


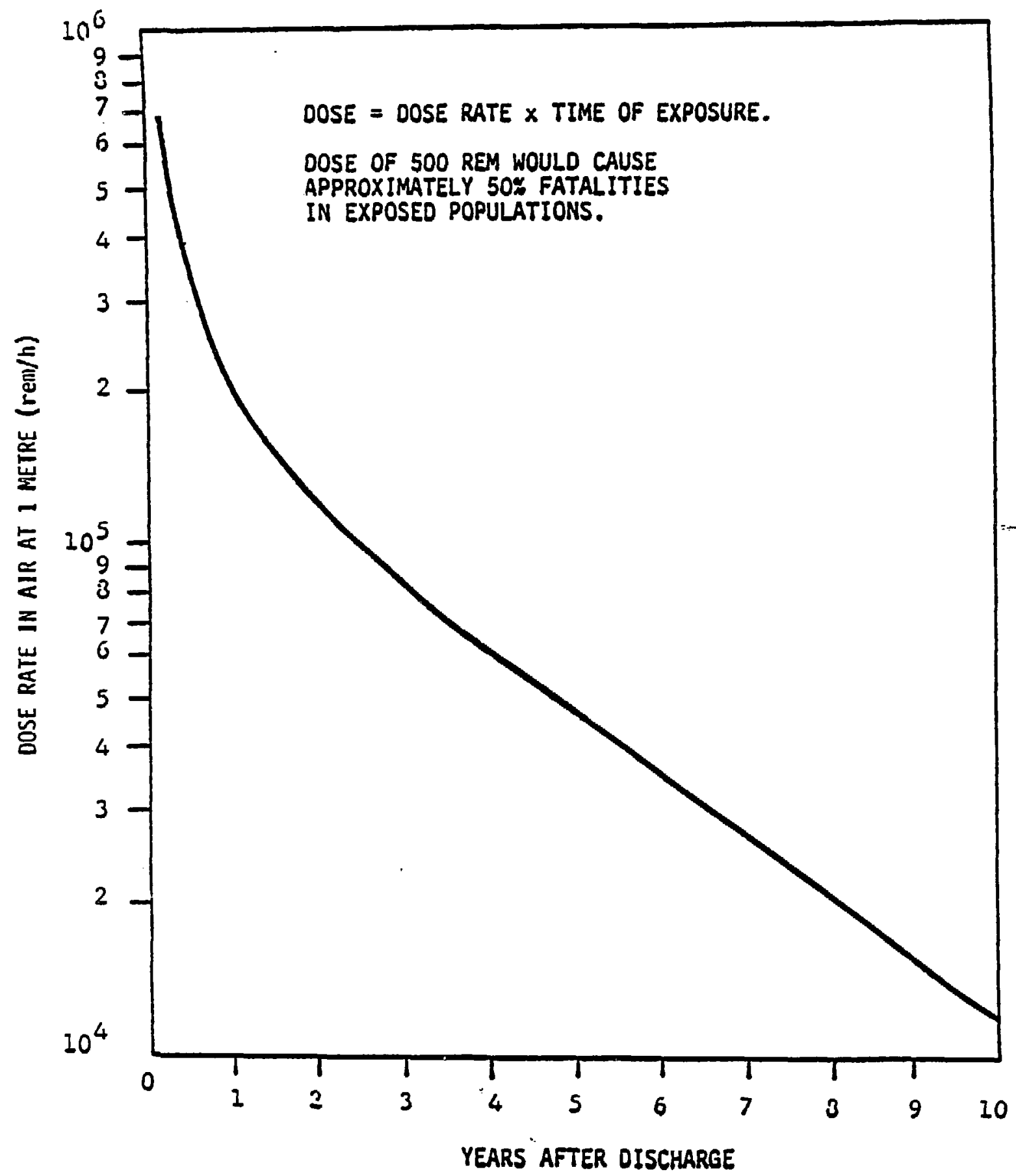

Figure VIII-1. Dose Rate from PWR Spent Fuel Assemb1y (from ref. 21) 


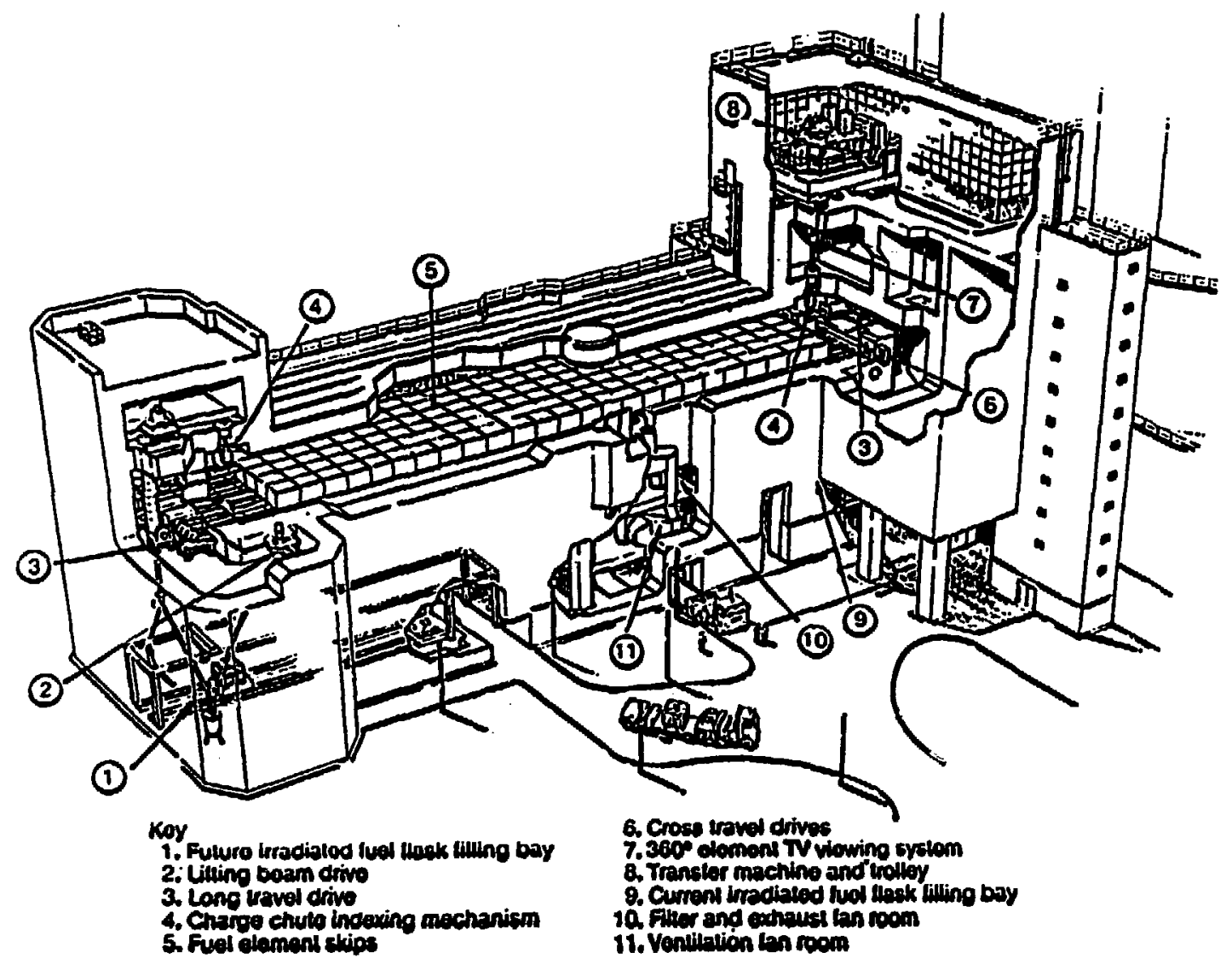

Figure VIII-2. Perspective Cutaway of Dry Store for Irradiated Magnox Fuel at Wylfa Nuclear Power Station 

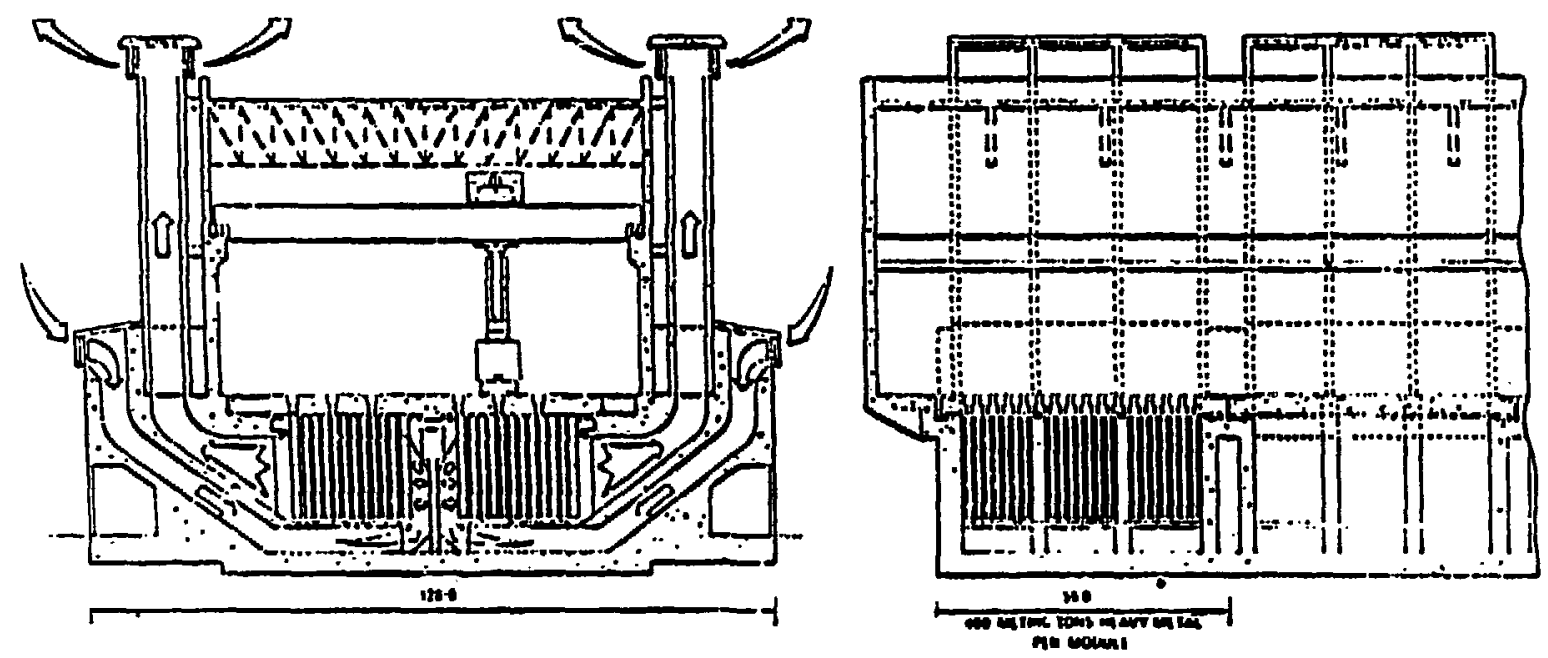

Figure VIII-3. Typical Section Through an LWR Store 


\section{Spent-Fuel Storage}
(1) An Oullat Unxis
(2) An InII Dust

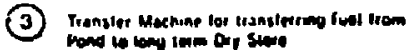
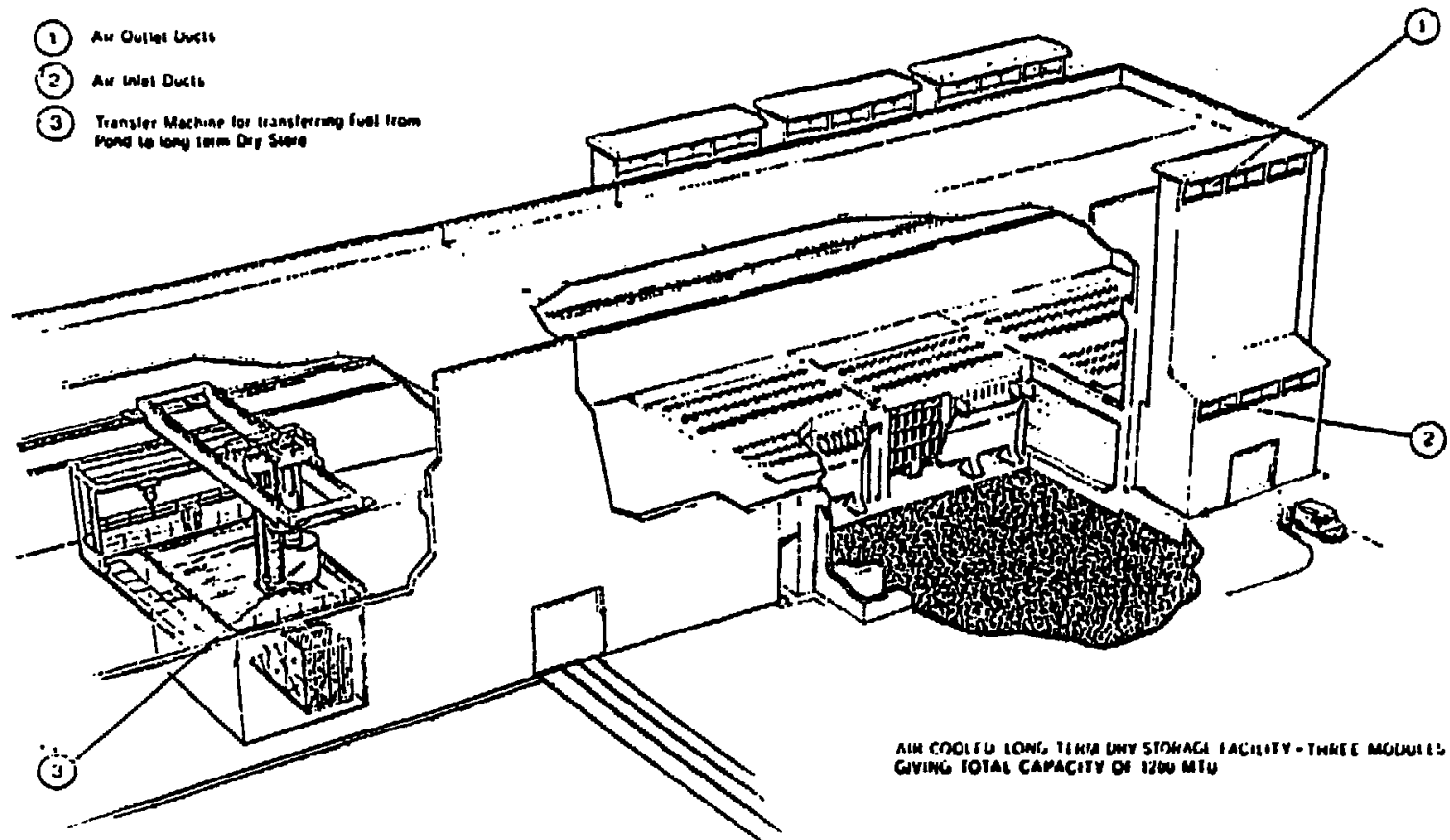

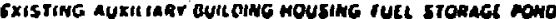
and II Asn manding Uay

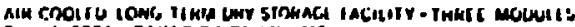

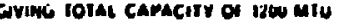

Bigure VIII-4. Perspective View of LWR Store Adjacent to Pond Building 


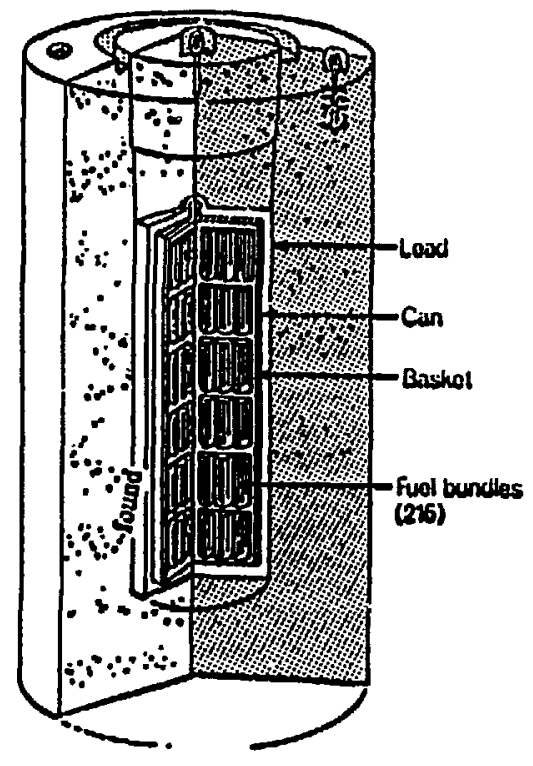

Figure VIII-5. Concrete Canister for Dry Interim Storage of CANDU Spent Fue1 


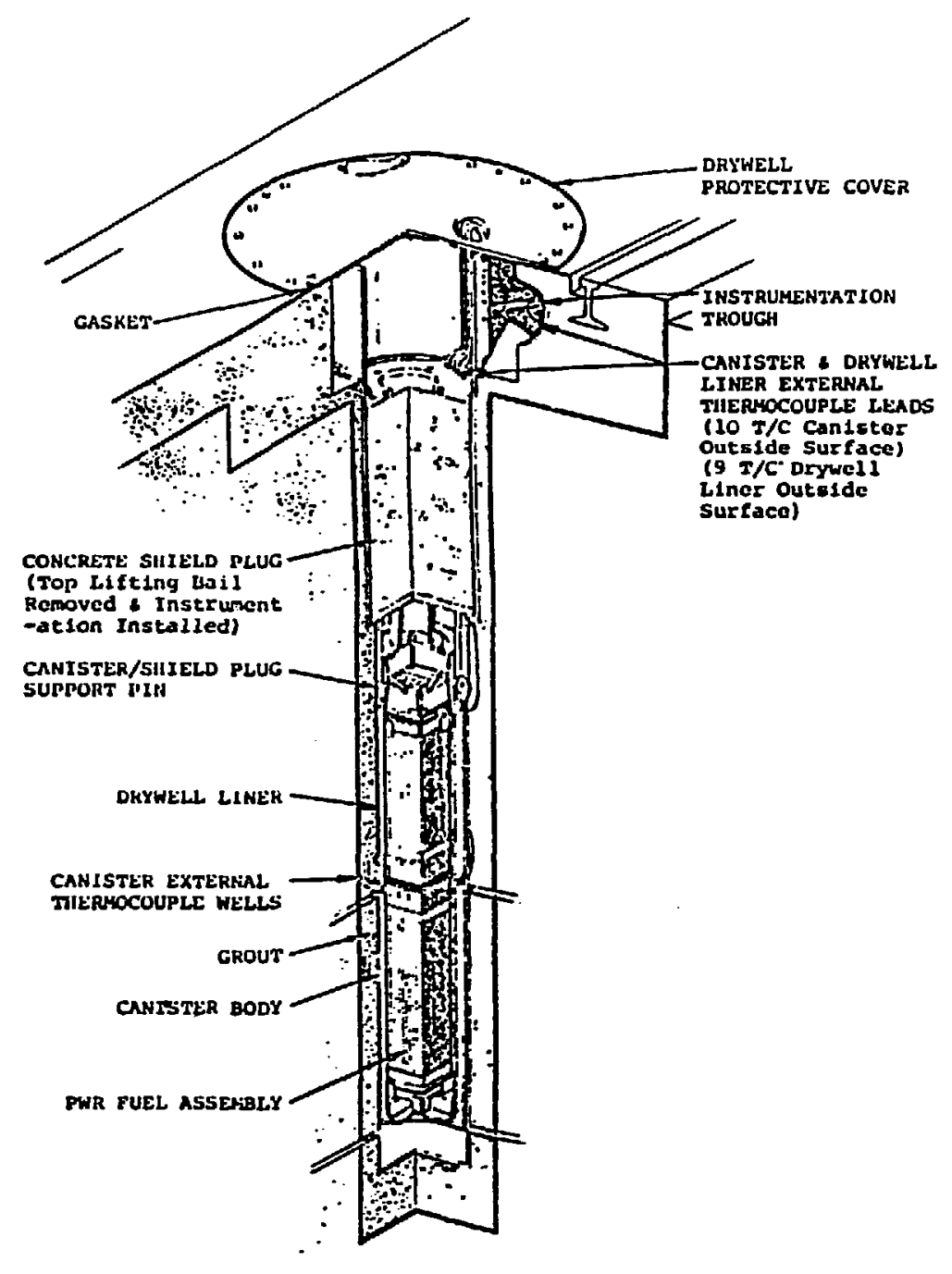

Figure VIII-6. Drywe11 Storage Arrangement 


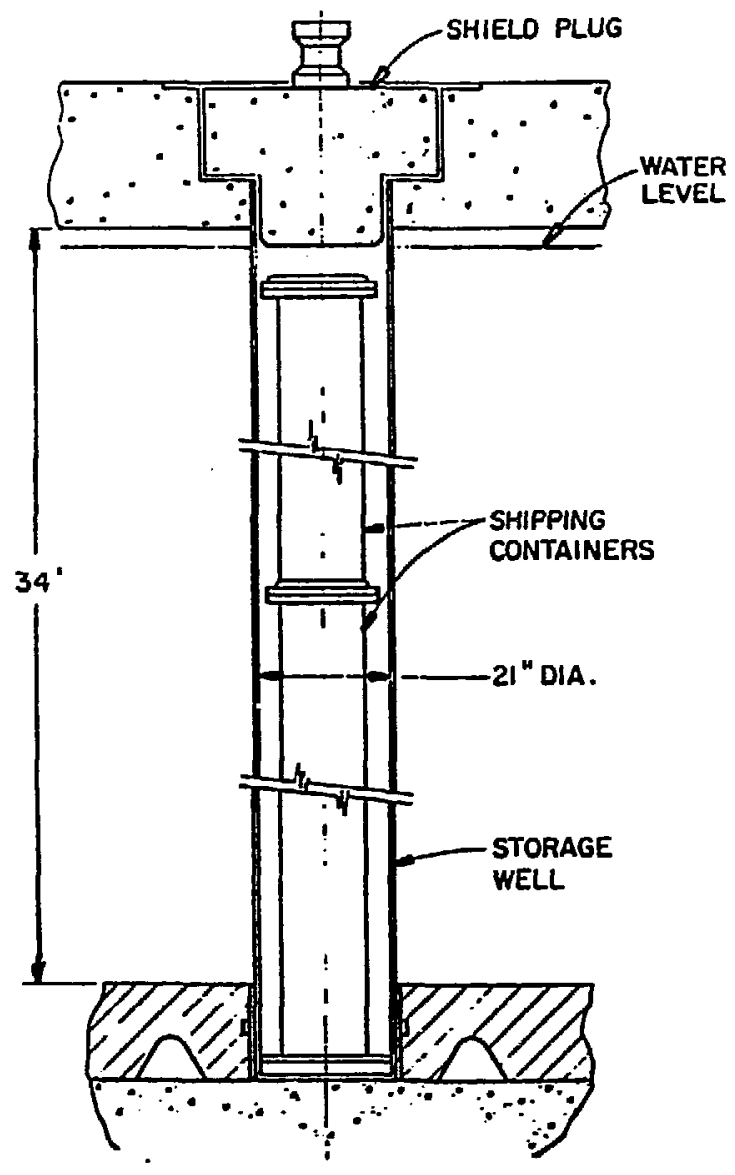

Figure VIII-7. Plug-Well Spent-Fuel Storage Concept 


\section{Appendices - Chapter VIII}

Two examples of proposed active surveillance systems for two interim storage schemes are described below. These system designs are preliminary and are intended to demonstrate the kind of system which can substitute for camera surveillance when the latter is not appropriate.

\section{Appendix VIII-A-I}

Active U1trasonic Surveillance of Spent Fuel Storage Buildings

The typical PWR and newly designed BWR spent fuel storage pools are housed in separate buildings which, during most of the year, are closed, with no traffic in or out. There are usually a passageway into the containment building via an air-lock, double-door arrangement and a large door for cask-carrying trucks. It is during spent fuel discharge and fresh fuel arrivals that the latter door is mainly used and, occasionally, heavy equipment is brought in there. For the rest of the time the building can be considered a closed container.

Safeguards within the building include the extremely important surveillance camera that periodically takes a picture frame. The movie cameras (2 cameras at each station) are commercial and not specifically designed to withstand the thousands of on-off cycles imposed on them each year. Consequently, there is a disturbingly large failure rate; about 1 camera failure every $2-1 / 2$ years or a probability of $\sim 0.01$ for both cameras failing between the 3 month inspection visits.

Viewing the thousands of frames and interpreting the activity of people performing routine maintenance and repair or operator training on the crane and hoist can be a straining and time-consuming activity for the inspector.

It has been proposed that a dual-speed control on one or both of the surveillance cameras be installed. (22) The point is that the dual-speed control 
can be switched to low when the building is closed (no diversion is possible) so that the frame rate is a small fraction of the high rate when the building is open (spent fuel can be diverted). With such a control, both of the problems of camera failure and inspector work load can be significantly reduced.

The dual-speed control (A) shown in the diagram (Fig. VIII-AI-1) can be triggered by a difference signal obtained from two detectors -- one placed inside the building (B) and one placed outside (C). Both detectors are tuned to the frequency of an ultrasonic signal generator or transducer (D) located in a central position inside the spent fuel building. Detector (B) receives the sma11 leakage ultrasonic energy while detector (c) receives the large internal energy. The null difference signal is (B-kC).*

An opening in the building will enhance (C) while reducing (B). This change in the difference signal will activate the dual-speed control, increasing the frame rate. When the difference signal returns to its normal level the dual-speed control will switch the frame rate back to low.

This arrangement of two detectors instead of an arrangement of one detector outside the building would make it very difficult for a divertor to construct a leaktight building immediately adjacent to the spent fuel building within which is a cask-carrying truck, open the door separating the buildings, and transfer an assembly without altering the difference signal.

The movement of personnel and small equipment inside the spent fuel building will not switch the frame rate if a discriminator level processing the detector signals is properly adjusted. Conservatively setting this level low might switch the frame rate to high even for the movement of people, but this inspec-

\footnotetext{
*Ideally, each detector shown would be two detectors operating in a (fast) electronic difference mode to detect attempts at (slow) mechanical tampering. $(23)$
} 
tor-set level, "randomly chosen", can only strengthen the system while stil1, in the long run, significantly reducing the total number of on-off cycles of the camera. 


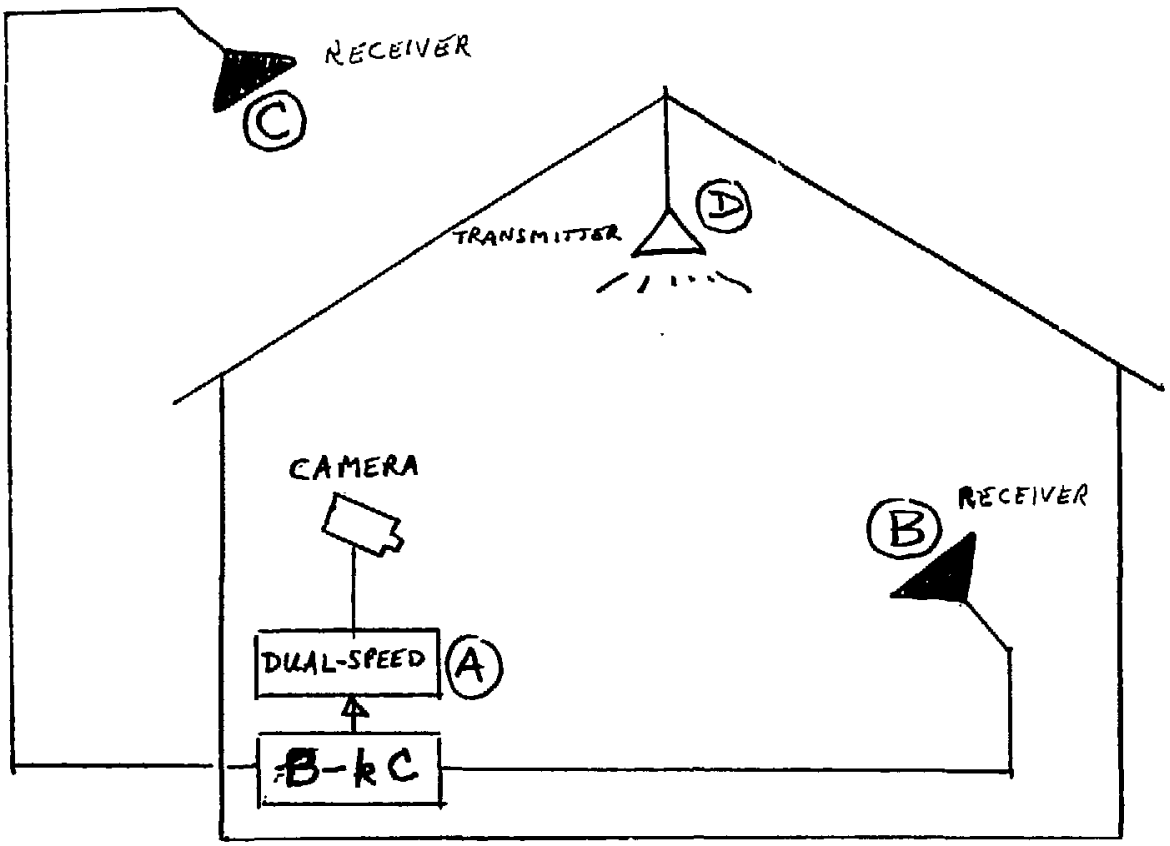

Basic Layout of the U1trasonic Surveillance System at Spent Fuel Buildings.

Figure VIII-AI-1 


\section{APPENDIX VIII-A-II}

Safeguards Applications of the Sandia or VACOSS-3 Elecironic Seal

One of the many interim storage schemes being considered for spent fuel assemblies after they leave the spent fuel storage pool (SFSP) is the transfer of assemblies to specially designed, low-cost casks ( 1 or 2 assemblies per cask). (12) These casks would probably be stored on-site at the reactor to avoid the extra cost of constructing casks that meet the much more stringent transport safety requirements (see Figure VIII-AII-I).

Safeguarding these "cask farms" using the standard IAEA camera surveillance system may be impractical for any one of a number of reasons; e.g., (a) the camera's cost-effectiveness is low because of the relatively few casks within the camera's field of view compared to the hundreds of assemblies in view at the SFSP, (b) the failure rate of the current dual-camera system is too high; i.e., the probability of both cameras failing within three months (typical inspection interval) is about 0.01 , so that a reasonably-sized cask farm with 20 casks per camera could have 20 or more camera systems, resulting in a likely system failure almost every year.

The active surveillance by the cameras could be replaced with a new system which uses a slightly modified electronic seal. $(13,24,25)$ The proposed scheme is shown diagramatically in Figure vIII-AII-2. The standard fibe: optics cable is replaced by one having one or more "light pulse repeaters" (LPRs) inserted in the loop. The LPR is coupled to an inexpensi load cell or load bolt (26) placed under the cask and bearing a sizable fr $c$ ion of the load. Any detectable change in the load switches off the LPR, which changes the state of the electronic seal with respect to normal operation.

Although still in a preliminary stage, one conceptional design of the LPR electronics is shown in Figure VIII-AII-3. The light pulse detector could be a 
phototransistor detecting the light pulses from the electronic seal. Its output is coupled to the light generator, e.g., a light-emitting diode (LED), through an AND gate. The other input to the AND gate comes from a circuit comprised of the load cell signal sampled by a COMPARATOR which compares the instantaneous signal with the integrated signal. Any change in the load cell output would trigger the COMPARATOR "low", which switches the AND gate "off".

To strengthen the system, a third input to the AND gate could come from another detector-comparator circuit such as a vibration monitor or radiation detector. (22)

The same tamper-indicating case and phototransistor, LEn circuitry used for the electronic seal can be adapted for the LPR unit. The load cell and detector connections are capable of being tamper-indicating. (22) To reduce the cost of the system further, several LPRs can be connected in series to one electronic seal (at the expense of some sensitivity). Even if the safeguards cost per cask for this sealing syster were comparable to that of a camera system, the ease of seal reading compared to film viewing and the probable advantage of a much lower failure rate would warrant its consideration. The VACOSS-3 seal also has a remote interrogation capability.

Other casks besides these spent fuel casks can be similarly safeguarded, e.g., $\mathrm{UF}_{6}{ }_{6 y l i_{k} d e r s}$ and the fresh fuel shipping casks. Furthermore, this type of combination seal-detector device can be applied wherever the electronic seal has application. The advantages of using an already developed safeguard device, the electronic seal, coupled to any one of a number of standard detection devices,(22) compared to developing a completely new monitor-detector combination are:

1. Most of the development work has already been done. 
2. The electronic seal monitor is probably as secure as any new monitor that would be developed, and maybe stronger because it still can be used as a seal.

3. The cost per unit would be low.

4. Uniformity of IAEA devices is a desirable goal. 

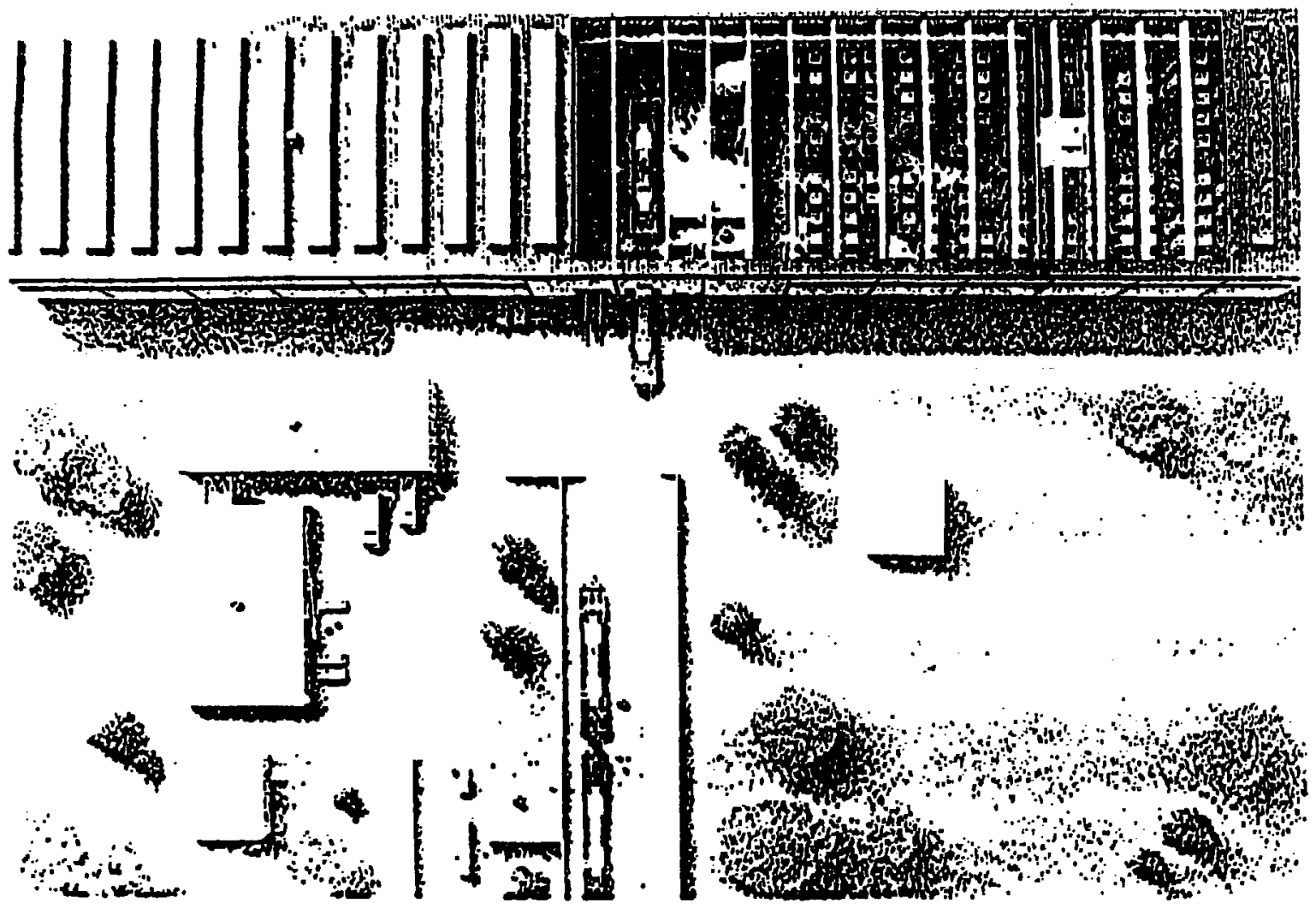

Figure VIII-AII-1. A C. isk Storage Arrangement 
ELECTRONIC SEAT,

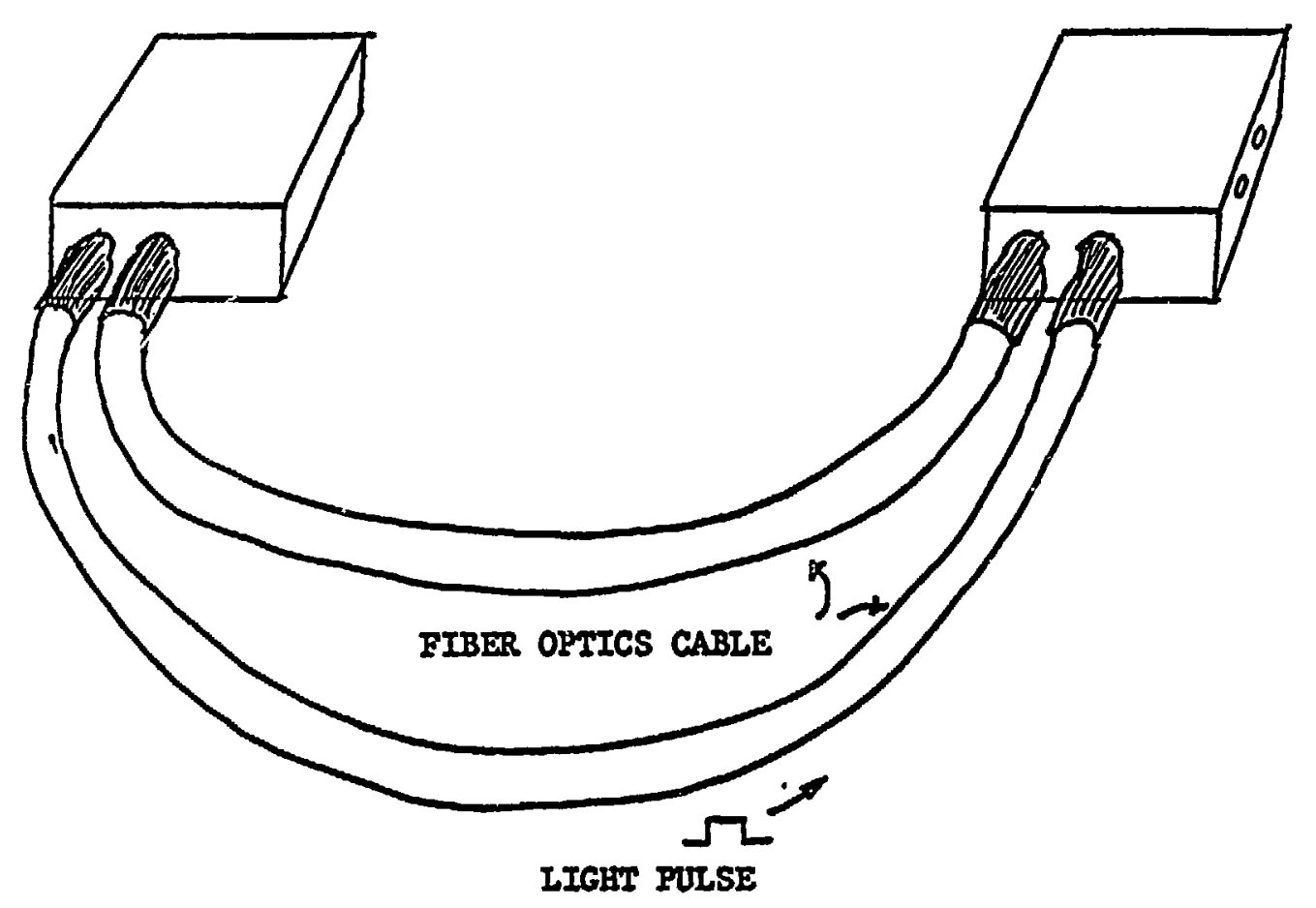

LIGHT PULSE REPEATER

DETECTOR

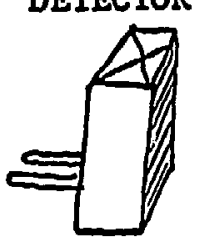

Figure VIII-AII-2. Electronic Seal with LWR 


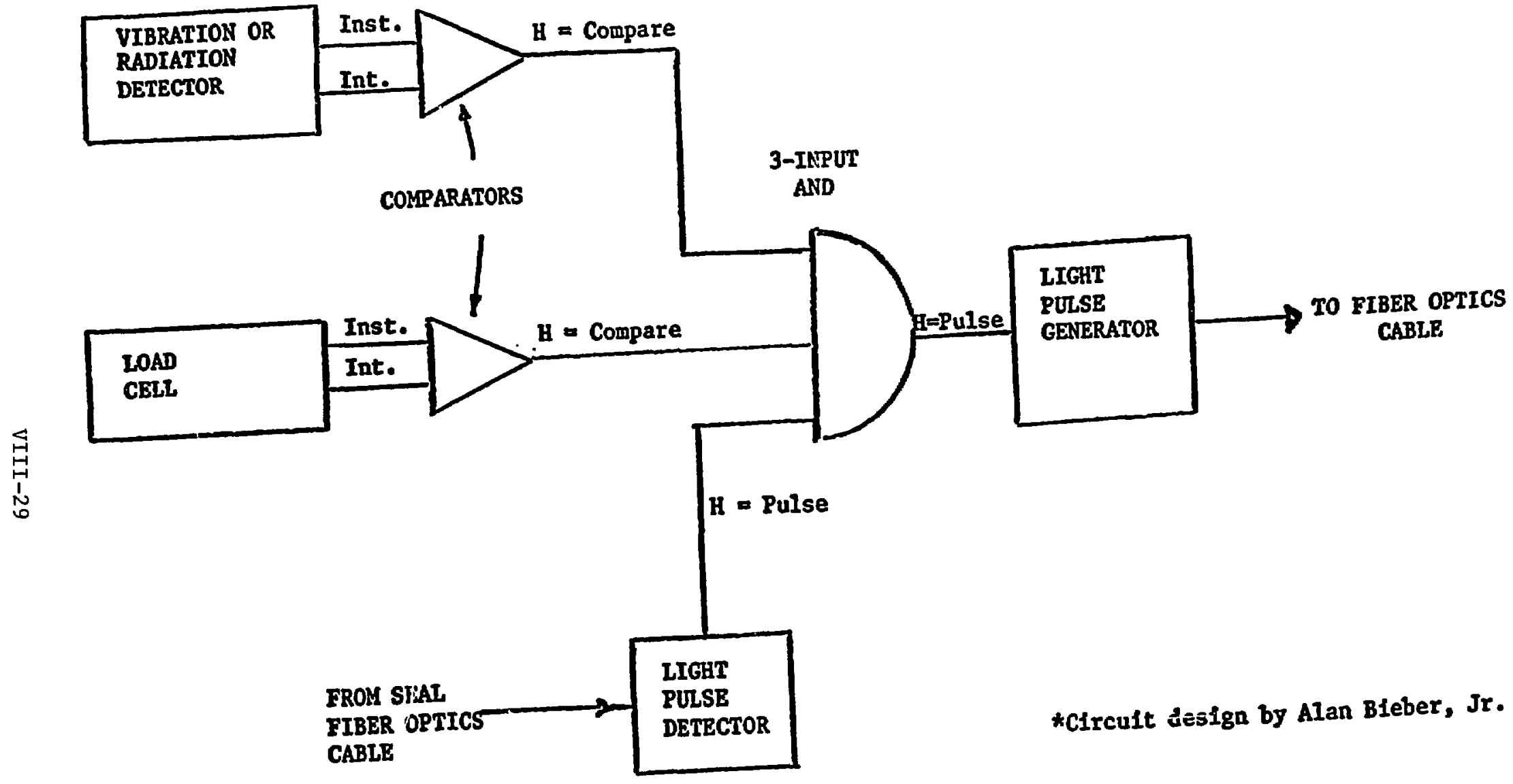

Figure VIII-AII-3. Light Pulse Repeater Circuit 
1. International Nuclear Fuel Cycle Evaluation, "Spent Fuel Management", INF CE /PC/2/6, January, 1980.

2. E.J. Dowdy, N. Nicholson, and J.T. Caldwe11, "Irradiated Fuel Monitoring by Cerenkov Glow Intensity Measurements," Sept. 1979, LA-7838-MS, (ISPO 非1).

3. J.R. Phillips, G.E. Bosler, J.K. Halbig, S.F. Klosterbuer, D.M. Lee, and H.O. Menlove, "Neutron Measurement Techniques for the NDA of Irradiated Fuel Assemb1ies," LA-9002-MS (ISPO \#156), Task A.49, 1981.

4. G.H. Bradley, D.E. McGovern, and I.G. Waddoups, "Containment and Surveillance Equipment Reliability Techniques," May 1981, SAND-81-0386, ISPO 非141.

5. S.J. Crutzen, C.J. Vinche, W.H. Bürgers, and M.R. Combet, "Remote Controlled and Long Distance Unique Identification of Reactor Fuel Elements on Assemblies", Nuclear Safeguards Technology 1978, STI/PUB/497, Vol. I, 561, International Atomic Energy Agency, Vienna, 1978.

6. S. Fiarman, M.S. Zucker, and A.M. Bieber, Jr., "Surveillance System for Spent Fuel," Proceedings of the 2nd Annual Symposium on Safeguards and Nuclear Material Management, ESARDA 11, p. 463, European Safeguards Research and Development Administration, Ispra, Italy, 1980.

7. Michael J. Lawrence, "Status of DOE AFR Studies," ANS Transactions, Annual Meeting, Atlanta, Georgia, Vol. 32 (1979) p. 413.

8. Maxwe11, E.O. and Deacon, D., "Wylfa Dry Store," Nuclear Energy, 1980, Vol. 19, February, No. 1, pp. 41-51.

9. David Deacon, "The Long-Term Dry Storage of Irradiated Oxide Fuel and Vitrified Waste," Nucl. Eng. Intern., August 1981, 26, p. 32.

10. E.g. C. Brückner, H. Heger, L. Pachl, R. Dennys, J.M. McKenzie, L.A. Suber, and L.F. Patterson, "Test of an LWR Fuel Assemb1y Sealing System in a Demonstration Experimental Nuclear Power Station", Proceedings of the Sixth Annual Symposium on Safeguards and Nuclear Material Management, ESARDA 17, P. 99, European Safeguards Research and Development Association, Ispra, Italy, 1984.

11. Fiarman, S. and Moodenbaugh, E.J., "Magnetic Scanning of LWR Assemblies," Proceedings of the 1st Seminar on Containment and Surveillance Techniques for International Safeguards, p. 104, European Safeguards Research and Development Administration, Ispra, Italy, 1980.

12. Davidson, R. and Deacon, D., "Spent Fuel Storage", ANs Transactions, November 17-21, 1980, Washington, D.C., Vo1. 37, P. 136 .

13. Johnson, E.F., "Characteristics and Development of the Electronic Fiber Op-

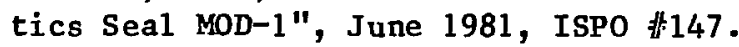


14. D. L. Amundrud, "The Safeguards of the WNRE Dry Storage Canister Demonstration Program - Interim Report 3," WNRE-286-3.

15. Burgoyne, R.M. and Holder, N.D., "Water-Cooled Storage Concepts for HTGR Spent Fue1," ANS Transactions, Annual Meeting, Atlanta, Georgia, June 3-7, 1979, Vol. 32, P. 419 .

16. J.H. Ellis, K.E. Plumer, H.G. Tepp, D.E. Savage, J.R. Butcher, and R.C. Edwards, "Waste Isolation Safeguards and Security System: Volume 1-Scoping Study", ONWI-128, Batte1le, 1980.

17. N. Nicholson, T.H. Kuckertz, and C.D. Ethridge, "A Microcomputer Based Shelf Storage System to Monitor Special Nuclear Material in Storage", Proceedings of the INMM Annual Meeting, June 30-July 2, 1980, Palm Beach, Florida, p. 649 .

18. F.J. Prokoski, "Global Monitoring of International Safeguards", Proceedings of the 5th Int. Conf. on Computer Communications, Int. Council for Computer Communications, Atlanta, Oct. 27-30, 1980.

19. E.V. Weinstock and J.B. Sanborn, "An Evaluation of a Remote Continual Verification System, RECOVER, for International Safeguards," ISPO-198, Brookhaven National Laboratory, 1983.

20. B. Keisch, "Safeguards Application of Remote Monitoring, Phase A - Light Water Reactors," ISPO-228, Brookhaven National Laboratory, 1984.

21. G. Hough, T. Shea, and D. Tolchenkov, "Technical Criteria for the App1ication of IAEA Safeguards," Nuclear Safeguards Technology 1978, IAEA/STI/PUB/497, p. 25, International Atomic Energy Agency, Vienna, Autstria, 1979.

22. C.L. Henderson and A.M. Fine, "Motion, Intrusion and Tamper Detection for Surveillance and Containnent," ISPO Report $\vDash 91$, March, 1980.

23. The basic system of emitter-detector can be easily and quickly tested at any spent fuel building such as the GE facility at Morris, Illinois and if successful, a prototype system including the dual speed control can be assembled.

24. F. Arning, H. Reuters, and H. Bueker, "VACOSS-3, A Versatile and TamperResistant Electronic Sealing System," Proceedings of the INMM Annual Meeting, July 13-15, 1981, San Francisco, CA., p. 360.

25. W. Kenneth Ream, H.D. Arlowe, D.S. Miyoshi, and A.E. Binder, "Status Monitoring (Alternate to Optical Surveillance)", ISPO Report \#72, January, 1980 .

26. Strain-Sert Corporation, Union Ha11 Industrial Park, West Conshohocken, Pennsylvania 19428 . 


\section{IMPACTS OF OTHER FUTURE TECHNOLOGIES}

\section{IX.1. Introduction}

The preceding chapters of this report have all dealt with possible future * nuclear technologies that could have a bearing on nuclear safeguards. The particular items considered and discussed were those for which current safeguards methodology will not be adequate. This chapter, by contrast, concerns nonnuclear technologies that are developing rapidly and are expected to become important in the next 20 or 40 years.

Several such technologies were considered as to possible impacts on safeguards and non-proliferation concerns. The question was posed for these, "Wi11 further development significantly ease the path to proliferation or otherwise affect the safeguards problem in an unusual manner?"

The development of advanced and commonplace laser technology was considered and is briefly discussed as a part of Chapter II. The appearance and growth of a true hydrogen-based energy economy could affect deuterium production methods and is discussed in Chapter VII.

Three additional technologies are discussed in this chapter: robotics, genetic engineering, and materials science. In the ensuing discussions, no solutions to suggested problems are offered. At this time, only the possible problems are posed and not in great detail. When scenarios are presented, an attempt is made to avoid incredibility, i.e., those scenarios that are not within the foreseeable capabilities of the field are excluded. However, it should be recognized that technological development over a period as long as 40 years can truly be "fantastic". 
IX.2. Robotics

Today, LWR spent fuel assemblies are generally stored in reactor spent fuel storage pools or a reprocessing plant spent fuel pool. However, as stated in Chapter VIII, these pools are filling up and other forms of storage, such as cask storage or canister storage, will soon be introduced. These containers are excellent targets for robotic diversion. E.g., consider the following scenario:

Sometime in the future, a cache of spent fuel, temporarily stored in casks or concrete silos, is protected from would-be divertors by a combination of surveillance devices such as a pair of closed-circuit TV cameras with integrated motion-detection devices and a gamma-ray monitor. These devices are arranged to operate reliably 24 hours/day, 7 days/week. However, the potential threat is assumed to be one that would involve normal access to the material and that would result in the removal of a cask or container in toto. Thus, one or more surveillance devices will have recorded the act. However, instead of the expected threat, a robot tunnels its way below ground remaining out of sight of the camieras. Using radiation detectors for guidance, it finds a position immediately below a cask. Extending a combined dril1-probe unit, the mechanism bores a hole through the cask bottom into the spent fuel itself. Then, over an extended period of time on the order of several days, the "meat" of the fuel with its plutonium is gradually dissolved and a mixture of fission products re-injected. Since the process is gradual and continuous, the gamma-ray monitor detects no change while this operation is carried out.

This scenario may be incredible today but becomes less so each day as we enter deeper and deeper into the robotic revolution. (1-4)

Arthur D. Little, Inc., has estimated the growth rate for the U.S. robotics industry ${ }^{(5)}$ to be $50 \% / y e a r$ for the next five years. Japan, the world's leader in industrial robot production, will experience an even faster growth in robotics. The Aron $\equiv_{25}$ Report $^{(6)}$ quotes the Japan Industrial Robot Industry Association (JIRA) as predicting a factor of 10 increase in export shipment from $\$ 500$ million in 1981 to $\$ 5$ billion in 1990 and much of the research in Japan wil1 be directed by the Ministry of Trade and Industry (MITI) toward intelligent robots. MITI recently announced a seven year, \$150 million national robot research program. 
Robots have been categorized into the following six classes:

1) manual manipulator - a manipulator that is worked by an operator.

2) fixed sequence robot - a manipulator which repetitively performs successive steps of a given operation according to a predetermined sequence, condition, and position, and whose set information cannot be easily changed.

3) variable sequence robot - a manipulator which repetitively performs successive $s$ teps of a given operation according to a predetermined sequence, condition, and position, and whose set information can be easily changed.

4) playback robot - a manipulator which can produce from memory operations originally executed under human control. A human operator initially operates the robot in order to input instructions. All the information relevant to the operations (sequence, conditions, and positions) is put in memory. When needed, this information is recalled (or played back, hence, its name) and the operations are repetitively executed automatically from memory.

5) NC (numerical control) robot - a manipulator that can perform a given task according to the sequence, conditions and position, as commanded via numerical data. The software used for these robots include punched tapes, cards, and digital switches. This robot has the same control mode as an NC machine.

6) intelligent robot - a robot with sensory perception (visual or tactile or both) that can detect chaiges by itself in the work environment or work condition and, by its own decision-making faculty, proceed with its operation accordingly.

The U.S. Robot Industry Association (RIA) defines a robot as including only classes 3-6. This report will emphasize intelligent robots because diverting nuclear fuel will probably require decision-making capabilities.

Let us expand on the attributes of the intelligent robot envisioned in the diversion scenario described in the opening paragraph. Only surveillance cam- 
eras and a gamma radiation monitor are assumed to be used by the IAEA for safeguarding the concrete canisters.

One relatively simple robot could be designed solely for digging the tunnel that will terminate directly under the canister. Actually, most of this work could be done manually since radiation levels would not be dangerous until the canister is breached. However, the robot-dug hole could be dug much more quietly at a slow pace, with the robot operating 24 hours/day with no life support systems. The hole could be much smaller than man-sized if the robots are capable of being so designed. Even if the IAEA places seismic detectors around the canister, the probability of detecting the digging might be low. This is so because the alarm setting of the detector depends on the background noise generated by heavy truck traffic, and many heavy trucks are expected to be traveling nearby (a) to haul concrete to build more canisters, (b) to carry spent fuel casks to the canisters, (c) to unload the casks, etc.

Once the tunnel is dug and the mining robot withdrawn, the canisterpenetrating robot enters to bore small holes in the concrete, again slowly and quietly. When the fuel is reached, it should be a simple task to direct dissolver solution at the fuel and methodically dissolve the spent fuel, pump it out through the tunnel to a small reprocessing facility (probably underground and well hidden from the view of the visiting inspector), and return the fission products. The inventory of spent fuel in the pipes and missing from the canister during this operation would be too small to be noticed by the gamma detector. If the IAEA also installs a neutron detector, then the isotopes responsible for most of the neutrons $\left({ }^{242} \mathrm{Cm},{ }^{244} \mathrm{Cm}\right)$ would be replaced or an equivalent neutron source installed.

The robot would have sensors that monitor the dissolving process, the radiation field, the returning fluids, etc., and capability to alter the process, 
such as redirecting flows, to achieve the goal. When the robot senses or is given the signal to terminate operations, it must have the ability to plug the holes and leave, to be used again.

Of course, the diverting nation would field-test its robot system on mock canisters and mock fuel elements until the system is reliable.

The robot described above need not be very intelligent compared to the capabilities of future robots. For example, in the above scenario, there has been limited or no use made of visual or tactile sensory perception, very little decision-making and few complicated mechanical manipulations.

Robots in the near future (less than 10 years) will have (a) sophisticated force or touch sensors and advanced system-control software programs to direct them, (b) vision systems that will be shortly developed and tested on research robots to recognize objects on a three-dimensional (3-D) viewpoint-independent level, and (c) wheeled locomotion coupled to acoustic sensors to avoid obstacles. The main difficulties in incorporating these developments in the diverting robot (if necessary) would be making the sensors radiation-resistant or protected by shielding (shielding touch sensors would desensitize the system) and reducing the robot's dimensions-miniaturization.

The credibility of a diversion scenario, besides hinging on its technical complexity, also depends on economic constraints, time requirements, and the risks that are borne by the divertor. The cost of the robots described above have been very roughly estimated by robotics researchers as about $\$ 10$ million and several years of research, development, and testing. However, as robotics research for industrial and research robots progresses, the cost and time needed to hand-make the diverting robots decreases.

These cost and time estimates do not compare unfavorably to the estimated time and cost required to construct a clandestine reactor or a clandestine 
enrichment facility. (7) Furthermore, the risk of discovery of diversion of spent fuel from temporary storage within concrete canisters or storage casks by means of robots is probably less than the risk of discovery of a clandestine reactor or enrichment facility. The risk of detection of a small clandestine reprocessing facility is on the other hand quite low, but the act of diverting highly radioactive whole assemblies from spent fuel pools, storage sites, or shipping casks has a high risk of detection and is a diversion route carefully monitored by the IAEA; e.g., witness the surveillance cameras and radiation detectors. The robotic route brings the reprocessing facility to the spent fuel and the scenario used in this report is just one example of a whole class of scenarios involving a mobile, robotic reprocessing plant. This postulated ultimate diversion robot can penetrate, chemically reprocess, and leave--undetected by surveillance cameras or radiation detectors. Similar capabilities have already been installed on the U.S. National Aeronautics and Space Adminstration (NASA) Mars Lander. It was mobile, had vision, had a manipulating arm to scoop up rocks for crude chemical analysis, and operated in a harsh environment. Future landers will have all of these capabilities enhanced by R\&D so that they would not be earth-controlled (too long a time delay in signal transmission) but will be able to look around for the most interesting place to go, travel there, safely avoiding obstacles, pick up objects that look interesting, analyze them, and report their results back to earth. $(8,9)$ These robots bear the closest resemblance to the diverting robot, whereas most industrial robots, although gaining in intelligence, are designed for specific, less complex tasks. However, an entire factary of only specialized robots can perform complex operations. In Japan several such factories already exist. In the U.S., one is being planned: 
"A customer wishing to have a few gears designed and fabricated walks into a small metal-working shop and hands a rough sketch to a human designer. The designer turns on a graphics terminal connected to a time-sharing network that offers computer-aided design and computeraided manufacturing capabilities. Using these, the designer designs the gears. If acceptable to the customer, the design program generates control software both for numerical-control cutting machines and for robots to set up and manipulate the parts. Robot conveyors assemble material from bins, and robot machinists then turn out the parts, unattended by any human. Robot vision compares the finished part for tolerance and flaws against master templates generated by the CAD/CAM program. The customer gets the finished parts."

- Planned as a feasibility demonstration in 1988 at the National Bureau of Standards meta1-working shop in Washington, D.C.

A sample of other attributes of robots not specifically mentioned above tut which generate safeguard concerns are the capability of (a) operating underwater in spent fuel pools (robotic-controlled submarine research is being directed by the U.S. Navy Ocean System Center in San Diego) and (b) being camouflaged to make them look like walls, high-density storage racks in SFSPs, or plutonium storage tank supports. (These would sip out plutonium and replace it with teflon-coated shot of the same density so that liquid level monitors and drawn samples would not be affected.)

The predominant face of robots in the nuclear industry is benevolent. They are used for inspection and repair of radioactive reactor vesse1s. (10) For safeguards, the IAEA might use a robot to independently analyze the many plutonium and uranium samples at a safeguarded reprocessing plant and do it all in a sealed chamber too small for human entry. However, whereas millions of dollars is an acceptable price for a diverting roboc, it is too high for an IAEA robot.

In summary, robots are just now coming of age, pushed along by the mature micro-computer revolution and the need to increase productivity in a fiercely competitive world. The estimates of industrial robot sales in the $1990 \mathrm{~s}$ is 
$\$ 5$ billion. (5)* Robots for home use are on the drawing boards in the U.S., Japan and Europe, and like the home computer of today, are expected to expand into a multi-billion dollar business in 10-20 years. (11) Although once only the stuff of science fiction, one can now realistically envision the use of robots for diversion as a cost-effective and relatively risk-free scenario. IX.3. Genetic Engineering Applications

In the bacteria-filled arena of the genetic engineer, where new geretic tools(12) are tackling an ever widening field of human problems such as world hunger, disease, and resource scarcity, the problems of nuclear safeguards are unheard of. However, rapidly expanding fields have a tendency to shoot out branches that could quickly engulf remote fields and maybe even nuclear safeguards. Two speculative examples of this process are

(a) uranium enrichment via bacteria or some other biological system and

(b) plutonium extraction by bacteria.

After discussing some aspects of genetic engineering with an eye toward future developments, we will indicate how these examples might affect safeguards.

\section{IX.3.1. Genetic Engineering}

Here, some of the accomplishments of genetic engineering will be mentioned along with predictions of where these trends can lead in the coming few decades. However, keep in mind a cautionary note; in this field of science, perhaps more than any other, surprises are bound to arise which can shrink the time scale or redirect the major avenues of research.

\footnotetext{
*Robots are meant to displace workers. Only a well-coordinated society such as Japan's, with a shrinking work force and an expanding economy, could introduce robots without increasing unemployment. In mcst other Western societies, unemployment wili probably increase for a period of time until society adjusts to robots. During that adjustment period, societal stability will most likely decrease and extreme actions from both the right and left are more probable. Such social upheavals could impact on the security aspects of nuclear safeguards.
} 
Proteins are a basic constituent of life and are found throughout every cell in every biological organism. They are thus found in the cell walls of bacteria and may someday be discovered or engineered to have uranium-enrichment or plutonium-extraction characteristics or both. Proteins are complicated 3-D structures made from a linear chain of amino acids. Twenty different amino acids can be incorporated in a protein, which can contain thousands of amino acid units. The coding for each protein sequence is transcribed from the cel1's deoxyribonucleic acid (DNA) to ribonucleic acid (RNA) and the RNA template is read by ribosomes, the tiny factories for building all conceivable proteins. Geneticists are able to extract a section of DNA coded Ior one protein (a gene) from a cell in one organism and transfer it via one of several "vectors" into another cell exactly the way a virus infects cells. Then the second cell's machinery proceeds to manufacture the adopted gene. If the gene is coded for a cell-wall protein, the new protein will be incorporated in the cell wall. This is all being done today. Furthermore, the geneticist can take a protein from a cell, string it out (denature it) and decode the amino acid sequence. He can then build the DNA segment corresponding to that sequence. This has been done to a few select proteins and presumably only time and resources are needed to do the same for any protein.

In the case of our hypothetical plutonium-extracting protein or our uranium-enrichment protein, the problem is to find the protein to make. If one exists in nature, then isolating it is the problem. If not, computer simulation may one day lead to the design of a protein with such specific properties. Many computer groups are vigorously studying protein structure and amino acid chains to learn the "rules" that govern protein 3-D configuration. 


\section{IX.3.2. Uranium Enrichment}

Diffusion enrichment plants enrich $\mathrm{UF}_{6}$ in the U-235 isotope by pumping huge volumes of $\mathrm{UF}_{6}$ gas through specially designed inorganic membranes. The efficiency of this enrichment process is determined by the difference in the diffusion constant $(\Delta K)$ between the slightly lighter ${ }^{235} \mathrm{UF}_{6}$ molecule compared to the ${ }^{238} \mathrm{UF}_{6}$ molecule. The enormous size and energy consumption of diffusion enrichment plants are to a first approximation inversely proportional to the small value of $\Delta R$, and this alone has been an effective deterrent to clandestine weapotis production. The less energy-intensive (by about a factor of 25) centrifuge process in full-scale comercial use today is less of a deterrent and is thought to be the path Pakistan has allegedly chosen to acquire nuclear weapons capability. The promise of even further reduced energy consumption also spurs the development of laser enrichment (see Chapter II) and its consequent safeguards problems.

Uranium enrichment using bacteria that exhibit an isotope effect, i.e., that absorb more of a U-235 loaded compound through its cell wall membrane than the U-238 loaded one, could be far more efficient than diffusion enrichment using current inorganic membranes, and this would further exacerbate nuclear safeguards. Isotope effects in biological aystems have been identified for such 1ight elements as hydrogen and si fur. (13) For example, $\mathrm{D}_{2} \mathrm{O}$ in mammalian biological systems is a poison. Concerning the efficiency of biological systems versus inorgaric systems, it is well known that protein enzymes are often ordersof-magnitude better catalysts than the best inorganic molecules. Uranium is known to form complexes with proteins and RNA, but no attempt at searching for an isotope effect has been made. (14) 


\section{IX.3.3. Plutonium Extraction}

Inorganic chemical extraction of plutonium from a complex matrix is routinely performed at nuclear reprocessing plants. Biological extraction of plutonium has also been studied because of the health effects of plutonium ingestion. Experiments have shown that plutonium absorption in the gut may be ennanced when the plutonium is "complexed with naturally occurring, organic ligands."(15) The precise nature of this complex has not been determined but may be due to a protein binding site specific for plutonium in much the same way iron is absorbed by our red blood cells. In the future, the specially structured protein molecules that cling to plutonium may be isolated from the organic compound, or, as knowledge of metalloproteins improves, a synthetic protein might be engineered. It may one day then be feasible to develop a hardy strain of bacteria containing these protein molecules, which would exhibit an intense affinity for plutonium.

In a reprocessing plant handling 1000 MTU per year, there are waste streams of dilute plutonium in a low-level radiation background matrix that contain many significant quantities of plutonium. A portion of this plutonium could be diverted by liquid- or air-borne, plutonium-chelating (extracting) bacteria which would then be filtered out and harvested. By this means, a waste stream, which had been heretofore thought to be too dilute for further practical plutonium extraction, could become a viable, clandestine source. Another example is the plutonium product storage tanks that lose solution due to evaporation or air sparging or both. If plutonium-digesting bacteria were introduced into this air flow, then the exiting air stream would carry off plutonium-rich bacteria. This protracted, simple diversion scenario could be easily regulated so that the loss of plutonium would be less than the limit of error of material unaccounted for of the plant. 


\section{IX.4. Materials Technology}

There is really no direct connection that can be established between new materials technology and non-proliferation concerns. Therefore, unlike in the last two sections, there are no scenarios presented here. Nevertheless, the development of new materials is going on constantly and the field is very active. And there are a few indirect ways in which advances can eventually affect safeguards.

1. There have been a number of recent advances in metallurgy which could impact on the future use of nuclear power. For example, new stainless steels have recently been developed ${ }^{(16)}$ which are one or two orders of magnitude better in corrosion resistance than the currently popular alloy, 316 . Such new alloys could help overcome misgivings, in certain quarters, about the long-term safety of nuclear power. There is also on-going research with notable progress in zirconium alloy composition(17), in the phenomenon of superplasticity of metals, (18) and in understanding and improving the radiation resistance of metals. (19) All of these cannot but help to improve the safety of nuclear reactors and accessory equipment. The public perception of such improvements can lead eventually to substantial growth in the use of nuclear power, with attendant increases in proliferation concerns.

2. A large expansion in aluminum manufacture has been anticipated. (20) This expansion is expected to include a number of locations, including heretofore less-developed parts of the world. New expansions will take place especially in Brazil, Verezuela, and Australia, and also Africa, the Middle East, ard South America. Since a part of the production of aluminum includes the manufacture of carbon anodes and cathodes, (21) and since this process is identical to an important part of that used to manufacture graphite, there will likely be a proliferation of potential sources of graphite throughout the world. The step 
from "ordinary" graphite to nuclear-grade graphite is a relatively small one(22) and hence, the control of this sensitive material will probably become extremely difficult in a short time (if not already difficult).

3. The development and production of a high-strength composite materials is growing and could eventually make centrifuge enrichment technology more accessible to less developed countries than it is at present.

The point is that a continuous improvement in materials technology can affect safeguards in many ways, some of which cannot be envisaged at this time. 
References - Chapter IX

1. Robots, Fact, Fiction and Prediction, Jasia Reichardt, Penguin Bookz, 1978. Amusing historical treatment of Robotics.

2. "Robotics Today", published by Robotics International of the Society of Manufacturing Engineers with the Robot Industry of America.

3. "The B Iue-Co1lar Robot", Robert Sugarman, IEEE Spectrum, Sept. 1980, p. 52.

4. "Robots to the Rescue", Leopold Froehlich, Datamation, January 1981, p. 84.

5. The largest robot manufacturer in the U.S. today is Unimation, Inc., 12 Shelter Rock Lane, Danbury, Connecticut 06810, although GM, GE and IBM, to name a few major manufacturers, are planning to manufacture their own robots.

6. Paul Aron Report 非5, July 28, 1981, Sponsored by Daiwa Securities America, Inc. (subsidiary of Daiwa Securities Ltd., Japan), One Liberty Plaza, New York, N.Y. 10006.

7. Office of Technology Assessment, Nuclear Proliferation and Safeguards: Vol. I, OTA-E-48, and Vol. II, OTA-E-50, Congress of the United States, Washington, D.C., 1977.

8. "Advanced Automation for Space Missions--Technical Summary", A report on the 1980 NASA/ASEE Sumer Study on the Feasibility of Using Machine Intel1igence in Space Applications", Sept. 15, 1980. (NASA-CR-163827).

9. Robots Leap Into the Space Age", New Scientist, Apri1 23, 1981, Vol. 90, p. 234 .

10. "Application of Robot Technology As Applied to the Inspection and Repair of Active Nuclear Plants", Brian R. Moody, ANS Transactions, San Francisco Meeting, Nov. 29-Dec. 3, 1981, p. 987.

11. "Home Robots", New Scientist, June 25, 1981, Vo1. 90, p. 860.

12. "The Molecular Theory of Radiation Biology", K.H. Chaswick and H.P. Leenhouts, Monographs on Theoretical and Applied Genetics, 5, SpringerVerlag, 1981 .

13. "Steady-State Model for Sulfur Isotope Fractionation in Bacterial Reduction Processes," C.E. Rees, Geochim. et. Cosmochim Acta, 37, pp. 1131-1162, 1973.

14. "The Nature of Uranium Occurrence in the Leaves of Coprosma Anstralia (A. Rich) Robinson", N.E. Whitehead, K.R. Brooks and P.J. Peterson, Aust. J. Biol. Sci., 24, pp. 67-73, 1971 . 
15. "Absorption of Plutonium from the Gastrointestinal Tract of Rats and Guinea Pigs After Ingestion of Alfalfa containing ${ }^{238}{ }^{\mathrm{Pu}}$ ", M.F. Sullivan, T.R. Garland, D.A. Cataldo, R.E. Wildung, and H. Drucker, Health Physics, 38, pP. 215-221, 1980 .

16. J.R. Maurer, "The New Stainless Steels: Materials for Energy Conversion" in Advances in Materials Technology in the Americas, Vol. II, p. 1771980 .

17. L.V. Ramanathan, "Structure and Oxidation Behavior of Zirconium-Based Alloys", (see ref. 18), p. 107.

18. J. Wadsworth, T. Oyama, and O.D. Sherby, "Superplasticity: Prerequisites and Phenomenology", (See ref. 18), p. 29.

19. G. Lucki and V.L. Galli, "Radiation Damage in Austenitic Stainless Steel", (see ref. 18 ), p. 79 .

20. J.W. Molerly, "Primary Aluminum Production in the 1980s", (see ref. 20), Vol. I, p. 5 .

21. Encyclopedia of Chemical Technology, 3rd Ed., Rirk-0thmer, Vol. 2, p. 150.

22. B. Keisch, "Export Controls on Nuclear-Grade Graphite", Report No. BNL31433, May 1982. 


\section{SUMMARY OF PROLIFERATION CONCERNS}

Herein is presented a summary of the proliferation concerns as discussed in al1 the preceding chapters. For details, particularly those pertaining to background, system operation, etc., refer to the appropriate chapter.

There is a wide variation in the kinds of facilities discussed in this work. A casual scan of the chapter titles quickly reveals that not all of the systems discussed are equally urgent or equally likely to be realized even to a rough approximation. One may, in fact, divide these systems into three broad classifications.

In the first class, one places those items that are likely to require action in the relatively short term, say less than 20 years. In this group may be included AVLIS enrichment technology, heavy-water production from hydrogen feed, long-term spent fuel storage, HTGRs, reprocessing by fluoride volatization, and perhaps, the use of robotics (although the latter might be more correctly placed in the next group).

In the second class, those that will probably require action in more than 20 years, one might include MSRs, pyrochemical reprocessing techniques, fusion reactors, processes involving genetics or bioengineering, and enrichment with PSP or MLIS.

Finally, there are some systems that are likely never to reach such a state of viability as to pose a proliferation problem. These may include accelerator breeders and fast mixed-spectrum reactors. Of course, these divisions represent an educated guess on the current and future outlook. The situation could easily change with ti.me.

Another way to consider the safeguards problems posed by the systems described here is to categ--ize the necessary safeguards or non-proliferation measures by technological difficulty. One may divide the problems into: 
- those that are already under study (not really considered here);

- those with solutions that can be readily envisaged as extensions of existing technology, e.g., safeguards for AVLIS and long-term fuel storage;

- those that will probably pose major development problems in the relatively short term, e.g., fluoride-volatility reprocessing and robotics; and

- those that may pose major development problems, but obviously in the long term, e.g., fusion systems.

Again, there are many uncertainties about this kind of classification.

Finally, there would appear to be a need to conduct a review, such as this one, every so often in order to remain alert to possible changes or new developments. It can be expected that, as time goes on, some problems will be solved, some will become more or less urgent, and some will be eliminated as a particular system becomes less viable. Perhaps a five-year cycle for a reexamination would be appropriate.

X.1. Future Enrichment Technology (Chapter II)

The safeguards and proliferation concerns of three new uranium-enrichment technologies are discussed. Others are only briefly mentioned.

The methods that are not fully discussed include:

(1) Gas-centrifuge technology, because it has already been adequately covered. (For example, U.S. export controls for this technology are already in place and an international consensus on the IAEA safeguards approach has been reached.)

(2) Aerodynamic methods (Becker nozzle, UCOR) and CHEMEX, because these are not in U.S. hands.

(3) Electromagnetic separation, because this older method is not likely to become a viable choice for uranium enrichment. 
(4) Chemical techniques for separation of isotopes (similar to CHEMEX) because the U.S. is not pursuing these methods on an industrial scale.

of the three uranium-enrichment technologies that are covered, one, Atomic Vapor Laser Isotope Separation (AVIS), was selected by DOE for further development and, hence, most of the discussion is concerned with AVLIS. The basic conclusion regarding proliferation concerns is that by 2000 or 2010 a number of nations could be in a position to develop AVLIS even with the utmost possible control over the exporc of U.S. technology. It is likely th.st such development will take place in as little as 5-10 years in some nations which already have on-going AVLIS development programs. International safeguards to detect the misuse of legitimate facilities, however, could be applied given the opportunity for the design and development of appropriate, forseeable instrumentation. Such an opportunity will no doubt arise given the time that is still required to complete development and construction of an AVLIS facility. It is foreseen that this time would be sufficient to permit necessary procedures for both domestic and international safeguards to be devised and perfected. It would be most appropriate for facility designs to include and accommodate safeguards features.

The second of the three technologies discussed is the Plasma Separation Process (PSP). The technology is, as in the case of AVLIS, difficult but, in a time scale of two or three decades, not impossible for several nations to develop. Instrumentation and inspection procedures similar to those for AVLIS and posing similar development problems would have to be devised during the time that the process itself is developed. (A limited amount of PSP development for $\mathrm{U}$ or $\mathrm{Pu}$ isotope separation has continued since the selection of AVLIS for continuing development as the advanced uranium-isotope separation process.) 
Funding for the third uranium-enrichment technology, Molecular Laser Isotope Separation (MLIS), was discontinued by DOE, al though there has been some support for work on an MLIS process for Pu isotope separation. Although MLIS involves the enrichment of $\mathrm{UF}_{6}$ while AVLIS and PSP involve U metal, the proliferation and safeguards concerns for MLIS are similar co those of the other two.

In addition to the discussion about the above processes, the following general policy issues are discussed:

(1) Sale and export of the technology.

Conclusion: Treat in a manner similar to gas-centrifuge technology, i.e., classify process details and impose export controls on the sale of important components. However, there is not likely to be any advantage of any of the newer technologies over the older ones over the long term.

(2) Offering of a U.S. AVLIS plant not having direct national-security significance for application of IAEA safeguards. Conclusion: Prepare for this eventuality by integrating appropriate safeguards sygtems into the design, recognize that the costs incurred in protecting sensitive technology are inherent in the Agreement between the U.S. and the IAEA, and attempt to minimize those costs by timely development of a iäfeguards approach.

(3) Plutonium isotope separation.

Conclusion: Plutonium isotope separation implies the availability of plutonium separated from irradiated reactor materials. The capability to separate plutonium isotopes presents a small incremental proliferation risk relative to that due to possession of the chemically separated plutonium.

\section{X.2. Non-Aqueous Reprocessing (Chapter III)}

In somparison with the fully developed, almost classic, aqueous extractive technology, which is now in widespread use for the reprocessing of spent nucleaz fuel, non-aqueous technologies have a number of advantages. These advantages 
have, through the years, provided a certain impetus to their study and development which, though slow, has continued both in the U.S. and abroad. There are several technologies under this broad heading but only two are discussed in Chapter III. These are: the Salt Transport Process (as a wel1-studied representative of a larger group of pyrochemical systems) and the Fluoride Volatility Process (as a high-interest example of a larger group of systems based on the volatility of halides of heavy metals).

The Salt Transport Process is based on selective transfer of actinides from one molten alloy to another by way of extraction into and stripping from a molten (transport) salt. The Fluoride Volatility Process is based upon the direct conversion of spent fuel metals, including actinides and fission products, to fluorides, followed by selective separation of the relatively volatile actinide fluorides. In spite of the differences in the processes, certain safeguardsrelated features are common to both. Fortunately the large amount of effort needed to commercialize either of these systems would give much time for safeguards planning, R\&D, and implementation.

One common feature is the compactness of the plants. This would improve both domestic safeguardability and inspection effort needed. However, materials accountability problems abound largely owing to the lack of a homogeneous input solution subject to easy sampling and analysis. For the Salt Transport Process, special sampling and analytical methods need to be developed, including unusual non-destructive analytical intrumentation. For the Fluoride Volatility Process, similar problems must be solved; in particular, the fuel powder that is input to the process is difficult to sample reproducibly. In both casen there appears not to be any real obstacle to the eventual development of appropriate methods and instrumentation. 
From the proliferative point of view there are advantages and disadvantages to the designs. Compactness aids in concealment of clandestine facilities yet also aids in inspectability of safeguarded plants. The uniqueness of the equipment requires developmental effort in accountancy, yet the same uniqueness may prevent a nation from obtaining materials and supplies not normally used in ordinary practice without arousing attention.

\section{X.3. Fusion Systems (Chapter IV)}

Representative candidate fusion technologies include a magnetic-confinement tokamak reactor, a laser-driven inertial-confinement reactor, and a magneticconfinement tokamak hybrid fusion-fission reactur. All would employ the deuterium-tritium (DT) thermonuclear reaction with tritium produced in a lithium breeding blanket (in the liquid-1ithium coolant in the inertial reactor) and externally supplied deuterium.

There are five safeguards and proliferation concerns: (1) the diversion of fusion materials from declared fusion reactors for thermonuclear weapons; (2) the dissemination of classified information that is involved in certain aspects of inertial-confinement fusion (an existing concern); (3) the clandestine production of fissile material, chief1y Pu-239 or D-233, from undeclared fertile material by "neutron diversion" in a declared fusion reactor; (4) the diversion of declared fissile material from declared hybrids; and (5) the clandestine production of fissile material or fusion materials in a clandestine hybrid or misused fusion research reactor. Quantitative estimates used to substanciate these concerns are based upon specific reactor designs anc idealized calculations and are iliustrative only.

First, fusion reactors would consume, breed, or contain enormous quantities of the fusion materials tritium and lithium (possibly isotopically enriched), 
corrosive, are relatively untested, and would require continuous reprocessing, but they could conceivably yield twenty significant quantities (SQ, equal to eight kilograms) of bred fissile material if the entire coolant were spiked for a year. In the latter case, fissile material could be produced if the structural and thermal properties of the illicit fertile and fissile materials were otherwise compatible with reactor operation. For the high-neutron-flux tritium-breeding-blanket location of the pure fusion tokamak under discussion, the estimated annual illicit production rate is $1.8 \mathrm{SQ}$ per square meter of wall area. Only a small. fraction of the 780 square meters of the segmented and periodically replaced wall could be involved at any one time. Both of these production scenarios are bizarre and could for the purè fusion reactors be easily detected and deterred by checking all reactor components at the times of installation or replacement or both using currently available nondestructive analysis techniques. Such checking would be harder for the hybrid reactor because of the legitinate presence of such materials. For hybrids, however, illicit emplacement is far less likely a scenario than undeclared production from the design breeciing blanket. This undeclared production could arise from slight alterations of the blanket operating parameters, including amounts of fertile material and neutron multipliers, but be masked by the uncertainty in declared production mentioned below.

Fourth, except for the additional problems associated with the fusion driver, the safeguards problems associated with the hybrid reactor would be similar to those expected for a fission breeder reactcr producing fissile material rich in fissile isotopes. Hybrid blanket designs include (a) those containing fertile materiai in bundles large or small, requiring periodic removal and zeprocessing elsewhere, or (b) those containing fertile material in fluid form and requiring continucus removal and reprocessing. Safeguards 
of potential use in thermonuclear weapons. Roughly one-half kilogram of tritium would be consumed and bred daily at a 1000 megawatt (electric) pure fusion power plant. Tritium would be subject to stringent physical containment. However, the threshold for U.S. Department of Energy reporting requirements is below the accountability accuracy achievable in fusion processing equipment by the present measurement techniques. The reporting requirements, not formulated for fusionreactor applications, may require revision or elaboration. For both tritium and lithium, there are no internationally accepted strategically significant quantities. Deuterium at fusion plants could be safeguarded more easily than tritium because none would be bred and because it does not decay. There is a provisional significant quantity for deuterium in the form of heavy water, as used in certain fission reactors, but this does not relate to fusion either in form or quantity.

Second, some aspects of inertial-confinement fusion are classified, a concern of current research and development that could extend to deployment of inertial-fusion power plants in the distant future. The underlying problem is the possible relation between inertial fusion and fusion weapons. A related future possible problem, if international safeguards are extended to fusion materials, is that a domestic inertial-fusion plant not having direct national-security significance would apparently be subject to international safeguards under the vo1untary U.S.-IAEA Agreement (suitably amended). Extra costs might have to be incurred in building such a plant or preparing for inspections to protect sensitive technology.

Third, neutron diversion could be attempted at fusion reactors because prodigous numbers of neutrons would be produced. Fissile material could be produced from undeclared fertile material put either in the primary coolant of the reactor or in the reactor structure. In the former case, the mixtures are 
corrosive, are relatively untested, and would require continuous reprocessing, but they could conceivably yield twenty significant quantities (SQ, equal to eight kilograms) of bred fissile material if the entire coolant were spiked for a year. In the latter case, fissile material could be produced if the structural and thermal properties of the illicit fertile and fissile materials were otherwise compatible with reactor operation. For the high-neutron-flux tritium-breeding-blanket location of the pure fusion tokamak under discussion, the estimated annual illicit production rate is $1.8 \mathrm{SQ}$ per square meter of wall area. Only a small fraction of the 780 square meters of the segmented and periodically replaced wall could be involved at any one time. Both of these production scenarios are bizarre and could for the pure fusion reactors be easily detected and deterred by checking all reactor components at the times of installation or replacement or both using currently available nondestructive analysis techniques. Such checking would be harder for the hybrid reactor because of the legitimate presence of such materials. For hybrids, hewever, illicit emplacement is far less likely a scenario than undeclared production from the design breeding blanket. This undeclared production could arise from slight alterations of the blanket operating parameters, including amounts of fertile material and neutron multipliers, but be masked by the uncertainty in declared production mentioned below.

Fourth, except for the additional problems associated with the fusion driver, the safeguards problems associated with the hybrid reactor would be similar to those expected for a fission breeder reactor producing fissile material rich in fissile isotopes. Hybrid blanket designs include (a) those containing fertile material in bundles large or small, requiring periodic removal and reprocessing elsewhere, or (b) those containing fertile material in fluid form and requiring continuous removal and reprocessing. Safeguards 
for such designs woulả be related to those applied at 1 ight-water reactors, at heavy-water reactors, or at reprocessing plants.

The hybrid reactor under discussion would breed annual1y about $2500 \mathrm{~kg}$ of plutonium and discharge it in more than seven hundred bundles, of which about three would yield one SQ. Conventional item accounting with surveillance of the water-storage pool, where the fuel cylinders would initially cool, and facility containment would be the likely safeguards methods.

Predictions of plutonium production in hybrids are uncertain given present-day calculation techniques. These uncertainties would amount to about fifteen SQ annually. For these reasons, material accounting could not be relied upon as a safeguards method in the absence of item accounting. Location of hybrids at internationally safeguarded fuel service centers would be a further measure to alleviate the fourth safeguards concern.

Fifth, if practical small fusion reactors could be built, then the possibi1ity exists of a clandestine hyb $₫ \mathrm{~d}$ or a misused fusion research facility for clandestine production of fissile material or fusion materials. It would be necessary to apply intelligence methods for detection and export controls for prevention of such possibilities. Fusion research facilities sufficiently large to be of proliferation concern would presumably be safeguarded to deter or detect their misuse.

To conclude, future scenarios for surreptitiously obtaining fissile material from a fusion reactor by misuse or clandestine construction seem far less plausible than scenarios involving clandestine conventional fission reactors. This is so because of the complexity of plausible fusion technology. Nevertheless, the likeliest way to obtain fissile material from fusion technology would be diversion from or undeclared blanket production at a declared fusion-fission hybrid reactor. Scenarios for obtaining fusion materials 
and using them in thermonuclear weapons ultimately involve, among other difficulties, the associated need for fissile materials for fission weapons. These conclusions must, of course, be judged in light of country-specific political interests and technological prowess.

\section{X.4. Accelerator-Driven Reactor Systems (Chapter V)}

Representative nuclear-fuel-cycle installations employing acceleratordriven reactor systems are the linear-accelerator fuel producer (LAFP) or "Spallator", the linear-accelerator fuel enricher and regenerator (IAFER), and the linear-accelerator driven reactor (LADR). In the LAFP design under discussion, the most promising candidate for further development, a 600 megawatt beam of protons would induce the spallation of neutrons from uranium atoms in a target. The neutrons would in turn be captured by other uranium atoms in the target to breed fissile plutonium and induce some fission. Heat generated in the target and converted conventionally into electricity would provide just enough power for the linear accelerator.

There are three proliferation concerns: (1) the diversion of some of a facility's declared fissile-material production (or, if applicable, feed); (2) clandestine production of fissile material in a declared facility; and (3) production of fissile material in a dedicated, clandestine facility or a misused research facility. Quantitative estimates used here to substantiate these concerns are based upon specific designs and idealized calculations and are illustrative only.

First, sone of a facility's declared fissile-material production (or feed in the case of the regenerative cycle of the LAFER) could be diverted. Small bundles similar to those in heavy-water reactors would be the structures in the LAFP for breeding bulk fissile material while conventional light-water-reactor 
fuel assemblies would serve in the LAFER and LADR. Periodic shuffling of these to yield more uniform irradiation would add to the diversion concern. Approximately fifty such bundles of the 18000 discharged annually fron the LAFP would be needed to yield one significant quantity (SQ; equal to eight kilograms) of bred fissile material. Strict item accounting and containment and surveillance would be the primary safeguards measures to prevent diversion. Bulk material accounting could not be relied upon because of the roughly five per cent uncertainty in fissile production based upon today's calculation techniques. Location of LAFPs at internationally safeguarded fuel service centers would be a further measure to alleviate the firgt concern.

Second, undeclared fissile material could be produced at a declared facility by diversion of the linear-accelerator beam or by neutron diversion. Construction of beam-diverting equipment would be easily noticed by inspection; monitoring the beam would also effectively safeguard against this strategem. About $19 \mathrm{SQ}$ of fissile material could be produced in one year by diverting neutrons to irradiate fertile material in large sections of the structure. Or, if fertile material were included as solute in the target's coolant, 10 so could be produced. These complex strategems could be deterred or detected by checking all system components for illicit fertile and fissile material at the time of installation or replacement.

Related to these methods would be undeclared production in the declared fuel bundles by altering the amounts of fertile material in them or by altering the amounts of neutron multipliers or neutron reflectors in the breeding regions or even by altering the energy of the accelerator beam. Such undeclared production could be masked by the aforementioned uncertainty in declared production. Design checks, beam monitoring, and item accounting of the fuel bundles would be the safeguards methods to deter and detect such undeclared production. 
Third, the possibility exists of a clandestine facility for production of fissile material. Though the construction of powerful lineax accelerators is not a commercial enterprise, the technical details underlying these devices are widely understood. However, linear accelerators now serving as scientific research facilities do not have the capability for producing significant amounts of fissile material. Intelligence methods and export controls on the relevant technologies would be the methods for detecting and preventing, respectively, clandestine facilities. Dedicated research facilities for accelerator breeding would require safeguards in accordance with their production capability.

To conclude, future scenarios for illegally obtaining fissile material from a linear-accelerator reactor system by misuse or clandestine construction seem less plausible than scenarios involving clandestine conventional fissile reactors. This is so because of the size and complexity of plausible accelerator systems. Nevertheless, the likeliest way to obtain fissile material. from accelerator systems would be diversion from or undeclared blanket production at a declared facility. These conclusions must of course by judged in light of country-specific political interests and technological prowess.

\section{X.5. New Reactor Types (Chapter VI)}

A reasonably complete 1 ist of unconventional reactor types was reviewed but only three were selected for further discussion. The selection was based upon potential future commercial viability combined with a need to solve unusual safeguards problems. The three selected types were Molten Salt Reactors (MSRs), High Temperature Gas-Cooled Reactors (HTGRs), and Fast Mixed Spectrum Reactors (FMSRs). The last was discussed in somewhat less detail than the others because of the relatively speculative status of the type. 
MSRs are characterized by the use of a molten mixture of salts which contain fissile as well as, possibly, fertile material. Several sub-types are possible, chiefly the MSBR (breeder) and the DMSR (denatured). The latter design is specifically intended to be non-proliferative since virtually no reprocessing (or for that matter fuel removal) is intended over the life of the reactor, all uranium is denatured, the plutonium inventory is always small, and its design facilitates the goal in other ways. Material accountability for the operating system is rather different than for reactors, such as LWRs, which have discrete units of fuel. In this respect accountability-related measurements and flow monitoring are rather more 1 ike that in a reprocessing plant than in the more common reactor situation. Thus, for example, designs and construction would have to be watched to guard against the installation of covert piping. New instrumentation, such as monitors, level measuring devices, and NDA equipment for measuring concentrations, would have to be built and new sampling and calibration techniques would have to be devised. All such developments will be special in order to work in the high-temperature, high-radiation environment and would probably have to be considered during reactor design and construction.

In contrast with the long lead time inherent in the future development of MSRs, HTGRs are alreay we11 along toward eventual commercialization. As a result, many of the safeguards and proliferation aspects have already been considered and are either solved or nearly so. Of special concern, however, is the potential use of HTGRs in many small units for producing process heat. The concern arises mainly over whether an inspectorate might be overwhelmed if there were a large number of small units. This might lead one to develop more automation for safeguards purposes. Other problems peculiar to HTGRs which are not yet solved involve the use of pebble-bed reactors in which the fuel units occur 
in large numbers, and accounting complications added to the reprocessing operation by the need to crush and burn the fuel matrix prior to dissolution.

FMSRs are designed to be non-proliferative by virtue of the fact that they are intended to run for long periods of time without fuel removal. Some proposals suggest that fuel for such reactors could be used for, literally, hundreds of years. At the present time, the actual development and demonstration of FMSRs is decades away. Nevertheless one can envisage at least two unusual safeguards problems. These are reliability of long-term seals and of institutional arrangements.

\section{X.6. Heavy Water (Chapter VII)}

Since plutonium may be produced in a natural-uranium-fueled, heavy-watermoderated (HW) reactor, there is interest in the international community in the control of the supply and production of heavy water and deuterium. Such interest has resulted in attempts to arrange safeguards for plutonium produced in $\mathrm{HW}$ reactors as a part of supplier agreements. The latter pertains both to the heavy water itself and to facilities to produce it. Direct applications of safeguards to HW production facilities necessarily involves the development and application of surveillance and measurement methods. Such development is currently under way in, for example, the U.S. and Canada. While methods are not yet available to the IAEA, it is assumed that ultimately they will be. It is thus expected that the IAEA will require assistance in the development and implementation of a safeguards approach.

However, the current efforts in safeguards technology development are concerned only with plants thyt extract deuterium from water. Another viable production route is to use hydrogen as a source. There are already two such 
processes, ammonia-hydrogen exchange and cryogenic hydrogen-distillation, deployed on a comnercial scale and others that have been investigated.

Because of the complexities of the hydrogen-fed plant, the simple extension of techniques under development for safeguarding water-fed plants may not be possible. It is likely that additional techniques will be required, particularly for the measurement of deuterium in vapor-phase streams.

The hydrogen-fed processes are not particularly attractive from an economic point of view except as an adjunct to the production and use of hydrogen on a large scale for other purposes. At this time, it is not so used. However, it is expected to become so in the future. Today, the greatest single usage is for fixation of atmospheric nitrogen through ammonia production. A relatively new and growing usage is in petroleum refineries to increase the yield of light hydrocarbons = In the longer term, the production and use from coal as a direct fuel or to produce fluid fuels may become important. And in the very long term, hydrogen may be used as a carrier for energy pioduced from nuclear fission or fusion or solar energy. The latter applications are probably 25-50 years off.

Despite the long time scale indicated, because the hydrogen-fed processes are already available, it may be desirable to begin the study of safeguards approaches for such plants rather soon (within the next few years).

\section{X.7. Long-Term Stórage (Chapter VIII)}

Eight distinct long-term storage schemes are considered and discussed with respect to long-term, redundant, effective safeguards programs. Some of the problems that remain to be satisfactorily solved are specific to certain storage schemes while others are generally applicable to many of them. Two important principles used in the discussion are that redundancy is an indispensable re- 
quirement and that spent fuel that is stored for a long time is more attractive than spent fuel that has just been removed from a reactor.

Problems encountered and discussed involve:

(a) Consolidation of material to save space as an impediment to surveillance. This could be solved either by providing redundancy in surveillance systems or by developing and installing active surveillance systems. Examples of the latter are discussed in Appendix VIII-A-I.

(b) Biological shielding used in dry storage schemes as an impediment to measurement and surveillance. As in (a) above, new active surveillance systems probably would be needed.

(c) Means to overcome possible diversion strategies that involve fast shuffling. At present, it is not clear how this problem would be handled.

(d) Provision of positive, unique identifications to counter in-transit concealment strategies. There have been a number of studies made of this problem. Although progress has been made, the problem has not yet been satisfactorily solved.

(e) Safeguarding very large away-from-reactor facilities (AFRs) with respect to the volume of material to be protected. This is probably a matter of enlarging surveillance systems with the addition of the aforementioned identification systems. However, careful studies would be required as to actual design and application to very large AFRs.

(f) Development of effective seals for casks and concrete silos. The development of seals has a long history and is still active. Probably, the further improvement of seals will continue for a long time. An example of a newly proposed seal is given in Appendix VIII-A-II.

(g) Protection against tunnelling scenarios. Such scenarios will most likely become viable with the further development of robots (see Chapter IX). 
Active surveillance of radiation fields may help but both the problem and possible solutions are, as one might expect, poorly defined at this time.

(h) Development of active surveillance with properties such as long 1 ife and remote interrogation capability. There appears to be no reason why such properties cannot be improved upon as required in view of the general progress in electronics technology.

\section{X.8. Other Future Technologies (Chapter IX)}

In addition to the direct effects of developing nuclear technologies discussed in the preceeding chapters, an attempt was made to envisage possible future non-nuclear developnents that could impact on nuclear safeguards. Several such technologies were considered. Those discussed in Chapter IX include robotics, genetics engineering (and other biologically oriented technologies), and materials science. A few distinct but highly speculative possibilities were proposed and discussed. Because of the nature of these speculations, only a few problems were posed for further consideration; no solutions were offered. 